Fátima Corrêa Oliver

SAÚDE MENTAL E SAÚDE DA PESSOA COM DEFICIÊNCIA: ESTUDO DO PROCESSO DE INCORPORAÇÃO DE ASSISTÊNCIA PELOS SERVIÇOS MUNICIPAIS DE SAÚDE NUMA REGIÃO DO MƯNICÍPIO DE SÃO PAULO (1989-1995)

Tese de doutorado apresentada à Faculdade de Saúde Pública da Universidade São Paulo, para obtenção do grau de doutor em Saúde Pública

Orientadora:

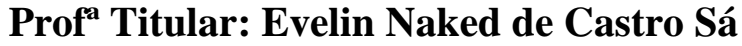


UNIVERSIDADE DE SÃO PAULO

FACULDADE DE SAÚDE PÚBLICA

\section{SAÚDE MENTAL E SAÚDE DA PESSOA COM DEFICIÊNCIA: ESTUDO DO PROCESSO DE INCORPORAÇÃO DE ASSISTÊNCIA PELOS SERVIÇOS MUNICIPAIS DE SAÚDE NUMA REGIÃO DO MUNICÍPIO DE SÃO PAULO (1989-1995)}


“Então, eu creio que a única forma que nós temos para modificar essa sociedade é fazer tudo aquilo que nós conseguimos fazer, como se nós estivéssemos numa outra sociedade, como se tudo fosse possível." (ROTELLI, 1994 p. 166) 
Agradeço às muitas mãos que tornaram este trabalho viável.

À Evelin, orientadora,

Às colegas do Centro de Docência e Pesquisa em Terapia Ocupacional - USP

que incentivam as iniciativas e contribuem para entender os caminhos trilhados,

À Adriana pela dedicação e paciência na preparação de tantas revisões de texto.

Na preparação e manutenção do cotidiano nos damos conta da existência em suas múltiplas dimensões.

À Laura, pelo apoio interminável, desde sempre

À Edinalva, grande lutadora pela e na vida.

Nos inúmeros e verdadeiros apoios do universo feminino a solidariedade é continuamente experimentada e exercitada, é possível, então, pensar fazendo e refazendo.

Trabalhando sempre, resistindo às dúvidas e às certezas. 
Para

Olívia, Letícia e Lamartine, que sabem, são luzes do meu caminho.

Para

Ró, Denise e Raquel, companheiras de muitos percursos.

\section{Para}

Aqueles que deram seus depoimentos, partilharam experiências e construíram gentilmente este trabalho. 


\section{RESUMO}

A pesquisa aborda a definição de políticas e processo de implantação das ações de saúde mental e da pessoa com deficiência em serviços municipais em São Paulo, na região de São Miguel Paulista, entre 1989-1995, não havendo anteriormente proposta assistencial organizada para esses grupos. Foi realizada através da análise de textos oficiais, de entrevistas com profissionais da assistência direta, gerentes e planejadores e com representantes do movimento social e da organização de banco de dados de pacientes atendidos, segundo idade, moradia, escolaridade e hipótese diagnóstica.

Buscou-se descrever o processo de criação de serviços, conforme a proposta assistencial, identificar seus atores e os principais problemas, nos três distritos de saúde da região de São Miguel. No período pesquisado, a Secretaria Municipal de Saúde de São Paulo passou por transformações institucionais, desde a criação das Administrações Regionais e Distritos de Saúde para a construção do Sistema Único de Saúde - SUS (1989-92) até a proposição do Plano de Assistência à Saúde - PAS em 1995.

A proposta de saúde mental tinha como diretrizes o combate à cultura manicomial através da criação de serviços e da estruturação do sistema de atendimento e da mobilização de técnicos, usuários e população em geral, para a discussão dos temas do movimento da luta antimanicomial.

A atenção à pessoa com deficiência dependeu mais da iniciativa de profissionais do que de uma proposta articulada institucionalmente. Em 1991 foi criado serviço pioneiro de fisioterapia nas enfermarias do Hospital Geral de Ermelino Matarazzo, que com a ampliação da equipe, torna-se referência para atendimento em reabilitação daqueles que passaram por internação. Por pressão do movimento de pessoas deficientes, a proposta de atenção a esse grupo foi apresentada em abril de 1992. Defendia-se a incorporação de ações em unidades básicas de saúde - UBS, hospitais gerais e a criação de centros de reabilitação regionais.

As características assistenciais dos serviços definiram o perfil dos usuários atendidos por demanda espontânea. As mulheres, 52,9\% dos usuários, tinham idade média de 38 anos e os homens $(47,1 \%)$ com idade média de 28 anos. Os homens mais jovens estavam nos Centros de Convivência e Cooperativa - CECCO e UBS. Os usuários mais velhos eram mulheres, na Unidade de Reabilitação e em algumas UBS. Os Hospitais-Dia - 
HD e a Enfermaria Psiquiátrica acompanhavam predominantemente psicóticos, as UBS, crianças com problemas de aprendizagem e adaptação à escola e, também, adultos psicóticos quando contavam com psiquiatra. A unidade de reabilitação caracterizava-se como serviço de fisioterapia para pessoas com disfunções traumato-ortopédicas. Os CECCO atendiam a grupos de jovens e adultos com deficiência mental, e psicóticos.

Identificou-se como a maior dificuldade a estruturação da assistência nas UBS, serviços que historicamente priorizaram a assistência materno-infantil. Problemas como a falta de espaço e recursos materiais específicos para o trabalho dos profissionais eram constantes, mais graves entre 1993-95. Já nos serviços para grupos específicos (CECCO, HD, Enfermaria Psiquiátrica e Unidade de Reabilitação) as dificuldades estavam na organização do trabalho interdisciplinar e na capacidade dos profissionais aceitarem o desafio técnico de criar e gerir novas instituições. Esperava-se uma integração interinstitucional entre os serviços criados que, na prática, se mostrava impossível, dificultando a assistência a portadores de transtornos graves.

Entre 1993 e 1995, com a mudança de governo houve o abandono de prioridades anteriores como política salarial, diretrizes de descentralização e autonomia dos serviços locais, provocando êxodo de profissionais e descaracterizando os serviços. Alguns técnicos que estavam em cargos de confiança na gestão anterior, permaneceram em função assistencial, na defesa da proposta, principalmente nos HD e nos CECCO.

O curto período (1991-95) para definir e implantar políticas, a diversidade temporal para obtenção dos vários insumos necessários e as dificuldades de incorporação das propostas em vários níveis, além da ruptura para outra administração dificultaram a continuidade da experiência. A marca das propostas foi a defesa da universalização contribuindo para possíveis mudanças nas condições de exclusão social desses grupos, aumentando sua visibilidade social. A existência e permanência dessas experiências dependeram da sensibilidade e compromisso de gestores e do engajamento cotidiano dos profissionais e população na sua construção, mais do que da continuidade necessária na Administração Pública. 


\begin{abstract}
This study approaches the definition of the polices and the process for the implementation of interventions in mental health and for people with disabilities in municipal services in Sao Paulo, in the region of Sao Miguel Paulista, between 1989-1995, whereas no assistance proposal was organized for these groups before this period. This study was accomplished by analyzing official documents, interviewing professional, managers and projectors, and representatives of the social movement, and organizing data bases of patients according to age, residence, scholarship and diagnosis hypothesis.

This investigation describes the process of upbringing services, accordant to the assistance proposal, identifying role players and the main problems, em all three districts of health from Sao Miguel region. During the period of this research, the Municipal Secretary of Health of Sao Paulo went throw institutional changes, since the creation of Regional Administrations and Health Districts to construct Sistema Único de Saúde - SUS (1989-92) until the proposition of Plano de Assistência à Saúde - PAS in 1995.

The proposal for mental health was focused to combat the asylum culture by creating services and structuring the assistance system and with the mobilization of professionals, clients and the general population, to discuss the movement against asylums.

The attention for people with disabilities depended on professional initiative than an institutional proposal. In 1991 the first Physical Therapy service in infirmary was introduced in the General Hospital of Ermelino Matarazzo, that after enlarging the team, it became reference for rehabilitation of former inpatients. Due to pressure coming from the movement in favor to people with disabilities, the proposal for this group was presented in April of 1992. It defended the incorporation of interventions in primary health units, general hospitals and the creation of centers of regional rehabilitation.

The assistance characteristics of each service defined the profile of their clients by spontaneous demand. The women, 52.9\%, had average age of 38 and men $(47.1 \%) 28$. The younger men were found in CECCO and UBS. The elderly women in Rehabilitation Units and in some UBS. The HD and the psychiatric infirmary accompany mainly psychotics, while UBS, children with learning disabilities and adults, psychotic where a psychiatrist was available. The rehabilitation unit is characterized as a Physical Therapy Service for
\end{abstract}


people with trauma-orthopedics dysfunction. The CECCO assist groups of teenagers and adults with mental handicap and psychotic.

The major difficulty was identified as being the structuring of UBS, service that historically gave priority to mother-infant assistance. Problems like lack of space and specific material for professionals to be able to work were constant, more severe between 1993-95. Em services for specific groups (CECCO, HD, Psychiatric Infirmary and Rehabilitation Unit) the difficulties was organizing the interdiscipline work and the capacity of professional to accept the technical challenge to create and generate new institutions. It was expected a interinstitutional integration between services created, which was considered impossible, making it difficult to assist severe disorders.

Between 1993 and 1995, while the government changed there was an abandonment of former priorities like salary polices, decentralization and autonomy of local services, provoking exodus of professionals and discharacterizing the services. Some professionals from former management maintain their assistencial function, to defend the proposal, mainly in HD and CECCO.

The short period (1991-95) to define and implement polices, the diversity to obtain what's necessary and the difficulty to incorporate the proposals in many levels, other than the rupture of the administration made it difficult to continue the experience. The demarcation of the proposals was the defense of universality contributing to possible changes of the social exclusion condition of these groups, increasing their social visibility. The existence and permanence of this experience depended on the sensibility and engagement of managers and the daily commitment of professional and population in its construction, more than in continuity necessary for Public Administration. 


\section{ÍNDICE}

\section{O Sistema Único de Saúde e a inclusão de novos grupos}

\section{populacionais}

1. Sistema Único de Saúde: notas sobre sua constituição 4

2. A universalização da atenção à saúde: exercício de cidadania .8

3. A proposta de assistência em saúde mental.......................................................12

4. A proposta de assistência em saúde da pessoa portadora de deficiência...................27

II. Procedimentos.

\section{São Miguel em suas distintas dimensões: conhecendo o território} entre 1989 e 1995

1. Panorama da organização da saúde e seus reflexos em São Miguel. 53

2. Indicadores de exclusão/inclusão social .71

3. Características gerais dos serviços municipais de saúde: estrutura, demanda e produção de serviços

\section{São Miguel: conhecendo o desenvolvimento das propostas} assistenciais

1. A atenção em saúde mental: o ponto de vista dos profissionais da saúde .90

1.1. Assessores, gerentes e planejadores no período de 1989 a 1992 ...........................90

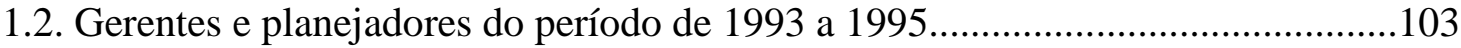

1.3 . Profissionais da assistência direta nas Unidades Básicas de Saúde. 105

1.4. Profissionais da assistência direta nos Centros de Convivência e Cooperativa. 107

1. 3. Profissionais da assistência direta nos Hospitais-Dia.

2. A atenção à saúde da pessoa com deficiência: o ponto de vista dos profissionais de saúde 112

2.1. Distrito de Saúde de Ermelino Matarazzo 114

2.2. Distrito de Saúde de São Miguel. 120 
2.3. Distrito de Saúde de Itaim Paulista.................................................................... 121

3. O perfil dos usuários: retratos do trabalho assistencial

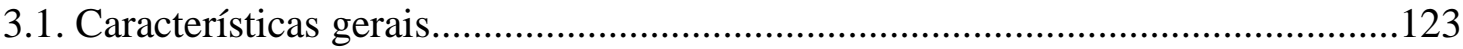

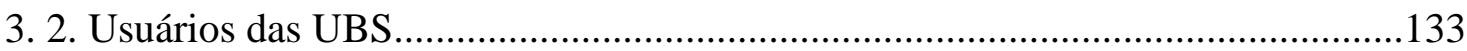

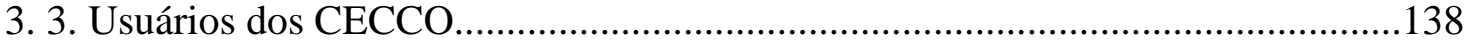

3. 4. Usuários da Unidade de Reabilitação e da Enfermaria Psiquiátrica......................142

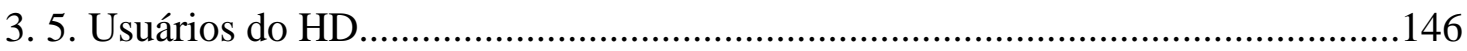

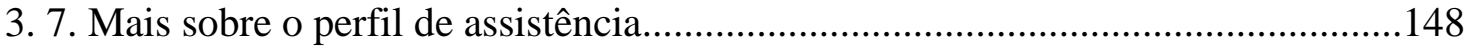

4. O ponto de vista dos representantes das Organizações e Movimento

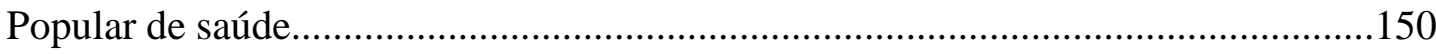

V. O modelo assistencial: o que se conseguiu implementar........................157

1. O modelo tecno-assistencial desenvolvido em saúde mental

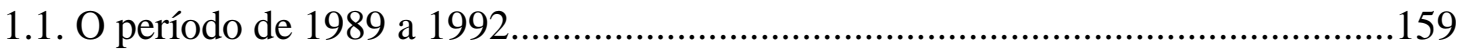

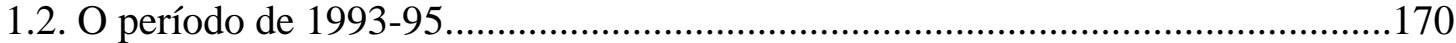

2. O modelo assistencial em saúde da pessoa com deficiência................................171

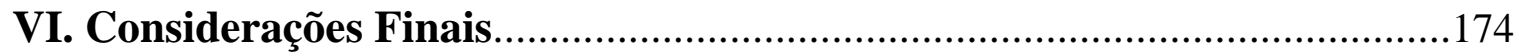

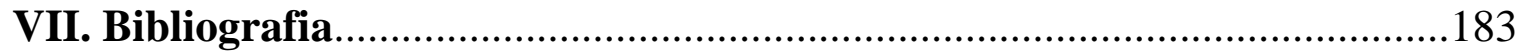

IX. Anexos

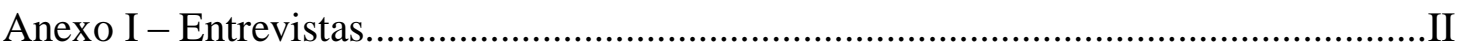

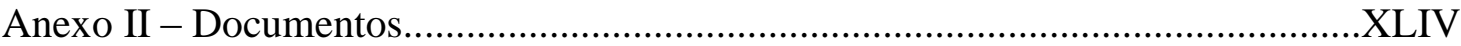

Anexo III - Banco de Dados sobre usuários...............................................................VI 


\section{ÍNDICE DE TABELAS, GRÁFICOS, QUADROS E FIGURAS}

TABELA 1. Número de leitos psiquiátricos em hospital geral, segundo natureza e UF, 1996.

TABELA 2. Número de Hospitais-dia, NAPS e CAPS, segundo a natureza e UF, 1996.

TABELA 3 Motivosde internação dos internos das Casas André Luiz, que participavam das atividades de terapia ocupacional.

TABELA 4 Idade da população moradora das Casas André Luiz, no momento da internação.

TABELA 5. Idade da população moradora das Casas André Luiz, em 1992.

TABELA 6. Tempo de internação da população moradora nas Casas André Luiz, em 1992

TABELA 7. Serviços de atenção à pessoa deficiente mental no município de São Paulo, 1992.

TABELA 8. Classificação dos distritos segundo o número de habitantes, município de São Paulo, 1991

TABELA 9. Discrepância dos distritos, segundo chefes de família sem rendimentos, município de São Paulo,1991.

TABELA 10 Discrepância dos distritos, segundo o rendimento dos chefes de família até 1,5 salários mínimos, município de São Paulo, 1991

TABELA 11. Classificação decrescente dos distritos de acordo com o Índice de discrepância de acesso a serviços básicos de saúde, município de São Paulo, 1993.

TABELA 12. Classificação dos distritos segundo o Índice de Autonomia, município 1991

TABELA 13. Classificação dos distritos segundo o Índice de Qualidade de Vida, Município de São Paulo, 1991.

TABELA 14. Classificação dos distritos segundo o Índice de Desenvolvimento Humano, município de São Paulo, 1991

TABELA 15 Classificação dos distritos segundo o Índice de Eqüidade, município de São Paulo, 1991

TABELA 16. Classificação dos distritos segundo Índice de Exclusão Social, Município de São Paulo, 1991

TABELA 17. Distribuição de óbitos por causas no município de São Paulo e na ARS-6, 1994.

TABELA 18. Distribuição dos óbitos por doenças de notificação compulsória no Município de São Paulo e na ARS-6, 1994.

TABELA 19 Taxa de mortalidade na infância ( 0 a 4 anos) e juvenil (15 a 24 anos de idade)

TABELA 20. Distribuição dos óbitos por causas violentas e acidentes, no município de São Paulo e na ARS - 6, 1994

TABELA 21. Distribuição de morbidade por tipo de unidade, no município de São 
Paulo e na ARS-6, 1994

TABELA 22 Serviços de saúde da Administração Regional de Saúde - 6, segundo Distrito de Saúde, 1996.

TABELA 23. Profissionais que desempenham funções assistenciais na ARS-6, segundo categoria

TABELA 24. Atendimentos por especialidades realizados nas Unidades Básicas de Saúde da ARS-6 entre 1990-1995.

TABELA 25. Atendimentos por especialidades realizados nas UBS do Distrito de Ermelino Matarazzo entre 1990-1995.

TABELA 26. Atendimentos por especialidade realizados nas UBS do Distrito de São Miguel entre 1990-1995.

TABELA 27. Atendimentos por especialidades realizados nas UBS do Distrito de Itaim Paulista entre 1990-1995....

TABELA 28. Usuários, segundo faixa etária.

TABELA 29. Usuários, segundo unidade de saúde e sexo

TABELA 30. Escolaridade dos usuários, segundo sexo e média de idade.

TABELA 31. Idades médias dos usuários, sem resposta para questão escolaridade, segundo Unidade de Saúde.

TABELA 32. Usuários, segundo sexo, média de idade e Unidade de Saúde

TABELA 33. Distribuição da Unidade de Saúde, segundo moradia dos usuários

TABELA 34. Distribuição dos usuários, segundo Hipótese Diagnóstica.....

TABELA 35. Idades médias dos usuários sem resposta para Hipótese Diagnóstica, segundo unidade de saúde.

TABELA 36. Sexo dos usuários, segundo as Unidades Básicas de Saúde............. 133

TABELA 37. Escolaridade dos usuários, segundo UBS ...................................... 135

TABELA 38. Residência dos usuários, segundo UBS.............................................. 135

TABELA 39 Hipótese Diagnóstica, segundo UBS................................................ 136

TABELA 40. Hipótese Diagnóstica dos usuários, segundo CECCO........................ 140

TABELA 41. Usuários dos CECCO, segundo acompanhamento anterior.............. 141

TABELA 42. Usuários da Enfermaria Psiquiátrica que passaram por internações anteriores, segundo tipo de instituição.

$\begin{array}{lll}\text { TABELA 43. Escolaridade dos usuários, segundo unidade de saúde..................... } & 144 \\ \text { TABELA 44. Residência dos Usuários, segundo unidade de saúde.................... } & 145\end{array}$

TABELA 45. Hipóteses Diagnósticas dos usuários, segundo unidade de saúde... $\quad 145$

TABELA 46. Hipóteses Diagnósticas dos usuários do Hospital Dia São

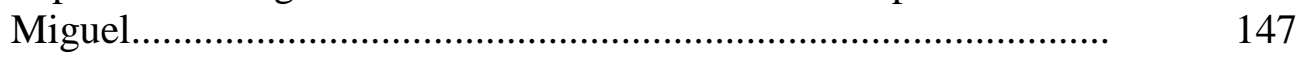

TABELA 47. Usuários do HD, segundo internações anteriores no serviço............ 148

GRÁFICO 1. Atendimento realizados nas UBS dos distritos de saúde da ARS-6, entre 1990-1995......

GRÁFICO 2. Atendimentos por especialidades realizados nas UBS do Distrito de Ermelino Matarazzo, entre 1990-1995 ........................................

GRÁFICO 3. Atendimentos por especialidades nas UBS do Distrito São Miguel, entre 1990-1995. 
GRÁFICO 4. Atendimentos por especialidade nas UBS do Distrito São Miguel, entre 1990-1995.

GRÁFICO 5. Usuários, Segundo Unidade de Saúde............................................ 124

GRÁFICO 6. Hipóteses Diagnóstica, segundo média de idade............................. 130

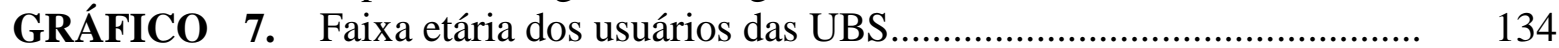

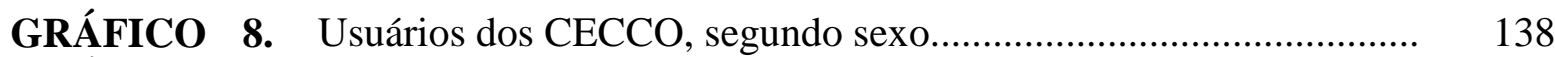

GRÁFICO 9. Faixa etária dos usuários dos CECCO.......................................... 139

GRÁFICO 10. Usuários da Unidade de Reabilitação e da Enfermaria Psiquiátrica, segundo sexo......................................................... 142

GRÁFICO 11. Usuários da Unidade de Reabilitação e da Enfermaria Psiquiátrica, segundo faixa etária............................................... 143

GRÁFICO 12. Usuários do Hospital-Dia, segundo sexo.......................................... 146

GRÁFICO 13. Usuários do Hospital-Dia, segundo faixa etária............................... 147

FIGURA 1. Modelo de atenção em saúde mental da Prefeitura Municipal de São Paulo (1989-92)..................................................................... 22

QUADRO 1. Elementos para discussão da prática assistencial em saúde mental, gestores, planejadores de nível regional, distrital, período de 1989-1992

QUADRO 2. Elementos para a discussão da prática assistencial em saúde da pessoa com deficiência no Distrito de Saúde de Ermelino Matarazzo, $\quad$ período 1989-1996 


\section{LISTA DE ABREVIATURAS E SIGLAS}

ACDEM - Associação Casa dos Deficientes de Ermelino Matarazzo

AIS - Ações Integradas de Saúde

APAE - Associação de Pais e Amigos Excepcionais

ARA - Ambulatório de Reabilitação do Alcoólatra

ARS - Administração Regional de Saúde

ARS-6 - Administração Regional de Saúde de São Miguel Paulista

AS - Assistente Social

ASPLAN - Assessoria de Planejamento da Secretaria Municipal de Saúde

AVC - Acidente Vascular Cerebral

AVD - Atividade da Vida Diária

CECCO - Centro de Convivência e Cooperativa

CEFOR - Centro de Formação de Trabalhadores da Saúde

CNS - Conferência Nacional de Saúde

COAS - Centro para Organização da Atenção à Saúde

CONASP - Conselho Consultivo da Administração de Saúde Previdenciária

CTA - Conselho Técnico Administrativo

DEN - Cirurgião - Dentista

DEPAVE - Departamento de Parques e Áreas Verdes

DS - Distrito de Saúde

DS EM - Distrito de Saúde de Ermelino Matarazzo

DS IP - Distrito de Saúde de Itaim Paulista

DS SM - Distrito de Saúde de São Miguel

EM - Ermelino Matarazzo

ENF - Enfermeiro

Entrev. - Entrevista

FISIO - Fisioterapeuta

FONO - Fonoaudiólogo 
FSEADE - Fundação Sistema Estadual de Análise de Dados

HD - Hospital-dia

INAMPS - Instituto Nacional de Assistência Médica da Previdência Social

IP - Itaim Paulista

OMS - Organização Mundial de Saúde

PA - Pronto Atendimento

PAS - Plano de Atendimento à Saúde

PMSP - Prefeitura do Município de São Paulo

PRO-AIM - Programa de Aprimoramento das Informações de Mortalidade no Município de São Paulo

PROF - Profissionais

PS - Pronto Socorro

PSICO - Psicólogo

PSIQ - Psiquiatra

PT - Partido dos Trabalhadores

RDNPM - Retardo no Desenvolvimento Neuro - Psico - Motor

SES - Secretaria de Estado da Saúde de São Paulo

SIA - Sistema de Informações Ambulatoriais

SIH - Sistema de Informações Hospitalares

SIMIS - Sistema Municipal de Informação em Saúde

SM - São Miguel

SMC - Secretaria Municipal da Cultura

SMS - Secretaria Municipal de Saúde

SUDS - Sistema Unificado e Descentralizado de Saúde

SUS - Sistema Único de Saúde

TLP - Tabela de Lotação de Pessoal

TO - Terapeuta Ocupacional

UBS - Unidade Básica de Saúde

UF - Unidade Federativa, Estado da União

$\mathbf{X}$ - Versus 


\section{INTRODUÇÃO}

Esta pesquisa é uma contribuição para o estudo das ações de saúde mental e de atenção às pessoas com deficiência desenvolvidas pelos serviços públicos municipais em São Paulo, a partir de um olhar preocupado com a constituição de políticas públicas que contemplem ações coletivas e de assistência individual a esses grupos. A partir de 1989, passaram a existir propostas assistenciais para o município, apresentadas a partir do nível central da Secretaria Municipal de Saúde, para lidar com as demandas da população que sofre psiquicamente e das pessoas com deficiência, grupos populacionais excluídos da assistência municipal. Um dos objetivos da proposta de saúde mental era a criação de uma rede de serviços para o município, experiência inédita até então ${ }^{\square}$.

O que existiu de comum na proposição das ações de saúde para esses grupos é que procuraram lidar com essas questões, de incorporação mais recente, na esteira da conquista da cidadania e dos direitos humanos. Esse é um passo inicial para delineamento e implantação dessas práticas assistenciais nos serviços públicos de saúde. É fundamental conhecer como se articulou a assistência para esses dois grupos, que tiveram programas criados em períodos próximos, durante um momento importante para a constituição da assistência em saúde, pautada por processos políticos para legitimação das diretrizes constitucionais de direito à saúde, através da construção do Sistema Único de Saúde com seus princípios de universalização, eqüidade e integralidade das ações de saúde.

A pesquisa descreve a experiência municipal de assistência em saúde mental e saúde da pessoa portadora de deficiência na Administração Regional de Saúde - São Miguel (ARS-6) da Secretaria Municipal de Saúde, no período entre 1989-95, onde todos os equipamentos propostos para a saúde mental foram criados e na qual se desenvolveram

\footnotetext{
$\square$ Nos anos 80, desenvolveu-se uma experiência de saúde mental na Zona Norte do município, em parceria com a Secretaria de Estado da Saúde, a então Secretaria de Higiene e Saúde de São Paulo, a cadeira de Psiquiatria da Faculdade de Ciências Médicas da Santa Casa de Misericórdia de São Paulo e o Instituto NacionaI de Assistência Médica da Previdência Social - INAMPS, com objetivo de criar atendimento regionalizado e hierarquizado buscando oferecer alternativas de atenção em saúde mental em uma região da cidade onde já se desenvolvia um projeto docente assistencial na área de medicina social com a mesma faculdade. O projeto funcionou até o final da gestão Mário Covas (1984), perdendo seu apoio institucional na prefeitura com a gestão Jânio Quadros e na Secretaria de Estado da Saúde com a gestão de Orestes Quércia (1987) (CESARINO, 1989)
} 
ações de saúde para a população portadora de deficiência, de acordo com as orientações do programa municipal.

Procura-se também, descrever o perfil da clientela atendida quanto à faixa etária, sexo, problemática que levava à busca de assistência e acompanhamento realizado nos serviços. E ainda, conhecer as estratégias utilizadas para implantação e desenvolvimento das ações de saúde mental e saúde da pessoa portadora de deficiência, identificando seus principais atores.

Nesse processo é feita uma análise do modelo assistencial proposto apresentando-se uma reflexão acerca do papel desempenhado pelos técnicos e pelo movimento social na construção da assistência a esses grupos.

Neste trabalho não se pretendeu discutir as propostas assistenciais como se propõem os estudos de avaliação em saúde coletiva (STENZEL, 1996). Buscou-se aqui enfocar distintos aspectos das propostas reconstituindo/analisando as experiências.

A criação das propostas assistenciais se apresentou como a concretização de um dos aspectos da universalização da assistência proposto pelo Sistema Único de Saúde, entendendo-o como possibilidade de exercício de cidadania, que pudesse minimizar o grau de exclusão social desses grupos, questões que são tratadas no Capítulo I.

Os procedimentos metodológicos e as principais dificuldades encontradas no trabalho de campo e no acesso a documentos estão apresentadas no Capítulo II.

A escolha da região de São Miguel Paulista deveu-se ao fato de que esta contou com a criação dos equipamentos de saúde mental previstos em 1989 como Centros de Convivência e Cooperativa, Hospitais-Dia, Emergência e Enfermaria Psiquiátricas e unidade de reabilitação em hospital geral, equipes de saúde mental e profissionais de reabilitação nas Unidades Básicas de Saúde (BARROS et al, 1995). É uma região onde o movimento popular de saúde tem, historicamente, grande atividade participando dos Conselhos Populares de Saúde e, entre 1989-96, dos Conselhos Gestores dos serviços.

No Capítulo III é apresentado, brevemente, o processo de implantação do SUS na região. O território de São Miguel também está caracterizado a partir dos indicadores de exclusão social (SPOSATI, 1996a) e da estrutura e funcionamento dos serviços de saúde. 
O desenvolvimento das práticas assistenciais está caracterizado no Capítulo IV pelos diferentes atores sociais envolvidos no processo, discutindo-se as distintas visões a partir do lugar institucional que ocuparam.

Por último, nos Capítulos V e VI, são levantadas as principais questões colocadas pelo modelo assistencial e pelo grau de implementação conseguido, procurando-se discutí-las como processo de constituição do SUS, num primeiro momento num contexto municipal de avanço das políticas públicas de saúde e, numa segunda etapa, de retrocesso para propostas mais conservadoras de gestão.

A atenção à saúde dessas populações é um dos problemas desses grupos que põe em relevo o lugar social que ocupam. Sua organização traz demandas e necessidades que estão além do atendimento médico estrito, sendo necessário construir um modelo de atenção integral que dimensione o papel dos serviços de saúde nos processos de inserção social dos referidos grupos.

Ao final estão apresentados anexos que auxiliam o entendimento do percurso da pesquisadora na construção analítica reflexões a que se propôs.

A escolha deste tema está vinculada ao processo de capacitação profissional da autora, como trabalhadora e militante do movimento de saúde nos serviços públicos e como docente na Universidade.

O Conselho Nacional do Desenvolvimento Científico e Tecnológico - CNPq financiou as atividades necessárias para o desenvolvimento da pesquisa. 


\section{I . Sistema Único de Saúde e a inclusão de novos grupos populacionais}

\section{Sistema Único de Saúde: notas sobre sua constituição}

O papel do Estado como ator no processo político e articulador do desenvolvimento das políticas sociais recoloca como tema a crise do Estado de Bem-Estar Social, que muitos autores analisaram e apresentaram contribuições importantes para sua compreensão (DRAIBE, S. \& HENRIQUE, W. 1988; ESPING-ANDERSEN, 1991 e 1995; FLEURY, 1994).

A discussão das políticas sociais na realidade brasileira, em especial aquelas da saúde, identifica e analisa a centralidade do Estado como grande mediador do acesso à assistência à saúde, quer promovendo as ações de saúde pública, quer assumindo a assistência médica individual através da compra de serviços privados de saúde; evoluindo do modelo sanitário campanhista para o modelo médico-assistencial privatista (OLIVEIRA, J. \& TEIXEIRA, S.M.F. 1989; MENDES, 1993; LUZ, 1991).

Entre os anos 30 e a década dos 60, com o desenvolvimento de políticas sociais pautadas pela noção de previdência e proteção social, financiadas pelos próprios trabalhadores, observa-se a estruturação da assistência médica individual sob responsabilidade dos Institutos e Caixas de Aposentadorias e Pensões. Haveria de se consolidar uma cisão clara entre as ações de saúde pública e aquelas de caráter individual. Com a unificação dos Institutos, nos anos 60, o Estado passa a ser o financiador e maior comprador de serviços privados de saúde, através de convênios com esse setor, que garantem clientela cativa nos serviços privados até sua capitalização e transformação em setor produtivo independente (LUZ, 1991; COHN, 1995 a; 1996 a e b).

Os anos 70 seriam de grandes gastos da previdência social para pagamento da assistência médica individual e de graves denúncias das péssimas condições de assistência oferecidas pelos serviços privados conveniados com o setor público. Um dos desdobramentos dessa crise é a proposição de planos para melhoria da cobertura assistencial do setor público e novas formas de controle para o setor privado conveniado. 
Com o desenvolvimento econômico então em curso, os serviços de saúde eram mais um dos bens disponíveis no mercado e, a exemplo do que ocorrera com os serviços educacionais nos anos 70, novos grupos teriam acesso a convênios e seguros-saúde em expansão. Com esse processo de privatização da assistência à saúde, têm-se, nos anos 80, um setor privado revitalizado, com novas formas de captação de clientela entre os grupos sociais de maior poder econômico. Era o setor com menor dependência do setor público, como as cooperativas médicas, empresas de seguros de saúde por pré-pagamento tanto para pessoas físicas como jurídicas, como também os serviços de saúde das próprias empresas privadas ou estatais (COHN, 1995 a).

A sociedade brasileira, no contexto dos movimentos pela redemocratização do país, num embate constante com o Estado militar e conservador, pode criar uma série de debates e lutas com repercussões importantes sobre o pensamento e a proposição de ações de saúde. Um dos atores sociais era o movimento pela Reforma Sanitária, com a participação de profissionais, estudantes de carreiras ligadas ao trabalho em saúde, no campo dos técnicos; e também dos movimentos sociais. Suas lutas, a problematização constante e pressão junto ao Estado se dava na perspectiva da construção da saúde como um direito da cidadania e um dever do Estado.

Nesse sentido, o texto constitucional (BRASIL,1988) reflete parte importante desse momento histórico de reconquista dos direitos sociais, que se deu em meio a embates no campo dos interesses privados e públicos no país.

O movimento sanitário defendia como princípios básicos do sistema de saúde seu caráter público-estatal, descentralizado e com participação suplementar do setor privado, sob fiscalização do Estado. Dessa forma, procurava-se garantir a universalização da atenção.

No entanto, os debates para a constituição do Sistema Único de Saúde foram amplos, colocando em pauta diferentes concepções de propostas para o SUS, que iriam se traduzir na Lei Orgânica da Saúde de 1990 e nas diversas Normas Operacionais que procuraram regulamentar a descentralização, o repasse de recursos, enfim, parte da materialidade para a implantação do SUS e para o processo de municipalização da saúde. 
Nesse contexto, também de nova ordem econômica mundial, as discussões sobre o papel do Estado na economia e no desenvolvimento de políticas sociais, sempre presentes, recolocam na cena política a necessidade de que se implemente um Estado, que procure

“ não só do ponto de vista econômico visar um aumento da competitividade global da economia, o que implica adaptar-se ao novo paradigma industrial e tecnológico, mas também do ponto de vista social implementar políticas públicas que incorporem no âmbito da cidadania a pobreza estrutural, à qual agora se associa a "nova pobreza", proveniente do novo padrão excludente de acumulação" (COHN, 1995a p. 239).

A discussão sobre que Estado, a necessidade de desprivatizá-lo, tornando-o mais democrático e permeável às demandas e necessidades sociais e com "capacidade de governo" será novamente colocada pelos intelectuais e políticos (COHN, 1995 a).

Nesse sentido, se inscrevem as discussões sobre quais seriam as instituições capazes de desempenhar as funções públicas, se aquelas mais próximas do setor privado ou mais próximas do setor público. Quais seriam as implicações das políticas de ajuste econômico e estrutural sobre a atenção à saúde? Ou sobre as políticas sociais de uma maneira geral? São temas também discutidos no campo da saúde e da seguridade social (POSSAS, 1995; FLEURY, 1995).

Assim, as experiências de administrações estaduais e municipais mais democráticas, defendendo uma reconstrução do papel do Estado com políticas sociais de caráter mais distributivo, possibilitaram o exercício de gestão na saúde que alteraram qualitativamente o papel do setor público nesse campo (CAPISTRANO, 1995; SILVA, 1996; DIMITROV, 1992; CAMPOS, 1992 a,b e c).

A gestão descentralizada dos serviços seria, portanto, questão fundamental para a consecução dos objetivos do SUS, porque possibilitaria a criação de novos espaços institucionais de participação, onde seria viável a incorporação de novos sujeitos, aqui entendidos como sujeitos coletivos, alterando a relação Estado-cidadãos e contribuindo para que novo projeto coletivo de SUS fosse construído (COHN, 1995 a).

Operacionalizar a descentralização como objetivo político é instrumentalizar novas formas de atenção em saúde. Possibilitar a participação dos movimentos e sociedade civil organizada é tarefa colocada e seu sucesso dependerá não só da redefinição do financiamento do setor saúde, mas de formas de gestão inovadoras que compreendam a 
cultura das organizações e instituições em jogo, redimensionando o papel dos profissionais também como sujeitos sociais, diretamente implicados nessa tarefa (GALLO, 1996; CAMPOS, 1997).

Esse intenso processo social forjado no interior dos movimentos e também das práticas assistenciais em curso nas gestões democráticas, tem revitalizado o setor, reconstruindo/construindo o projeto de SUS como processo social (MENDES, 1996).

A incorporação recente de atenção em saúde mental e da pessoa com deficiência é aqui entendida como ampliação das responsabilidades do Estado, que inicia um processo de construção de política pública para a pessoa com deficiência e amplia seu papel na atenção em saúde mental desenvolvida pelo setor público.

Essa também pode ser observada conhecendo-se seu percurso, revelando as dificuldades para seu equacionamento, como propostas de política de ações concretas para grupos específicos (THOMPSON, 1981).

A incorporação de outras demandas da população, que não aquelas tradicionalmente colocadas para o setor público, como as ações de promoção da saúde, prevenção de doenças transmissíveis ou tratamento de pessoas acometidas por doenças de importante repercussão no grupo social, redimensiona a cidadania dessas populações e radicaliza a concepção de universalização.

O processo de construção de políticas para esses grupos tem sido obstruído com argumentos tais como falta de recursos, impossibilidade de avançar em setores de atenção tradicionalmente entendidos como de alta complexidade, atrelada às questões relativas à atenção em níveis primário e secundário. Esses argumentos são muitas vezes utilizados para mascarar um descompromisso do Estado em relação a parte importante da população, que traz, em si mesma, marcas contundentes do processo de luta social. São evidentes as necessidades de assistência a esses grupos, principalmente quando se observa o perfil epidemiológico da população brasileira (POSSAS, 1989; MINAYO, 1995).

Ousar propostas de atenção em saúde mental e da pessoa com deficiência é traduzir em prática assistencial o princípio da universalização. 


\section{A universalização da atenção à saúde: exercício de cidadania}

A defesa intransigente da universalização da assistência é a própria construção do Sistema Único de Saúde em sua complexidade, exigindo revisão das atribuições dos serviços existentes, dos seus atores como profissionais da assistência, gerentes, planejadores e do movimento social. É a defesa do direito à saúde e à cidadania (BERLINGUER, 1996 a e b; PITTA \& DALLARI, 1992).

Para alguns autores a universalização da assistência poderia supor :

"a existência de um processo de universalização excludente, em que cada movimento de expansão universalizante do sistema é acompanhado de mecanismos de racionamento (queda na qualidade dos serviços, filas etc.) que expulsam daquele diversos segmentos sociais.

Portanto, a universalização dos serviços públicos de saúde no Brasil, possuindo uma velocidade distinta daquela imposta à expansão da sua rede de serviços, resultou na entrada em operação de mecanismos clássicos de racionamento, como forma de acomodar a demanda ampliada a uma oferta em lento crescimento. Os setores menos privilegiados, até mesmo por falta de opções, resistem dessa forma com mais vigor a essas pressões de reacomodação do sistema, enquanto os diversos outros segmentos sociais passam a buscar cada vez mais os serviços do subsistema privado"(FAVERET, P. \& OLIVEIRA, P.J., 1990 p.274-5).

Pode-se considerar também que aqueles que necessitam de atenção em saúde mental, bem como as pessoas com deficiência, em sua maioria, têm baixo poder aquisitivo, o que impossibilita a compra de serviços no setor privado. Por outro lado, aqueles que tenham possibilidades de financiar seus seguros e planos privados de saúde não contam com cobertura assistencial. É clara a determinação dessas empresas de não oferecerem assistência além da consulta médica e, em alguns casos, de cobertura para acompanhamento em fisioterapia, fonoaudiologia, psicologia e terapia ocupacional, limitando-se ao modelo de assistência que reproduz a clínica individual. Não se tem notícia de serviços, seja de saúde mental, seja para pessoas com deficiência, financiados pelos seguros ou planos privados de saúde, com exceção dos mantidos por associações de amigos ou de pais, ligados ou não a determinadas categorias profissionais, como no caso de bancários e metalúrgicos, entre outros.

No caso da pessoa com deficiência a assistência é desenvolvida, prioritariamente, por instituições beneficentes e filantrópicas. A ampliação do papel do Estado nesse campo, a 
defesa da universalização seria de fato avanço, possibilidade de acesso a direitos, conquista de cidadania. Ao mesmo tempo, que a contribuição dessas instituições deveria ser redimensionada, já numa discussão sobre o caráter público de instituições não governamentais com a participação dos grupos diretamente envolvidos nessa assistência e não apenas como objeto de ações filantrópicas.

No caso da atenção em saúde mental já existe uma política pública definida e desenvolvida pelos serviços públicos e pelo setor privado conveniado. A ampliação da assistência, preocupada com a melhoria da qualidade de vida desses grupos, só será possível com a defesa da universalização. Nesse sentido a universalização seria a mesma dos procedimentos de alta especialidade e custo tecnológico que permanecem sob responsabilidade do setor público (FAVERET \& OLIVEIRA, 1990).

A defesa da universalização da assistência em saúde pressupõe o reconhecimento de que grupos importantes da população estariam desassistidos pela política de saúde e não só por ela, sem acesso a direitos básicos. Implica reconhecer que no processo social o desenvolvimento econômico e as políticas sociais adotadas ampliam o contingente de pessoas que estão não só à margem do processo econômico, mas também excluídas social e politicamente.

"Cerca de 1/5 da população sequer atinge as franjas do espaço público, não adquire a igualdade de direitos que o regime político democrático potencialmente lhe ofereceria. Como não constituem massas de homo faber sua ausência do espaço público sequer é notada. São massas desarraigadas e supérfluas constituídas por indivíduos isolados uns dos outros e, portanto impotentes"(ESCOREL, 1993 p. 53).

Nesse sentido, a exclusão social, como categoria cultural e política contribui para o entendimento do lugar social que ocupam determinados grupos. A exclusão social,

" na acepção de Hannah Arendt é uma categoria da esfera cultural e política que pode chegar a dizimar a vida íntima do indivíduo ainda que sempre se inicie pela exclusão do espaço social. É uma categoria que permite uma análise abrangente das relações sociais, particularmente dos valores culturais que as permeiam, quando comparada com a categoria de marginalidade que caracteriza a exclusão de uma esfera econômica, mas não do mundo dos homens, de uma sociabilidade mínima"(ESCOREL, 1993 p. $55)$. 
A exclusão social inclui pobreza, discriminação, subalternidade, não eqüidade, não acessibilidade, não representação pública, configurando-se como processo, onde coexistem situações de privação da autonomia, do desenvolvimento humano, da qualidade de vida, da equiidade e da igualdade. Pode-se dizer que existem graus e formas de exclusão:

“- exclusão estrutural: decorrente do processo seletivo do mercado, que não garante emprego a todos, gerando contínua desigualdade;

- exclusão absoluta: decorrente da condição de pobreza absoluta de um crescente segmento da sociedade brasileira;

- exclusão relativa: sofrida por aqueles que possuem os níveis mais baixos de acesso e apropriação da riqueza social e das oportunidades historicamente acessíveis ao ser humano;

- exclusão da possibilidade de diferenciação: decorrente do grau de normalização e enquadramento que as regras de convívio estabelecem entre grupos de uma sociedade, não efetivando os direitos de minorias. No caso, o padrão de tolerância/intolerância inclui ou não as heterogeneidades de gênero, etnia, opção sexual, opção religiosa, necessidades especiais etc.;

- exclusão de representação: grau pelo qual a democracia de uma sociedade possibilita tornar presentes e públicas as necessidades, interesses e opiniões dos vários segmentos, especialmente na relação Estado-sociedade.

- exclusão integrativa: onde a exclusão é perversamente a forma de um segmento da população permanecer precariamente presente na lógica da acumulação, principalmente a de caráter neoliberal, enquanto outro usufrui do desenvolvimento, da riqueza e da cidadania" (SPOSATI, 1996 p.13).

É também nessa direção que se quer entender a condição daqueles que necessitam de atenção em saúde mental ou das pessoas com deficiências, como populações "duplamente", impedidas de reconhecer, desenvolver, exercitar suas habilidades como seres humanos, pelo processo social e pela inexistência dos apoios sociais necessários ao seu desenvolvimento ou sua visibilidade social.

Por outro lado, é interessante a contribuição de CASTEL (1994) quando recoloca a questão da exclusão social redimensionando-a como desfiliação, ampliando-a para todos aqueles grupos que estão privados do acesso a bens, mas também com seus vínculos sociais dissociados. Para o autor

"Não se trata de subestimar a dimensão econômica da questão. Sabe-se que, quase sempre, uma falta de recursos materiais faz um indivíduo cair na dependência e o constitui em cliente de um serviço social. Trata-se, todavia, de uma situação mais patética que a da pobreza strito sensu. Se esta pode ser lida como um estado onde se inventariam as formas em termos de falta (falta de ganhos, de alojamento, de cuidados, de instrução, falta de poder ou de atenção...) gostaria, de minha parte, de encarar as situações de privação 
como um efeito na conjunção de dois vetores: um eixo de integração/não-integração pelo trabalho; um eixo de inserção/não inserção em uma sociabilidade sócio-familiar" (CASTEL, 1994 p.22-23).

Por esses motivos as intervenções sociais para esses grupos deveriam estar pautadas na identificação dessa complexidade, pois são populações que,

“estão não somente ameaçadas pela insuficiência de seus recursos materiais como também fragilizadas pela labilidade de seu tecido relacional; não somente em vias de pauperização mas também em processo de desfiliação, ou seja, em ruptura de vínculo com o social. Ao final do processo, a precariedade econômica torna-se privação, a fragilidade relacional isolamento. São duas faces de uma mesma condição"(CASTEL, 1994 p.21-23).

Reconhecer a dimensão e complexidade dessa experiência particular e social de exclusão social e de desfiliação, representada pela doença mental ou pela deficiência é trazer novos conteúdos para as propostas de assistência, é dimensioná-la para além de recursos materiais ou humanos disponíveis para a consecução de políticas.

A defesa intransigente da universalização da atenção em saúde deve necessariamente articular a compreensão da complexidade dos processos de exclusão social desses grupos com a identificação das contribuições do setor saúde, como um dos espaços institucionais a ser ocupado, para possibilitar experiências de inclusão e maior contratualidade social. 


\section{A atenção em Saúde Mental}

A atenção em saúde mental é tema que pode ser analisado do ponto de vista histórico, conhecendo a psiquiatria e a consolidação de suas práticas e instituições no contexto brasileiro, como também pontuando as influências da política de saúde na determinação da assistência mental, uma das faces da política social. Outro ponto de vista poderia ser o percurso do movimento sanitário brasileiro e a participação dos trabalhadores de saúde mental na discussão e proposição de estratégias para o estabelecimento de políticas públicas para o setor, participação essa fundamental para os rumos da reestruturação da assistência.

São diversos os pesquisadores que realizaram estudos e reflexões sobre a assistência mental no Brasil (REZENDE, 1987; DELGADO, 1987; AMARANTE, 1992; BERNARDO, 1992).

Para apresentar a política oficial de saúde mental o recorte escolhido será aquele apresentado por LUZ (1994), quando a discute como política oficial. A autora entende por política:

"o conjunto de formas de intervenção concretas, na sociedade, que o Estado aciona para equacionar o problema das condições sociais de existência de grandes camadas populacionais, daquelas que dependem, para sua sobrevivência, apenas de sua capacidade de trabalhar. Em termos mais claros: a maneira como o Estado conduz o problema das condições de vida das classes trabalhadoras. Empregamos a expressão, classes, assim no plural, para especificar que há mais de uma classe, às vezes interesses sociais diversos, que vivem apenas de seu trabalho: camponeses, operários agrícolas, operários urbanos, comerciários, todos vivendo sob as mesmas relações sociais, delas sofrendo os mesmos efeitos, embora pertençam a diferentes segmentos sociais dos trabalhadores" (LUZ, 1994 p.86).

Para a autora as políticas de saúde mental, em especial, seriam "formas políticas de marginalização", favorecendo "a exclusão econômica e social de setores da sociedade". Nesse texto, a autora trabalhou com a noção de "Estado restrita ao conjunto de seus aparelhos institucionais, repressivos e ideológicos" [incluindo] "tanto a escola, o hospital, como o cárcere, a política, a lei, a norma - forma do discurso institucional - e os Ministérios" (LUZ, 1994 p.86-87). 
Para a autora as instituições de saúde mental não estariam restritas àquelas vinculadas à psiquiatria,

"outros espaços institucionais - inclusive o consultório com seu divã - e outros discursos teóricos foram organizados sobre o mesmo objetivo (...) a loucura não está contida em um aparelho específico de Estado, como o asilo, ou que os saberes que se elaboraram sobre ela se destinem só aos loucos (...) para compreender as políticas de saúde mental é preciso ter claro que elas mediatizam saberes e práticas institucionais distintas, com uma evolução histórica específica, e que tanto esses saberes quanto as práticas de intervenção institucional que eles originam não são monolíticos nem coerentes. Ao contrário, são muitas vezes contraditórios, tanto no nível do saber quanto no nível da intervenção. Daí resultam muitas contradições entre discurso - entendido como planos, programas, norma - e prática institucional."(LUZ, 1994 p.94).

Por outro lado, os profissionais exerceriam papel fundamental na articulação desses saberes e práticas, "colocando-os em ação", isto é funcionando como agentes para legitimação do papel das instituições no contexto social (LUZ, 1994; BARROS, 1991).

A noção de política, de Estado, definição das instituições e o papel dos técnicos, como agentes institucionais, são apresentados por LUZ como elementos fundamentais para compreensão da história da política oficial.

Historicamente, por volta da década dos 80 do século XIX, eram duas as preocupações da saúde pública: as epidemias e a loucura, para as quais se desenvolveram estratégias de saúde/atendimento pelo Estado. Esses eram problemas a que estava exposta a maior parte das populações urbanas do país, colocando em risco tanto os negócios de exportação como os interesses políticos internos. Eram problemas que, potencialmente, poderiam atingir distintos grupos sociais, "uns mais que outros".

O Estado então, através das instituições de saúde contribuiria para a produção de um “discurso sobre a cidade: sobre o meio ambiente urbano, a estrutura sanitária das metrópoles, a habitação, os hábitos alimentares, morais e sexuais; sobre os costumes" (LUZ, 1994 p.91).

Para a autora, a criação dos primeiros hospícios no país responderiam, via discurso da ordem, à legitimação de espaços de exclusão, administrados pelo saber científico médico-psiquiátrico. Permaneceriam inquestionáveis as condições objetivas de produção do sofrimento psíquico ligadas ao processo de legitimação da nova ordem social, e um novo código se estabeleceria para a leitura dos padrões de vida daqueles que não encontrassem as 
condições para a sobrevivência nesse processo de luta social. Esse período teria sido propício para que as discussões sobre a hereditariedade, raça e loucura ganhassem corpo; assim como outras relativas ao necessário trabalho de educação moral dos excluídos, como forma de adequar parcelas importantes da população ao novo padrão de conduta necessário à industrialização em curso.

O asilo permaneceria como única resposta de assistência com reconhecimento científico, no campo da Saúde Pública e, posteriormente, na Previdência Social, respondendo por grande parte do mercantilismo produzido na saúde.

Ainda segundo a autora, outros saberes como a psicologia nos anos 50 e a psicanálise nos anos 60, assimilaram a defesa de outras alternativas de assistência e influenciaram diretamente a família, os espaços de trabalho, o desenvolvimento da sexualidade, os espaços de assistência à saúde como o hospital e unidades básicas de saúde.

“O papel mais orientador, persuasivo, desses novos discursos e práticas, não está menos ligado, entretanto, ao Estado, que o discurso/prática psiquiátrico-asilar. Se um tem um aspecto mais dominantemente repressivo, os outros têm um aspecto positivo de organizadores do espaço psíquico da sociedade, indispensável ao assentamento consensual da dominação. Seu papel é muito mais estratégico, face à hegemonia, que a repressão excludente do hospital. Trata-se agora de não mais incluir pela marginalização. $O$ controle psicossocial muda de natureza: trata-se de organizar, de planificar, para incluir na ordem política (...) Não somente as instituições, mas cada comportamento, desejo ou aspiração humana podem ser ordenados. Assim, pelo fato de perder seu caráter dominantemente repressivo, marginalizador, os discursos e práticas sobre a loucura não perdem seu caráter de "Estado" (LUZ, 1994 p.94).

Em continuidade, a autora reafirma o papel dos técnicos, como agentes institucionais fundamentais, delegados da função controladora do Estado, que pelo reconhecimento de sua inserção social, de seu papel profissional poderiam ou não estar em crise diante dessa função.

AMARANTE et al (1995) quando discutem a Reforma Psiquiátrica apontam a importância da constituição de novos atores, como o Movimento de Trabalhadores de Saúde Mental, as Associações de Familiares e de Usuários de serviços como novos interlocutores para o campo, na definição e implementação da atenção em saúde mental e na discussão das instituições de saúde e seu papel social. 
Os autores dividem, apenas didaticamente, a Reforma Psiquiátrica em três períodos denominados de: trajetória alternativa, trajetória sanitarista e trajetória da desinstitucionalização ou da desconstrução/invenção.

É no bojo dos movimentos da sociedade civil por liberdades democráticas que os profissionais, que de certa forma entraram em crise com seu papel, motivados pelo questionamento da inoperância dos serviços de saúde, pela falta de acesso da população ao direito à saúde e pelas condições de trabalho, colocaram em discussão a organização social e modo de produção, compondo o conjunto das forças de oposição.

Os movimentos de estudantes, intelectuais e profissionais da saúde nos anos 70 e 80 questionavam o modelo assistencial em saúde e conseguiram problematizar o tema da atenção em saúde mental como uma questão de direitos humanos. Denunciavam as condições sub-humanas de existência das pessoas institucionalizadas, as condições salariais e de trabalho dos técnicos, motores importantes para a necessária rediscussão da política de saúde mental no país como questão de direitos humanos (DELGADO, 1987; MARSIGLIA, 1987; DALLARI, 1992).

Em diferentes regiões do país essas discussões foram gestando entre os técnicos um movimento importante para a definição dos rumos da reestruturação da assistência psiquiátrica. Esse movimento se intitulou Movimento de Trabalhadores de Saúde Mental MTSM (AMARANTE, 1995).

O MTSM se associou a várias entidades que lutavam pela redemocratização do país e, ao mesmo tempo, participou de Congressos de Psiquiatria levando as questões relativas à necessária Reforma Psiquiátrica, somando forças na discussão da Reforma Sanitária empreendida pelo Movimento Sanitário e empreendendo Encontros e Congressos Nacionais próprios (AMARANTE et al, 1994).

Por outro lado, a política de saúde mental produzia um abandono progressivo das instituições públicas através do esvaziamento de recursos financeiros e da transferência de pacientes para as instituições conveniadas que, a partir de um discurso de maior competência técnica e administrativa, passam a dominar o campo da assistência psiquiátrica (REZENDE, 1987; DELGADO, 1987).

À medida que o processo de redemocratização foi se instalando, parte das lideranças dos movimentos sanitário e de saúde mental seriam chamadas a compor os quadros de 
órgãos estaduais e federais de saúde, colaborando na apresentação de propostas de transformação da assistência e na gestão dos serviços, durante os anos 80. Desenvolveram-se experiências de atenção em saúde mental apoiadas nas diretrizes e na reorientação da assistência em saúde do plano CONASP que puderam implantá-las a partir dos recursos do convênio das Ações Integradas de Saúde - AIS.

No Estado de São Paulo procurou-se estabelecer uma política de fortalecimento dos serviços públicos de saúde deslocando a ênfase hospitalocêntrica de assistência para serviços extra-hospitalares e internação de curta permanência, prevendo o processo de descentralização, regionalização e hierarquização, segundo níveis de complexidade resolutiva e recursos tecnológicos que a demanda exigisse (COORDENADORIA DE SAÚDE MENTAL, 1983; MÂNGIA,1990).

O hospital psiquiátrico ainda era o modelo hegemônico de assistência e os esforços dos Encontros e Conferências Estaduais de Saúde Mental e de Coordenadores de Saúde Mental da Região Sudeste (1985, 1986 e 1987) seriam para produzir uma assistência ambulatorial integrada, interinstitucionalmente entre os serviços estaduais federais e municipais, com criação de leitos psiquiátricos em hospitais gerais, a expansão da rede básica, promovendo a integração da assistência em saúde mental ao sistema de saúde. Os princípios seriam os da universalização, da regionalização, da hierarquização, da participação comunitária, da integralidade e da eqüidade defendendo a articulação interinstitucional, prioridade ao setor público, modificação do modelo assistencial hospitalocêntrico, desenvolvimento de recursos humanos, promoção de estudos epidemiológicos e ênfase terapêutica psicoterápica e socioterápica (BRASIL, 1987).

Parte do MTSM acreditava que a participação nas estruturas de poder viabilizaria, desde que respeitados os princípios de planejamento e gestão participativa, um projeto assistencial coerente com as perspectivas do movimento de saúde mental colocadas pelos MTSM e Movimento da Reforma Sanitária. Isto de certa forma garantiu também as articulações políticas na sociedade civil para que a proposta SUS fosse incorporada ao texto constitucional. Os espaços ocupados por esses técnicos seriam espaços de decisão política e de administração de serviços cuja complexidade e contradição permaneciam presentes.

\footnotetext{
$\square$ Plano CONASP - Conselho Consultivo da Administração de Saúde Previdenciária para reorientação da assistência à saúde no âmbito da Previdência Social com diretrizes para diversos setores, inclusive saúde mental (OLIVEIRA \& TEIXEIRA, 1989).
} 
Esse período poderia ser chamado de trajetória sanitarista, pelas influências que recebeu/exerceu no Movimento Sanitário. No entanto, é importante:

"não desvalorizar o fato de que a trajetória sanitarista (...) representa avanço sob alguns aspectos. Primeiro, porque é preciso considerar as conjunturas em que se situa, pois são períodos de difíceis enfrentamentos seja com empresários da loucura, seja com adeptos da psiquiatria clássica, organicista, institucionalizante ou mesmo violenta e repressora. $E$ não foram poucas as vezes em que esses enfrentamentos se deram em níveis literalmente violentos, com agressão física, ameaças e perseguições." (AMARANTE et al., 1995 p.101).

Em 1986, durante o II Congresso de Trabalhadores de Saúde Mental, organizado pela Secretaria de Estado da Saúde de São Paulo novas lideranças surgiriam a partir dos conflitos com os profissionais mais identificados com as posições oficiais para a assistência. Essas lideranças representavam-se no Plenário de Trabalhadores de Saúde Mental, que se propunha a democratizar as discussões acerca da política assistencial. Eram profissionais que participavam desses novos serviços, recolocavam a discussão da política de saúde mental propondo a defesa de serviços mais próximos às demandas da população, flexíveis o suficiente para a criação de alternativas para se contraporem à instituição psiquiátrica. Essa tendência articulou-se nacionalmente, influenciando a I Conferência Nacional de Saúde Mental. Ainda em 1987, se realizou o II Congresso Nacional de Trabalhadores de Saúde Mental

"realmente inovador: procura-se discutir as práticas e a viabilidade de transformar as realidades; a sociedade os usuários e os familiares participam como força ativa; a opção de "ganhar a opinião pública" é alcançada com visível êxito nessa primeira iniciativa(...) 0 movimento pela reforma psiquiátrica reencontra suas origens e se distancia do movimento pela reforma sanitária. Parte da explicação desse afastamento pode ser encontrada no fato de que, apesar de todos os desvios de rota, de todas as contradições e paradoxos, o movimento psiquiátrico sempre mantém um viés desinstitucionalizante, isto é, mantém em debate a questão da institucionalização da doença e do sujeito da doença, ao passo que o movimento sanitário perde de vista a problematização do dispositivo de controle e normatização próprio da medicina enquanto instituição social" (AMARANTE et al. 1995 p.87, 99). 
Foi nesse processo que se teria forjado o terceiro período, da trajetória da desinstitucionalização ou da desconstrução/invenção.

Outro avanço importante foi a participação do movimento de trabalhadores de saúde mental e das associações de familiares e usuários de serviços como interlocutores/atores privilegiados no processo de consolidação da Reforma Psiquiátrica no Brasil (AMARANTE, 1995).

Muitos dos processos e avanços na construção de sistemas de saúde identificados com a trajetória sanitarista ou inspirados na desconstrução e desinstitucionalização, puderam se desenvolver em administrações municipais, que vinham buscando caminhos para o equacionamento dos gravíssimos problemas dos sistemas locais de saúde. É dentro deste quadro de luta pela equiidade do direito e acesso real à assistência, que vêm se desenhando projetos assistenciais a populações segregadas e tuteladas, como os doentes mentais (DALLARI, 1992; KALIL, 1992; CAPISTRANO, 1995; CATÂNIO, 1996; CAMPOS, 1996).

A política de saúde mental no Brasil produziu a necessária implantação e implementação de serviços seja com experiências de superação da assistência psiquiátrica convencional, seja por alternativas assistenciais ligadas à psiquiatria comunitária. Sem dúvida, não com a velocidade e volume de serviços que os profissionais engajados nessa luta política pretendiam, mas com mudanças substantivas nas possibilidades de inserção desse grupo da população nos serviços de saúde.

Essas mudanças são resultado do movimento de trabalhadores, técnicos e sociedade civil articulados nacional e internacionalmente acompanhando as decisões sobre a reestruturação da assistência psiquiátrica (ORGANIZAÇÃO PANAMERICANA DE SAÚDE, 1992).

Pode-se observar como um dos desdobramentos do maior controle sobre os hospitais psiquiátricos exercido pela política da saúde mental, a diminuição do número de hospitais psiquiátricos entre 1981 e 1996 (de 430 hospitais em 1981 para 269 em 1996) Entre 1991 e 1996 também ocorre um decréscimo no número de leitos em hospitais psiquiátricos no país ( em 1991 era de 85.037 e em 1996 de 68.462), conforme afirma ALVES (1996, p.6, 7). 
Esses dados associados ao aumento do número de hospitais-dia (HD), Centros de Atenção Psicossocial (CAPS) e Núcleos de Atenção Psicossocial (NAPS), além da inclusão de atendimentos grupais, visitas domiciliares, entre outros, também em serviços ambulatoriais, podem significar uma mudança na qualidade da atenção aos doentes mentais.

Nota-se na Tabela 1, que em 1996 os serviços eram, em sua grande maioria, públicos ou ligados a Universidades revelando consonância com os princípios do movimento pela Reforma Psiquiátrica.

TABELA 1. Número de Hospitais-dia, NAPS e CAPS, segundo a natureza e UF, Brasil, 1996.

\begin{tabular}{ccccccc}
\hline UF & \multicolumn{3}{c}{ Hospitais-dia } & \multicolumn{3}{c}{ NAPS / CAPS } \\
\hline & C & A & \multicolumn{2}{c}{ B } & A & B \\
\hline AC & --- & --- & --- & --- & --- & --- \\
AM & --- & --- & --- & --- & --- & --- \\
AP & --- & --- & --- & --- & --- & --- \\
AL & 1 & --- & --- & 2 & --- & --- \\
BA & --- & --- & --- & --- & 2 & --- \\
CE & 1 & 1 & --- & 6 & --- & --- \\
DF & 2 & --- & --- & 2 & --- & --- \\
ES & --- & --- & --- & 1 & --- & --- \\
GO & --- & 1 & --- & --- & --- & --- \\
MA & --- & 2 & --- & --- & 1 & --- \\
MG & 2 & --- & 1 & 8 & 6 & --- \\
MS & --- & --- & 1 & --- & --- & --- \\
MT & 1 & --- & --- & --- & --- & --- \\
PA & 1 & --- & --- & --- & --- & --- \\
PB & --- & --- & --- & --- & 1 & --- \\
PE & 2 & --- & --- & 3 & 1 & --- \\
PI & --- & 1 & --- & 2 & --- & --- \\
PR & 1 & 2 & --- & 2 & --- & --- \\
RJ & 5 & 1 & 2 & 2 & --- & --- \\
RN & --- & --- & --- & 2 & --- & --- \\
RO & --- & --- & --- & --- & --- & --- \\
RR & --- & --- & --- & --- & --- & --- \\
RS & --- & --- & 2 & 5 & --- & --- \\
SC & 1 & --- & --- & 2 & --- & --- \\
SE & --- & --- & --- & --- & --- & --- \\
SP & 12 & 3 & 2 & 9 & --- & --- \\
TO & --- & --- & --- & --- & --- & --- \\
\hline Total & 29 & 11 & 8 & 46 & 11 & --- \\
\hline Fonte: COSAM/DAPS/SAS/MS - Abril 1996 apud ALVES, & 1996 p.10 & & \\
A- Públicos & B & Contratados & C- Universitários & & \\
& & & & & & \\
\hline
\end{tabular}


A política de saúde mental preconizada pelo Ministério da Saúde tem priorizado investimentos nos serviços públicos buscando, no processo de descentralização para gestão do SUS, a criação de serviços que possam combater a cultura manicomial.

A mesma tendência é observada para os leitos psiquiátricos em hospital geral, onde o setor público e as universidades são responsáveis por grande parte deles, principalmente no Estado de São Paulo, conforme Tabela 2. Nesse caso, a presença do setor contratado também é significativa contando com $39,15 \%$ dos leitos.

TABELA 2. Número de leitos psiquiátricos em hospital geral, segundo natureza e UF, Brasil, 1996.

\begin{tabular}{|c|c|c|c|c|c|c|}
\hline \multirow[t]{3}{*}{$\mathrm{UF}$} & \multicolumn{3}{|c|}{$\mathrm{N}^{\circ}$ de hospitais gerais } & \multicolumn{3}{|c|}{$\mathrm{N}^{\circ}$ de leitos psiquiátricos } \\
\hline & \multirow[t]{2}{*}{ A } & & \multirow[t]{2}{*}{$\bar{B}$} & \multirow[t]{2}{*}{ A } & \multicolumn{2}{|c|}{$\mathrm{B}$} \\
\hline & & $\mathrm{C}$ & & & $\mathrm{C}$ & \\
\hline $\mathrm{AC}$ & $\overline{---}$ & $\overline{---}$ & $\overline{---}$ & $\overline{---}$ & $\overline{---}$ & $\overline{---}$ \\
\hline $\mathrm{AM}$ & --- & --- & --- & --- & --- & --- \\
\hline AP & 1 & --- & --- & 14 & --- & --- \\
\hline $\mathrm{AL}$ & --- & --- & --- & --- & --- & --- \\
\hline BA & 3 & 1 & --- & 76 & 30 & --- \\
\hline CE & --- & --- & --- & --- & --- & --- \\
\hline DF & --- & --- & 1 & --- & --- & 35 \\
\hline ES & 1 & --- & --- & 30 & --- & --- \\
\hline GO & --- & 1 & --- & --- & 20 & --- \\
\hline MA & --- & --- & --- & --- & --- & --- \\
\hline MG & 2 & 2 & 3 & 21 & 60 & 70 \\
\hline MS & --- & 1 & 2 & --- & 16 & 52 \\
\hline MT & --- & --- & --- & --- & --- & --- \\
\hline PA & 1 & --- & --- & 30 & --- & --- \\
\hline PB & --- & --- & --- & --- & --- & --- \\
\hline PE & 3 & --- & 1 & 90 & --- & 8 \\
\hline PI & --- & 3 & --- & --- & 45 & --- \\
\hline PR & --- & 2 & --- & --- & 60 & --- \\
\hline RJ & 3 & --- & 1 & 90 & --- & 30 \\
\hline RN & 1 & --- & --- & 7 & --- & --- \\
\hline RO & 1 & --- & --- & 20 & --- & --- \\
\hline RR & --- & --- & --- & --- & --- & --- \\
\hline $\mathrm{RS}$ & --- & 11 & 3 & --- & 196 & 90 \\
\hline SC & --- & 14 & --- & --- & 234 & --- \\
\hline SE & --- & --- & --- & --- & --- & --- \\
\hline SP & 11 & 1 & 7 & 217 & 30 & 149 \\
\hline TO & --- & --- & --- & --- & --- & --- \\
\hline Total & 27 & 36 & 18 & 595 & 691 & 434 \\
\hline
\end{tabular}


Obs: registrados hospitais com no mínimo 3 leitos

Foi nesse contexto de implantação de política de saúde que se delinearam os princípios norteadores da Política Municipal de Saúde Mental no Município de São Paulo, identificada com o ideário do Movimento Sanitário, como a defesa intransigente do Sistema Único de Saúde e a luta por construir uma administração municipal de caráter democrático-popular, com ampla participação e parceria do Movimento Popular de Saúde.

\section{A assistência municipal - movimento na direção da luta antimanicomial}

Os profissionais de saúde mental participaram da elaboração da proposta para o governo municipal de São Paulo (1989-1992) estavam historicamente ligados ao MTSM, tendo integrado equipes de saúde mental na Secretaria de Estado da Saúde de São Paulo. Eram profissionais críticos da política de saúde mental implementada pelo governo estadual considerando-a pouco permeável ao movimento social, quer dos trabalhadores de saúde mental, quer do movimento social no campo da saúde (SECRETARIA MUNICIPAL DE SAÚDE, 1989).

As bases da política municipal de saúde mental em São Paulo inscreveram-se no movimento de críticas às diretrizes políticas até então adotadas, como o modelo asilar de assistência, hospitalocêntrico e de reiteração da cultura manicomial e o não confronto com os grupos de poder econômico, no campo da assistência psiquiátrica (DELGADO, 1987; REZENDE,1987; AMARANTE, 1992).

As lideranças que propuseram o Programa de Saúde Mental tinham participação histórica no MTSM defendiam um modelo de atenção em saúde mental que tinha como alicerce:

“1. combate à Cultura Manicomial presente nas instituições e na maioria da população;

2. criação de um Modelo Assistencial em Saúde Mental que torne desnecessária a internação psiquiátrica asilar;

3. confronto político do poder público contra a Instituição Psiquiátrica Manicomial e Asilar e seus subjacentes." (SECRETARIA MUNICIPAL DE SAÚDE, 1989, p.17). 
A materialidade da nova política se traduzia na forma de organização de serviços: propunha-se a eliminação da internação asilar, criação de leitos psiquiátricos em hospitais gerais, pronto-socorro psiquiátrico com equipe multiprofissional e criação de serviços territoriais hierarquizados, formando um conjunto múltiplo e diferenciado de serviços segundo a complexidade das ações, conforme Figura 1.

Desta forma, cada região de saúde deveria contar com os seguintes equipamentos e serviços: Emergência e Enfermaria Psiquiátricas em hospital geral, Unidades Básicas de Saúde, Hospital Dia, Centro de Convivência e Cooperativas e Lares Abrigados. Nos textos oficiais do programa, com esse conjunto de serviços em atividade plena se defendia a idéia de que seria possível prescindir do atendimento e internações nos hospitais psiquiátricos especializados, que deveriam ser desativados.

FIGURA 1. Modelo de atenção em saúde mental da Prefeitura Municipal de São Paulo (1989-92)

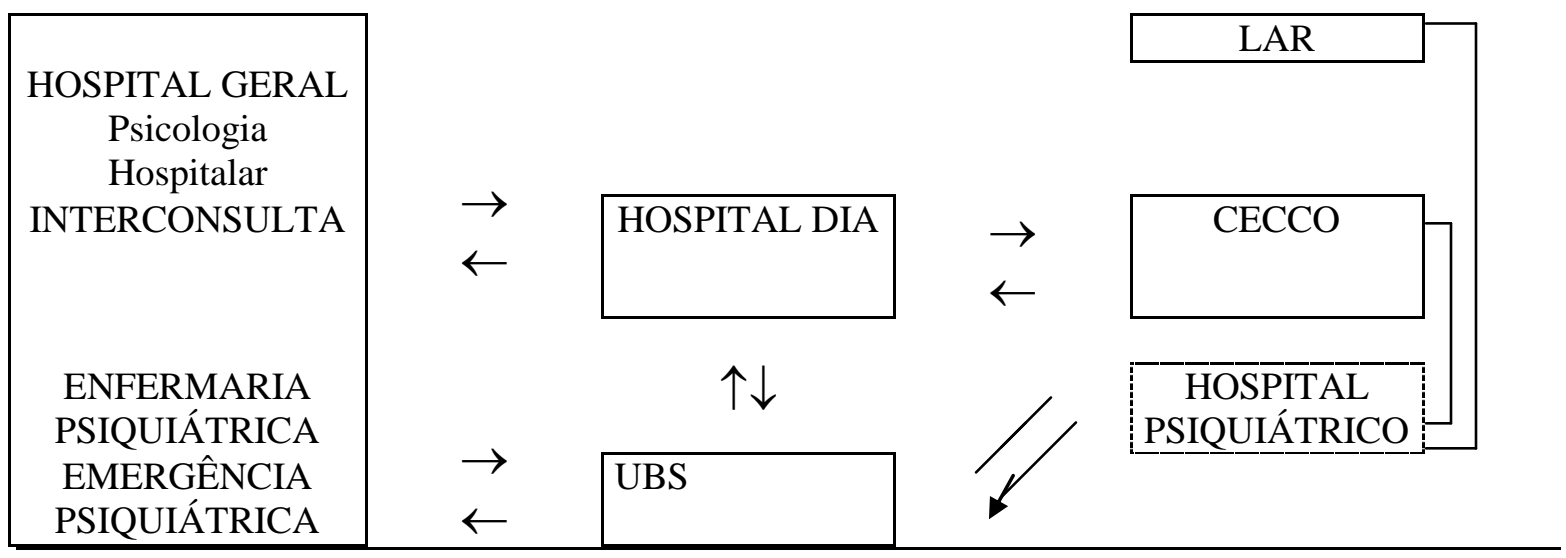

FONTE: SECRETARIA MUNICIPAL DE SAÚDE, 1989 p.21.

As atribuições antes colocadas no ambulatório estadual de saúde mental se ampliam dando lugar a diferentes equipamentos que teriam por função lidar com a diversidade da problemática de saúde mental da população, tarefa que não seria desempenhada por uma única estrutura de serviços, como o antigo ambulatório de saúde mental. Para a consecução da nova política seriam exigidos serviços e ações diversificadas.

Nesse sentido, foram criados serviços de saúde mental que tinham como objetivo:

"oferecer respostas em nível de resolutividade dos problemas mais graves (psicose, alcoolismo, deficiência mental, situações de crise, etc.) e agir sobre condições ambientais e institucionais geradoras destes problemas; evitar 
uma ação individualizadora que funcione como mecanismo potencial de controle social; e em oferecer serviços cuja complexidade possibilite trabalhar as tensões familiares, conter as demandas por reinternações e liberar a mão de obra ativa responsável pela sobrevivência familiar" (SECRETARIA MUNICIPAL DE SAÚDE, 1989, p.20).

Os novos equipamentos de saúde mental e a contratação de pessoal para sua implementação criaram parte das condições necessárias para o desenvolvimento da nova política. Em 1992, as ações de saúde mental foram apresentadas em documento que previa normas técnicas de funcionamento dos serviços (SECRETARIA MUNICIPAL DE SAÚDE, 1992b).

$\mathrm{Na}$ unidade de saúde mental em Hospital Geral, composta por Emergência Psiquiátrica (com leitos de observação de 72 horas); Enfermaria Psiquiátrica (com tempo de permanência de no máximo 15 dias) e Psicologia Hospitalar estaria uma equipe composta por médicos, psicólogos, assistentes sociais e enfermeiros. Esse equipamento deveria funcionar como um "mecanismo de contenção do paciente candidato ao hospital psiquiátrico" pois teria maior resolutividade e vinculação com serviços de saúde da região, facilitando o encaminhamento e acompanhamento extra-hospitalar.

Outro equipamento proposto foi o Hospital-dia:

"previsto no modelo de atenção à saúde mental de SMS e cumpre papel fundamental nesse sistema complexo que visa combater a cultura manicomial ainda presente em nossa sociedade. Sua função é oferecer atenção intensiva ao paciente com sofrimento psíquico intenso sem excluí-lo do convívio familiar e social. Visa substituir a internação hospitalar em regime fechado por uma modalidade de tratamento ambulatorial intensiva $\mathrm{e}$ aberta. Tem também por objetivo respaldar os pacientes egressos de hospitais psiquiátricos, visando dar seguimento à Reforma de Atenção em Saúde Mental, cujos objetivos são a diminuição e progressiva extinção dos manicômios (...) O hospital-dia é um equipamento de saúde indicado para tratamento de casos em momentos de sofrimento psíquico intenso que configurem uma situação de crise (grau intenso de comprometimento funcional, desestruturação familiar e social)." (SECRETARIA MUNICIPAL DE SAÚDE, 1992b p.76).

O Hospital-dia ofereceria continência ao paciente em crise, proporcionando um aporte social, respondendo à tensão produzida pela situação de crise, tanto para o paciente como para as famílias. O trabalho se realizaria, diariamente, com suporte de uma equipe interdisciplinar. 
Nas unidades básicas de saúde, porta de entrada do sistema, a equipe interdisciplinar de saúde mental se integraria aos demais profissionais do serviço, estudando e contribuindo para a definição da assistência, que respondesse aos problemas de saúde da população, a partir do estudo do perfil epidemiológico da região oferecendo oportunidades de participação dos usuários nos espaços organizados da comunidade e favorecendo o contato com instituições e equipamentos sociais como creches, escolas e clubes.

Propunha-se, também, um novo equipamento social, aqui não mais vinculado apenas às demandas de saúde da população usuária, apresentado como Centro de Convivência e Cooperativa. Esse seria um espaço cultural e educativo concebido para lidar com a necessidade de integração dos grupos populacionais marginalizados, apoiados por técnicos de saúde, educação e agentes sociais diversos, onde se procuraria lidar com questões cotidianas colocadas pela mitificação da loucura e da deficiência. Trabalharia no

"combate à cultura manicomial favorecendo a integração social de grupos auto-geridos pela população, atendendo às necessidades de jovens, idosos, mulheres, crianças e grupos que se caracterizem por diferentes graus de deficiência física ou mental" (SECRETARIA MUNICIPAL DE SAÚDE, 1992, p. 10).

O Centro de Convivência e Cooperativa teria por objetivo também

"possibilitar o encontro dos diferentes, das assimetrias expressas, sejam elas expressas na relação com a natureza, com o fenômeno do sofrimento humano, mental ou não, expressas nas chances de vida de determinados grupos sociais, no resultado da relação dominador-dominado, que concorrem para delinear-sombrear uma "ecologia da subjetividade", onde o se perceber diferente poderá remeter à noção de estrangeiro, potencial interno desconhecido/potencial do outro reconhecido, tecendo novas relações que preservem a vida, recriem papéis e direitos, num contínuo-crítico questionamento do desejo, da cidadania. Este exercício de convivência dos tido como diferentes, estruturado sob o eixo da solidariedade e da não segregação dará contorno a uma abordagem em saúde mental de ruptura com a cultura manicomial para a efetivação de contratos sociais anti-discriminatórios e anti-paternalistas, para nesta fratura conquistar relações democráticas e desalienantes." (SECRETARIA MUNICIPAL DE SAÚDE, 1992b p.93).

O caráter inovador dessa proposta, concebida fora dos espaços tradicionais das ações de saúde, trouxe à experiência também dificuldades para sua implementação na prática cotidiana, onde a contratação dos recursos humanos não tradicionais, como 
oficineiros, para o desenvolvimento de atividades, para o trabalho de convivência e dos embriões de cooperativas, foi polêmica até o final da gestão.

Os equipamentos têm uma dinâmica de trabalho específica. No CECCO torna-se mais visível a tendência à interdisciplinariedade, ao mesmo tempo em que esta é menos enfática na organização e desenvolvimento das ações no hospital-dia (SECRETARIA MUNICIPAL DE SAÚDE, 1992b).

A criação de serviços de saúde mental e contratação de pessoal para sua implementação alcançou grande impulso, no período de 89 a 91, facilitando o desenvolvimento da nova política. No entanto os obstáculos encontrados relacionavam-se aos diferentes ritmos para contratação, liberação de recursos financeiros para equipamentos e materiais de consumo para esses novos serviços, situação comum ao desenvolvimento de políticas públicas e que estão descritas na literatura, como no caso do estudo empreendido por THOMPSON (1981) quando buscou conhecer os processos de implementação de políticas nos EUA.

Em 1992 estavam em funcionamento 130 equipes de referência em saúde mental em UBS, 13 Hospitais-dia e 19 CECCO. Em hospitais gerais havia 3 Enfermarias Psiquiátricas, 15 Emergências Psiquiátricas e 50 clínicas, que contavam com acompanhamento psicológico, sendo essa a materialidade atingida pelo modelo proposto (SECRETARIA MUNICIPAL DE SAÚDE, 1992b p.II-III).

A maior parte dos recursos humanos do Programa de Saúde Mental foram destinados a compor as equipes de saúde mental em UBS, como uma estratégia que privilegiava a atribuição desse equipamento para o delineamento da política de saúde mental. Esse modelo de atenção teria suas raízes na compreensão preventivista dos distúrbios de saúde, sem que se tenha questionado o papel que as UBS vinham desempenhando na assistência à saúde da população com ações de saúde junto à população de crianças e mulheres em idade fértil.

Contraditoriamente, as maiores questões levantadas como relevantes na constituição do sofrimento psíquico sempre passaram ao largo das ações de saúde da UBS, preocupada, tradicionalmente, com ações preventivas.

A política de saúde mental tinha como componentes essenciais a implantação de novos serviços e uma discussão cotidiana entre técnicos, população usuária e população em 
geral, sobre a cultura manicomial e as formas concretas de combatê-la, num trabalho de mobilização cultural, que foi levado como tema de diversas manifestações pela cidadania e pelos direitos humanos, nos eventos de luta antimanicomial, em seminários, divulgação e defesa dos projetos de lei federal e estadual sobre a extinção progressiva dos manicômios e criação de estruturas alternativas de atendimento (SECRETARIA MUNICIPAL DE SAÚDE, 1990).

Uma das conquistas do processo de constituição desses serviços foi a valorização concreta do trabalho dos profissionais não médicos, inclusive na divisão do poder, no gerenciamento, assessoria e administração dos serviços (Entrev. n 7, 1996 p.3).

A chegada dos profissionais, tanto médicos quanto psicólogos ou terapeutas ocupacionais para a equipe de saúde mental nos equipamentos de saúde teve ritmos diferentes. Nem sempre foi possível constituírem-se equipes completas ao mesmo tempo. Essa situação trouxe diversas questões para os profissionais recém-chegados, tradicionalmente não vinculados aos serviços, ou então aos que chegavam com a tarefa de organizar e criar, na prática, os equipamentos de saúde planejados. Eram levantados problemas organizacionais, que iam da inexperiência profissional com a clientela à disponibilidade de recursos para a instalação dos serviços como aluguel ou reforma de área física, compra de material e equipamentos, entre outros.

Essa foi a tônica do trabalho em saúde mental até o final de 1992. Quando da mudança de administração em 1993, não houve pelo que se sabe, nenhum documento de trabalho que se contrapusesse aos princípios já firmados. O que se deu foi uma prática contraditória à política anterior, reduzindo ou retirando o poder dos trabalhadores de saúde mental organizados e reiterando o poder médico no gerenciamento e administração dos serviços. Além disso, não existiu aumento de recursos financeiros refletindo-se diretamente no funcionamento dos serviços recém criados. Dessa forma, ficou comprometida a implantação daquele modelo assistencial.

No Capítulo IV são apresentados os principais momentos e o percurso para a construção dessa proposta na Administração Regional de Saúde-6 - São Miguel Paulista. 


\section{A atenção à Saúde da Pessoa com Deficiência}

A maior parte dos serviços de reabilitação existentes em nosso país foram constituídos a partir da criação de instituições de assistência beneficentes e filantrópicas, por iniciativa da sociedade civil.

A atenção a esse grupo como política social desenvolvida pelo setor público nunca se estabeleceu. Desenvolveram-se apenas iniciativas pontuais como a da Previdência Social, quando criou o Centro de Reabilitação Profissional para readaptação ao processo de trabalho de segurados que se acidentaram, resposta institucional aos alarmantes índices de acidentes de trabalho e à falta de serviços que buscassem lidar com essa problemática no âmbito do setor público. Outras iniciativas foram as das Universidades quando criaram serviços de reabilitação com objetivos mais ligados à capacitação técnica de profissionais desse campo do que propriamente para desenvolver assistência (SOARES, 1987; OLIVER, 1990).

A política social para esse grupo inscreveu-se como assistência social subsidiada pelo Estado por organizações como Fundação Legião Brasileira de Assistência, Fundação Nacional para o Bem-Estar do Menor - FUNABEM, que, através de programas especiais para idosos, portadores de deficiência e crianças, credenciavam instituições beneficentes e filantrópicas para o atendimento a esses grupos, quer em tratamento e reabilitação, quer na escolarização e preparação para o trabalho em regime ambulatorial ou asilar.

Grande parte dos adultos deficientes, principalmente aqueles diagnosticados como deficientes mentais, compõe um importante contingente da população internada nas instituições psiquiátricas.

Por outro lado, é recente, da década dos 40, a constituição de instituições de tipo asilar e custodial, especificamente para deficientes mentais e/ou físicos, que passam a atender aquelas pessoas acometidas por quadros mais graves. Nesses locais a clientela se inscreve como "consumidora passiva" de uma assistência organizada segundo a lógica da filantropia. A prioridade explicitada seria a necessidade que cada pessoa teria de cuidados especiais, administrados por técnicos especializados como a equipe de enfermagem, psicólogos, fisioterapeutas, fonoaudiológos, terapeutas ocupacionais, pedagogos e médicos. No entanto, a internação por longos períodos ou até durante toda a vida, termina por 
excluir, definitivamente, essas pessoas do convívio social, segregando-as. Na quase totalidade das vezes sua população é internada compulsoriamente, seja pelo perigo que possa representar, seja pela incapacidade de gerir sua existência no espaço familiar.

Dessa forma a trajetória das famílias que têm pessoas portadoras de deficiência, em busca de ajuda ou de atendimento especializado, é sempre árdua e penosa. Desde o momento do reconhecimento da diferença, quer por suspeita da própria família, quer por diagnóstico dos profissionais qualificados para apontá-la, existe um percurso doloroso a realizar.

Em estudo realizado em 1993, nas Casas André Luiz, tradicional asilo para pessoas com deficiência mental e/ou motora e/ou sensorial, observou-se que 88,7\% da população residente recebia subvenção da Secretaria de Estado da Promoção Social para o custeio da internação, enquanto que os restantes $11,3 \%$ tinham a internação custeada pela instituição (OLIVER, 1993).

Nas Casas André Luiz, para parte significativa da população ficava explícita a internação como resposta às condições de vida. Constatava-se, conforme apresentado na Tabela 3, que as dificuldades financeiras mais as necessidades de tratamento especializado representavam $41,9 \%$ dos motivos de internação, enquanto que 12,6\% eram representados pela necessidade de tratamento especializado.

TABELA 3. Motivos de internação dos internos das Casas André Luiz, que participavam das atividades de terapia ocupacional. São Paulo, 1992.

\begin{tabular}{lccc}
\hline \multicolumn{1}{c}{ Motivo de internação } & FREQUÊNCIA & $\begin{array}{c}\text { \% ACUMU } \\
\text { LADO }\end{array}$ \\
\hline 1-Dificuldades financeiras + necessidade de tratamento especializado & 60 & 41,9 & 41,9 \\
2-Necessidade de atendimento especializado. & 18 & 12,6 & 54,5 \\
3-Lar desorganizado + dificuldades financeiras + necessidade de & 15 & 10,5 & 65,0 \\
atendimento especializado. & & & \\
4-Abandono. & 12 & 8,4 & 73,4 \\
5-Dificuldade financeira. & 8 & 5,6 & 79,0 \\
6-Lar desorganizado + dificuldade financeira. & 8 & 5,6 & 84,6 \\
7-Lar desorganizado. & 7 & 4,9 & 89,5 \\
8-Lar desorganizado + necessidade de atendimento especializado. & 6 & 4,2 & 93,7 \\
9-Abandono + necessidade de atendimento especializado. & 5 & 3,5 & 97,2 \\
10-Outros motivos. & 4 & 2,8 & 100,0 \\
\hline TOTAL & 143 & 100,0 & 100,0 \\
\hline
\end{tabular}

FONTE: OLIVER, 1993 p. 10 
Ainda na Tabela 3, os motivos de natureza econômico-financeira e aqueles relativos à desestruturação familiar como: abandono, a desorganização do lar, representavam em torno de 24,5\% demonstrando como era flagrante a precária condição de vida de grande parte dos grupos familiares dos internos. A quase inexistência de serviços de reabilitação tanto de saúde quanto de educação de caráter ambulatorial, que ofereçam apoio à permanência da pessoa portadora de deficiência no contexto familiar, aliada às condições de vida demonstradas nos motivos de internação, levam a que a internação represente um alívio no cotidiano familiar.

Por outro lado, a internação também era um momento de separação sendo necessário estar atento ao que ocorreria nesse processo. Conforme demonstra a Tabela 4, 73,8\% dos internos tinham entre 0 e 9 anos de idade no momento da internação e, com certeza, a separação ocorreu com grandes dificuldades para a família e para a criança.

TABELA 4. Idade da população moradora das Casas André Luiz, no momento da internação. São Paulo, 1992.

\begin{tabular}{c|ccc}
\hline Idade de Internação & FREQUÊNCIA & $\%$ & $\begin{array}{c}\text { \%ACUMU } \\
\text { LADO }\end{array}$ \\
\hline 0 a 4 & 185 & 23,3 & 23,3 \\
5 a 9 & 402 & 50,6 & 73,8 \\
10 a 14 & 187 & 23,5 & 97,4 \\
15 a 19 & 18 & 2,3 & 99,6 \\
20 a 24 & 2 & 0,3 & 99,9 \\
25 a 29 & - & - & - \\
30 a 34 & 1 & 0,1 & 100,0 \\
\hline TOTAL & 795 & 100,0 & 100,0 \\
\hline
\end{tabular}

Fonte: OLIVER, 1993, p.18

O fato de que 50,6\% dos internos tenham sido internados entre 5 e 9 anos de idade

demonstra que durante tempo significativo as famílias foram continentes dessa pessoa. É importante salientar que o processo de detecção da deficiência também contribui para essa permanência e assume diferentes contornos.

MISÈS (1977, p.41). refere que

"o modelo médico tradicional e a insuficiência habitual de uma formação em psicopatologia levam maciçamente os obstetras, os pediatras e clínicos a desprezar durante os primeiros anos de vida da criança os elementos que os induziriam a levar em conta os parâmetros em jogo. Por isso, uma abordagem curativa multidimensional só poderia ser praticada tardiamente, 


\section{e uma reticência persiste, no entanto, quando o problema aparece enfim, em toda a sua complexidade."}

Ainda, segundo estudo de SANJUAN \& SOUZA (1986) sobre a clientela Deficiente Mental de um serviço especializado de Salvador (Bahia, Brasil), percebeu-se que em 44,11\% dos 102 casos estudados "a mãe foi quem primeiro notou sinais de deficiência mental na criança", em segundo lugar estava a professora $(20,58 \%)$ e em seguida os parentes próximos $(11,76 \%)$ e os médicos $(10,78 \%)$.

A permanência dos internos junto às famílias poderia ser resultado de uma percepção tardia da deficiência, apenas quando já se esgotaram as esperanças de que o tempo resolvesse os problemas percebidos (hipotonia, atraso na aquisição da fala e da locomoção independente, entre outros). Em outros casos, o contexto familiar não permitiria mais a presença da mãe ou responsável pelo cuidado cotidiano, pois seriam maiores as necessidades de busca da sobrevivência do grupo familiar.

De qualquer maneira, a experiência do convívio familiar estava presente nas relações afetivas, no cuidado, mesmo que considerado precário, por quem não é parte desse contexto, e a separação significaria um momento de ruptura, bastante difícil de suportar.

TABELA 5. Idade da população moradora das Casas André Luiz, em 1992.

\begin{tabular}{c|c|c|c}
\hline Idade (em anos) & Frequência & $\%$ & $\%$ Acumulado \\
\hline 0 a 4 & 1 & 0,1 & 0,1 \\
5 a 9 & 31 & 3,9 & 4,0 \\
10 a 14 & 123 & 15,5 & 19,5 \\
15 a 19 & 201 & 25,3 & 44,8 \\
20 a 24 & 112 & 24,1 & 58,9 \\
25 a 29 & 138 & 17,4 & 76,2 \\
30 a 34 & 112 & 14,1 & 90,3 \\
35 a 39 & 67 & 8,4 & 98,7 \\
40 a 44 & 6 & 0,8 & 99,5 \\
45 a 49 & 3 & 0,4 & 99,9 \\
55 a 59 & 1 & 0,1 & 100,0 \\
\hline TOTAL & 795 & 100,0 & 100,0 \\
\hline Fonte: OLIVER, 1993 p.20
\end{tabular}

Durante o $2^{\circ}$ semestre de 1992 estavam internadas 795 pessoas na instituição, sendo que 44,7\% delas tinham entre 5 e 19 anos de idade e 25,3\% entre 15 e 19 anos, ou seja, uma população jovem, conforme Tabela 5. 
O tempo de internação dessa população era questão fundamental para o entendimento do papel da instituição no contexto da assistência. É difícil constatar que 54,7\% dessa população estava internada há aproximadamente 10 anos e 36,5\% há mais de 20 anos, conforme Tabela 6, revelando a trajetória pessoal possível para cada internado e a função social dessa instituição.

TABELA 6. Tempo de internação da população moradora nas Casas André Luiz, em 1992

\begin{tabular}{cccc}
\hline $\begin{array}{c}\text { Tempo de internação } \\
\text { (em anos) }\end{array}$ & Frequência & $\%$ & $\begin{array}{c}\% \text { Acumu } \\
\text { lado }\end{array}$ \\
\hline 0 a 4 & 70 & 8,8 & 8,8 \\
5 a 9 & 172 & 21,6 & 30,4 \\
10 a 14 & 187 & 23,5 & 54,0 \\
15 a 19 & 76 & 9,6 & 63,5 \\
20 a 24 & 177 & 22,3 & 85,8 \\
25 a 29 & 101 & 12,7 & 98,5 \\
30 a 34 & 12 & 1,5 & 100,0 \\
\hline & 795 & 100,0 & 100,0 \\
\hline Total & & &
\end{tabular}

A necessidade de tratamento especializado, asilar, mesmo após muito se ter buscado atendimento ambulatorial, se sobreporia àquelas advindas da falta de condições objetivas para permanência da pessoa deficiente no contexto familiar. No contexto de precariedade de condições de vida, apoio social e serviços especializados para esse grupo, na maior parte das vezes a internação é entendida, tanto pela família como pelos serviços, como uma melhora nas condições objetivas de existência, que justificariam a segregação na instituição.

Ainda compondo o quadro geral de assistência a essa população, talvez uma face menos segregadora mas, mesmo assim, reveladora da cidadania desse grupo é verificar como se distribuia a rede de serviços disponíveis no município de São Paulo.

A maior parte dos serviços concentra-se em determinadas regiões o que obriga a população a longos e onerosos deslocamentos pela cidade.

Como se observa na Tabela 7 , a região sul do município de São Paulo concentra grande parte dos serviços públicos e privados de atenção à pessoa deficiente mental, quer nos ambulatórios, clínicas, escolas especializadas, hospitais e oficinas. No caso das classes especiais, que são as opções públicas para a escolarização desse grupo a distribuição pelas 
regiões é mais equitativa exceto para a região Centro. A região Leste do município é a segunda em número de instituições para esse grupo.

TABELA 7. Serviços de atenção à pessoa deficiente mental no município de São Paulo, 1992.

\begin{tabular}{|c|c|c|c|c|c|c|}
\hline \multirow[b]{2}{*}{ SERVIÇOS } & \multicolumn{6}{|c|}{ da $\quad$ Cidade } \\
\hline & CENTRO & NORTE & SUL & OESTE & LESTE & TOTAL \\
\hline INAMPS & 5 & 2 & 3 & 1 & 3 & 14 \\
\hline Prefeitura & 1 & 2 & 1 & 1 & -- & 5 \\
\hline $\begin{array}{r}\text { Ambulatórios-ARS Santo } \\
\text { Amaro /Parelheiros }\end{array}$ & -- & -- & 10 & -- & -- & 10 \\
\hline Saúde Mental Est. & 1 & 1 & 3 & 2 & 3 & 10 \\
\hline Classes Especiais & -- & 62 & 47 & 45 & 59 & 213 \\
\hline Clínicas & 2 & 7 & 38 & 11 & 8 & 66 \\
\hline Escolas Especializadas & 1 & 6 & 36 & 4 & 7 & 54 \\
\hline Hospitais & 3 & -- & 25 & 5 & 4 & 37 \\
\hline Instituições & 1 & 5 & 23 & 7 & 25 & 61 \\
\hline Oficinas & -- & 1 & 5 & 1 & 1 & 8 \\
\hline Total & 14 & 86 & 191 & 77 & 110 & 478 \\
\hline
\end{tabular}

Fonte: APAE, 1992

No que diz respeito às iniciativas públicas as alternativas educacionais foram mais presentes do que as do setor saúde, criando e mantendo parte dos serviços de educação especial, mesmo que limitando-se às classes especiais e algumas escolas especializadas para portadores de determinadas deficiências. Essas iniciativas também favorecem a segregação e dificultam a integração desse grupo.

Acompanhando as discussões geradas pelo Ano Internacional do Deficiente em 1981 e os processos de mobilização social de pessoas com deficiência, toma corpo no início da década dos 80 o debate sobre o papel do Estado na assistência em saúde, educação e na inclusão dessas pessoas.

Quase ao mesmo tempo, em 1982, no âmbito internacional foi aprovado pela Assembléia Geral das Nações Unidas o Programa de Ação Mundial para as Pessoas com Deficiência. O programa defendia como princípio a participação desse grupo na tomada de decisões sobre diretrizes e/ou políticas nacionais e locais e a necessidade de se tornar acessível as tecnologias de prevenção, tratamento e reabilitação já disponíveis. E, ainda, divulgando e problematizando as questões da população com deficiência como questões para o coletivo e levantando a bandeira do acesso à reabilitação e à igualdade de 
oportunidades, como tarefas a serem cumpridas pelos governos e pela sociedade civil. Em que pesem as recomendações desses organismos internacionais, quando preconizam ações ou políticas para as quais os limites locais estão dados pelo modelo econômico e político hegemônicos e pela ordem econômica internacional, essas diretrizes facilitaram a organização da população com deficiência em torno de interesses comuns, levantados e referendados internacionalmente como direitos (ONU, 1982).

Nestas diretrizes internacionais é esperado que os movimentos de defesa dessa população pressionem o poder público em seus diferentes níveis, impulsionando a elaboração de propostas e apoio jurídico (MORTARI \& PAULA, 1997; SILVA, 1997; MINISTÉRIO DA JUSTIÇA, 1996). E por outro lado o atendimento em saúde deveria respeitar as diretrizes de descentralização, hierarquização e articulação interinstitucional dos serviços.

Em São Paulo, em 1985, foi proposto o Programa Estadual de Saúde da Pessoa Portadora de Deficiência pela Secretaria de Estado da Saúde. Em diversas regiões de saúde do Estado, discutiu-se a proposta e, em algumas, foi possível implantar atendimento em Unidades Básicas de Saúde, seja por iniciativa das unidades estaduais, seja por iniciativa dos próprios serviços municipais, sensibilizados pela situação específica desse grupo da população. Parte dos recursos necessários para o desenvolvimento de ações de prevenção de incapacidades, de tratamento e de reabilitação no âmbito da saúde foram provenientes do Programa de Ações Integradas de Saúde, que transferia recursos públicos federais para serviços públicos estaduais e municipais, procurando gerar condições para que estes assumissem parte da assistência (OLIVER, 1990). Essa utilização de recursos representou um reconhecimento das necessidades desse grupo e compromisso da política pública com o desenvolvimento de propostas de seu interesse, resultado do longo processo de organização das pessoas deficientes e da pressão social que exerceram em momento importante do processo de redemocratização da sociedade brasileira.

No interior do Estado eram menos freqüentes as instituições preparadas para o atendimento à pessoa com deficiência. Desta forma, o Programa da Secretaria de Estado representou um impulso ao estabelecimento de iniciativas, mobilizadas, inclusive, pelas propostas de municipalização no campo da saúde. 
A partir do final dos anos 80, as mudanças organizacionais da Secretaria de Estado da Saúde, e, principalmente, a reorganização das forças sociais e políticas na administração do Estado, levaram à fragilização da proposta. Era grande a insatisfação dos profissionais de saúde, em relação às condições salariais e de trabalho, conduzindo a um êxodo para outros serviços, públicos ou privados (SECRETARIA DE ESTADO DA SAÚDE, 1988).

O mérito do Programa Estadual de Saúde do Deficiente foi maior ao levantar a discussão da necessidade de incorporação dessa população nos equipamentos de saúde do que por conseguir assumir, na prática, a assistência a essa população. O que representa um avanço no interior das políticas públicas que, até então, apenas financiavam parte da assistência privada de caráter filantrópico (OLIVER, 1990).

Representando os esforços para a integração da pessoa com deficiência, em nível federal foi criada, em 1986, a Coordenadoria para Integração da Pessoa Portadora de Deficiência - CORDE, com representantes do Ministério da Educação e Cultura, da extinta Legião Brasileira de Assistência - LBA, da Fundação Nacional para o Bem-Estar do Menor - FUNABEM, dos Ministérios da Previdência e Assistência Social, do Trabalho e da Saúde e ainda, de outras instituiçõos prestadoras de serviços para essa população. Nesse período lança-se o Plano de Ação, composto por quatro programas: de conscientização, de prevenção de deficiências, de atendimento às pessoas portadoras de deficiência e de inserção no mercado de trabalho. Buscava-se oferecer

\section{"uma diretriz politicamente firme e socialmente transformadora que dê unidade e integre ações de atendimento, previdência e assistência, num só esforço e nele incorpore governo e sociedade no mesmo movimento"(CORDE, sdp).}

De forma semelhante foram criados Conselhos Estaduais e Municipais para coordenação de atividades e esforços no campo das ações públicas e da sociedade civil, no sentido de favorecer a integração desses grupos e a discussão e estabelecimento de diretrizes básicas para ações a serem desenvolvidas. A eficácia do trabalho desses conselhos estaria diretamente ligada à legitimidade e representatividade de suas instituições e de seus membros, enquanto interlocutores com poder e vontade política para criar respostas para as demandas da população com deficiência. Esses Conselhos ou Coordenadorias representariam uma resposta política, seja da União, do Estado e/ou dos 
Municípios às pressões internacionais, de grupos organizados de pessoas com deficiência e das instituições prestadoras de serviços.

Ao mesmo tempo, os movimentos organizados de pessoas portadoras de deficiência criavam espaços para a incorporação de temas como direito à saúde, educação, trabalho e reabilitação, aparecendo como atores sociais, com visibilidade, com voz e propostas, população que deveria ser priorizada no delineamento de ações nesses campos, a partir da constituição de 1988 (OLIVER, 1990).

Outras iniciativas tornaram públicos os problemas concretos da assistência a esse grupo. Um exemplo foi a intervenção do Ministério Público e das Secretarias de Estado da Saúde em instituições asilares (como a da Casa de Davi em São Paulo), cujo objetivo inicial era investigar denúncias de desvios de recursos conseguidos pela comunidade para manutenção da instituição. Essas denúncias levaram o poder público a intervir, tentando garantir assistência e cuidados mínimos para os internos e exercendo na prática o direito de fiscalizar a atenção financiada pelas verbas públicas (OLIVER, 1993).

Os programas de assistência das instituições asilares para pessoas com deficiência caracterizam-se pela custódia e asilamento, onde a qualidade de vida e dos cuidados recebidos são questionáveis. Conforme apontado anteriormente, existem outras instituições em São Paulo que atendem populações por deficiências, proporcionando escolarização, tratamento e/ou reabilitação ambulatorialmente. A efetividade de serviços dirigidos a apenas pessoas com deficiência é discutida pelos organismos internacionais tanto pelo isolamento e segregação que proporcionam como pelos procedimentos técnicos que priorizam, muitas vezes envolvendo tecnologia de custo elevado e de difícil absorção no cotidiano da população com deficiência (OMS, 1981).

Ao mesmo tempo em que, no final dos anos 80, se desarticulam as possibilidades mais concretas de crescimento da atenção à saúde pelo governo do Estado de São Paulo esse tema é recolocado na agenda do município de São Paulo após a eleição de 1988. Lideranças do movimento de pessoas com deficiência participaram ativamente da campanha eleitoral de Luiza Erundina apresentando oficialmente, após a posse da prefeita, reivindicações específicas como a reorganização do Conselho Municipal do Deficiente, a criação de serviços regionais de reabilitação, leitos específicos para tratamento de pessoas com escaras provenientes de deficiências e outras propostas no campo do acesso a emprego 
público, aos transportes e ao ensino de primeiro e segundo graus em escolas da rede regular.

Até 1988, havia no âmbito dos serviços municipais o Centro Educacional Hellen Keller, para crianças e adolescentes com deficiência auditiva e as Clínicas Psicológicas do Departamento de Saúde Escolar que desenvolviam assistência a crianças com problemas de aprendizagem. O Departamento de Saúde Escolar foi extinto e suas atribuições incorporadas pela Secretaria Municipal de Saúde com grande resistência por parte de seus profissionais.

Entre 1989 e 1990 existiu um grupo de trabalho ligado à Assessoria de Saúde da Criança, com participação de técnicos da Secretaria da Educação e da Universidade de São Paulo. Esse grupo iniciou uma discussão sobre assistência aos portadores de deficiência nos serviços de saúde tentando lidar com essa questão juntamente com a desativação das clínicas. O grupo não elaborou proposta assistencial com agilidade e logo se esvaziou por falta de apoio institucional.

Na década dos 90, foi uma constante a discussão e apresentação de propostas para a atenção à pessoa com deficiência nas diferentes esferas de poder, municipal, estadual e federal.

Assim, em 1991, parte dos técnicos protagonistas do Programa Estadual de Saúde do Deficiente foi chamada a incorporar-se à equipe técnica do Fundo Social de Solidariedade do Estado de São Paulo. Essa iniciativa recolocaria a discussão sobre a pessoa com deficiência no campo das propostas públicas de assistência social, tradicionalmente atribuição do trabalho das primeiras damas, sejam elas da República, do Estado ou do Município.

Essa equipe de trabalho do Fundo de Solidariedade propôs o Programa Estadual de Atenção à Pessoa Portadora de Deficiência

"com objetivo de desenvolver trabalhos integrados com as Secretarias de Estado e demais órgãos públicos e da sociedade civil com objetivo de tentar garantir o direito de cidadania do portador de deficiência, estimular a conscientização da sociedade sobre a condição das pessoas portadoras de deficiência com objetivo de eliminar o preconceito, de forma a favorecer sua integração; ampliar o atendimento nas redes de educação, saúde, trabalho e promoção social; desenvolver ações específicas de prevenção, a fim de reduzir a ocorrência de deficiências; e incentivar a eliminação de barreiras arquitetônicas, visando a integração do portador de deficiência à 
comunidade em que vive" (FUNDO SOCIAL DE SOLIDARIEDADE, 1991 p.3).

Na realidade, o Programa deveria sensibilizar os municípios para lidar com as questões relativas à pessoa com deficiência e não tinha como objetivo desenvolver ações concretas de assistência. Tratava-se de proposta de técnicos para produzir, nas estruturas de assistência social das cidades do interior do Estado, uma discussão sobre determinada forma de responder às demandas desse grupo, que não fosse apenas através do assistencialismo (distribuição de equipamentos e materiais auxiliares, ou da promoção de ações de solidariedade para a manutenção de instituições locais de beneficência).

Ao mesmo tempo esse programa representaria, politicamente, os esforços do governo do Estado para lidar com as reivindicações historicamente apresentadas por esse grupo social, ganhando os fóruns de discussão da assistência social, fortemente influenciada pela tradição assistencialista, ampliando os ouvintes da proposta. Por outro lado, a iniciativa de atenção em saúde nos serviços estaduais já bastante desarticuladas permaneceriam no mesmo patamar. Esse novo eixo político para o tema foi amplamente divulgado em nível estadual, nacional e internacional, sendo importante para a consolidação do poder político do então governador do Estado.

\section{A proposta municipal - resultado da mobilização das pessoas portadoras de deficiência}

Um dos resultados do processo de implantação dos serviços de saúde mental entre 1989-92, no município, foi o aparecimento de novas demandas trazidas pelos profissionais contratados com experiência no atendimento de outros grupos populacionais, o que favoreceu a proposição de ações para portadores de deficiência em hospitais gerais, unidades básicas de saúde e ambulatórios de especialidades. Entretanto, estas ações não se constituíam como programa específico de assistência (BARROS et al, 1995).

Em junho de 1991, o movimento organizado das pessoas portadoras de deficiência, através do Conselho Municipal do Deficiente, reiterava, uma vez mais, suas pressões junto à Secretaria Municipal de Saúde para o atendimento de reivindicações apresentadas. Ou ainda, projetos apresentados à Secretaria em 1990, como o das Casas Comunitárias para 
portadores de deficiência, que viviam em instituições totais, por não terem suporte social, para assumirem a vida cotidiana (SECRETARIA MUNICIPAL DE SAÚDE, 1992 b).

O movimento social recolocava a necessidade de que fosse discutida a questão de uma política municipal de saúde para a pessoa portadora de deficiência, agora pensada em nível de programa e não mais como um grupo de trabalho isolado, como havia sido entre 1989 e 1990.

Assim, em setembro de 1991, foi constituído grupo de trabalho, com representantes do Conselho Municipal do Deficiente, do Programa Municipal de Saúde do Idoso e do Programa Estadual de Saúde da Pessoa Portadora de Deficiência, nomeado pelo Secretário de Saúde para elaborar uma proposta municipal, apresentada em abril de 1992.

O programa de atenção à saúde da pessoa deficiente tinha como princípios gerais:

"a) As pessoas portadoras de deficiências são parte integrante da população em geral e, como tal, devem ter o mesmo acesso aos serviços de saúde.

b) as pessoas deficientes devem ter suas necessidades de atenção às intercorrências de saúde resolvidas nos mesmos locais do restante dos cidadãos.

c) a deficiência não deve ser confundida com doença e nem sempre se constitui em fator de agravamento das doenças.

d) todos estão sujeitos à instalação de deficiências e incorre-se em omissão, quando não se garante o atendimento.

e) o atendimento à saúde da pessoa portadora de deficiência deve ter como base o enfoque da interprofissionalidade.

f) a atendimento ao deficiente deve ter como grande meta o desenvolvimento de suas potencialidades, buscando-se uma melhor qualidade de vida para o mesmo.

g) deve-se atender o deficiente como uma pessoa completa que é; um sujeito que tem uma história de vida e que vive em seu meio ambiente particular, com condições singulares de vida, interagindo com esse contexto (que também o suporta).

h) a pessoa portadora de deficiência é cidadã e, enquanto tal, um sujeito com direitos e deveres perante a sociedade.

i) as ações de saúde voltadas às pessoas portadoras de deficiências, implantadas na rede, devem ser sistematicamente avaliadas pelos planejadores, dirigentes, executores e usuários, com o propósito de possibilitar mudanças e redirecionamento para que o atendimento prestado nos diversos níveis do sistema seja continuamente aprimorado." (SECRETARIA MUNICIPAL DE SAÚDE, 1992 b, p.16-7).

Os princípios gerais eram os mesmos defendidos pelo Programa Estadual de Saúde do Deficiente de 1984, na Secretaria Estadual de Saúde, pelos organismos internacionais e 
pelas organizações de deficientes nas Conferências Municipais de Saúde de 1990 e 1991 (SES, 1985; OMS,1981; ONU, 1982). A participação dos deficientes nessas conferências foi tão marcante que "a questão do estigma, da discriminação e da segregação social se desmistificava na prática da discussão conjunta com outros grupos da população." (SECRETARIA MUNICIPAL DE SAÚDE, 1992 b, p. 2).

Definiram-se também, uma série de ações a serem desenvolvidas nos diferentes serviços para a promoção da saúde, prevenção primária e detecção precoce de deficiências, que não dependeriam da ação específica de uma equipe de reabilitação. Já nas ações de prevenção de incapacidades, como em hanseníase, geriatria, doenças crônico-degenerativas, gestações de alto risco, alcoolismo, epilepsia e outras situações, o trabalho seria desenvolvido pela equipe de saúde da UBS com retaguarda de uma equipe de reabilitação, alguns equipamentos e materiais simples e de baixo custo. Outra preocupação seria o acompanhamento do desenvolvimento neuropsicomotor nos primeiros anos de vida, principalmente com bebês de risco, que poderia ser desenvolvido pela equipe da unidade, acompanhada da equipe de reabilitação.

Da mesma maneira que para o Programa de Saúde Mental, trabalhou-se com a idéia de criação de equipes de profissionais nos diferentes níveis de complexidade dos serviços, para dar suporte objetivo à necessidade de atenção, juntamente com o restante da população, nas UBS, nos hospitais gerais, ambulatórios e laboratórios mais próximos do local de moradia do deficiente, oferecendo atendimento o mais próximo possível da moradia da pessoa, "respeitando a proximidade sócio-cultural com a comunidade, fatores fundamentais do processo de reabilitação/habilitação" (SECRETARIA MUNICIPAL DE SAÚDE, 1992 b, p.22).

As UBS "devem se constituir no local por excelência de atendimento ao deficiente" (SECRETARIA MUNICIPAL DE SAÚDE, 1992b, p.22) e para que isso ocorresse apontavam para a importância da eliminação de barreiras arquitetônicas, da preparação dos profissionais para o atendimento ao deficiente e da contratação de técnicos capacitados para atendê-los, segundo os princípios gerais apresentados.

Ao mesmo tempo, apontavam para a necessidade de que a equipe interprofissional de reabilitação atuasse "entendendo saúde como uma determinação social, expressão 
das condições de vida e trabalho a que está submetida a população numa determinada sociedade"(SECRETARIA MUNICIPAL DE SAÚDE ,1992b, p.23).

Nas UBS comuns, naquelas com equipe de referência, como também nos ambulatórios de especialidades, estavam previstas ações para acompanhamento e controle dos grupos de risco para instalação de incapacidades, grupos de re-socialização e promoção da autonomia, grupos de orientação e acompanhamento de usuários com incapacidade instalada, leve e moderada. Ao mesmo tempo, estariam previstas ações desenvolvidas por técnicos visando a manutenção do grau de autonomia já alcançado.

No programa também estavam delineadas ações gerais a serem desenvolvidas nas unidades hospitalares com o objetivo de facilitar a prevenção ou impedir o agravamento de incapacidades já instaladas, desde a movimentação no leito e exercícios respiratórios até o atendimento no leito de usuários com incapacidades instaladas, através de interconsultas e terapias da equipe de reabilitação. Nesse caso, a unidade deveria contar com assistente social, enfermeiro, fisiatra, fisioterapeuta, fonoaudiólogo, nutricionista, psicólogo e terapeuta ocupacional.

Já para as ações complexas de reabilitação propôs-se a criação de Serviços Regionais de Reabilitação, com apoio hospitalar, para o momento em que o usuário recém adquiriu a deficiência, necessitando por isso de intervenções com caráter mais intensivo e de duração relativamente curta. Esses serviços contariam com equipe completa de reabilitação, espaço físico, materiais e equipamentos detalhadamente apresentados e se estruturariam para oferecer atendimento, segundo o perfil epidemiológico da população de referência.

No tocante à operacionalização das ações sugere-se o diagnóstico da realidade regional, em nível de distrito de saúde, no que diz respeito aos indicadores de saúde, à disponibilidade de recursos assistenciais e de profissionais da rede, à identificação e caracterização de pessoas com deficiência, bem como ao estabelecimento de nexos causais para a compreensão da prevalência de deficiências nas diferentes regiões. Num segundo momento, haveria a constituição dos níveis de atenção e do sistema de referência e contra-referência distrital e regional. Posteriormente, a elaboração de estratégias de trabalho 
em nível das diferentes unidades de saúde, em termos de intervenção individual, grupal e coletiva.

Um outro ponto importante do programa era a apresentação detalhada das funções e competências dos profissionais por categorias e da equipe interprofissional de reabilitação. Foram apontados princípios éticos da ação profissional que deveria ter postura de compromisso junto à equipe de trabalho e à clientela. A prática cotidiana não deveria fragmentar o deficiente, atribuindo-lhe um lugar de sujeito concreto, contribuindo para a criação de uma nova mentalidade que impregnasse as relações sociais estabelecidas com a população deficiente e com os técnicos de uma maneira geral.

Valorizava-se a invenção de práticas solidárias de apoio e orientação para a multiplicação de uma nova visão sobre a pessoa deficiente e sobre a qualidade dos serviços a ela prestados.

O Programa de Saúde do Deficiente apontava, claramente, para a necessidade de estabelecimento de ações interprofissionais para uma atenção voltada às necessidades do usuário. Uma postura dessa natureza favoreceria a participação destes na condução do processo de tratamento e uma visão mais integral do atendimento a ser desenvolvido.

A interprofissionalidade defendida pelo programa apresentava detalhadamente as principais atribuições de cada categoria profissional, uma maneira de explicitar certo grau de responsabilidade profissional na implantação e constituição da assistência. Dessa forma, delineava as contribuições por categoria profissional e para a equipe interprofissional, como também as estratégias para implantação do programa a curto, médio e longo prazos.

Pretendia-se, assim, trabalhar a partir dos recursos humanos existentes, definindo atribuições e atividades a serem incorporadas ao cotidiano da assistência das unidades de saúde. Quanto aos recursos físicos e materiais, que também foram identificados pelo programa, não se apresentaram mecanismos para viabilizar sua aquisição. Entendia-se que o programa forneceria as diretrizes gerais e específicas para a abordagem da problemática desse grupo, para sensibilizar gestores centrais e regionais e profissionais da assistência direta para a proposta. Sua viabilização como atividade assistencial de fato, seria objeto de ações político-administrativas nas ARS, que com sua autonomia de gestão teriam condições de definir caminhos de implantação do programa nas diferentes regiões do Município. 
No período de abril a dezembro de 1992 procedeu-se à discussão e apresentação do programa para regiões e distritos de saúde, com o objetivo de sensibilizar os profissionais de nível regional para a implantação dessas ações de saúde. Utilizou-se a mesma estratégia adotada para o programa de saúde do idoso, que se havia demonstrado eficaz: reuniões regionais com a participação dos gestores, profissionais da assistência direta e representantes do grupo de trabalho que havia proposto o programa.

Os primeiros treinamentos de equipe foram realizados em dezembro de 1992, já no final da gestão, que havia se iniciado sem a existência do programa e com uma série de dificuldades para sua discussão. Entretanto, já existiam ações que eram desenvolvidas para grupos de pessoas portadoras de deficiência, ações estas apresentadas e discutidas no Capítulo IV.

Um importante desdobramento da proposta municipal de atenção à saúde da pessoa com deficiência de 1992 foi ser assumida na íntegra como proposta da Coordenação de Atenção a Grupos Especiais do Ministério da Saúde em documento divulgado em 1993: "Atenção à Pessoa Portadora de Deficiência no Sistema Único de Saúde Planejamento e Organização de Serviços".

A esse texto foram agregadas informações sobre distintas concepções de reabilitação e a descrição do modelo assistencial proposto foi melhor organizada que a de 1992, em seus diferentes níveis, a saber:

"Nível 1:

Fornecer atenção em reabilitação, incluindo a prevenção e detecção precoce da incapacidade, mediante recursos existentes não especializados em reabilitação, usando tecnologia apropriada e para alcançar $100 \%$ de cobertura

Ações:

- de promoção da saúde, prevenção primária e detecção precoce de deficiências: incorporadas às ações de rotina das unidades básicas de saúde.

- de prevenção primária a serem desenvolvidas nas unidades hospitalares gerais: no primeiro atendimento em nível de pronto-socorro, na movimentação passiva no leito, com exercícios respiratórios, interconsultas com equipe.

- de prevenção a serem desenvolvidas nas maternidades: prevenção de sofrimento fetal, detecção de neonato de risco, pesquisa de rotina de erros inatos do metabolismo entre outras.

- de prevenção secundária: evitando incapacidades em pessoas com hanseníase, em idosos, gestantes de risco, epilépticos, alcoolistas entre outros. 
- de estimulação do desenvolvimento neuropsicomotor.

- grupos de re-socialização e promoção de autonomia para adolescentes e adultos com deficiências severas ou quadros crônicos. Estas pessoas têm muita dificuldade para receber atendimento nas instituições de maneira geral.

\section{Nível 2:}

Fornecer tratamento em reabilitação, para os casos referenciados, mediante recurso de profissional especializado, atuando com critério e base epidemiológica e utilizando tecnologia apropriada para o desenvolvimento das ações.

Ações:

- grupos de orientação e acompanhamento de usuários com incapacidade instalada leve ou moderada.

- grupos de estimulação global do desenvolvimento de crianças deficientes.

- acompanhamento, orientação e intervenções terapêuticas outras, visando a manutenção do grau de autonomia alcançado.

- básicas de reabilitação, re-socialização e integração social: como avaliações, orientações e demais intervenções terapêuticas necessárias, desenvolvidas pela equipe interprofissional.

- diagnóstico da deficiência e desvantagem, incluindo a patologia e suas causas, grau e extensão da lesão envolvendo a avaliação da situação e dinâmica familiar, os recursos emocionais e intelectuais da pessoa, sua situação sócio-econômica, cultural e educacional, suas expectativas no processo de reabilitação, com a participação da pessoa com deficiência.

Nível 3:

Fornecer atenção em reabilitação e atenção em saúde às pessoas deficientes, mediante a utilização de recursos humanos e materiais estruturados em diversos graus de complexidade, dentro da unidade de saúde aparelhada com tecnologia apropriada.

Ações:

- complexas de reabilitação, tradicionalmente desenvolvidas nos Centros de Reabilitação, por serem mais complexas demandam suporte hospitalar. Podem desenvolver-se em Serviços Regionais de Reabilitação." (MINISTÉRIO DA SAÚDE, 1993 p.25-38).

Foram apresentados os mesmos elementos básicos para o planejamento e operacionalização das ações previstas em 1992. Agregaram-se questões específicas ligadas à organização do SUS como a promoção da necessária participação e controle social dos serviços pelos usuários, profissionais e representantes da administração dos serviços. Outro 
ponto relevante seria o financiamento do sistema, que como para todas as demais áreas programáticas, deveria ser assumido pelas três esferas de governo, conforme Constituição e Lei Orgânica da Saúde.

Salientou-se a necessidade de particular atenção para essa área dada sua recente incorporação como política pública, necessitando por isso de maior aporte de recursos. As tabelas de financiamento do SUS (SIA - Sistema de Informação Ambulatorial e SIH Sistema de Informação Hospitalar) já incluíam o pagamento dos diversos procedimentos recomendados. Foi ressaltada a necessidade de investimentos para a capacitação de recursos humanos para o desenvolvimento do modelo proposto, que redimensionaria a prática dos profissionais de reabilitação, imprimindo uma dimensão assistencial não contemplada na formação acadêmica tradicional.

Outro aspecto de grande importância para a população portadora de deficiência é o acesso a órteses, próteses e equipamentos auxiliares, cuja aquisição tenta ser garantida através do SUS. Os processos de compra ainda eram lentos, burocratizados e dificultados pela falta de serviços públicos que acompanhassem a prescrição e adaptação dos usuários a esses equipamentos. Além disto, são muitas as restrições técnicas já levantadas por representantes de organizações e por profissionais da área de reabilitação quanto ao tipo de material financiado, tempo de espera para compra, possibilidade de garantia de manutenção e substituição dos materiais entre outros.

Os pressupostos básicos da proposta de atenção à pessoa com deficiência no Sistema Único de Saúde redimensionaram as reflexões e experiências, mesmo que pontuais, já realizadas no âmbito do serviço público e das instituições de reabilitação que buscam maior integração com a comunidade. A implantação dessa proposta poderia contemplar aspectos importantes das reivindicações do movimento de pessoas portadoras de deficiência na defesa de processos de reabilitação, onde o deficiente possa ser sujeito, intervir diretamente como cidadão e consumidor de serviço.

No mesmo período em que se lançava a proposta para o SUS, em nível nacional realizava-se uma pesquisa no Estado de São Paulo, coordenada pelo Fundo de Solidariedade, que buscava conhecer os recursos existentes nos municípios para a atenção às pessoas com deficiências e ações de prevenção.

As conclusões desse trabalho permitiram saber que 
"a quantidade reduzida de unidades assistenciais, a predominância de ações indiretas e de baixa cobertura assistencial dos serviços especializados, sinalizam a necessidade de se criar ou implementar a assistência às pessoas portadoras de deficiência em suas necessidades fundamentais: saúde, educação e, particularmente, trabalho.

O número relativamente bom de ações preventivas, se comparadas a sua efetivação em situações ou idades não tão precoces quanto se desejaria, aponta para a urgente ampliação das mesmas para o mais cedo possível, tornando-as mais eficientes e eficazes. É necessário uma maior qualificação dos recursos, coordenação e sistematização das medidas preventivas.

Os dados indicam também a necessidade de ampliar e qualificar mais, dar maior resolutividade (capacidade de resolver melhor o maior número possível de casos de deficiência) aos serviços públicos de saúde e educação, visando ampliar o volume de atendimentos especializados, dado que um grande número dessas unidades já está desenvolvendo ações.

É flagrante a necessidade de se investir na área de qualificação profissional e, sobretudo, na de colocação no mercado de trabalho de pessoas portadoras de deficiência, sob pena de não alcançarmos o objetivo último da educação e da reabilitação: a integração e a participação social desses cidadãos.

Assim, nesse sentido, é importante que as atividades de convivência, esporte, cultura e lazer - instrumentos extremamente úteis para a socialização e integração de quaisquer pessoas - sejam desenvolvidas em espaços de uso público (centros esportivos, de convivência, sociais, urbanos, oficinas culturais etc.) e não predominantemente em serviços de atenção exclusiva à pessoa portadora de deficiências" (FUNDO SOCIAL DE SOLIDARIEDADE,1993 p. 39).

Esses resultados apontavam o quanto de trabalho e energias institucionais, em todos os campos, seria necessário investir para tornar a atenção a essa população um campo de práticas assistenciais relevantes diante das necessidades e demandas desse grupo.

Este relato das iniciativas de criação de propostas assistenciais são um recorte daquilo que se produziu nos últimos 15 anos, como vem se construindo uma concepção de atenção à população com deficiência, como responsabilidade do setor público e como política social a ser implantada pelo Estado, principalmente, e por organizações não governamentais de caráter público.

Essa concepção de assistência, de reabilitação e de participação social das pessoas com deficiência resulta de experiências assistenciais, de fóruns de discussão de organizações de deficientes, de reflexões nos espaços acadêmicos sensíveis à problemática dessa população, como grupo social. Esses espaços poderiam representar as interfaces de campos como o das 
Ciências Sociais, da Saúde Coletiva e da Psicologia Social (ALMEIDA, 1993; ROCHA, 1991; GHIRARDI, 1993; NALLIN, 1992).

Procura-se, com grandes esforços e muitas resistências de diversas ordens, romper com uma visão de reabilitação, que prioriza a intervenção sobre a deficiência em si. A complexidade, as múltiplas dimensões da vida das pessoas com deficiência na relação com suas dificuldades e as desvantagens colocadas no processo social de determinação dessa problemática, não podem ser reduzidas a uma única e hegemônica visão sobre assistência, reabilitação, acesso a direitos e participação.

Os pressupostos da filantropia, do conhecimento científico e das intervenções técnicas, tidos como neutros, têm que ser questionados como uma forma de se aproximar, mesmo que lentamente, de novas formas de atenção, também cotidianamente discutidas. 


\section{Procedimentos}

O presente estudo se inscreve no campo das pesquisas qualitativas, buscando também incluir informações quantitativas para compreender o processo de incorporação da assistência em saúde mental e a pessoas com deficiência no caso de uma região da cidade de São Paulo. Seria uma maneira de apreender diferentes aspectos e dimensões de realidade, entendendo que são informações complementares sobre o processo de constituição da assistência (PEDERSEN, 1990; MINAYO, 1992; CHIZZOTTI, 1991).

"Inspirada" no questionamento que os estudiosos das Ciências Humanas construíram ao indagar sobre o conhecimento e seu sentido nas sociedades contemporâneas, ousa-se apontar como MAFFESOLI (1995, p. 13)

“À maneira de um objeto fugidio e em plena maturação, é preciso por em ação um pensamento lábil, sinuoso, que não teme repetições. Cada uma delas, de fato, traz seu toque específico, permitindo assim aperfeiçoar ou completar o quadro proposto. $O$ impressionismo a que isso induz é tanto mais necessário quanto a época é de heterogeneização, e não se deixa reduzir a um conceito, nem mesmo a um conjunto de conceitos. Na análise científica clássica, face a um objeto morto ou estabilizado, pode-se, segundo a exigência legitimamente admitida, passar do concreto ao abstrato. Isso se dá de forma totalmente diferente quando uma nova cultura, em seu estado nascente, encontra-se em efervescência e burburinho. É necessário por conseguinte, adotar uma postura intelectual que, com flexibilidade, contenta-se em descrever, em registrar, em "monstrar" o que é. Ainda que, por muitos de seus aspectos, este estado de coisas seja monstruoso"

Em muitos momentos da apresentação da pesquisa as informações serão reiteradas e recolocadas, procurando exprimir idéias, "que podem ser comparadas a variações musicais em torno de um tema conhecido, floreios elaborados a partir de uma melodia"(MAFFESOLI, 1995 p. 13).

A pesquisadora diante da realidade e do campo contribuiria construindo uma das possíveis interpretações que o tema possibilita; resultado do percurso profissional na defesa da atenção pública, objeto deste trabalho. Os pressupostos básicos da Saúde Pública e a militância foram os balizadores da formação profissional. O momento desta pesquisa foi período fértil e propício às discussões dos dilemas da Saúde Coletiva como corpo de práticas assistenciais na direção da melhoria da qualidade de vida para todos. Essa foi a 
maneira de se apropriar de uma metodologia que estuda o processo da formulação de políticas públicas e sua implantação, evidenciando os variados erros, preconceitos, imprecisões entre outros aspectos, que aí estão presentes, conforme se verifica no estudo de THOMPSON (1981) sobre as questões relativas à implantação de políticas públicas.

A pesquisa foi realizada a partir:

1. do estudo de documentos, incluindo textos oficiais, relatórios, conferências, produzidos sobre as propostas de atenção, conforme Anexo II (p. XLIV-LV).

2. de entrevistas semi-estruturadas, utilizando-se os roteiros do Anexo I (p.II-VI).

De agosto de 1995 a 3/09/96 foram realizadas 83 (oitenta e três) entrevistas com gestores locais e centrais, profissionais que atendiam diretamente a clientela e que estiveram vinculados às propostas entre 1989 e 1995, e representantes dos movimentos sociais no campo da saúde dessa região, distribuídas segundo Anexo I (p.VII-XIV).

Optou-se por conhecer os depoimentos de profissionais vinculados de maneira distinta às propostas em estudo. As entrevistas com os gestores e planejadores buscam encontrar as motivações e apresentar a trajetória de constituição das propostas como diretrizes políticas, assumidas de diferentes maneiras no período estudado. Nas entrevistas com os profissionais ligados à assistência da população busca-se conhecer a constituição da prática assistencial em si, o envolvimento e papel desses técnicos, os entraves encontrados e a visão destes sobre o processo de criação de serviços.

Inicialmente, foram entrevistados os gestores locais, regionais e centrais, que apresentaram um panorama da assistência entre 1993-95, indicando os serviços que mantinham profissionais que desenvolviam ações ligadas às propostas em estudo. Essas entrevistas, associadas ao levantamento de documentos recuperaram outros atores ligados às experiências nesse período e no anterior (1989-1992) e que também foram entrevistados. 
3. de banco de dados sobre usuários/pacientes acompanhados pelos serviços

A partir de levantamento de dados de prontuários de usuários dos serviços entre 1989-1995 foi possível criar um banco de dados com informações como: nome, idade, sexo, endereço, moradia, escolaridade, motivo e serviço que realizou o encaminhamento para a unidade de saúde, hipótese diagnóstica e atendimento recebido na unidade de saúde, a partir da estrutura apresentada no Anexo III (p.LVII-LIX) . Foram 1093 ( mil e noventa e três) usuários escolhidos entre os serviços que desenvolviam ações em saúde mental e da pessoa com deficiência e que mantinham registros sobre esse tipo de atendimento.

É importante ressaltar que esse banco de dados terá por principal função caracterizar a população acompanhada pelos serviços e fornecer elementos para se avaliar o alcance da prática desenvolvida em relação às diretrizes gerais propostas para a atenção em saúde mental e da pessoa com deficiência. Este banco não se constitui como uma amostra estatisticamente representativa do conjunto da população atendida pelos serviços de saúde, devendo ser entendido mais pelas características gerais desses pacientes, dadas as dificuldades encontradas para acesso às informações sobre as pessoas acompanhadas nos serviços em questão.

\section{Principais dificuldades}

Como "a pesquisa e os pesquisadores vivem sob o signo das contingências históricas de sua atividade"(MINAYO, 1992 p.27) foram diversos os problemas encontrados no desenvolvimento do trabalho de campo.

Percebeu-se durante o levantamento de dados e documentos que as diferentes fontes dispunham de informações divergentes quanto a registro de atendimentos realizados nos diferentes serviços, mesmo quando essas fontes trabalhavam a partir dos mesmos dados

primários, como era o caso das informações sobre produção dos serviços registradas no SIMIS e posteriormente divulgadas pela FSEADE.

O período estudado incluía um calendário eleitoral para escolha de nova administração municipal, que tornou mais difícil o acesso a dados próprios da SMS entre 1993-95.

Acredita-se que sejam dificuldades correntes quando se procura analisar políticas e serviços da administração pública. 
A informação sobre quais foram os pacientes acompanhados não estava disponível de maneira sistematizada, principalmente nas UBS. Em algumas havia um caderno de registro específico para os pacientes encaminhados à saúde mental. Foi necessário, na maioria delas, levantar com os profissionais que atendiam diretamente e que eram responsáveis pelo agendamento, as listas de nomes dos usuários para, posteriormente, realizar a consulta dos prontuários. Essa dificuldade pode revelar o grau de autonomia das equipes de profissionais e a não preocupação com o registro geral de pacientes acompanhados nessas duas modalidades assistenciais.

No caso das pessoas com deficiência acompanhadas nas UBS tornava-se mais difícil, pois não foi encontrado nenhum registro conjunto de agendamento. Para se obter dados sobre os pacientes acompanhados foi necessário consultar agendas de fonoaudiólogos, psicólogos, fisioterapeutas e terapeutas ocupacionais e a partir dessas informações, constituir o perfil da clientela acompanhada pelo serviço.

Nos Centros de Convivência, na Enfermaria Psiquiátrica, equipamentos específicos de saúde mental, o percurso para obtenção dos dados foi menos longo.

Foi necessário contato direto com os profissionais que desenvolviam assistência. Ter acesso a sua agenda ou a seus apontamentos dependeu da colaboração direta dos profissionais interessados.

O período abrangido pela pesquisa é entre 1989-95 e na região os serviços passaram a funcionar a partir de 1991, como o Centro de Convivência Chico Mendes e Enfermaria Psiquiátrica de Ermelino Matarazzo. A dificuldade foi grande para recuperar essas informações no primeiro semestre de 1996; então optou-se por levantar o máximo de informações dos locais onde estas estavam disponíveis, como nos equipamentos específicos (Enfermaria Psiquiátrica, Unidade de Reabilitação e Centro de Convivência). Estas foram, em sua maioria, de usuários que estavam em atendimento. Por isso as informações sobre alta e desligamento foram menores.

Os dados sobre Hospitais-Dia se restringiam ao H-D de São Miguel. Foram dados gerais como sexo, endereço, idade, data de inscrição e hipótese diagnóstica. No H-D de Ermelino Matarazzo a diretoria se negou a autorizar a pesquisa em prontuários alegando que estavam trabalhando intensamente sobre eles tendo em vista a iminente chegada do 
Plano de Atendimento à Saúde - PAS ${ }^{\varpi}$. Desde a inauguração do serviço (segundo semestre de 1992) até 1996 foram acompanhados cerca de 90 usuários (Entrevista n.29, 1996).

As informações do boletim do Sistema de Informações Ambulatoriais - SIA do SUS sobre a produção dos serviços caracterizaram os serviços da região, pois são relativas a atendimentos realizados e não usuários acompanhados no período. $\mathrm{O}$ acesso às informações do Sistema Municipal de Informações de Saúde - SIMIS dependeu de muitas negociações com a Secretaria Municipal de Saúde - SMS e a Assessoria de Planejamento ASPLAN. Infelizmente, não foi possível ter acesso às informações relativas a movimentação de profissionais na SMS entre 1989 e 1995, apesar de diversas tentativas.

Como o período de realização do trabalho de campo foi o mesmo de implantação da proposta do PAS foi impossível realizar a observação da dinâmica e funcionamento dos serviços, que estava alterada pelos desdobramentos que a proposta implicou. Não havia definição quanto a prazos e lugar reservado à saúde mental e da pessoa com deficiência na implementação dessa política de saúde e de gestão de serviços.

\section{Análise do material coletado}

Os documentos e entrevistas foram considerados como reveladores de parte da história do processo de incorporação da assistência a essas populações e analisados identificando-se os principais momentos e questões colocadas pelo processo de implantação

\footnotetext{
PAS é uma proposta de política de saúde municipal lançada em janeiro de 1995, fundamentada na gestão compartilhada em parceria com cooperativas de profissionais de saúde servidores municipais. Iniciou-se em janeiro de 1996, transferindo da administração direta para as cooperativas toda a infra-estrutura de 14 hospitais, 166 unidades básicas de saúde, 17 pronto-socorros, hospitais-dia e centros de convivência (RAMOS et al, 1996a). Para sua implantação a SMS empreendeu um êxodo de profissionais provocando a "desocupação humana de unidades de saúde por parte dos servidores públicos, para ser possível a ocupação pelo pessoal do PAS (...) $\mathbf{2 4 . 5 0 5}$ servidores de SMS que exerciam funções típicas da saúde foram retirados da rede de serviços"(SÁ, 1997 p.38). Estes servidores foram deslocados para outras secretarias municipais ou para alguns dos serviços municipais de saúde que permaneceram sob administração direta, como no caso dos Centros de Referência, dos recém criados centros que atendiam portadores de doenças sexualmente transmissíveis em geral, e em particular daqueles com AIDS entre outros. Com esse plano operou-se o desmonte de serviços de saúde, que passaram a funcionar sob outras bases, ficando sob responsabilidade da administração direta os serviços já referidos e as atividades de vigilância epidemiológica e de fiscalização do PAS. O PAS sofre uma série de questionamentos jurídicos quanto ao uso de recursos públicos, quanto ao modelo gerencial, que transfere recursos públicos para gestão privada; e também quanto ao modelo assistencial que privilegia as ações curativas, a centralidade na assistência médica. Com essa política estão em questão também os princípios de universalização e eqüidade defendidos na proposta constitucional do SUS. Estudo detalhado sobre sua constituição foi coordenado por COHN \&ELIAS (1997).
} 
da assistência.

Foram criados diversos quadros explicativos da prática assistencial desenvolvida, apontando a cronologia dos principais eventos relativos às propostas (Anexo I p.XV-XXII) e também as principais atividades desenvolvidas nos diferentes serviços de saúde mental e para as pessoas com deficiências (Anexo I p.XXIII-XXX). Buscou-se organizar as informações dispersas nas entrevistas e documentos.

A partir desses quadros procurou-se levantar os principais elementos para a discussão do modelo assistencial desenvolvido nas duas modalidades assistenciais, segundo os diferentes períodos do estudo: 1989-92 e 1993-95. Essas informações estão colocadas conforme a inserção institucional dos profissionais entrevistados, separando gestores, planejadores de nível central, daqueles de nível regional e distrital e dos profissionais diretamente envolvidos na assistência, por se considerar que esse lugar institucional diferenciado baseia-se em atribuições e responsabilidades e percepções também diferentes dos diversos atores do processo de construção das propostas.

No caso das entrevistas com os profissionais que desenvolviam a atenção em saúde mental estão apresentados os elementos segundo os diferentes serviços, UBS, CECCO e $\mathrm{HD}$, pelas características e funcionamentos peculiares de cada um.

No caso da assistência à pessoa com deficiência, as informações estão colocadas segundo os distritos de saúde, pelas condições peculiares de implantação da assistência em saúde em cada um deles.

Esses quadros explicativos são parte do Capítulo IV. 


\section{São Miguel em suas distintas dimensões: conhecendo o território entre 1989 e 1995}

\section{Panorama da organização da saúde e seus reflexos em São Miguel}

\section{O período de 1989-92}

Em 1989 assume o governo municipal uma administração que tinha como proposta de governo democratizar a administração e gestão dos serviços municipais com participação popular. Os cargos de governo foram ocupados por lideranças políticas e profissionais da saúde comprometidos com os princípios do SUS.

\footnotetext{
"Foi um governo essencialmente político, no sentido de tentar firmar uma proposta alternativa (...)

(...) processo de mudanças dentro da Secretaria da Saúde se traduziu em diversas maneiras."

(Entrevista n. 1, 1996, p.7).
}

As diretrizes do SUS eram evidentes nas propostas de governo da Secretaria de Saúde, pela prioridade dada às questões relativas ao processo de gestão, segundo estudo sobre o processo de descentralização e democratização dos serviços de saúde no período de 1989 a 1992, desenvolvido pelo Centro de Estudos de Cultura Contemporânea (COHN, 1995). Eram basicamente três as propostas de governo: democratização da gestão, a construção do Sistema Único de Saúde no município nos moldes previstos pela Constituição Federal e a implementação de um novo modelo assistencial que tinha como eixo orientador o enfrentamento das condições violentas de vida através da mudança de concepção da saúde dentro de um contexto mais amplo das relações sócio-econômicas .

A democratização da gestão seria possível estimulando a participação da população organizada tanto no controle dos serviços como na formulação das políticas de saúde, através do Conselho Municipal de Saúde, das Comissões de Gestão das unidades de saúde e das Conferências Municipais de Saúde, conforme os documentos apresentados no Anexo II (p.L). 
Até o segundo semestre de 1991 estavam implantadas 90 (noventa) Comissões de Gestão e 7 (sete) estavam em processo de implantação, para um total de 196 equipamentos de saúde distribuídos nos distritos (CEDEC, 1992 p.4).

A coerência da administração com a política definida também poderia ser sentida na articulação que se procurou estabelecer com o poder legislativo, para construir uma interlocução concreta com a Câmara Municipal, já que se tinha clareza da necessidade de sensibilizar os representantes eleitos para as propostas da administração na saúde. Foi a Secretaria que criou suporte para facilitar essa comunicação e diálogos constantes entre representantes na Câmara e o movimento social organizado, constituindo verdadeiro "lobby" para a defesa das propostas de governo no campo da saúde.

Para aquela administração a saúde era entendida como processo, determinado pela forma de organização da sociedade, resultante das condições de vida, acesso a trabalho, terra, lazer, assistência e qualidade de vida. E por isso seria estratégico o envolvimento dos distintos setores como educação, cultura, transportes, meio ambiente e administração na proposição de ações que pudessem lidar com a complexidade dos problemas de saúde.

A administração teve como proposta principal a defesa do Sistema Único de Saúde através da municipalização dos serviços, de um novo modelo de assistência, da democratização na gestão e de uma nova política de recursos humanos (Entrevistas $\mathrm{n}^{\circ} 1,7$, $12,17,70,74,81,82,1996)$.

O governo municipal elegeu o problema das condições violentas de vida em geral, e da violência institucional, em particular, como eixo de ação e nesse caso o acesso aos serviços de saúde e o hospital aberto seriam pontos estratégicos (COHN, 1995b).

A política de saúde foi definida e implementada em toda a cidade, como uma forma de lidar com as contradições colocadas no setor e também ousada de entender o alcance de uma administração municipal e os compromissos assumidos diante do movimento social e da população da cidade. As entrevistas referendam esses aspectos:

\section{“(...) nós não tínhamos como usar essa idéia do efeito demonstração, até porque ela seria injusta, na medida em que a população tem necessidades, espalhadas pela periferia de São Paulo.}


(...) o governo não era homogêneo, ele tinha contradições internas. Segundo, que mesmo sendo bem intencionado, existiam compreensões diferenciadas do ritmo das mudanças, a partir do próprio local onde cada um estava situado."

(Entrevista $\mathrm{n}^{\circ} 1,1996$ p. 8, 13).

Operacionalizar as propostas de governo passava por efetivar, no âmbito da Secretaria Municipal de Saúde, a descentralização administrativa, defendida para o conjunto da administração municipal através da criação das subprefeituras. A reforma administrativa na saúde foi definida em início de gestão e implantada como uma das primeiras medidas para viabilizar sua democratização, sofrendo restrições no interior do próprio governo. Discutia-se o processo de criação das subprefeituras, o que envolvia redimensionar papéis e poderes institucionais e intersetoriais.

"Eles diziam que iriam conceituar as coisas. E nós dizíamos: "Pelo nosso conceito não é isso. É outra coisa". Então, a gente foi quebrando a estrutura burocrática. E aí o Eduardo foi vivo, porque ele já fez a reforma logo de cara. Se ele não tivesse feito, não saía. Ele fez a reforma para criar a estrutura da Secretaria. Quando ele fez essa reforma, ele descentralizou as coisas para a saúde, entendeu? Então não ficou tudo na mão da Secretaria da Administração."

"Tinha, senão não ia ter nada, a gente ia ficar brigando com eles e não ia fazer nada."

(Entrevista $\mathrm{n}^{\circ} 81,1996$ p.7,8).

A criação das Administrações Regionais de Saúde e dos distritos de saúde seria uma forma de

“(...) integrar a questão da assistência com as ações de saúde, tirar o profissional de saúde de dentro da unidade e fazer com que ele, assumindo o papel de cidadão, interagisse com a população; onde ela mora, onde ela estuda, onde ela trabalha...de tal forma que o trabalho mais importante não era dentro de quatro paredes na unidade de saúde, mas era um trabalho de campo buscando conhecer os problemas através da territorialização, através da definição das prioridades, da identificação dos problemas mais importantes em cada localidade e priorizando esses problemas com a participação da população e, em função disso, juntos repensando as políticas."

(Entrevista n.1, 1996 p.5).

Para o desenvolvimento dos distritos sanitários eram necessárias mudanças nas práticas sanitárias em curso exigindo que técnicos revissem concepções sobre seu papel 
profissional, dos serviços e unidades de saúde; ao mesmo tempo que a experiência traria questões sobre os problemas concretos, "o como fazer" o processo. Muitos profissionais estavam dispostos a investir apostando na viabilização do SUS, como defesa da utopia, vivida e pensada na relação de técnicos comprometidos com o movimento social.

"(...) a maioria dos distritos e dos cargos de direção, era ocupado por pessoas que assumiam isso sem qualquer ganho financeiro adicional, mas porque tinham convicção de que era uma proposta boa, correta e por militância (...)"

(Entrevista $\mathrm{n}^{\circ} 1,1996$ p.10).

Por outro lado, o desenvolvimento da experiência contava com as dificuldades organizacionais esperadas para romper com as práticas anteriores. Ao final do processo a avaliação era de que a proposta

“(...) teve muita dificuldade para chegar no cotidiano das pessoas, dos funcionários para que eles percebessem que existia uma lógica diferente envolvida nessa forma diferente de agir."

(Entrevista n.1, 1996 p.6).

O período de 1989-92 teve uma agenda extremamente rica, exigindo dos profissionais nos diferentes níveis da administração municipal da saúde a presença em muitas frentes de trabalho, assistencial, de negociação e proposição política; pois estavam em curso a apresentação da Lei Orgânica da Saúde, que regulamentava o SUS e a Lei Orgânica da Saúde de São Paulo com ações propostas de programas como: vigilância sanitária e epidemiológica; saúde do trabalhador; da mulher; do idoso; da criança e do adolescente; portadores de deficiências; doente mental; saúde bucal e zoonoses (COHN, 1995b ).

O texto da lei municipal apresentava discussão específica para a organização dos serviços de saúde mental que deveriam

"ser coordenados pelo Sistema de Saúde no âmbito municipal, estando incluídas as ações preventivas e extra-hospitalares, a implantação de emergências e internação psiquiátricas; ao doente mental está previsto o seu atendimento através do desenvolvimento das seguintes ações: criação e manutenção de serviços relativos ao setor; o desenvolvimento de ações preventivas e extra-hospitalares e implantação de emergências psiquiátricas; o direito de cidadania do doente mental, ficando vedada a utilização de procedimentos violentos e desumanos" (COHN, 1995b p. 14-5). 
Ao mesmo tempo apontava para o problema da assistência a usuários de drogas sugerindo a criação e manutenção de programas de prevenção e combate ao uso de entorpecentes, alcoolismo e ao uso de drogas. A esse respeito, "a legislação estadual mostra-se mais precisa, uma vez que garante o funcionamento de unidades terapêuticas com esse fim." (COHN, 1995b p. 15).

Também estão presentes as disposições sobre controle público/participação social na legislação municipal, onde o município deve "garantir o direito à saúde com a participação da comunidade e também o acesso às informações da saúde e a divulgação, obrigatória, de qualquer dado que coloque em risco a saúde individual ou coletiva." (COHN, 1995b p.17).

Existe a concepção de que os serviços de saúde deveriam ser mantidos pelo setor público.

Diante dessas atribuições concretas para os serviços municipais e de posse de uma avaliação sobre os principais problemas, tendo como eixo o enfrentamento das condições da violência, foram eleitas algumas prioridades como:

"O resgate imediato, nos casos de acidente, agravos agudos à saúde e partos; as centrais de vagas, nos casos de AIDS, politraumatizados, queimados, partos, etc.; e o reconhecimento das dimensões da demanda espontânea através do instrumental epidemiológico são os três aspectos principais propostos pelo Executivo para o equacionamento da problemática do acesso aos serviços.

A proposta de Hospital Aberto, que incluiria o parto humanizado, política antimanicomial, hospital-dia e lares abrigados, viria como uma busca de uma nova ética nas relações com a população. Essa nova ética deveria pressupor transparência das ações executadas nos serviços, com a possibilidade de auditorias para apuração de situações de violência institucional.

A partir dos dois pontos estratégicos, acesso e hospital aberto, o Executivo municipal propõe que várias ações se desenvolvam aglutinadas nos programas de saúde da criança, da mulher, do trabalhador, do idoso, bucal, mental e AIDS, procurando fazer frente aos problemas específicos de cada grupo de risco. A proposta da distritalização aparece como reconhecimento da necessidade de se conhecer e de se planejar de acordo com as necessidades locais, demonstrando a sensibilidade da gestão para as disparidades geográficas contidas no espaço urbano. Portanto, a definição da ação prioritária se daria em comum acordo com a prioridade geográfica, assim ditada pelo diagnóstico distrital"' (COHN, 1995b p.40). 
Nesse estudo, observou-se que existiram avanços importantes no processo de descentralização e democratização da saúde e muitas dificuldades para a implementação de ação intersetorial (COHN, 1995). Algumas dessas ações foram protagonizadas, inclusive, pelo programa de saúde mental na criação dos CECCO, cujas dificuldades serão descritas posteriormente.

Outra questão apontada foi a criação do programa de saúde do idoso, pois o envelhecimento da população é um dado objetivo, exigindo respostas dos serviços municipais mas, no entanto, o perfil etário dos usuários dos serviços municipais estava entre crianças e mulheres entre 20 e 49 anos, características comuns das unidades que tradicionalmente desenvolveram ações para a população materno-infantil (COHN, 1995b p. 42).

Uma das questões fundamentais para a estruturação do SUS era o encaminhamento dado à municipalização.

“(...) o poder público municipal, além de responder apenas por uma pequena parcela da produção de serviços de saúde no município, não dispõe de instrumentos político-administrativos que lhe permitam cumprir as diretrizes do Sistema Único de Saúde, mesmo gastando, como em 1991, US\$ 69,70 per capita do orçamento municipal na área da saúde. Por outro lado, as esferas federal e estadual, com um gasto per capita cerca de 3 vezes inferior através dos recursos do SUS alocados no município, na prática detém um poder de intervenção significativamente superior àquele da área da saúde, já que é o Ministério da Saúde quem contrata a prestação dos serviços hospitalares e a Secretaria de Estado quem realiza as distribuições das cotas de AIH e providencia os pagamentos correspondentes." (COHN, 1995b p. 29).

Ampliar o acesso dos usuários aos serviços bem como o oferecimento de alternativas assistenciais dependia do processo de municipalização dos serviços de saúde na cidade, com maior repasse de recursos financeiros e controle dos serviços privados. No entanto, a implantação do SUS dependia do estabelecimento de ações de caráter coletivo, da integralidade da assistência, do controle social e da profissionalização dos servidores. Apenas a descentralização não seria suficiente para que serviços de saúde tivessem qualidade de assistência e eqüidade no acesso.

Entre 1989-1992 houve a ampliação do quadro de profissionais da saúde com a incorporação de novas categorias profissionais, não por pressão de suas corporações, mas 
pela definição de propostas e programas de assistência que buscavam atender às novas diretrizes da política de saúde municipal. Nesse período foram realizados cerca de 80 concursos, pois a maior parte dos funcionários não era concursada.

Essas contratações respondem às necessidades de estruturação da assistência e acompanham a tendência do setor saúde nos últimos vinte anos (MARSIGLIA,1993 p.389). No caso da SMS houve um política específica de capacitação do pessoal de enfermagem através do CEFOR - Centro de Formação dos Trabalhadores de Saúde e de contratação de auxiliares de enfermagem, buscando melhorar a qualidade da assistência prestada.

É com esse objetivo que

"Houve um acréscimo de 3 mil médicos, 4.600 auxiliares de enfermagem, 2.400 enfermeiras e também na área de reabilitação, de outubro de 1992(...)nós passamos de 75 funcionários que existiam, incluindo aí Físio, Fono e T.O., para 544 funcionários, com um incremento de $625 \%$."

(Entrevista n.1, 1996 p.7).

Além da contratação de profissionais trabalhou-se com formas diversas de treinamento e capacitação em serviço. Inicialmente, realizaram-se cursos de introdução às propostas assistenciais que se pretendia implementar discutindo-se necessidades de saúde da população, criação de serviços e diretrizes gerais do SUS. Ao longo do tempo, foi implementada uma política de recursos humanos, que incluiu a criação de um centro de formação desenvolvido em parceria com a Secretaria da Educação, especificamente para os servidores da saúde, responsável por desenvolver propostas de formação e capacitação.

“(...) nós tínhamos a oportunidade de fazer isso de forma articulada com serviço, na idéia de treinamento em serviço, fazendo pesquisa participante, fazendo com que as pessoas pudessem ter cursos descentralizados (...) investindo também inclusive na qualificação, na educação formal, já que muitos servidores não tinham o primeiro grau completo."

(Entrevista n.1, 1996 p.9).

Essas atividades pedagógicas funcionavam como formas de sensibilização dos profissionais para a política de saúde que se pretendia implantar. No entanto, verificou-se que a participação dos profissionais não foi homogênea em freqüência e nas diferentes categorias, sendo que os médicos tinham maiores resistências a participar dessas propostas.

Ao longo do tempo, os profissionais foram contratados obedecendo a um planejamento e definição de recursos humanos realizado desde o nível central da Secretaria, passando pelos níveis regionais e locais conhecido como Tabela de Lotação de Pessoal - 
TLP. Procurava-se com isso trabalhar com a idéia de equipe de profissionais necessária para as atribuições de assistência, administração, gerência e planejamento tanto nas unidades como nos distritos de saúde. Esse trabalho de planejamento em nível de recursos humanos deu o contorno para as equipes de saúde dos serviços.

"Os primeiros concursos foram feitos pela [Secretaria da] Administração, mas depois todos os outros concursos foram feitos pela própria Saúde. E aí você faz uma espécie de indústria de concursos. (...) E foi nesse período que foi se consolidando a idéia de você ter uma nova TLP de unidades que contemplassem um conjunto de programas, por exemplo, a saúde mental, que não havia a nível da Prefeitura; a saúde do trabalhador que também não havia, uma tentativa de se contemplar uma visão de vigilância sanitária (...)" “(...) fomos abrindo os concursos rapidamente e brigando ao mesmo tempo para conseguir isso."

“(...) era difícil você lotar o pessoal na Saúde. Quando a gente descentralizou foi mais fácil, porque você gerenciava o seu Quadro. Nós brigamos muito para ter o Quadro [de profissionais] da Saúde e nós não conseguimos isso do jeito que nós gostaríamos, porque havia a resistência do pessoal da Secretaria da Administração, além da resistência política mesmo."

(Entrevista $\mathrm{n}^{\circ} 81,1996$ p.8, 12).

A chegada de profissionais não médicos nos serviços representava uma mudança no perfil de atendimento, não mais a assistência médica individual, somente. Eles viriam compor as equipes das unidades e o projeto era que fossem profissionais dos serviços, equipes de saúde das unidades e não apenas vinculados a programas específicos. Foram inúmeros os problemas surgidos nesse processo de ampliação de quadros de profissionais.

"O profissional que chegava, nem a chefia estava antenada! O que dirá o pobre profissional que chegava lá nessa hora? No começo, era muito esperado isso. Por isso que a gente achava que era super importante uma política de desenvolvimento de pessoal em um centro, que a gente chamou de formação e que, hoje, nós estamos revendo e eu acho que é capacitação."

"A gente começou por nós, para depois ir para os distritos, para as unidades... Era uma necessidade de reciclagem geral, porque também nós tínhamos um monte de idéias, de coisas... Mas a nossa experiência não era a de um governo petista, o que você pode fazer. Então, você também tinha que reciclar a sua cabeça para aquilo."

(Entrevista $\mathrm{n}^{\circ} 81,1996$ p.15). 
A chegada desses profissionais nos serviços foi apresentada como muito contraditória, cheia de problemas.

“Então, daí quando eu entrei aqui não tinha nada implantado, eles nem sabiam direito o que era tal. Eu tentei fazer assim, passar para as pessoas mais ou menos o que que era, para chefe na época o que que era, quais eram os tipos de serviços que poderiam ser feitos. Eu não sabia, dentro de uma UBS, o que poderia ser feito, qual era o trabalho dentro da UBS (...)"

(Entrevista $n^{\circ} 61,1996$ p.1).

Estavam colocadas novas questões para esses serviços, para a concretização de propostas de assistência em locais muitas vezes sem infra-estrutura para tanto. A resposta de gerentes e planejadores a essas questões traduzia, de certa forma o grau de contradição daquela realidade, onde era necessário realizar quase tudo ao mesmo tempo, propor diretrizes de trabalho, contratar profissionais e criar serviços. A margem da complexidade do trabalho em nível gerencial era dada em como compatibilizar as diretrizes da política de saúde e os matizes concretos de seu desenvolvimento. Era uma estratégia específica da política, pois grande parte do trabalho concreto e dos recursos financeiros estavam sendo empregados na ampliação dos quadros de profissionais.

Essa leitura da vinculação dos técnicos às propostas assistenciais pode significar tanto a possibilidade de construção autônoma da assistência, no sentido de melhor adequá-la à realidade local, como a autonomia profissional que circunscreve a assistência somente à experiência do profissional, muitas vezes deixando de lado as necessidades de saúde da população daquela região, ou usuária, em particular, daquele serviço. Isso no caso dos portadores de deficiência teve diferentes repercussões:

“(...) porque os documentos eram aprovados, tudo o que os deficientes falavam era aprovado integralmente. $E$ eles começaram a cobrar: se era aprovado, porque não está acontecendo, aí é vontade política, fugia, fugia a determinação que saía na Conferência (...)"

“(...) porque essa história toda de portas fechadas pra eles, entende? Então não tinha como refutar, não tinha contra argumento na história, a não ser quando falava que era problema financeiro, que não tinha dinheiro pra fazer, que o custo era alto, mas os deficientes não exigiam nada além do que o cidadão queria." 
“(...) o que eles traziam não tinha como, não era porque, não entrava a linha de pena, não era isso, era a questão, era muito argumentado, não tinha, tudo baseado na Constituição. Eles não iam chorando as pitangas, não, eles iam em cima da Constituição, discutindo a questão constitucional, então que era uma obrigação de dar respostas pra eles. (...) é o problema da reabilitação, que eu acho que é uma questão seríssima (...)"

(Entrevista $n^{\circ} 5,1996$ 12-13).

Nesse contexto foram contratados profissionais como terapeutas ocupacionais, fonoaudiólogos, fisioterapeutas e psicólogos para unidades básicas de saúde, hospitais gerais e centros de convivência da região, o que facilitaria a ampliação da assistência em saúde para além da atenção materno-infantil e atendimento de emergência, tradicionalmente desenvolvidos pelos serviços municipais. Foi a partir de um esforço institucional de criação de outras alternativas de assistência e da pressão cotidiana, de assessores e interlocutores de programas, como por exemplo o de saúde mental, que se deu essa ampliação.

“Então, eles ficavam sempre à mercê da direção, do que a direção dizia que era importante e tal. Então o que acontecia, se tiver um grupo de barganha, mesmo os profissionais que entravam e pediam, isso se dava a qualquer custo. A ordem, as pessoas ficavam esperando, não acontecia, entendeu?, o processo era esse, o grupo mais forte ganhava, quem falasse mais alto ganhava."

(Entrevista n. 5, 1996 p.10).

A idéia de ampliar os quadros de profissionais prevaleceu e foi a estratégia.

"Nós temos que entupir essa rede com profissionais qualificados", mas com essa visão geral de você ter espaços de atenção especializada e ampliar para a população, um pouco na linha da universalização mesmo, e na concepção desse nosso discurso antigo que a periferia tinha que ter essas coisas que tinham no centro. Nós tínhamos que abrir na periferia. Mas na periferia o trabalho é diferente, teria que ser diferente (...)"

(Entrevista $\mathrm{n}^{\circ}$ 7, 1996 p.23).

As áreas periféricas do município concentram grande parte da população e os serviços de saúde têm grande dificuldade para completar seu quadro de profissionais tendo em vista que a distância desses serviços das regiões centrais implica em grandes deslocamentos num município com as dimensões geográficas como as de São Paulo. É nas 
áreas centrais que residem parte dos profissionais e onde estão outras oportunidades de trabalho a serem associadas ao emprego no serviço público. Então, como proporcionar a fixação de profissionais nas regiões mais periféricas da cidade? Incorporando ao salário básico adicionais de distância e realizando processos seletivos, que definissem melhor o perfil dos profissionais e para quais programas ou ações de saúde.

"Era pensado um perfil para cada um desses profissionais? Eu me reunia com as categorias porque eu achava importante ter o perfil, eu achava importante defender alguma coisa que as pessoas propunham enquanto perfil profissional. Mas por outro lado, fazendo isso, por menos que eu Quisesse, eu reforçava a corporação. Eu era muito questionada por isso, porque eu sentava com as pessoas e discutia."

(Entrevista $\mathrm{n}^{\circ} 81,1996$ p.20).

Nesse sentido, o trabalho novo de consolidação da rede de serviços implicou definir melhor o papel e as atribuições, ter maior clareza de onde se desejava chegar.

"Nós não tínhamos um projeto claro do que iria ser feito. Nós tínhamos a expectativa de que o próprio profissional teria que ir achando o seu espaço, construindo, definindo e trabalhando no seu espaço."

"E voluntarista mesmo. A gente viveu isso. $\mathbf{E}$ quando virou autoridade, acabou fazendo igual (risos). Um pouco foi isso, mesmo."

"Eu acho que realmente consolidar essa coisa dependia de tempo."

(Entrevista $\mathrm{n}^{\circ}$ 5, 1996 p.24).

Por outro lado, o investimento institucional na Secretaria Municipal da Saúde foi evidente, traduzindo-se na ampliação do orçamento como fator fundamental para as ações que seriam desenvolvidas. A saúde foi constituindo-se, na prática, em prioridade de governo.

“(...) com um orçamento que em toda a história da Prefeitura nunca foi superior a $8 \%$ e que nós fomos aumentando gradativamente, $(10,3 \%$ no primeiro ano de governo, $11,2 \%$ no segundo ano, passou para mais de $13 \%$ no terceiro) deixamos a Secretaria da Saúde com $15 \%$ do orçamento municipal) (...)"

(Entrevista n.1, 1996 p.8).

Evidenciavam-se as dificuldades de implantação da proposta pela administração, num município com as dimensões de São Paulo, comprometido com a ousadia de fazer 
cumprir a lei e executar as propostas pensadas técnica e politicamente. As contradições para transformar a lógica de funcionamento dos serviços eram inúmeras

“(...) o dia a dia do trabalho é muito difícil, porque você tem ao mesmo tempo que repensar a proposta que se mostrou insuficiente e muitas mudanças tiveram que ser feitas por ato do Executivo, por decreto, ou por resoluções do Secretário. São medidas frágeis do ponto de vista de se sustentarem numa mudança de governo para outro, uma vez que aquelas que dependiam da Câmara Municipal, nós não tivemos força suficiente para aprová-las." (Entrevista n.1, 1996 p.10).

Cabe assinalar, ainda, o grau de contradições colocadas para uma gestão que propunha a presença do Estado na defesa e garantia de acesso a direitos sociais, num período de agenda eleitoral extensa, em 1989, 1990 e 1992.

\section{O período de 1993-95 e a proposta assistencial}

Em 1992-93 houve uma mudança radical na administração municipal. Entre 1989-92 a gestão estava pautada na defesa de políticas públicas voltadas para o reconhecimento e enfrentamento das desigualdades sociais através de investimentos em setores sociais no âmbito do município (COHN, 1995b, DIMITROV, 1992).

Entre 1993-96, a nova gestão municipal reconheceu nas condições de assistência à saúde um dos problemas para os quais seria necessário produzir respostas institucionais. Nesse período, a Secretaria Municipal de Saúde teve quatro secretários ${ }^{\square}$. Durante esta pesquisa foi possível entrevistar apenas o primeiro secretário, apesar das diversas tentativas para se entrevistar os demais.

Num primeiro momento, foram convocados profissionais reconhecidos técnica e academicamente pelo exercício da medicina, para a gestão da Secretaria Municipal de Saúde existindo um reconhecimento de que

$\square$ Entre janeiro e julho de 1993 foi Secretário da Saúde o Prof. Dr Raul Cutait; entre agosto de 93 e de 94 , o Prof. Dr. Silvano Raia, entre setembro de 94 e de 95 o Dr. Getúlio Hanashiro; e de outubro de 95 a dezembro de 96 o Dr. Roberto Paulo Richter. 
“(...) a Secretaria da Saúde é uma secretaria que sempre foi bastante politizada, com uma característica muito interessante, que tem muita gente que trabalha por amor ao que está fazendo, apesar das condições de trabalho inadequado apesar dos pisos salariais baixos nas funções dos profissionais liberais."

"Outro pilar importante eram os programas matriciais, que são aqueles programas que valem para toda a rede que são atenção à mulher, à criança, ao idoso, AIDS, saúde mental e etc."

(Entrevista $\mathrm{n}^{\circ} 2,1996$ p.1-2).

Em estudo sobre os funcionários públicos MARSIGLIA (1993) observou que a categoria médica na administração municipal caracterizava-se por manter sua identidade advinda da especialidade técnica pelas atividades de vigilância sanitária e assistência de emergência que os serviços municipais desempenharam historicamente. Por outro lado, refere ainda que pela

"migração de médicos sanitaristas da administração estadual em dois momentos para a administração municipal (em 1983 com o PMDB e em 1989 com a eleição do PT) representaram temidos riscos de "politização" da administração, o que significava a destruição da identidade própria da Secretaria Municipal, baseada na qualificação técnica e na neutralidade política" (MARSIGLIA, 1993 p.397).

Reconhecia-se que haveria oposição à administração que se iniciava, como tradução dessa politização da Secretaria, entendida vinculando-a à dedicação profissional e pessoal dos técnicos (apesar das dificuldades colocadas pelas condições salariais e de trabalho). Não existia o reconhecimento de que na gestão anterior havia uma proposta de política de saúde, contrária à que se iniciava. Ou seja, reconhecia-se, sim, uma excessiva politização da Secretaria, isto é de seus técnicos, ao mesmo tempo que parte dos profissionais não estaria suficientemente estimulada a desenvolver suas atividades com qualidade.

“(...) quer dizer, não é que você não tem excelência, você tem coisas de qualidade, não tem mais porque as pessoas não são estimuladas a fazer alguma coisa. Então, eu acho que dentro da rede pública, pela própria estruturação existe um grande desperdício de recursos humanos e econômicos."

"Existe gente muito capaz na Prefeitura o que falta mais é motivação."

“(...) brigar mais por qualidade, que esse é o grande drama do setor público."

(Entrevista $\mathrm{n}^{\circ}$ 2, 1996 p.1). 
Identificavam-se problemas na produtividade de serviços e técnicos e na qualidade da assistência prestada, que estariam diretamente vinculados ao grau de motivação dos profissionais. Pensava-se consolidar a continuidade das propostas assistenciais apesar das mudanças de gestão nos serviços, produzindo-se estabilidade suficiente para que técnicos permanecessem motivados através de capacitação gerencial e criação de cargos e salários vinculados aos serviços e à capacidade que seus profissionais tivessem de se desenvolver academicamente, atualizando-se e refletindo sobre a prática assistencial em desenvolvimento.

“Então, a minha proposta era criar uma condição tal que as pessoas dos vários níveis técnicos não fossem mudadas a toda hora, nem quando mudasse o Secretário."

"(...) o estímulo para qualidade e produtividade era muito baixo."

“(...) os pilares da minha gestão se eu tivesse continuado (...) era fazer um grande programa de capacitação gerencial para criar uma condição interna de atuação melhor do que a que vinha ocorrendo até então. $O$ segundo pilar seria criar uma lei, isso chegou acontecer, que criasse, que fosse um projeto de cargos e carreiras que estaria acoplado a uma divisão no setor público em áreas que tivessem uma certa conotação acadêmica (...)"

“(...) os mais capacitados iriam receber até o dobro dos menos capacitados. com uma série de privilégios para poder trabalhar que valeria a pena o cara qualificar."

“(...) quanto melhor você for, mais você trabalha não para atender aquela demanda que está lá, mas para atender aquela e mais duas ou três vezes aquela que vai chegar a seguir, entendeu?"

$\left(\right.$ Entrevista $\mathrm{n}^{\circ} 2,1996$ p.1, 8).

Para a questão dos cargos e salários o que ocorreu foi aumento salarial diferenciado para médicos, jornadas de trabalho flexíveis, onde contratos de trabalho de profissionais com turno diário de 4 horas passavam a ser organizados em plantões de 12 horas, reduzindo o número de profissionais nas unidades e modificando a qualidade da assistência prestada. Por volta de 1995 essas medidas se estenderam para outros profissionais de nível universitário, principalmente aqueles vinculados aos serviços hospitalares.

Por outro lado, existia uma compreensão de que as diretrizes assistenciais ou para determinados problemas não poderiam ser desenvolvidas apenas pelos quadros dos serviços públicos. A estabilidade das propostas seria conseguida a partir das parcerias com instituições públicas, filantrópicas, nacionais e internacionais, que pudessem auxiliar na 
condução de determinados projetos, como por exemplo no caso da AIDS, cujo programa de atendimento

“(...) tivesse como donos não só a Prefeitura, mas a Prefeitura, várias ONGs, Rotary, Organização Panamericana de Saúde, um grupo que decide uma política para a cidade. Onde a Prefeitura pode ser a coordenadora mas não exclusivamente quem decide, porque você acaba criando um programa que afeta milhões de pessoas vindo da cabeça de uma só pessoa, ou de grupos muito pequenos. Isso é muito inconsistente, perigoso e volátil que a hora que o indivíduo sai tende a morrer tudo o que aconteceu lá."

(Entrevista n², 1996 p.2).

Era uma crítica à atuação da administração anterior, pela forma como definiu suas prioridades e propostas de trabalho e pelo envolvimento de profissionais e representantes dos movimentos na proposição e implantação dos serviços, via Conselho Municipal de Saúde e Conselhos Gestores.

“(...) muitas experiências [que] foram iniciadas na gestão anterior foram criadas com a conotação de que eram coisas que o partido é que tinha feito, e portanto eram coisas do partido e se fosse outro partido não existiriam mais."

(Entrevista n², 1996 p.6).

Possivelmente, essas experiências estariam ligadas às propostas de programas ou de políticas que foram iniciadas na gestão anterior, tomadas como comprometidas com a visão de saúde e de gestão dos serviços com incentivo e organização da participação popular. Um dos exemplos citados eram os serviços de saúde mental.

No início de 1993, organizou-se o Fórum Paulistano de Saúde Mental, com entidades e representantes dos movimentos sociais que defendiam as propostas de saúde mental em desenvolvimento. Esse Fórum seria uma das formas de diálogo com os representantes institucionais da gestão que se iniciava, para tentar garantir a continuidade da política de saúde em curso. No diálogo que se estabeleceu, parte das propostas de funcionamento dos serviços foi incorporada pela nova gestão, não existindo documento que revelasse proposta diferente.

As propostas de saúde mental, e da pessoa com deficiência, não estavam colocadas como prioridades para o novo governo já que, segundo sua visão, era necessário primeiro lidar com problemas como os serviços de emergência, a falta de leitos hospitalares, 
principalmente para maternidade. Em algumas regiões da cidade essas eram questões que estavam sendo levantadas pelo movimento popular de saúde, denunciando as condições de assistência e a falta de prioridade dada pelo novo governo aos setores sociais.

“(...) prioridade (...) segurar as pontas tentando melhorar o que era mais visível e mais agudo. Ao mesmo tempo eu tinha um grupo muito forte que estava trabalhando nos grandes programas."

(...) eu aprendi com essas mulheres mais do que eu aprendi sobre o tema maternidade no Campo Limpo com todos os meus assessores."

(Entrevista n², 1996 p.11,13).

Havia o entendimento de que

“(...) reabilitação é lá no fim da lista."

“( ) tem que cuidar da atenção primária, metade das UBS são da Prefeitura e têm que se preocupar com tantas coisas que a reabilitação nunca foi prioritária (...)"

“(...) e demora tanto quanto o próprio objetivo da reabilitação (...) Eu acho que no meu tempo lá a gente avançou muito pouco."

(Entrevista n², 1996 p.10).

Isso influenciou o desenvolvimento dos serviços como CECCO, HD, UBS com equipes de saúde mental e de reabilitação, pois se traduziu em pequeno ou inexistente apoio institucional para essas propostas, que ficaram reduzidas às iniciativas daqueles profissionais que as assumiam no cotidiano do trabalho como tarefa individual.

Pensava-se em realizar a municipalização dos serviços,

“(...) vamos fazer de acordo com a metodologia científica, vamos fazer uma região, que seja a mais fácil de todas para fazer, aprender como é que isso tem que ocorrer e em pouco tempo a gente consegue espalhar para a cidade." "A região escolhida tinha sido Perus-Pirituba (...)"

“(...) antes de estar tudo assinado e formalizado os nossos técnicos da prefeitura já estavam trabalhando no hospital do estado, absolutamente irregular."

"Vamos dizer informalmente, (...) quando são impostas elas acabam tendo uma dinâmica que quebra um pouco o encantamento, que faz com que muitas pessoas trabalhem na saúde."

“(...) não chega por decreto com toda a dinâmica; agora você ganha passo a passo cada coisinha que você implanta em cada região e depende das pessoas. É igual padaria (...)"

(Entrevista n², 1996 p.14,15). 
Também se defendia a descentralização dos serviços na prática, e após percebido os resultados sua institucionalização.

A defesa de uma agenda para a saúde que não dependesse totalmente das mudanças na administração, definida como resultado de discussões políticas de caráter suprapartidário, exigiria compromissos éticos e políticos entre as diferentes forças sociais em defesa da presença do Estado nos setores sociais. Essa poderia ser a postura defendida pelos técnicos da saúde, mas que não tinha sustentação política .

"Isso é o tipo da coisa que depois de alguns anos geraria um grande falatório (...) "Puxa vida que coisa, que linha interessante, faz duas, três gestões que está assim e veja como mudou".

(Entrevista $\mathrm{n}^{\circ} 2,1996$ p.17).

O significado da primeira mudança de Secretário da Saúde no período 1993-95, nos termos em que ocorreu e segundo o titular que saia:

"(...) eu fui demitido o Prefeito achou melhor mudar, (...)"

"(...) eu estaria lá para fazer as coisas que eu acho que deveriam acontecer. Umas das visões um pouco diferentes que de certa forma acabaram me inviabilizando na Secretaria."

“(...) no setor público você tem que aprender a driblar as dificuldades que a falta de uma administração eficiente e de um modelo gerencial eficaz causam, você tem que achar, sabe?"

“(...) existe uma necessidade, muitas vezes, de respostas imediatas que você precisa se concentrar nelas, por isso que não é um jogo linear (...)"

(Entrevista $\mathrm{n}^{\circ} 2,1996$ p.18,21).

Após 7 meses desse primeiro período, outra gestão no âmbito da Saúde foi iniciada ainda em 1993. No campo da saúde mental, e da pessoa com deficiência, não foram apresentadas outras propostas, apenas reiterado o caráter secundário da assistência a esses grupos. Outros pontos que permaneceram implícitos foram, dentre outros, a redução do orçamento municipal para a saúde, o enfraquecimento das estruturas regionais e distritais de saúde e o êxodo de profissionais, principalmente médicos.

Em 1995, a proposição do PAS - Plano de Atendimento à Saúde recolocou a questão da gestão dos serviços públicos de saúde no cenário político. Havia um questionamento claro da competência dos técnicos do serviço público invocando-se argumentos de racionalidade administrativa e necessidade de modernização da assistência. 
A saúde como prioridade é tema recorrente nas campanhas eleitorais incorporado ao discurso dos candidatos aos cargos eletivos desde o processo de redemocratização do país. Resulta das discussões que o movimento social produziu acerca do acesso à saúde, reconhecido como direito de todos os cidadãos e não apenas daqueles vinculados ao processo produtivo (LUZ, 1991). Este teria sido um dos avanços do processo de redemocratização do país e da constituinte que encerrou seus trabalhos em 1988.

Esse discurso é organizado, geralmente, a partir da denúncia das condições de assistência à saúde e das condições de vida em geral, responsabilizando-se os administradores de gestões anteriores pelo caos e pela falta de atendimento. Raramente se associa a esse discurso uma reflexão sobre o contexto, a produção social dessas condições de vida e de assistência à saúde, ou o acesso à educação, entre outros direitos. 


\section{Indicadores de exclusão/inclusão social}

São Miguel é uma região periférica da cidade de São Paulo, um dos bairros mais antigos da cidade. Na divisão administrativa da Secretaria Municipal de Saúde a chamada Administração Regional de Saúde -6 São Miguel era composta por três Distritos de Saúde:

1. Ermelino Matarazzo, que corresponde ao distrito censitário de mesmo nome e o de Ponte Rasa;

2. São Miguel, que corresponde aos distritos censitários de São Miguel, Jardim Helena, Vila Jacuí e Vila Curuçá;

3. Itaim Paulista, que também corresponde ao distrito censitário de mesmo nome.

Essa região representa $8,3 \%$ do total do território do município, ocupando uma área de 5\% da cidade, com densidade demográfica maior que a do município, conforme Tabela 8.

TABELA 8. Classificação dos distritos segundo o número de habitantes, Município de São Paulo, 1991

\begin{tabular}{lcccc}
\hline \multicolumn{1}{c}{ Distrito } & $\begin{array}{c}\text { total de } \\
\text { domicílios }\end{array}$ & $\begin{array}{c}\text { população } \\
\text { total }\end{array}$ & $\begin{array}{c}\text { área } \\
\mathbf{( k m 2 )}\end{array}$ & $\begin{array}{c}\text { Habitantes/ } \\
\mathbf{k m 2}\end{array}$ \\
\hline 42.* Ponte Rasa & 26.282 & 102.702 & 15,40 & $6.668,96$ \\
12. Itaim Paulista & 37.721 & 163.269 & 12,00 & $13.605,75$ \\
25. Vila Curuçá & 29.267 & 124.300 & 9,70 & $12.814,43$ \\
28. Jardim Helena & 27.616 & 118.381 & 9,10 & $13.008,90$ \\
40. São Miguel & 25.760 & 102.964 & 13,20 & $7.800,30$ \\
44. Vila Jacuí & 23.865 & 101.236 & 7,70 & $13.147,53$ \\
50. Ermelino Matarazzo & 24.071 & 95.609 & 8,70 & $10.989,54$ \\
\hline & & & & \\
Total da região & 194.582 & 808.461 & 75,80 & $10.665,71$ \\
& & & & \\
\hline Total MSP** & 2.630 .138 & 9.646 .185 & $1.509,00$ & $6.392,44$ \\
\hline
\end{tabular}

Fonte: SPOSATI, 1996a p.27

* os números que precedem os distritos são relativos à posição de cada um na classificação geral em relação ao indicador em questão, neste caso o número de habitantes do município.

**no texto original as tabelas estão organizadas desta forma. Apesar de não respeitarem as regras formais de apresentação tabular procurou-se mantê-las como no original para oferecerem informações que possibilitem comparação com os dados gerais do MSP - Município de São Paulo

As informações organizadas pelo Mapa da Exclusão/Inclusão Social da cidade de São Paulo são apresentadas como elementos auxiliares no conhecimento da região de São Miguel, pois são importante instrumento para análise das condições de vida da população do município (SPOSATI,1996). 


\subsection{Indicadores de exclusão social}

No Mapa da Exclusão/Inclusão Social trabalhou-se com indicadores de discrepância e de exclusão social na cidade. Os indicadores de discrepância foram calculados por polaridade, observando-se em cada variável a distância entre o distrito com melhor condição de inclusão e o de pior condição de inclusão, portanto com maior exclusão. Para os indicadores de exclusão social fixaram-se padrões básicos de inclusão a que se atribuíram valor zero e um intervalo de -1 a +1 , que refletiriam os índices de exclusão social distrital, que agregados levaram ao indicador de exclusão social de São Paulo, estabelecendo uma classificação dos distritos. Assim, o maior valor representa as piores condições para inclusão social.

Ao se observar a discrepância em relação aos chefes de famílias sem rendimentos percebe-se, na Tabela 9, que no Distrito de Saúde de São Miguel, Jardim Helena tem a pior posição e Vila Curuçá a menos ruim da região.

TABELA 9. Discrepância dos distritos, segundo chefes de família sem rendimentos, Município de São Paulo, 1991

\begin{tabular}{ll}
\hline 6. Jardim Helena & 4,15 \\
13. Ermelino Matarazzo & 3,23 \\
19. Itaim Paulista & 3,07 \\
31. São Miguel & 2,48 \\
33. Vila Jacuí & 2,42 \\
50. Ponte Rasa & 2,08 \\
86. Vila Curuçá & 1,29 \\
\hline
\end{tabular}

Fonte: SPOSATI, 1996 a p.34

Quando os rendimentos dos chefes de família são de até 1,5 salários mínimos, Jardim Helena ainda tem o maior índice e Ermelino Matarazzo o melhor, segundo Tabela 10.

TABELA 10. Discrepância dos distritos, segundo o rendimento dos chefes de família até 1,5 salários mínimos, Município de São Paulo, 1991

\begin{tabular}{lc}
\hline 3. Jardim Helena & 11,24 \\
4. Itaim Paulista & 10,92 \\
6. São Miguel & 10,13 \\
7. Vila Curuçá & 9,78 \\
9. Vila Jacuí & 9,45 \\
18. Ponte Rasa & 8,40 \\
32. Ermelino Matarazzo & 7,81 \\
\hline
\end{tabular}

Fonte: SPOSATI, 1996a p.35 
Quando se trata de acesso a serviços básicos de saúde, observa-se na Tabela 11 que Vila Curuçá ocupa a pior posição.

TABELA 11. Classificação decrescente dos distritos de acordo com o índice de discrepância de acesso a serviços básicos de saúde, Município de São Paulo, 1993

\begin{tabular}{lc}
\hline 14. São Miguel & 2,34 \\
15. Jardim Helena & 3,38 \\
16. Vila Jacuí & 6,15 \\
64. Ermelino Matarazzo & 7,88 \\
70. Itaim Paulista & 8,41 \\
79. Ponte Rasa & 10,91 \\
83. Vila Curuçá & 12,15 \\
\hline
\end{tabular}

Fonte: SPOSATI, 1996a p.48

No referido mapa trabalha-se com o conceito de autonomia como:

"- a capacidade e a possibilidade do cidadão de suprir suas necessidades vitais, especiais $^{\varpi}$, culturais, políticas e sociais, sob as condições de respeito às idéias individuais e coletivas, supondo uma relação com o mercado, onde parte das necessidades deve ser adquirida, e com o Estado, responsável por assegurar outra parte das necessidades;

- a possibilidade de exercício de sua liberdade, tendo reconhecida a sua dignidade, e a possibilidade de representar pública e partidariamente os seus interesses sem ser obstaculizado por ações de violação dos direitos humanos e políticos ou pelo cerceamento à sua expressão" (SPOSATI,1996a p.57).

Exclusão da autonomia seria, então, estar em situação social limite a de abandono, viver no limiar de sobrevivência cotidiana, ausência de condições de partilhar da consciência social, impossibilidade de representar suas necessidades, interesses e idéias, ausência de garantias a necessidades especiais sem cobertura a situações de vulnerabilidade e riscos, ausência de democracia e de fóruns de decisão participativa, ausência de segurança pessoal e de segurança pública. Nesse campo, as pessoas com deficiência ou portadoras de sofrimento psíquico podem viver experiências particulares, dadas as dificuldades suplementares com as quais terão que lidar para o exercício da autonomia.

\footnotetext{
$\square$ necessidades especiais seriam aquelas advindas de características singulares, como por exemplo no caso da pessoa com deficiência, que tenha grave problema motor necessitará de dispositivos específicos para locomoção ao mesmo tempo que tem necessidades vitais, culturais e sociais semelhantes às das outras pessoas.
} 
Os índices de autonomia da Tabela 12 revelam que no Itaim Paulista a população em geral tem menores condições de autonomia.

TABELA 12. Classificação dos distritos segundo o Índice de Autonomia, Município de São Paulo, 1991

\begin{tabular}{lr}
\hline 2.Itaim Paulista & $-0,90$ \\
7.Jardim Helena & $-0,76$ \\
14.Vila Curuçá & $-0,68$ \\
18. Vila Jacuí & $-0,62$ \\
20. Ermelino Matarazzo & $-0,62$ \\
21. São Miguel & $-0,52$ \\
35. Ponte Rasa & $-0,47$ \\
\hline \multicolumn{1}{c}{ Fonte: SPOSATI, 1996a } & p.53
\end{tabular}

Um outro aspecto é o da qualidade de vida, assim conceituada

"a qualidade e a democratização dos acessos às condições de preservação do homem, da natureza e do meio ambiente. Sob esta dupla consideração entendeu-se que qualidade de vida é:

- a possibilidade de melhor redistribuição - e usufruto - da riqueza social e tecnológica aos cidadãos de uma comunidade;

- a garantia de um ambiente de desenvolvimento ecológico e participativo de respeito ao homem e à natureza, com menor grau de degradação e precariedade."(SPOSATI,1996a p.71)

É nesse sentido que se apontam como situações de exclusão de qualidade de vida viver em precária situação urbana, provocada pela segregação espacial da pobreza com poucos serviços instalados e difíceis condições para seu acesso, vivência sob situação de sofrimento e violência e sob crise social, presença de movimentos e grupos de luta contra a exclusão, pelos direitos humanos e sociais e das minorias. Assim, Jardim Helena e Itaim Paulista figuram entre aqueles de pior qualidade de vida, conforme Tabela 13.

TABELA 13. Classificação dos distritos segundo o Índice de Qualidade de vida, Município de São Paulo

\begin{tabular}{lc}
\hline 3. Jardim Helena & $-0,62$ \\
9. Itaim Paulista & $-0,43$ \\
12. Vila Curuçá & $-0,37$ \\
14. São Miguel & $-0,35$ \\
31. Ermelino Matarazzo & $-0,20$ \\
32. Vila Jacuí & $-0,19$ \\
40. Ponte Rasa & $-0,08$ \\
\hline
\end{tabular}

Fonte: SPOSATI, 1996a p.54 
O mencionado estudo considerou ainda o desenvolvimento humano, a partir das proposições da ONU, entendendo-o como:

“- a possibilidade de todos os cidadãos de uma sociedade melhor desenvolverem seu potencial com menor grau possível de privação e sofrimento,

- a possibilidade da sociedade poder usufruir coletivamente do mais alto grau da capacidade humana." (SPOSATI, 1996a p.89)

As situações de exclusão do desenvolvimento humano seriam relativas à privação das energias criativas das pessoas e de suas capacidades, pelo não acesso à saúde, educação, cultura, para gerar oportunidades econômicas e sociais para si mesmos e para a sociedade; à baixa utilização produtiva do desenvolvimento humano e à privação de vida decente pela modernidade neoliberal e pela crise econômica. Novamente Itaim Paulista e Vila Curuçá estão entre os piores índices do município, segundo Tabela 14.

TABELA 14. Classificação dos distritos segundo o Índice de Desenvolvimento Humano, Município de São Paulo, 1991

\begin{tabular}{lr}
\hline 3.Itaim Paulista & $-0,95$ \\
8. Vila Curuçá & $-0,76$ \\
19. Vila Jacuí & $-0,55$ \\
21.São Miguel & $-0,54$ \\
27. Ermelino Matarazzo & $-0,44$ \\
29. Jardim Helena & $-0,40$ \\
37. Ponte Rasa & $-0,25$ \\
\hline \multicolumn{2}{c}{ Fonte: SPOSATI, 1996a p.55 }
\end{tabular}

Os distritos de Itaim Paulista e Vila Curuçá estão entre os de maior número de casos de homicídios da cidade, juntamente com distritos da zona sul e zona norte.

Os indicadores também contemplam a noção de eqüidade entendida como:

"O reconhecimento e a efetivação, com igualdade, dos direitos da população, sem restringir o acesso a eles nem estigmatizar as diferenças que conformam os diversos segmentos que a compõem. Assim, eqüidade seria:

- a possibilidade das diferenças serem manifestadas e respeitadas, sem discriminação;

- a condição que desfavoreça as práticas de subordinação ou de preconceito em relação às diferenças de gênero, políticas, étnicas, religiosas, culturais, de minorias, etc." (SPOSATI, 1996a p.105). 
Nesse sentido, as situações de exclusão de eqüidade se revelariam através da vivência de formas de discriminação, da inexistência de apoios a necessidades especiais; do não provimento de uma rede de proteção social para enfrentar as situações de vulnerabilidade e risco principalmente dos mais pobres; do caráter assistencialista e discriminatório da rede de atenção à população em vulnerabilidade e risco. São Miguel tem o pior índice na região, conforme Tabela 15.

TABELA 15. Classificação dos distritos segundo o Índice de Eqüidade, Município de São Paulo, 1991

\begin{tabular}{lc}
\hline 10.São Miguel & $-0,65$ \\
20. Vila Curuçá & $-0,53$ \\
23. Jardim Helena & $-0,51$ \\
25.Itaim Paulista & $-0,50$ \\
40. Ponte Rasa & $-0,42$ \\
42. Vila Jacuí & $-0,42$ \\
67. Ermelino Matarazzo & $-0,28$ \\
\hline
\end{tabular}

Fonte: SPOSATI, 1996a p.56

O conjunto desses indicadores compõe o índice de exclusão social que colocam os distritos da região entre aqueles que mereceriam um tratamento diferenciado das políticas públicas no município. Itaim Paulista, Vila Curuçá e Jardim Helena estão entre os distritos de maior exclusão social do município, conforme Tabela 16.

TABELA 16. Classificação dos distritos segundo índice de Exclusão Social, Município de São Paulo, 1991

\begin{tabular}{lc}
\hline 2.Itaim Paulista & $-0,95$ \\
7. Vila Curuçá & $-0,80$ \\
9.Jardim Helena & $-0,78$ \\
14. São Miguel & $-0,71$ \\
22.Vila Jacuí & $-0,60$ \\
28. Ermelino Matarazzo & $-0,52$ \\
33. Ponte Rasa & $-0,42$ \\
\hline
\end{tabular}

Fonte: SPOSATI, 1996a p.52 


\subsection{Morbidade e mortalidade}

A distribuição de óbitos por causa, segundo doenças de notificação compulsória ou por causas violentas e acidentes são apresentadas para auxiliar na composição do perfil epidemiológico da região, em relação ao município de São Paulo.

$\mathrm{Na}$ distribuição dos óbitos segundo causas, observa-se na Tabela 17, que os índices relativos a tumores, doenças do aparelho circulatório, AIDS/Diabetes /Desnutrição são menores que os do município. Já os relativos a violências/acidentes/suicídios, causas perinatais, doenças infecto-parasitárias são maiores que os da cidade, evidenciando a necessidade de ações específicas para sua redução.

TABELA 17. Distribuição de óbitos por causas no município de São Paulo e na ARS-6, 1994.

\begin{tabular}{lcccc}
\hline \multirow{2}{*}{ CAUSA } & \multicolumn{2}{c}{ Município São Paulo } & \multicolumn{2}{c}{ ARS-6 } \\
\cline { 2 - 5 } & $\mathrm{N}^{\circ}$ & $\%$ & $\mathrm{~N}^{\circ}$ & 29,3 \\
\hline 1. Doenças do Aparelho Circulatório & 20.551 & 31,5 & 1.355 & 11,2 \\
2. Tumores (Câncer) & 9.457 & 14,5 & 518 & 16,9 \\
3. Violências / Acidentes / Suicídios & 9.329 & 14,3 & 780 & 13,0 \\
4. Doenças do Aparelho Respiratório & 8.573 & 13,1 & 602 & 7,9 \\
5. AIDS / Diabetes / Desnutrição & 5.209 & 8,0 & 366 & 4,8 \\
6. Doenças do Aparelho Digestivo & 3.158 & 4,8 & 222 & 5,7 \\
7. Causas Perinatais & 2.413 & 3,7 & 265 & 4,1 \\
8. Doenças Infecto-Parasitárias & 2.279 & 3,5 & 190 & 73 \\
9. Doença do Aparelho Geniturinário & 1.071 & 1,6 & 255 & 5,6 \\
10. Demais causas de morte & 3.239 & 5,0 & 4.626 & 100,0 \\
\hline TOTAL & 65.279 & 100,0 & & 5 \\
\hline For
\end{tabular}

Fonte: SECRETARIA MUNICIPAL DE SAÚDE, 1994

As proporções de óbitos por doenças de notificação compulsória, como meningite, doença meningocócica e tuberculose, são maiores que os do município revelando condições de morbidade distintas da cidade como um todo, conforme Tabela 18. 
TABELA 18. Distribuição dos óbitos por doenças de notificação compulsória no Município de São Paulo e na ARS-6, 1994

\begin{tabular}{lcccc}
\hline \multirow{2}{*}{ CAUSAS } & \multicolumn{2}{c}{ Município São Paulo } & \multicolumn{2}{c}{ ARS-6 } \\
\cline { 2 - 5 } & $\mathrm{N}^{\circ}$ & $\%$ & $\mathrm{~N}^{\circ}$ & $\%$ \\
\hline 1. AIDS & 2.943 & 75,00 & 182 & 67,00 \\
2. Tuberculose & 601 & 15,30 & 45 & 17,00 \\
3. Meningite & 208 & 5,30 & 25 & 9,20 \\
4. Doença Meningocóccica & 102 & 2,60 & 13 & 4,80 \\
5. Esquistossomose & 45 & 1,10 & 02 & 0,70 \\
6. Leptospirose & 19 & 0,50 & 03 & 1,10 \\
7. Encefalite Viral & 04 & 0,10 & - & - \\
8. Leishmaniose & 03 & 0,08 & 01 & 0,40 \\
9. Tétano & 02 & 0,05 & - & - \\
10. Polimielite & 02 & 0,05 & - & - \\
11. Febres Tifóides e Paratifóide & 01 & 0,02 & - & - \\
12. Hanseníase & 01 & 0,02 & - & - \\
\hline TOTAL & 3.931 & 100,00 & 271 & 100,00 \\
\hline FoT & & & &
\end{tabular}

Fonte: SECRETARIA MUNICIPAL DE SAÚDE, 1994

Outros dados relevantes para o conhecimento das condições de vida e saúde são os coeficientes de mortalidade na infância e na juventude, conforme se observa na Tabela 19.

TABELA 19. Taxa de mortalidade na infância ( 0 a 4 anos) e na juventude (15 a 24 anos de idade), por 10.000 habitantes, 1991

\begin{tabular}{lcc}
\hline Distritos & Mortalidade na infância & Mortalidade juvenil \\
\hline Ermelino Matarazzo & 71,71 & 27,63 \\
Vila Jacuí & 48,26 & 21,24 \\
São Miguel & 93,62 & 32,43 \\
Jardim Helena & 58,19 & 21,13 \\
Vila Curuçá & 69,15 & 20,66 \\
Itaim Paulista & 70,53 & 29,35 \\
\hline \multicolumn{2}{c}{ O pior e os melhores distritos da cidade } & 45,30 \\
\hline Santo Amaro & 158,53 & -- \\
Marsilac & 25,03 & --- \\
Anhanguera & --- & \\
\hline
\end{tabular}

Fonte: SPOSATI, 1996b p.14

São Miguel, Itaim Paulista e Ermelino Matarazzo têm as maiores taxas de mortalidade na juventude, sugerindo que sejam áreas de maior violência, enquanto para mortalidade na

\footnotetext{
$\square$ LAURENTI et al (1987) e ALMEIDA FILHO \& ROUQUAYROL (1992) utilizam como sinônimos os termos taxa e coeficiente referindo-se a um quociente entre valores numéricos que expressariam determinado risco, isto é entre um número de eventos reais e aqueles que poderiam acontecer. Também pode-se entender que o termo coeficiente expressaria um evento no tempo de caráter mais estático, não revelando a evolução do fenômeno; enquanto que taxa seria uma possibilidade de mensuração mais dinâmica (BERTI, 1997). Neste caso optou-se por apresentar o termo apresentado no mapa da exclusão/inclusão social.
} 
infância aparecem São Miguel, Itaim Paulista, Ermelino e Vila Curuçá com os maiores valores.

As mortes por causas externas são importante parcela dos óbitos em quase todos os países, com distribuição diferenciada. MELLO JORGE et al (1997 p.5) revelaram que no período de 1977 a 1994 passaram a ser a segunda causa de morte no país e no grupo entre 15-39 anos são a primeira causa, com a maior parte dos óbitos entre 15-19 anos. Chama a atenção entre as mortes por causas externas, o aumento dos homicídios no país no período entre 1977 e 1994.

No caso específico do município de São Paulo a mortalidade de jovens (15 a 24 anos)

“era decrescente até a década de 70(...) Após os anos 60 as causas violentas passaram a ocupar a primeira posição, principalmente acidentes de trânsito e homicídios(...) A partir da década de 80 a tendência é crescente, determinada pela mortalidade masculina"(VERMELHO \& MELLO JORGE, 1996 p. 319).

Quando se observa a distribuição dos óbitos por causas violentas como homicídios e queda, São Miguel tem valores maiores que os do Município, conforme demonstra a Tabela 20. Esses problemas exigem atenção especial por parte dos serviços públicos dependendo de ações intersetoriais.

TABELA 20. Distribuição dos óbitos por causas violentas e acidentes, no município de São Paulo e na ARS - 6, 1994

\begin{tabular}{lcccc}
\hline \multicolumn{1}{c}{ CAUSAS } & \multicolumn{2}{c}{ Município São Paulo } & \multicolumn{2}{c}{ ARS-6 } \\
\cline { 2 - 5 } & $\mathrm{N}^{\circ}$ & $\%$ & $\mathrm{~N}^{\circ}$ & $\%$ \\
\hline 1. Homicídios & 4.495 & 48,2 & 396 & 50,8 \\
2. Acidentes de Trânsito de Veículo Motor & 1.710 & 18,3 & 140 & 17,9 \\
3. Demais Acidentes & 986 & 10,6 & 66 & 8,5 \\
4. Suicídios & 476 & 5,1 & 38 & 4,9 \\
5. Quedas & 391 & 4,2 & 50 & 6,4 \\
6. Afogamentos & 133 & 1,4 & 12 & 1,5 \\
7. Demais Causas Externas & 1.138 & 12,2 & 78 & 10,0 \\
\hline TOTAL & 9.329 & 100,0 & 780 & 100,0 \\
\hline Fonte: SECRETARIA MUNICIPAL DE SAÚdDE, 1994 & & \multicolumn{3}{c}{}
\end{tabular}

Essas informações, associadas à distribuição da morbidade ambulatorial, de urgência e de internação na região e no município, conforme Tabela 21, permitem compor um cenário regional. Observa-se um perfil epidemiológico de transição, e com grande importância ainda para as doenças infecto-parasitárias, exigindo dos serviços de saúde um certo grau de 
complexidade, que contemple na assistência tanto os agravos relativos às doenças infecto-parasitárias como as crônico-degenerativas.

Vale ressaltar que a morbidade ambulatorial e de urgência/emergência para as doenças do aparelho circulatório e respiratório, as causas externas e os transtornos mentais já indicavam a necessidade de intervenções assistenciais no campo da saúde da pessoa com deficiência, e em saúde mental. Necessidade esta reafirmada pelo aparecimento das afecções perinatais e doenças do aparelho circulatório e respiratório nos serviços de internação. Muitos dos acometimentos dessa natureza exigem continuidade da assistência nos outros níveis de atenção organizada segundo a lógica da integralidade das ações.

TABELA 21. Distribuição de morbidade por tipo de unidade, no município de São

Paulo e na ARS-6, 1994

\begin{tabular}{|c|c|c|}
\hline UNIDADE & MUNICÍPIO DE SÃO PAULO & ARS-6 \\
\hline AMBULATORIAL & $\begin{array}{l}\text { 1. D. Aparelho Respiratório } \\
\text { 2. Gravidez Normal } \\
\text { 3. Supervisão Saúde da Criança } \\
\text { 4. Hipertensão } \\
\text { 5. Helmintíases }\end{array}$ & $\begin{array}{l}\text { 1. D. Aparelho } \\
\text { Respiratório } \\
\text { 2. Infec. Parasitária } \\
\text { 3. Ap. Circulatório } \\
\text { 4. Ap. Geniturinário } \\
\text { 5. Transtornos Mentais }\end{array}$ \\
\hline $\begin{array}{c}\text { URGÊNCIA / } \\
\text { EMERGÊNCIA }\end{array}$ & $\begin{array}{l}\text { 1. D. Aparelho Respiratório } \\
\text { 2. Hipertensão Arterial } \\
\text { 3. Causas Mal Definidas } \\
\text { 4. GECA } \\
\text { 5. Dor Abdominal }\end{array}$ & $\begin{array}{l}\text { 1. D. Aparelho } \\
\text { Respiratório } \\
\text { 2. Aparelho Circulatório } \\
\text { 3. Causas Externas } \\
\text { 4. Aparelho Ortomuscular } \\
\text { 5. Aparelho Digestivo } \\
\end{array}$ \\
\hline INTERNAÇÃO & $\begin{array}{l}\text { 1. Parto Normal } \\
\text { 2. Abortamento } \\
\text { 3. BCP } \\
\text { 4. Causas Externas }\end{array}$ & $\begin{array}{l}\text { 1. Obstetrícia } \\
\text { 2. D. Aparelho } \\
\text { Respiratório } \\
\text { 3. D. Aparelho } \\
\text { Circulatório } \\
\text { 4. D. Aparelho Digestivo } \\
\text { 5. Afeccões Perinatais }\end{array}$ \\
\hline
\end{tabular}

Fonte: SECRETARIA MUNICIPAL DE SAÚDE, 1994.

Na região de São Miguel, assim como em outras do município, estava colocada a necessidade de criação de serviços de saúde mental, e para a pessoa com deficiência. Além disso os indicadores de exclusão/inclusão já apresentados demonstram a necessidade de o Estado, investido de sua função pública, favorecer e possibilitar a criação de equipamentos sociais e de políticas específicas que possam lidar com a complexidade do quadro social da região. 


\section{Características gerais dos serviços : estrutura, demanda e produção}

A região contava com 2(dois) hospitais gerais, 2(dois) hospitais-dia, 3(três) centros de convivência, 1(um) mini pronto socorro e 14(catorze) unidades básicas de saúde, sendo uma delas associada a um pronto atendimento, conforme está apresentado na Tabela 22.

TABELA 22. Serviços de saúde da Administração Regional de Saúde - 6, segundo Distrito de Saúde, 1996

\begin{tabular}{lll}
\hline \multicolumn{1}{c}{ D.S. SÃO MIGUEL } & D.S. ERMELINO MATARAZZO & \multicolumn{1}{c}{ D.S. ITAIM PAULISTA } \\
\hline 1. Hospital Tide Setúbal & 1. Hospital Alípio Corrêa Neto & 1. UBS/PA Atualpa G. Rabelo \\
& $\begin{array}{l}\text { 1.1 Enfermaria Psiquiátrica } \\
\text { 1.2 Unidade de Reabilitação }\end{array}$ & \\
2. Ambulatório Tito Lopes & 2.1 UBS Pedro J. Nunes & 2.1 UBS Cidade Kemel \\
3.1 UBS Jd. Helena & 2.2 UBS Jd. Popular & 2.2 UBS Camargo Novo \\
3.2 UBS Jd. Maia & 2.3 UBS Dr. Pedro S. Campos & 3. Mini PS Julio Tupy \\
3.3 UBS V. Progresso & 2.4 UBS Dr. Carlos Muniz & 4. CECCO Parque Sta. Amélia \\
3.4 UBS V. Jacuí & 2.5 UBS V. Císper & \\
3.5 UBS V. Nova Curuçá & 2.6 UBS V. Fidelis Ribeiro & \\
4. CECCO Chico Mendes & 3. CECCO & \\
5. Hospital-Dia & 4. Hospital-Dia & \\
Fonte: a partir de SECRETARIA MUNICIPAL DE SAÚDE, 1996a
\end{tabular}

A rede de serviços de saúde mental proposta pelo programa de saúde mental em 1989 estava completa apenas no Distrito de Ermelino Matarazzo. No Distrito de São Miguel foram criadas as equipes de saúde mental em UBS, o Centro de Convivência, o hospital-dia e a emergência psiquiátrica, faltando apenas a enfermaria psiquiátrica no hospital geral. Já no Distrito de Itaim Paulista, contava-se, apenas, com equipe de saúde mental na UBS Camargo Novo e acompanhamento psicológico na UBS/PA Atualpa Rabelo.

Conforme Tabela 22, os distritos de São Miguel e de Ermelino Matarazzo dispunham do maior número de unidades contando com serviços de diferentes níveis de complexidade, facilitando a organização de referência e contra-referência. O mesmo não ocorria no distrito de Itaim Paulista, com menor número de serviços e de menor complexidade.

Quando se fala do acesso a serviços públicos de saúde SPOSATI (1996b p.23) refere que os distritos de Jardim Helena, Vila Jacuí e São Miguel têm menor possibilidade de acesso.

Na assistência à pessoa com deficiência, em agosto de 1993, cerca de 70\% das UBS da região desenvolviam alguma ação programática em saúde da pessoa com deficiência e $68 \%$ 
ações programáticas em saúde nas escolas. Naquela época havia 293 profissionais distribuídos conforme Tabela 23, que desempenhavam atividades assistenciais na ARS-6.

TABELA 23. Profissionais que desempenham funções assistenciais* na ARS-6, segundo categoria profissional, agosto de 1993

\begin{tabular}{lc}
\hline Psiquiatra & 19 \\
Ortopedista & 19 \\
Pediatra & 69 \\
Enfermeiro & 81 \\
Assistente Social & 37 \\
Psicólogo & 26 \\
Fonoaudiólogo & 11 \\
Fisioterapeuta & 21 \\
Terapeuta Ocupacional & 10 \\
\hline \multicolumn{2}{c}{ Total } \\
\multicolumn{2}{c}{ Fonte: SECRETARIA MUNICIPAL DE SAÚDE, 1993.} \\
\hline * relacionadas às propostas assistenciais em estudo.
\end{tabular}

Uma das maneiras de dar visibilidade às atividades assistenciais das equipes de profissionais seria o registro destas nos boletins de produção dos serviços. Havia uma discussão entre os profissionais que atuavam nas equipes de saúde mental sobre quais seriam os objetivos desse registro, se para o controle do trabalho do profissional individualmente (como se através dele se estivesse priorizando um enfoque assistencial baseado na produtividade dos serviços e não em sua qualidade) ou para outra finalidade.

Muito possivelmente esta era uma falsa questão, por que nela estariam colocadas dimensões relativas a distintas concepções de gerência, de papel e autonomia profissional. É tarefa dos profissionais de planejamento trabalhar avaliando o desempenho dos serviços, também a partir de informações sobre atividades, subsidiando a avaliação das propostas assistenciais, onde o registro das atividades cumpre um papel específico e o retorno dessas informações dos níveis distritais e regionais de planejamento, elemento fundamental para a continuidade e aperfeiçoamento de parte do processo de avaliação dessas práticas.

No entanto, parece possível inferir que a administração desse período seria pouco permeável às influências dos profissionais da assistência e, no caso, a regulação do registro estaria funcionando na dimensão do controle. Parte importante dos profissionais vinha de experiências em saúde mental da Secretaria Estadual, que, num determinado momento de 
implantação do SUDS, passou a trabalhar remunerando diferentemente os profissionais médicos, segundo adicional de produtividade.

Até junho de 1992, os dados disponíveis sobre atenção em saúde mental, e da pessoa com deficiência, eram os relativos a consultas psiquiátricas, psicológicas, de terapia ocupacional, de fonoaudiologia e de fisioterapia desenvolvidas nas UBS e ambulatórios de especialidades, conforme Tabela 24.

TABELA 24. Atendimentos por especialidades realizados nas Unidades Básicas de Saúde da ARS-6 entre 1990-1995

\begin{tabular}{lcccccc}
\hline & \multicolumn{7}{c}{ ANOS } \\
\cline { 2 - 7 } Especialidades & 1990 & 1991 & 1992 & 1993 & 1994 & 1995 \\
\hline Terapia Ocupacional & ---- & ---- & 2.130 & 5.718 & 6.983 & 7.887 \\
Psicologia & 8.969 & 7.983 & 17.731 & 20.750 & 21.449 & 27.923 \\
Psiquiatria & 1.794 & 3.173 & 10.055 & 9.741 & 9.933 & 6.410 \\
Fonoaudiologia & --- & 1.350 & 5.150 & 8.659 & 9.562 & 9.930 \\
Fisioterapia & ---- & --- & 1.377 & 7.023 & 10.949 & 12.912 \\
Serviço Social & ---- & --- & 10.516 & 21.753 & 35.091 & 43.512 \\
\hline \multicolumn{1}{c}{ Fonte: SECRETARIA MUNICIPAL DE SAÚDE, $1996 \mathrm{~b}$}
\end{tabular}

Em 1992, foram propostas planilhas de registro próprias para os HD e CECCO que procurariam registrar o número de usuários acompanhados, capacidade de atendimento, saídas, faltas, número de grupos realizados, taxas de ocupação entre outras, um salto de qualidade na informação sobre a assistência desde que trabalhada local e regionalmente.

Os profissionais entrevistados da região referem que em 1993 e 1994 existiu uma mudança no ritmo de trabalho das equipes pelo êxodo de profissionais médicos dos serviços ambulatoriais para os hospitalares. Ao mesmo tempo, que se estabelece uma política de registro de informações, que não era priorizada anteriormente. Por isso as informações das Tabelas de 25 a 27 devem ser relativizadas.

Em todos os distritos os atendimentos psiquiátricos decresceram a partir de 1993, o que revela que o acompanhamento médico não se realiza mais em nível das UBS exigindo dos usuários a busca de consulta na emergência psiquiátrica, principalmente em momento de crise. Em algumas situações, como nos CECCO, os técnicos assumiram papel de interlocutores dos

\footnotetext{
$\square$ as informações sobre atendimentos nos CECCO e HD não serão apresentadas porque foram contraditórias entre si, mesmo que emitidas pela ASPLAN/SMS
} 
usuários na busca desse atendimento, ou até oferecendo outras oportunidades de acompanhamento no próprio serviço, como no caso dos CECCO (Entrevista nº 33 e 54, 1996).

Nos hospitais-dia isso levou à diminuição do número de pacientes em tratamento, pela redução do número de médicos psiquiatras, dificultando ainda mais a referência de pacientes a esse serviço. Já não é possível manter o mesmo patamar de não internação de usuários nos manicômios registrados entre 1991 e 1993 na Enfermaria Psiquiátrica.

No distrito de Ermelino Matarazzo, que apresentava todos os serviços de saúde mental propostos em 1989, procurava-se manter o número de médicos e outros profissionais de saúde mental nas UBS e H-D, como tentativa de não desmantelar a já frágil rede de referência e contra-referência. $\mathrm{O}$ mesmo não ocorrendo com as equipes de profissionais da emergência e enfermaria psiquiátricas, que tiveram seus profissionais trabalhando em regime de plantão de 24 horas, levando a uma descaracterização das atividades assistenciais realizadas na enfermaria, com a diminuição das atividades e acompanhamento grupal dos usuários e de suas famílias. O trabalho na enfermaria reduziu-se a acompanhamento individual e medicamentoso pelos diferentes técnicos o que comprometia a qualidade da assistência prestada.

Essa mudança de rumos na gerência e administração dos serviços levou a uma diferenciação muito significativa em termos de jornada de trabalho, como por exemplo um fisioterapeuta, terapeuta ocupacional ou médico do hospital podendo realizar entre 13-15 plantões mensais de 12 horas, enquanto que o mesmo profissional na UBS ou H-D estava sujeito a jornada de 20, 30 ou 40 horas semanais, pelo mesmo salário, conforme seu contrato de trabalho. Essa estratégia de trabalho levou a diminuição da qualidade da assistência prestada reconhecida pelos próprios profissionais (Entrevistas $\mathrm{n}^{\circ} 11,12,19,23,24,25,48,49$, 1996).

Como era de se esperar o distrito de Ermelino Matarazzo que contava com a maior parte dos equipamentos era responsável pelo maior número de atendimentos da região, conforme Gráfico 1. 
GRÁFICO 1. Atendimentos realizados nas UBS dos distritos de saúde da ARS-6, entre 1990-1995

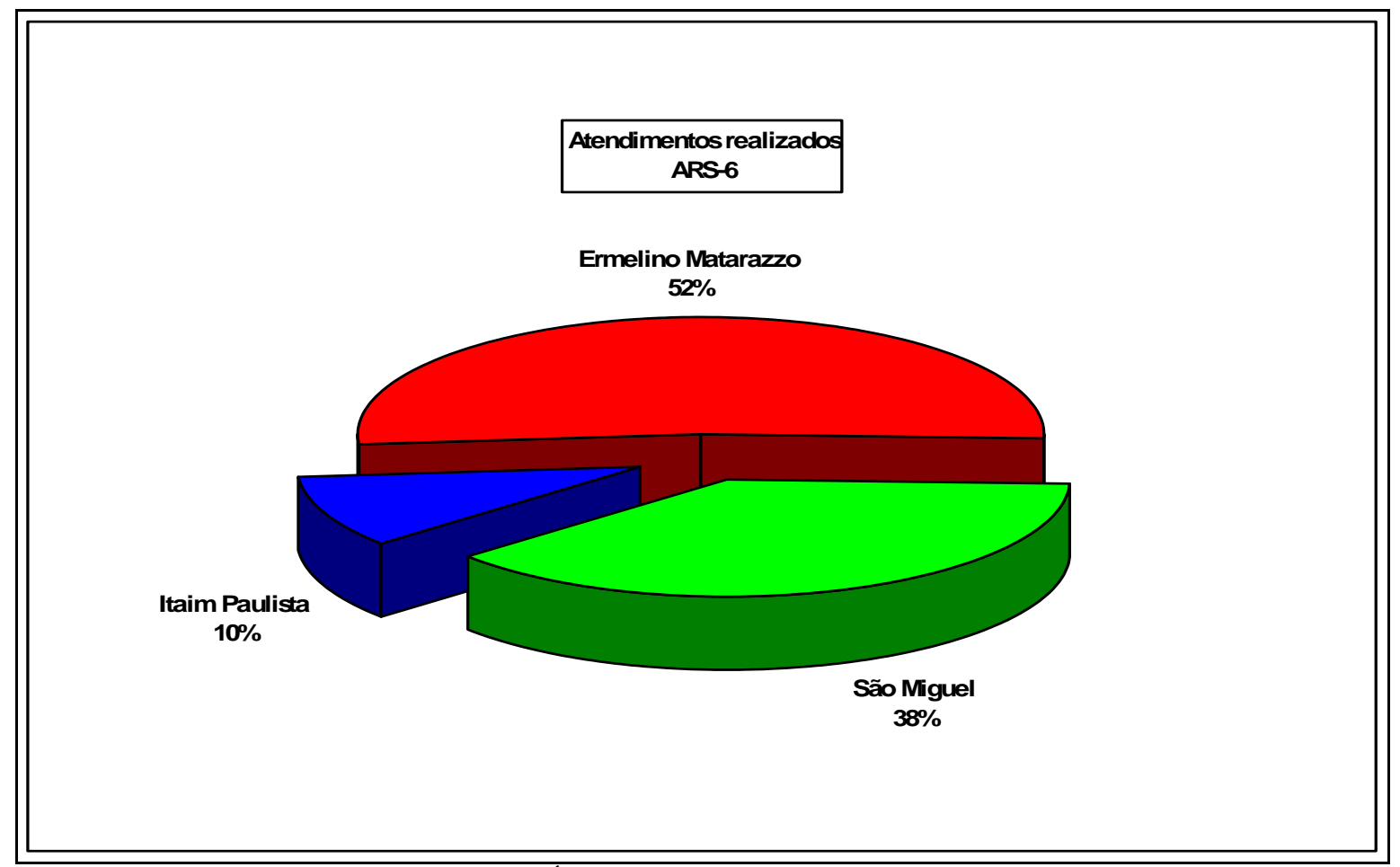

Fonte: SECRETARIA MUNICIPAL DE SAÚDE, 1996b.

Ao se analisar os registros de atendimentos por diferentes categorias profissionais observa-se na Tabela 25, que o serviço social e psicologia que contavam com maior número de profissionais também eram responsáveis pela maior parte dos atendimentos. Como se trata de registros de atendimentos realizados nas UBS, parte do trabalho assistencial de fisioterapeutas, terapeutas ocupacionais e psiquiatras não estavam contemplados.

No Distrito de Ermelino Matarazzo os atendimentos são crescentes ao longo do período, conforme Tabela 25, o que confronta os depoimentos dos profissionais sobre as condições de trabalho. 
Os atendimentos nas especialidades eram crescentes até 1992, exceto os de psiquiatria que decrescem entre 1992 e 1994; e em 1995 voltam a crescer não chegando a retornar ao patamar de 1992.

TABELA 25. Atendimentos por especialidades realizados nas UBS do Distrito de Ermelino Matarazzo entre 1990-1995

\begin{tabular}{l|cccccc}
\hline & \multicolumn{7}{|c}{ ANOS } \\
\cline { 2 - 7 } Especialidades & 1990 & 1991 & 1992 & 1993 & 1994 & 1995 \\
\hline $\begin{array}{l}\text { Terapia } \\
\text { Ocupacional }\end{array}$ & ---- & -- & 1.811 & 2.298 & 3.033 & 3.728 \\
Psicologia & 6.520 & 4.838 & 9.521 & 10.120 & 11.948 & 15.289 \\
Psiquiatria & 1.794 & 3.173 & 5.861 & 4.265 & 3.883 & 4.650 \\
Fonoaudiologia & ---- & 1.350 & 3.145 & 3.546 & 3.851 & 4.432 \\
Fisioterapia & ---- & ---- & 614 & 2.499 & 3.580 & 5.369 \\
$\begin{array}{l}\text { Serviço } \\
\text { Social }\end{array}$ & ---- & ---- & 5.001 & 10.686 & 18.021 & 25.449 \\
\hline \multicolumn{7}{l}{ Fonte: SECRETARIA MUNICIPAL DE SAÚDE, 1996b } \\
\end{tabular}

Fonte: SECRETARIA MUNICIPAL DE SAÚDE, 1996b

Ao se discutir esses dados com os profissionais ligados à assistência e com gestores pode-se perceber que parte daqueles que está nos serviços apresenta resistências a realizar o registro de atividades desenvolvidas, pois considera que seria uma estratégia de controle de produtividade com viés apenas quantitativo, não revelando a qualidade da assistência prestada. Ao mesmo tempo o não registro dos atendimentos realizados, mesmo que de forma insuficiente dificulta estratégias de planejamento e avaliação na administração pública.

O Gráfico 2 facilita perceber a distribuição dos atendimentos nas diferentes especialidades. Nota-se que o serviço social e psicologia realizaram a maior parte dos atendimentos registrados, no entanto essas estão entre as categorias profissionais mais antigas na rede municipal. 
GRÁFICO 2. Atendimentos por especialidades realizados nas UBS do Distrito de Ermelino Matarazzo, entre 1990-1995

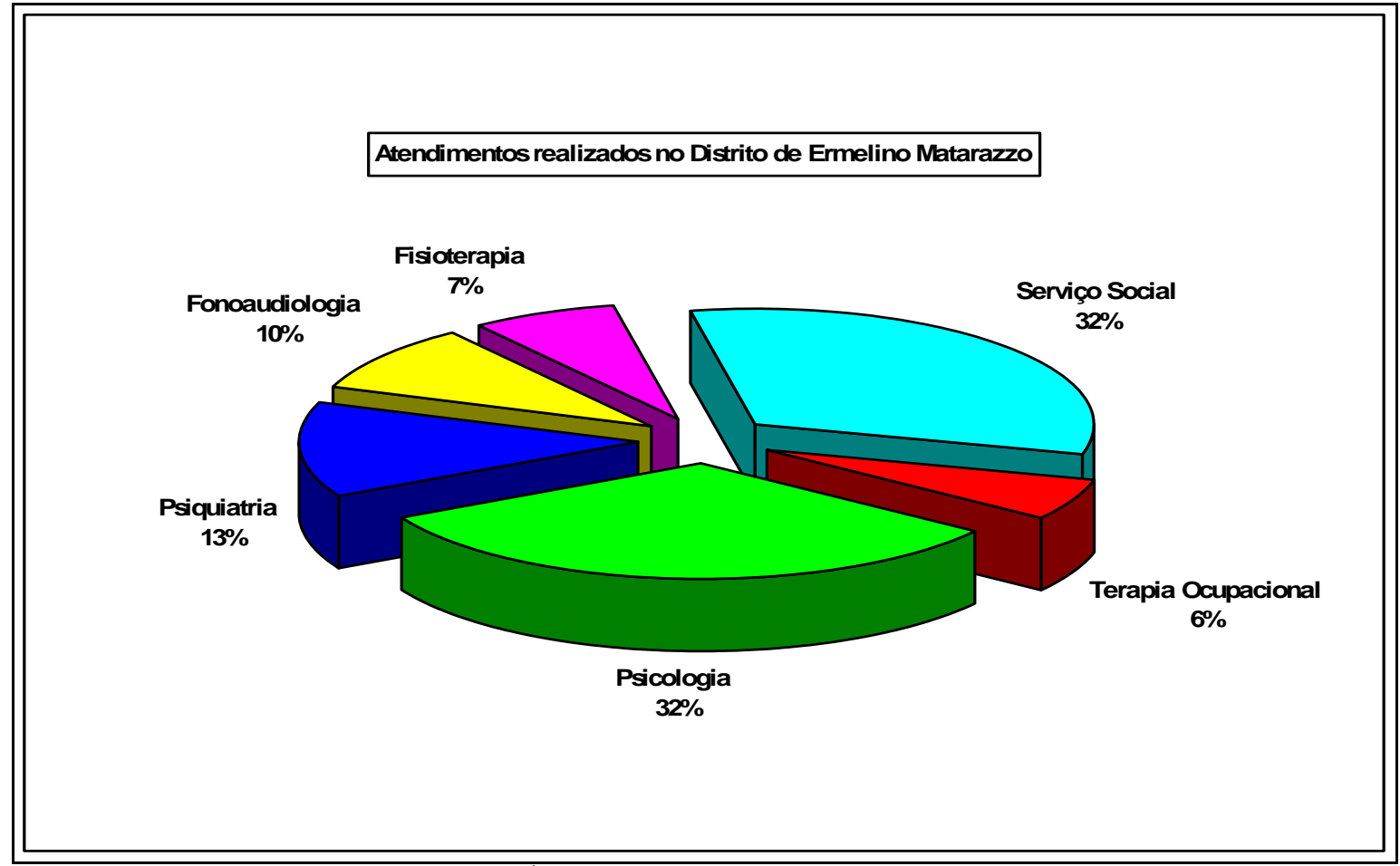

Fonte: SECRETARIA MUNICIPAL DE SAÚDE, 1996b

No Distrito de São Miguel mantiveram-se percentuais próximos aos de Ermelino entre especialidades, conforme Tabela 26 e Gráfico 3.

TABELA 26. Atendimentos por especialidade realizados nas UBS do Distrito de São Miguel entre 1990-1995

\begin{tabular}{l|cccccc}
\hline & \multicolumn{7}{|c}{ ANOS } \\
\cline { 2 - 7 } Especialidades & 1990 & 1991 & 1992 & 1993 & 1994 & 1995 \\
\hline Terapia & ----- & 90 & 3.420 & 3.379 & 3.365 \\
$\begin{array}{l}\text { Ocupacional } \\
\text { Psicologia }\end{array}$ & 3.145 & 2.449 & 6.113 & 7.900 & 8.479 & 11.090 \\
Psiquiatria & ---- & ---- & 3.165 & 4.455 & 5.036 & 1.760 \\
Fonoaudiologia & ---- & ---- & 1.156 & 4.508 & 5.711 & 5.498 \\
Fisioterapia & ---- & --- & 75 & 2.945 & 5.392 & 4.032 \\
$\begin{array}{l}\text { Serviço } \\
\text { Social }\end{array}$ & ---- & --- & 4.196 & 8.017 & 13.263 & 13.306 \\
\hline
\end{tabular}

Fonte: a partir de SECRETARIA MUNICIPAL DE SAÚDE, $1996 \mathrm{~b}$. 
GRÁFICO 3. Atendimentos por especialidades nas UBS do Distrito São Miguel, entre 1990-1995

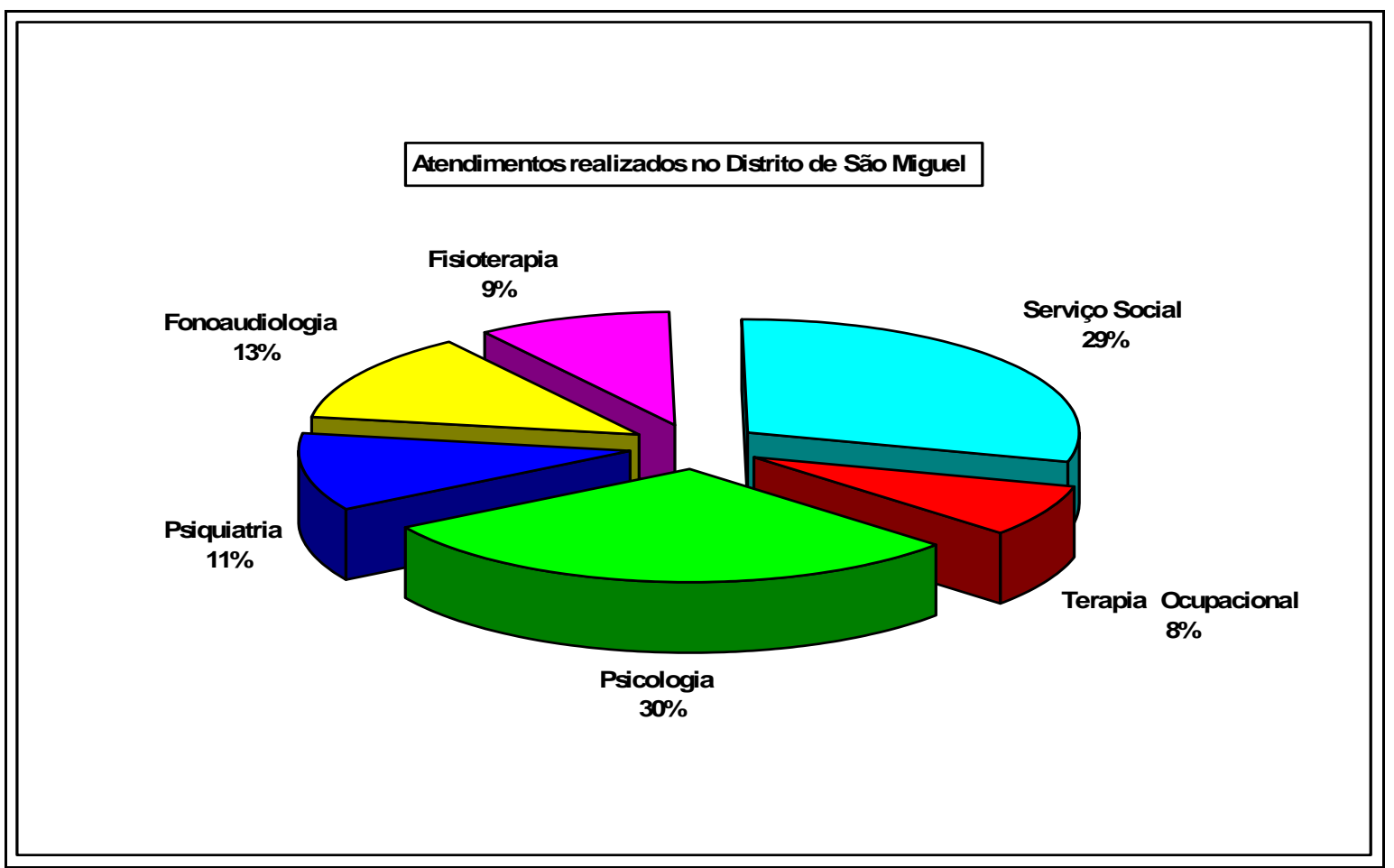

Fonte: SECRETARIA MUNICIPAL DE SAÚDE, 1996b.

Ainda, conforme Tabela 26, ao longo do período decresceram em números absolutos os atendimentos em psiquiatria, pela mudança de médicos para os serviços hospitalares. A reforma da unidade com serviço de fisioterapia e a diminuição do número de fonoaudiólogos foram responsáveis pela redução nos atendimentos.

O aumento significativo dos atendimentos de psicologia não apresentavam uma razão clara, que se evidenciasse nas entrevistas.

Observa-se na Tabela 27, que no distrito de Itaim os atendimentos foram crescentes no caso de fisioterapia e serviço social, e decrescentes no caso de psiquiatria e fonoaudiologia que em 1995 não contava mais com os profissionais. No caso de terapia ocupacional, em 1993 não havia nenhum profissional apresentando um reduzido número de atendimentos em 94-95. No caso da psicologia um de seus profissionais foi transferido para o CECCO o que se refletiu no número de atendimentos em 1994-95. Profissionais entevistados na região referiam que as condições de trabalho nas UBS eram tão adversas sendo quase impossível dar continuidade às atividades assistenciais (Entrevistas n.64 e 65, 1996). O distrito do Itaim era o que dispunha do menor número de serviços de saúde. 
TABELA 27. Atendimentos por especialidades realizados nas UBS do Distrito de Itaim Paulista entre 1990-1995

\begin{tabular}{|c|c|c|c|c|c|c|}
\hline \multirow[b]{2}{*}{ Especialidades } & \multicolumn{6}{|c|}{ ANOS } \\
\hline & 1990 & 1991 & 1992 & 1993 & 1994 & 1995 \\
\hline Terapia & ---- & ---- & 229 & ---- & 521 & 794 \\
\hline Ocupacional & & & & & & \\
\hline Psicologia & ---- & ---- & 2.097 & 2.730 & 1.022 & 1.544 \\
\hline Psiquiatria & ---- & ---- & 1.029 & 1021 & 1.014 & ---- \\
\hline Fonoaudiologia & ---- & ---- & 849 & 605 & ---- & ---- \\
\hline Fisioterapia & ---- & ---- & 688 & 1.579 & 1.977 & 3.511 \\
\hline Serviço & ---- & ---- & 1.319 & 3.050 & 3.807 & 4.757 \\
\hline Social & & & & & & \\
\hline
\end{tabular}

Fonte: SECRETARIA MUNICIPAL DE SAÚDE, 1996b.

A participação das diferentes especialidades no atendimento nas UBS era proporcionalmente diferente no Distrito de Itaim que nos demais, conforme Gráfico 4.

GRÁFICO 4. Atendimentos por especialidade nas UBS do Distrito São Miguel, entre 1990-1995

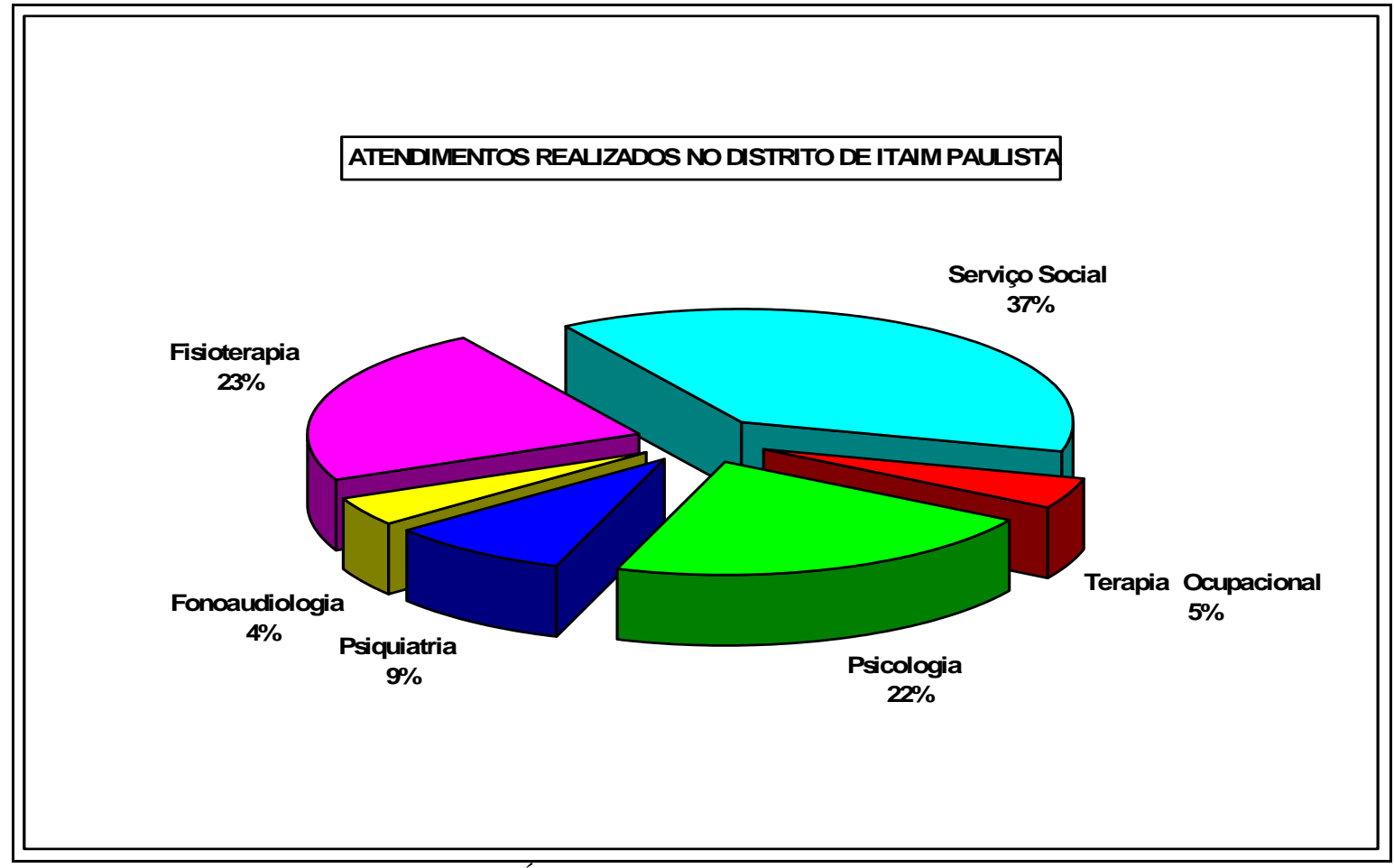

Fonte: SECRETARIA MUNICIPAL DE SAÚDE, 1996b. 


\section{São Miguel: conhecendo o desenvolvimento das propostas assistenciais}

\section{A atenção em saúde mental: o ponto de vista dos profissionais da saúde}

A partir de diversos quadros explicativos, apresentados a seguir e no Anexo I (p. XXXI-XLIII), são colocados os principais elementos para a compreensão da prática assistencial. Essas informações serão organizadas separando os depoimentos de assessores, gerentes e planejadores, e profissionais da assistência dos diferentes serviços (UBS, HD e CECCO). Entende-se aqui que o lugar institucional ocupado por esses técnicos lhes confere responsabilidades e visões distintas do processo transitando entre espaços de poder de decisão, de pressão sobre as instâncias deliberativas e espaços de execução das propostas a despeito das condições de trabalho.

\section{1. Os assessores, gerentes e planejadores no período de 1989-92}

Neste caso, trabalhou-se a partir da identificação de distintas fases do processo desde a constituição das assessorias técnicas, implantação das diretrizes e dos serviços, planejamento em nível de recursos humanos, materiais e capacitação profissional, acompanhamento e avaliação e os principais problemas apontados pelos interlocutores da proposta de saúde mental nos diferentes períodos.

Conforme apresentado no Quadro 1, os princípios gerais da política de saúde mental foram definidos em discussões desenvolvidas no âmbito do Núcleo de Saúde Mental do Partido dos Trabalhadores, grupo de profissionais trabalhadores de serviços públicos de saúde e engajados na militância partidária, em sua maioria, desde a fundação daquele partido político.

Vencida a eleição em 1988, as Assessorias Técnicas da Secretaria Municipal de Saúde foram indicadas pelas instâncias partidárias e deveriam refletir o compromisso com a defesa do programa de governo da candidatura Erundina e com o movimento social na saúde. O mesmo critério foi utilizado para a assessoria regional acrescido de experiência profissional na região. A chegada desse profissional foi tensa, com muitas resistências, porque não se considerava necessário criar uma interlocução específica de saúde mental em São Miguel. 
Como a Secretaria Municipal de Saúde não tinha uma tradição de serviços de saúde mental, a maior parte dos profissionais vinculados a assessorias distritais vieram comissionados da Secretaria de Estado da Saúde, com experiência em saúde mental e engajados no movimento de luta antimanicomial (essa era uma realidade também para os demais programas).

No processo de contratação de novos profissionais havia alguns que se identificavam com a proposta assistencial e passaram a compor as equipes dos serviços, a interlocução de saúde mental nos distritos e o colegiado de saúde mental no município.

No distrito de Itaim Paulista, última região a ser sensibilizada em São Miguel convidou-se, também, profissional recém-chegado a fazer interlocução de vários programas ao mesmo tempo.

A proposta deveria ser compreendida como diretrizes gerais para uma política de saúde mental e não como um programa verticalizado. Assim, estavam em pauta medidas de impacto para a definição do papel dos serviços no atendimento em saúde mental, medidas como fechamento de celas fortes ou similares e proibição do uso de camisas de força nos serviços de emergência. Uma outra medida foi a discussão constante e a proposta de fechamento do ARA - Ambulatório de Reabilitação do Alcoólatra, que funcionava sobre bases disciplinares rígidas de inspiração militar e religiosa.

Os princípios gerais da política eram de redução de internação, ampliação de leitos psiquiátricos em hospitais gerais, criação de serviços alternativos aos ambulatórios de saúde mental como HD e CECCO e ampliação das equipes de saúde mental nas UBS, tendo como população-alvo para todo esse sistema as pessoas com transtornos graves como psicose, os alcoolistas e usuários de outras drogas. Esses princípios iriam instrumentalizar o combate à cultura manicomial, conferindo a essa administração o objetivo de impulsionar o movimento de luta antimanicomial no município.

Vencida a etapa do convencimento da maior parte das direções regionais e também como parte desse mesmo processo, havia que planejar a contratação de profissionais para as equipes de saúde mental dos serviços já existentes, como UBS e hospitais gerais e para a criação dos novos serviços - os CECCO e HD.

Durante grande parte dos anos de 1989 e 90, se discutiu em nível central o perfil dos profissionais a serem contratados em todas as categorias profissionais. Ao mesmo tempo, se 
buscava na negociação contínua com a Secretaria Municipal de Administração formas de participação da Secretaria Municipal de Saúde no processo de seleção dos futuros servidores, visto que a nova gestão procurava descentralizar essa atividade, para atender melhor aos objetivos assistenciais da saúde. Discutidos os perfis profissionais e organizados os dimensionamentos de profissionais para os serviços e das instâncias regionais, era necessário, negociar a criação de cargos, processo político que envolveu distintos níveis de governo e o movimento popular de saúde.

No Distrito de Itaim Paulista chegou-se até a realizar a contratação descentralizada de pessoal em caráter de emergência, maneira pela qual se resolveu o problema de abertura de novos serviços, que já dispunham de instalações físicas e não tinham pessoal contratado.

No campo dos recursos materiais, incluindo aqui, instalações, equipamentos e materiais de consumo procurou-se trabalhar desde o início "ocupando" os equipamentos disponíveis. Foi o caso das UBS e das Clínicas Psicológicas de Apoio ao Escolar da Secretaria Muncipal da Educação, incorporadas à SMS, com seus profissionais transferidos para os serviços de saúde.

Reconhecia-se a dificuldade objetiva da obtenção de recursos orçamentários para a construção de novos equipamentos, no cotidiano do trabalho. Recursos para a compra de materiais ou equipamentos estavam sempre condicionados à disponibilidade orçamentária e às prioridades regionais e locais. No entanto, buscava-se trabalhar a partir da sensibilização das direções, colocando-se uma discussão de princípios e não de simples contraposição entre medicamentos essenciais versus outros materiais de consumo. Se os novos serviços e equipes eram propostas de implantação de uma política, os recursos necessários para sua manutenção, deveriam estar disponíveis. Foi mais fácil obtê-los para os novos equipamentos, principalmente para mobiliário e profissionais do que para as equipes de saúde mental das UBS. Essa sempre foi uma questão a ser negociada quase que serviço a serviço, equipe a equipe. Além do que, o processo de compra, burocratizado, era um ponto frágil na implantação da proposta.

A divulgação e convencimento para a proposta sempre estiveram juntos da discussão e sua problematização, existiu um tensionamento constante das relações institucionais entre os diferentes níveis hierárquicos da Secretaria. Parece que esta era a estratégia principal do programa de saúde mental, no primeiro período dessa administração. Vencidos os primeiros 
obstáculos o tensionamento, pelo menos no nível central, parecia não ser mais necessário, mas se transferia para os níveis regionais e locais, como característica de uma prática político-institucional.

Havia uma resistência cotidiana de profissionais para o desenvolvimento da assistência, principalmente nas UBS, que pressionada pela demanda da população usuária tradicional, obstaculizava a incorporação de outros grupos. Os assessores regionais não esperavam o grau de resistência encontrado entre os profissionais. Faziam uma leitura como sendo esse um sinal da não adesão à proposta e não das dificuldades objetivas da prática assistencial em constituição e da inexperiência com os principais temas da reforma psiquiátrica. Esperavam encontrar maiores problemas para detectar as necessidades regionais de assistência em saúde mental, resultado de processos de estudo do território e da população dos serviços.

No caso dos CECCO foram muitas as negociações entre SMS e SMC e DEPAVE, para se estabelecer o funcionamento do serviço. Para o CECCO Itaim Paulista houve até oposição concreta de profissionais identificados com a administração anterior. Não permitiram as reformas necessárias para a construção de galpão, que possibilitasse o desenvolvimento das atividades previstas, o que levou à instalação de um container como sede do CECCO.

O suporte técnico para as equipes era uma reivindicação constante dos profissionais da assistência. Na proposta de implantação da política não estavam planejadas estratégias de suporte para seu desenvolvimento. As idéias de cursos, supervisão institucional e de equipes foram sendo gestadas como resposta às demandas do trabalho.

Por outro lado, os interlocutores analisaram que parte dessa solicitação de capacitação e formação dos profissionais eram formas de resistir a integrar-se ao trabalho e maneiras de se ausentar das unidades. Ao mesmo tempo que, a autonomia concreta dos profissionais de saúde, levava a que muitos, a maioria, realizassem suas atividades segundo sua formação específica, sem compromisso com a função pública dos serviços e sem coerência com a proposta assistencial. Os cursos e supervisões propostos eram insuficientes para lidar com os mecanismos de avaliação e acompanhamento constantes necessários.

Parte do suporte técnico no Distrito de Itaim se dava pela presença constante dos interlocutores nas unidades, significando o apoio político e a defesa contínua e militante da proposta realizando-a no contexto da estrutura institucional existente, incipiente e 
condicionada pela pouca experiência dos profissionais em nível de planejamento e de desenvolvimento dos serviços de saúde mental, em particular.

Ao se discutir os principais problemas percebeu-se que existia uma avaliação, em nível central, de que não houve tempo suficiente para desenvolvê-la integralmente, e que no processo de implantação respeitou-se, em demasia, a distritalização e as gerências locais. As resistências à proposta foram trabalhadas apenas tecnicamente e não politicamente.

Considerou-se que a maior resistência dos profissionais, vinha das UBS, serviço mais fragilizado do sistema proposto. Ao mesmo tempo que na distritalização, a metodologia empregada fazia com que os problemas mentais desaparecessem do rol das prioridades locais, pois segundo os interlocutores se trabalhava a partir da quantificação para a tomada de decisões.

Os interlocutores distritais preferiam dizer que a proposta foi parcialmente experimentada e que deveria ser vista como processo. Apesar das críticas que faziam ao "carreirismo" de determinados profissionais, com uma visão estreita de saúde mental em saúde pública e uma prática algumas vezes autoritária; também apontavam a dificuldade para se conhecer as necessidades de saúde e as demandas das comunidades, onde estavam os serviços. No entanto, alguns sugeriam a necessária revisão das diretrizes gerais da proposta que compartimentalizaria o atendimento retirando dos serviços mais abertos a possibilidade de acompanhamento dos usuários no momento de crise.

Os Distritos de São Miguel e de Itaim não dispunham da enfermaria psiquiátrica, o que se refletia no funcionamento dos demais serviços. No geral, se considerou que havia um fluxo de informação e comunicação suficientes para experimentar a proposta sendo que o tempo teria sido insuficiente para acompanhá-la e reavaliá-la.

Enquanto a maioria dos profissionais envolvidos no programa eram aqueles comissionados da SES, que defendiam o mesmo projeto político, havia apoio e compromisso, adesão às diretrizes de trabalho em curso. No momento da ampliação de quadros, após os concursos públicos, a adesão era de outra ordem. Era necessário criar estratégias de capacitação e formação, que buscassem deixar claras as atribuições e o projeto de assistência a ser implantado.

Por outro lado, o processo seletivo não foi capaz de selecionar profissionais com experiência anterior em saúde mental e a postura resistente de alguns significou o não 
aproveitamento de uma oportunidade ímpar de crescimento profissional. Essas dificuldades estavam somadas àquelas já esperadas de fixação de profissionais, principalmente os médicos numa região periférica do município, mesmo quando existiam adicionais salariais compensatórios das dificuldades de locomoção.

Os recursos materiais deveriam estar disponíveis para os serviços nas ARS que optaram por criá-los, como um compromisso das direções com a implantação de uma política. A dificuldade para acessar esses recursos estaria ligada à excessiva burocratização dos processos de compras de materiais e à inexperiência nas compras dos materiais característicos dos serviços que estavam sendo criados.

Trabalhou-se intensamente sobre essa questão procurando relativizar o processo e não contrapor a discussão recursos para medicamentos ou materiais de emergência versus materiais para as equipes de saúde mental. Tratava-se de financiar os serviços criados na complexidade de sua proposta de funcionamento.

No que diz respeito ao processo de capacitação dos profissionais, a SMS estava criando o Centro de Formação para Trabalhadores da Saúde - CEFOR e, então, essas propostas foram agregadas ao trabalho do centro. No entanto, a supervisão das equipes não pode se desenvolver naquela estrutura, sendo necessário contratar de emergência profissionais para tal tarefa, o que se realizou apenas em meados de 1991. Posteriormente, foi necessário agilizar convênios já existentes com a Universidade para dar conta desse aspecto da proposta, mas já no último ano da gestão.

Também era necessário relativizar essa demanda dos profissionais, contextualizá-la tendo em vista o compromisso dos profissionais com sua função pública na saúde. 


\subsection{Os gerentes e planejadores no período de 1993-95}

Para os profissionais de nível central a proposta assistencial desse período permanecia a mesma do período anterior, principalmente, no que dizia respeito à manutenção dos serviços. Apontavam a necessidade de redimensionamento das competências e dinâmica de funcionamento das equipes nas UBS e nos HD e rediscutiam o caráter do CECCO. No Anexo I (p. XXXI-XXXII) são apresentas as questões levantadas pelos depoimentos.

Falava-se em evitar a internação nos hospitais psiquiátricos tradicionais, em implementar as emergências e enfermarias psiquiátricas, ou seja em desospitalização e não mais em luta antimanicomial.

Para os profissionais de nível regional a proposta permaneceria a mesma, sem os apoios institucionais necessários que viabilizariam a não internação. Revelaram que o índice de transferência de pacientes da emergência psiquiátrica para o hospital psiquiátrico sobe de em torno de 3\% em 1992, para 50\% da demanda entre 1993-95.

Entre os profissionais de alguns distritos existia denúncia velada sobre o boicote da gestão petista aos profissionais que não eram do mesmo grupo. Para eles, prevalecia um discurso técnico, mas que na prática "não se colocava a mão na massa". Ao mesmo tempo que a população não teria sido suficientemente trabalhada, pressionando política e fisicamente os profissionais da assistência para a internação. Isso seria mais contundente no Distrito de São Miguel, com emergência psiquiátrica e sem a enfermaria psiquiátrica no hospital geral. As pressões institucionais foram fortes nas duas gestões.

A assistência se desenvolveu de maneira diferente nos três distritos. O Distrito de Ermelino Matarazzo continuava sendo a referência para internação e para serviços nas UBS, muito mais restritos nos demais.

Em São Miguel desenvolvia-se, desde 1993, trabalho pioneiro de acompanhamento de usuários de drogas, por iniciativa de um grupo de profissionais, psiquiatra, psicólogos e assistentes sociais com apoio de escolas de psicologia da região, oferecendo campo de formação para futuros profissionais mantendo-se basicamente pela tenacidade dos profissionais e trabalho voluntário de muitos outros.

Um dos principais problemas levantados no âmbito dos recursos humanos era o esvaziamento dos serviços pela política salarial imposta, pela transferência de médicos para os 
serviços hospitalares, deixando as UBS e HD sem profissionais, impossibilitando a referência e contra-referência para os demais serviços. No entanto, essa foi uma proposta "autorizada" pelos interlocutores e direções distritais de saúde.

A grande autonomia profissional também foi apontada como um problema. Os dirigentes ao apresentarem outras propostas assistenciais a serem desenvolvidas pelos profissionais, criticavam seu discurso de oposição, e também tinham dificuldades para que estes aderissem a outras propostas, entendendo essa resistência como falta de compromisso com a população.

Estes também referem a necessidade, já reconhecida, de formação e capacitação de recursos humanos e que foi tratada a partir do desenvolvimento de cursos pontuais e não de processos de formação continuada.

Quanto aos recursos materiais reconhecia-se sua insuficiência e dificuldade crescente de obtê-los pelas prioridades gerais da saúde.

Existia defesa intransigente das direções distritais na implantação do PAS, pois seria um salto de qualidade tanto na autonomia administrativa para se lidar com a política salarial como de contratação/demissão de profissionais. As propostas de funcionamento desses serviços no PAS não estavam claramente definidas.

Inicialmente, as dúvidas estavam em se comporiam ou não o conjunto de serviços das Cooperativas, tendo em vista as características de funcionamento. Após a decisão de inclusão o discurso era de permanência do funcionamento e da proposta, apenas com ampliação da clientela acompanhada. Através das Cooperativas, acreditava-se, seria possível elevar o número de pessoas acompanhadas nos serviços de saúde mental, considerado insuficiente diante das necessidades da periferia. 


\section{3. Profissionais da assistência direta nas Unidades Básicas de Saúde}

A maior parte desses profissionais iniciou suas atividades durante 1992, conforme Anexo I(p. XV-XXII). Dos entrevistados pode-se observar que referiam que sua chegada nos serviços não era esperada, sendo que as direções de algumas unidades demonstravam desconhecimento sobre as atividades que o profissional viria desenvolver, o que lhes trazia grande insegurança.

Conforme apresentado Anexo I (p.XXXIII-XXXIV), o processo foi identificado a partir de como os profissionais perceberam a acolhida que tiveram no início do trabalho, a implantação dos serviços e acompanhamento e o modelo assistencial que desenvolveram.

Os profissionais não percebiam reconhecimento do papel profissional e nem mesmo clareza, por parte da unidade, sobre qual seria o trabalho a ser desenvolvido; situação comum, principalmente, para os profissionais fisioterapeutas, fonoaudiólogos e terapeutas ocupacionais, categorias recém incorporadas nas unidades. Para os psicólogos, já havia maior conhecimento sobre sua prática profissional identificada genericamente como "acompanhamento psicológico," para que atendessem crianças com problemas de aprendizagem, demanda muito presente nas unidades que contavam com esse profissional.

O mesmo não ocorreu com os profissionais que já estavam nas unidades, que percebiam que a proposta assistencial apresentada em 1989 não era clara quanto às atividades a serem desenvolvidas com a população-alvo do programa. Colocavam-se como questionadores da viabilidade de sua execução e porta-vozes dos usuários, que já eram atendidos nos serviços de psicologia das UBS, ou nas Clínicas Psicológicas de apoio ao escolar cujos profissionais foram transferidos à revelia para a SMS, no programa de saúde mental.

A principal questão era o que fazer com as crianças que apresentavam queixa sobre dificuldades no desempenho escolar, demanda presente e crescente dos serviços e como incorporar outros grupos da população-alvo, com os quais não se sentiam habilitados a trabalhar. Ou seja, para os profissionais as demandas trazidas pela proposta de 1989 referiam-se a organizar assistência para populações-alvo: psicóticos, alcoolistas e usuários de outras drogas. Para os profissionais recém chegados acolher significava apresentar uma proposta de trabalho previamente discutida para os recém-chegados, dando-lhes as diretrizes. 
Como isso não ocorreu, lhes é solicitada a proposição de atividades e organização de assistência de forma autônoma, num cenário desconhecido.

A divulgação das diretrizes assistenciais, isto é do projeto político institucional para a saúde mental e da pessoa com deficiência era a principal estratégia utilizada para a implantação da proposta, construindo um caminho de convencimento para adesão. Os profissionais que já estavam nos serviços consideraram que foi um processo autoritário, incoerente com a proposta de gestão democrática. Por outro lado, os assessores e gestores consideravam o questionamento sobre "o como e onde fazer" como sinônimos de resistência à proposta e não de seu aprimoramento e viabilização. Os profissionais não se manifestavam contra as diretrizes da luta antimanicomial, mas sim questionadores de como realizá-la preservando sua autonomia profissional e com as condições objetivas de trabalho (insuficiência/inexistência de espaço, de recursos materiais e humanos) principalmente nas UBS, pouco preparadas para acompanhar demandas da complexidade daquelas das pessoas com sofrimento psíquico.

Como organizar a assistência a psicóticos com profissionais sem experiência? Essa era a principal questão colocada pelos técnicos, antigos ou recém chegados, muitas vezes significando resistência ao trabalho. $\mathrm{O}$ fato das discussões sobre o funcionamento dos serviços serem realizadas em grandes fóruns entre profissionais de todos os equipamentos de saúde mental era apontado como uma grande dificuldade da implantação, inviabilizando o aprofundamento da proposta de assistência e seus desdobramentos nas situações concretas de trabalho. Os profissionais das UBS percebiam que os seus questionamentos eram lidos pelos interlocutores como questões menores, inadequadamente colocadas, para as quais as respostas eram óbvias "tratava-se de integrar esses usuários na atenção da unidade".

Por outro lado, o acompanhamento da implantação, sempre problematizado em grandes reuniões e fóruns coletivos nos distritos ou na região, era entendido como vontade política de viabilização de uma proposta, mas, que na prática, manteve as dificuldades das equipes de saúde mental em suas UBS. Quer por uma visão estreita dos interlocutores, quer pelo tempo necessário para que mudanças importantes pudessem ocorrer.

Os profissionais desenvolviam modelo de atenção que incorporava, marginalmente, pacientes graves, principalmente psicóticos, em acompanhamento ambulatorial nas unidades com psiquiatras, conforme Anexo I (p. XXIII-XXVI). Cresceu a demanda de usuários com 
outros problemas a serem acompanhados pela equipe de saúde mental, como problemas de aprendizagem e problemas emocionais de jovens; com extensa lista de espera e grande dificuldade de articulação de trabalho interprofissional.

No caso da demanda das crianças com problemas de escolarização, em alguns serviços já existia acompanhamento do trabalho de professores em escolas e creches próximas das UBS, procurando discutir a questão da escola, seus métodos e formas de facilitar a abordagem das crianças com problemas.

As equipes de saúde mental tinham grande autonomia e, na maior parte das vezes, funcionavam isoladas na UBS. Aquelas equipes que procuraram maior integração com as atividades gerais da unidade perceberam que era difícil dar respostas a outras demandas, sem dificultar o agendamento em saúde mental.

No período entre 1993-95, os profissionais referiram que o apoio institucional foi menor ou quase inexistente, principalmente pelo êxodo de técnicos ocasionado pelo arrocho salarial, e facilitado pela política de privilégio a plantões nos hospitais, o que facilitou a desarticulação do acompanhamento médico psiquiátrico nas UBS no Distrito de São Miguel, principalmente. Nos demais distritos foi maior a evasão de profissionais por demissão e por transferência para serviços mais centrais.

Nesse período o controle do trabalho era de outra natureza, não havia mais uma preocupação com as diretrizes assistenciais e sim com a manutenção das atividades assistenciais que pudessem desenvolver-se inercialmente, mais por esforço dos profissionais do que por uma estratégia de assistência articulada institucionalmente.

\section{4. Profissionais da assistência direta nos Centros de Convivência e Cooperativa}

No Anexo I (p.XXVII) estão apresentadas as principais atividades desenvolvidas nos CECCO.

Conforme apresentado no Anexo I (p.XXXV-XXXVI), o processo de constituição da equipe e da proposta assistencial, sua implantação e o modelo assistencial foram levantados pelos profissionais dos CECCO. Estes optaram por desenvolver suas atividades nesses serviços, parte deles inclusive escolheu as vagas da região, comprometidos que estavam com a proposta assistencial, pois acreditavam que atendia melhor a suas perspectivas de trabalho em 
saúde, com uma possível inserção comunitária e em articulação com as possibilidades de inserção social dos usuários que se pretendia acompanhar. Um serviço centrado numa concepção de convivência das populações excluídas em espaços públicos, que buscava trabalhar no sentido da autonomia e integração, congregava profissionais dispostos a bancar o desafio de construção da proposta, que significava sensibilizar as direções distritais, batalhar regionalmente os recursos materiais, seja de equipamentos e mobiliário até espaço e dinâmica de funcionamento.

A maior parte dos profissionais participou dos grupos de trabalho que criaram os serviços e que normatizaram suas ações, no final de 1992. Para estes, o fato de não haver clareza sobre qual a dinâmica de funcionamento significava a possibilidade de ousar, experimentar, exercitar seu papel profissional, autorizados que estavam pelas direções locais e regionais a implementar uma proposta assistencial na direção da luta antimanicomial. Uma das maiores dificuldades sentidas foi articularem-se com as Secretarias de Cultura, do Verde e do Meio Ambiente, parceiros "naturais" da proposta apresentada originalmente pela Secretaria Municipal de Saúde, para garantir, no mínimo, a infra-estrutura básica para funcionamento, espaço, recursos humanos para desenvolvimento das oficinas de atividades.

Outra importante dificuldade apontada era construir a referência e contra-referência para o CECCO, havendo necessidade de inúmeros, constantes e permanentes contatos com os demais serviços de saúde mental, principalmente as UBS, para retaguarda no acompanhamento médico dos usuários ou para outras intervenções que o usuário viesse a necessitar. A autonomia dos profissionais, e consequentemente dos serviços, obrigava a discussão constante do papel dos serviços de saúde mental e sua real e possível articulação para se lidar com as distintas demandas dos usuários. O fato de se lidar com usuários que poderiam permanecer grande parte do dia em atendimento, participando das oficinas e atividades dos parques e centros e não se trabalhar com agendamento da mesma forma que na UBS, trazia para o cotidiano do trabalho as contradições da qualidade e das oportunidades de vida dos usuários, tornando-se referência cotidiana para esse grupo.

No período de 1993-95 principalmente, momento de implementação da proposta, a pergunta principal era qual a ligação desse serviço com os demais de saúde e de apoio social, com as organizações comunitárias. Ou ainda, qual era o papel de fato de um serviço com essas características num momento de desestruturação dos demais serviços de saúde. 
Essas questões levaram a que um dos CECCO passasse a oferecer atendimento em áreas específicas a usuários dos serviços, tentando lidar com suas necessidades e oferecendo respostas institucionais redimensionadas para o período, realizando e revendo seu papel e funcionamento.

Nos CECCO da região desenvolviam-se grande parte das atividades previstas no documento de normatização dos serviços de saúde mental de 1992. Os profissionais levantavam questões sobre qual seria o seu papel na dinâmica dos serviços, como lidar com a participação de oficineiros na proposta? Ou ainda, qual seria a viabilidade concreta de participação da população-alvo com a população em geral dos parques e centros, pois as oportunidades de convivência e inserção social são resultado de construções e relações sociais complexas, que um serviço de saúde ou social tem condições relativas de alterar.

Entre as expectativas e possibilidades de inserção social da população-alvo existiria um longo caminho a trilhar, que exigiria discussão cotidiana e processos de formação para o trabalho desenvolvidos local e regionalmente, de forma a não desarticular a assistência em nome da capacitação profissional.

Parte dos profissionais que permaneceram nos CECCO estava a eles vinculados desde o início de seu funcionamento, construindo a proposta assistencial de forma comprometida com os objetivos iniciais, mas também abertos aos desdobramentos que a realidade objetiva da assistência exigia.

\section{5. Profissionais da assistência direta nos Hospitais-Dia}

No Anexo I(p.XXVIII-XXX) estão apresentadas as principais atividades desenvolvidas no HD. Os HD foram os serviços específicos de saúde mental inaugurados mais tardiamente, em agosto de 1992 o de Ermelino Matarazzo e em dezembro de 1992 o de São Miguel. Representavam a proposta de acompanhamento intensivo dos usuários em situação de crise que contavam com apoio familiar.

Conforme apresentado no Anexo I (p.XXXVII), discute-se a constituição da equipe dos serviços, a proposta assistencial e sua implantação. Os critérios de admissão de usuários estabelecidos pelas equipes levavam os técnicos dos demais serviços a questionarem sua viabilidade e adequação para apoio a pacientes em crise, principalmente, no que dissesse 
respeito a trabalhar para não internação em manicômios. Esses critérios limitavam o uso desse equipamento a poucas pessoas. As mais graves, já com uma carreira de doente mental estabelecida, teriam dificuldades para romper com o ciclo de internação nos hospícios, um dos objetivos da política de saúde mental. Por outro lado, os profissionais dos HD defendem os critérios de admissão de usuários a partir de uma visão clínica de assistência que privilegia o olhar sobre os usuários, família e equipe, pouco permeáveis às necessidades colocadas pelos demais serviços de referência.

A autonomia profissional desses técnicos foi tão intensa que delineou a proposta assistencial a partir de critérios que privilegiam o papel dos técnicos na delimitação do trabalho institucional.

A equipe de um dos HD vive tamanha sorte de conflitos internos para definição de uma linha de abordagem teórica para o trabalho assistencial, que inviabiliza a constituição do trabalho interprofissional tendo como resultado a divisão da equipe e dos pacientes entre os técnicos.

O HD é visto como um equipamento com dinâmica e necessidades próprias, e cuja autonomia revela parte da contradição da proposta de modelo assistencial colocada e desenvolvida nos dois períodos.

Era grande o grau de autonomia profissional para constituição dos serviços e a dificuldade institucional da Secretaria Municipal em mediar esses conflitos nos níveis locais e distritais.

Os próprios profissionais reconhecem esses limites e sua fragilidade ficaria mais evidente no momento em que se propõe a criação do PAS, pois os recursos humanos utilizados para o número de usuários acompanhados expressa uma dinâmica de trabalho própria e serão utilizados como argumentos entre custo versus benefício da assistência. Os técnicos fazem a leitura de que se trata de uma questão entre quantidade de assistência versus qualidade assistencial. O PAS coloca para parte da equipe de um dos HD algumas contradições: os usuários terão acesso apenas a atividade assistencial ambulatorial? Como se estruturariam os HD-PAS? Continuando o acompanhamento intensivo dos usuários, evitando a internação e procurando lidar com a crise o mais próximo possível do contexto dessas pessoas, sem obrigá-las ao confinamento nos manicômios? 
Essas questões levaram a que parte da equipe e dos usuários se mobilizasse na defesa da assistência e dos interesses dos usuários, constituindo-se, em 1996, a Associação Recriar para lidar com a continuidade do atendimento, apesar do PAS, e de maneira mais vinculada ao grupo social. Essa iniciativa pode ocorrer a partir da experiência de um técnico da equipe do HD, com trajetória profissional de trabalho junto a organização de grupos e associações mais autônomas, na luta por melhores condições de moradia, que passa a fazer parte da equipe.

Foi necessário romper com o papel tradicional, clínico institucional do HD para se criarem os vínculos mais estreitos entre usuários, técnicos e movimento social organizado, tornando mais visível para essa região esse grupo da população e suas necessidades de assistência. 
2. A atenção à saúde da pessoa com deficiência: o ponto de vista dos profissionais de saúde

Os profissionais de nível central, assessores e planejadores reconhecem que para esse grupo da população foi necessário esforço e poder de pressão próprios para que a SMS se mobilizasse a produzir uma proposta assistencial específica, apesar da organização das pessoas com deficiência, através do Conselho Municipal do Deficiente e de suas propostas.

"Ah, a questão da deficiência ficou lá para o fim. A proposta de trabalho para deficiente apareceu eu acho que em 92."

"Então, ficou muito para o final. Foi uma questão que não teve ninguém que tivesse abraçado e feito.

É muito mais difícil você trabalhar com essa questão."

“(...) a dimensão do problema era muito maior e a dificuldade também. Não tinha gente articulada em cima da questão, não tinha um trabalho anterior. Demorou muito para se conseguir produzir alguma coisa nesse sentido."

(Entrevista ${ }^{\circ}$ 81, 1996 p.21)

"Ficou uma coisa meio mal parada, eu não lembro quem começou a assumir aquilo... Eu lembro que eu fui e depois outras pessoas começaram a assumir, mas ficou uma coisa que não foi encampada. Quando o pessoal da mental assumiu é que as coisas andaram. É assim que avalio, pelo que eu me lembro... porque depois eu perdi um pouco o contato, eu estava ali mais para estimular, não dava tempo de fazer um monte de coisas."

(Entrevista n 81, 1996 p.11)

A Secretaria Municipal de Saúde, pressionada pelo Conselho Municipal do Deficiente, cria um grupo de trabalho para discutir e propor um programa de atenção ao deficiente no âmbito dessa secretaria.

"São programas que foram elaborados através de grupos de trabalho, constituídos através de atos do Secretário e publicados em Diário Oficial, com composição mista que envolvia a participação de técnicos, de funcionários, da sociedade civil organizada naquela área específica, programa esses que uma vez elaborados foram levados à discussão nas várias instâncias de decisão da Secretaria da Saúde, ou seja, à nível dos conselhos técnico-administrativos existentes no gabinete do secretário, na regional e no distrito de saúde e também nos espaços de representação da sociedade dentro dos conselhos gestores e no Conselho Municipal de Saúde."

(Entrevista n. 1, 1996 p.3)

Uma das estratégias utilizadas para divulgação e sensibilização tanto do CTA quanto das regiões de saúde foi a discussão da proposta de programa nas diferentes regiões com os profissionais das direções regional, distrital e local e os representantes do grupo de trabalho, incluindo principalmente os membros do Conselho Municipal do Deficiente. Ao participarem 
localmente dessas discussões levantavam questões de acessibilidade, quer pelas barreiras arquitetônicas dos serviços de saúde quer pelo despreparo das equipes para o acompanhamento dessa população.

“(...) trabalhar com deficientes não dá status nenhum, não dá status, não tem lobby, o número de deficiente é pequeno. Então, assim, não existe uma repercussão tão forte (...)"

"A discussão foi feita a nível de todas as regiões, em reunião ampliada do CTA e sempre na linha de problematização e em todas essas reuniões teve participação de deficientes."

“(...) botava no braço, trazia, a cadeira de rodas ficava fora. Isso tudo já levantava toda reflexão a respeito do problema, da dificuldade de acesso, tal, e esse processo foi muito bom por conta disso, porque daí as pessoas começaram a quebrar porta, dar espaço maior e tal. Eu acho que é um marco, um marco e os deficientes tiveram que ajudar, sem eles não teria condições.”

(Entrevista n5, 1996 p.6)

No caso da ARS-6 não se realizou esse tipo de sensibilização, envolvendo os técnicos dos distintos serviços, mas alguns profissionais chegaram a participar de propostas de treinamento mais centralizadas que se desenvolveram a partir de 1993. Na ARS-6 o grau de organização da assistência a essa população foi bastante diferenciado nos distritos de saúde, segundo a disponibilidade de recursos humanos, materiais e de espaço das unidades de saúde desde as UBS até os CECCO e hospitais gerais. Ao mesmo tempo, não era uma atividade reconhecida no conjunto dos serviços.

“(...) se eu não me engano, Ermelino está equipado com uma área de reabilitação física. Mas o Tide nunca teve (...) É complicado, porque você tinha que fazer desenhos de readequação de espaços nos hospitais e nos ambulatórios que haviam. $E$ sempre havia demandas de variadas ordens em que o espaço que, teoricamente, uma equipe ligada à área de reabilitação ocuparia acabava ficando em segundo plano (...) Porque se você não tem o profissional você também não tem a pressão para garantir a existência desses espaços."

(Entrevista n7, 1996 p.11)

A eliminação das barreiras arquitetônicas foi talvez a atitude mais específica em nível regional para possibilitar o atendimento a portadores de deficiência naquilo que os serviços já realizavam de assistência.

A contratação de profissionais como terapeutas ocupacionais, fonoaudiólogos para as equipes de saúde mental das unidades abriu a possibilidade de incorporação de portadores de deficiências motoras, sensoriais e/ou mentais, adultos ou crianças. Dependeu da 
disponibilidade e experiência do profissional. Nos serviços que contrataram também fisioterapeutas o atendimento a esses grupos era mais completo. A região não dispunha de serviços assistenciais para essa população, obrigando-a a grandes deslocamentos na cidade.

As informações recolhidas nas entrevistas são apresentadas e organizadas segundo os Distritos de Saúde identificando a constituição da equipe de profissionais, sua chegada e experiência profissional anterior, a proposta assistencial e sua implantação e os principais problemas identificados no processo e na proposta de trabalho.

\subsection{Distrito de Saúde de Ermelino Matarazzo}

No caso específico da ARS - 6 o Distrito de Ermelino Matarazzo dispunha de uma Unidade de Reabilitação no hospital geral, que se organizou inicialmente como serviço de fisioterapia para acompanhamento dos pacientes durante a internação e posteriormente em ambulatório, mas apenas para aqueles que passaram por internação. Esse serviço se inicia em 1991, acompanhando os pacientes nas enfermarias.

O espaço próprio para reabilitação iniciou suas atividades em maio de 1992, tendo como objetivo: "o acompanhamento global da saúde de sua população satélite, através da aquisição de sua autoestima e confiança em sua produção diária e independência pessoal” (SECRETARIA MUNICIPAL DE SAÚDE, 1992c p.73).

Conforme apresentado no Quadro 2, a seguir, o serviço se caracterizou mais como de fisioterapia, pelo número predominante de fisioterapeutas em seu quadro, e pela problemática dos usuários com problemas traumato-ortopédicos em sua grande maioria. Não que não houvesse demanda de outros tipos, mas os profissionais, em sua maioria homens, tinham uma preferência quase que pessoal pelo tratamento dessa clientela. As pessoas com comprometimento neurológico, outra demanda importante, eram acompanhadas também, mas

principalmente pelas profissionais mulheres, que referiam ter maior disponibilidade para trabalhar com pessoas com problemas de evolução mais lenta. Por avaliação dos próprios profissionais o perfil feminino oferecia maior continência para essas pessoas. 
A equipe dessa unidade se amplia com fonoaudiólogos, terapeuta ocupacional, assistente social e fisiatra.

Havia um despreparo e desconhecimento dos profissionais sobre o que era o funcionamento de um hospital geral e do que se esperava realizar de atendimento. Esses técnicos tiveram autonomia para organizar o serviço segundo suas prioridades, desde que se respeitasse as características do hospital. Referiam que não receberam suporte técnico para o desenvolvimento do serviço, sempre trabalhando de maneira autônoma. A equipe se constituiu ao longo de 1991 e meados de 1992, no entanto, a remoção zerada de profissionais de 1992, possibilitou que alguns se transferissem para outras unidades de SMS, desarticulando parte do trabalho, que se caracterizava como de acompanhamento em diferentes especialidades, fisioterapia, fonoaudiologia entre outras. A fonoaudiologia desenvolveu seu atendimento em outro local pela inadequação do espaço da Unidade de Reabilitação, ruídos excessivos, pouca ventilação, que inviabilizavam o atendimento. Os profissionais também acompanhavam pacientes nas enfermarias. O contato da equipe se realizava no momento de discussão de casos, mais intenso quando a equipe estava mais completa. Como era um dos poucos serviços especializados da região a demanda que procura o serviço para acompanhamento ambulatorial era reprimida, principalmente quando as UBS perderam parte de seus profissionais de reabilitação, a partir de 1994 e 1995.

Quando o programa de saúde do deficiente foi criado a Unidade de Reabilitação já existia. $\mathrm{O}$ grupo de trabalho que elaborou o programa não teve contato com aquele serviço e seus profissionais a consideraram como um documento a mais a ser conhecido.

No Distrito de Ermelino Matarazzo, o CECCO também acompanhava usuários com, deficiência mental e/ou motora ou sensorial. Técnicos do distritos e das UBS propuseram e realizaram pesquisa para identificação de pessoas com deficiências nas unidades e, a partir daí, ofereceram acompanhamento àquelas que pudessem participar das atividades dos CECCO e das UBS. O trabalho se desdobrou na criação de uma proposta de acompanhamento daqueles chamados de portadores de necessidades especiais, discutida e encaminhada, conjuntamente, com a Secretaria Municipal de Educação. Tratava-se de oferecer suporte aos núcleos regionais de educação e às escolas e professores, em particular, para que as crianças com deficiências pudessem participar das classes comuns. Essa foi uma experiência de sucesso, com as dificuldades esperadas para a proposta e que se manteve muito por iniciativa dos 
próprios profissionais, principalmente, após a mudança de gestão em 1993. Foi um trabalho do qual participaram diversos técnicos de diferentes instituições de saúde e educação.

As pessoas com deficiência compuseram um contingente importante dos usuários dos CECCO. No entanto, se reconheceu que as propostas de atendimento apresentadas eram insuficientes para as muitas necessidades desse grupo, por exemplo no que dizia respeito à integração e participação social, ou mesmo preparação para uma vida mais autônoma.

Nas UBS o acompanhamento de pessoas deficientes se deu por iniciativa dos técnicos, pressionados pela demanda de usuários que buscavam atendimento; e pelos encaminhamentos de profissionais que conheciam o quadro de recursos humanos das unidades. No entanto, os maiores problemas apontados - espaço inadequado, com salas pequenas que não comportavam pequenas adaptações para atendimento a pessoas com deficiências motoras, a falta de equipamentos ou recursos materiais mínimos como colchonetes e espelhos, material pedagógico básico, entre outros, faziam com que os profissionais "desistissem" no decorrer do tempo de atender pessoas com problemas graves. Nessas unidades eram acompanhadas pessoas com seqüelas leves de AVC, crianças com paralisia cerebral leve, deficientes mentais jovens e crianças sem comprometimentos psiquiátricos associados. Esses problemas de infra-estrutura ocorreram nos diferentes períodos do estudo, independente do período de administração.

Os profissionais das UBS perceberam que não existia clareza entre os dirigentes regionais e distritais sobre quais seriam ações de assistência para as equipes de reabilitação, tanto no hospital como nas UBS, envolvidos que estavam com outras prioridades, como atenção materno-infantil, pronto-atendimento e emergência.

Entre 1993 -96 houve uma diminuição progressiva dos profissionais nas equipes dos serviços e uma não preocupação com o preenchimento das vagas existentes, revelando o lugar da atenção a essa população na Secretaria Municipal de Saúde, naquele contexto histórico. 


\subsection{Distrito de Saúde de São Miguel}

Conforme apresentado no Anexo I (p. XXXVIII-XL), em todas as UBS desse distrito houve pelo menos um profissional da equipe de reabilitação contratado, durante parte do período estudado. No hospital geral não havia acompanhamento específico de reabilitação e as equipes das UBS seriam a referência para as pessoas com deficiência. Havia os mesmos problemas de recursos materiais e de espaço. Apenas na UBS Vila Progresso foi realizada uma reforma ampla, entre 1994 e 1995, com recursos orçamentários conseguidos em nível central, o que possibilitou a criação de um serviço de fisioterapia. Após o término da reforma o profissional responsável aderiu ao PAS em outra região e o serviço não chegou a funcionar. A autonomia profissional é extrema em algumas situações e o compromisso do profissional com o atendimento obedecia a outros critérios que não aqueles relativos às necessidades de assistência.

Em uma das UBS havia maior preocupação desses profissionais em constituírem um trabalho em equipe. Entre 1992-93 essa foi iniciativa do grupo, pois na época as condições de trabalho e a implantação da proposta dos serviços, ainda teriam vitalidade suficiente para propiciar que os profissionais tentassem um trabalho interprofissional. Quando ficaram autorizadas as práticas correntes de não cumprimento da carga horária, profissionais em horários de trabalho incompatíveis com o estabelecimento de trabalho em equipe; além de um cenário de não incentivo ao trabalho, com maior facilidade se institucionalizou o trabalho individual, autônomo, definido a partir de necessidades particulares.

No CECCO, serviço criado em 1991, um dos grandes grupos de usuários era o das pessoas com deficiência mental, que se integravam ao trabalho em geral ou, então, estavam constituindo o grupo de trabalho, embrião da Cooperativa. A carência de serviços na região tornava o CECCO uma possibilidade concreta, uma saída para esse grupo e seu núcleo familiar.

Os profissionais sempre problematizaram as questões relativas à autonomia, inserção e integração social dessa população. Não a consideravam pela deficiência específica mas suas necessidades como cidadão. O apoio ao trabalho foi conseguido a partir da criação do serviço. Sua consolidação como proposta dependeu do engajamento profissional dos técnicos, identificados que estavam com as questões colocadas pelo funcionamento, e dos apoios 
institucionais recebidos, pois se constituía como serviço específico para o qual existiam recursos definidos, mesmo que insuficientes. As UBS, ao contrário, dependiam da destinação de recursos para o conjunto de suas atividades, nas quais aquelas com a pessoa deficiente eram consideradas não prioritárias, mesmo que isso implicasse subutilização de recursos humanos. Ou então, no atendimento de uma demanda reprimida e nem sempre reconhecida como de responsabilidade daquele serviço.

\subsection{Distrito de Saúde de Itaim Paulista}

Por iniciativa dos profissionais que constituíram a equipe da UBS Camargo Novo e pelos apoios institucionais recebidos entre 1991-92, foi possível constituir a atenção a portadores de deficiência. Inicialmente, o profissional de fisioterapia organizou seu atendimento a partir da experiência profissional anterior.

Conforme apresentado no Anexo I (p. XLI-XLIII), como a região não dispunha de serviço de fisioterapia no setor público passou-se a atender as pessoas com problemas ortopédicos e/ou traumatológicos mais comuns, como lombalgias entre outros. Entre os profissionais da equipe de saúde mental (médico psiquiatra, fonoaudiólogo, psicólogo e terapeuta ocupacional e o fisioterapeuta) procurou-se a estratégia para criar espaço adequado

para o trabalho com as diferentes populações. O atendimento em terapia ocupacional e fisioterapia passou a se realizar pela "ocupação" progressiva da sala de reuniões, espaço comum de trabalho desses profissionais. Realizava-se atendimento simultâneo de diferentes pacientes. As discussões conjuntas e as dúvidas dos profissionais em relação aos casos, levaram a que se desenvolvesse em algumas situações atendimentos em co-terapia: fisioterapeuta-terapeuta ocupacional. Um fator limitante do trabalho era a inexistência de ambulatório de especialidades no distrito, onde se pudesse realizar acompanhamento dos usuários.

O trabalho em equipe com essa população se ampliou enquanto havia as condições de trabalho e apoios institucionais, até meados de 1993.

Apoio institucional, neste caso, seria a discussão constante com a chefia de distrito e da UBS, os quais apesar de poucas condições de apoiar materialmente, sempre investiram na 
discussão da proposta e em apoio material como equipamentos e materiais básicos. Os profissionais reconheciam as dificuldades da direção regional, mas também o esforço por desenvolver uma proposta assistencial com a qual se sentiam identificados apesar de não terem formação profissional específica para o trabalho numa unidade de saúde com as características da UBS. Sentiam-se responsáveis por pensá-la, desenvolvê-la e reavaliá-la.

Esses pontos trazem a discussão sobre qual seria o papel de uma equipe de reabilitação; numa UBS, como implementar atividades no campo da prevenção de deficiências e incapacidades; como lidar com as atividades relativas ao tratamento/acompanhamento dos casos de deficiências já instaladas para as quais não havia serviço na região, porém a UBS também deveria ser uma referência. Eram questões presentes que tiveram sua força diminuída à medida que a equipe de profissionais foi se desestruturando por demissões e transferências para outras regiões. Algumas dessas realizadas no final da gestão 89-92 e apontadas como privilégio pessoal, para aqueles que percebiam as pequenas chances de trabalho numa futura administração de caráter conservador. Para os profissionais que permaneceram, as dúvidas foram se consolidando e algumas tentativas de atividades também no campo da prevenção foram desenvolvidas, quer em creches para acompanhamento do desenvolvimento infantil, quer nas escolas para detecção de problemas de saúde nas crianças, onde foram identificadas diversas crianças com problemas posturais importantes, que a longo prazo poderiam trazer repercussões para sua saúde. Foi trabalho desenvolvido pelos chamados "ônibus da saúde" que periodicamente saiam em "visitas" a regiões desprovidas de serviços, oferecendo assistência no campo da saúde infantil, bucal e da mulher, principalmente.

A partir do final de 1993, o profissional de fisioterapia passou a ser interlocutor de saúde da pessoa com deficiência no distrito e ter contato mais direto com a proposta de programa. Participou de alguns cursos e treinamentos realizados a partir daí e se comprometeu a discutir as questões relativas a essa população no distrito. No entanto, os limites já apontados revelaram-lhe as dificuldades da administração pública incorporar rapidamente mudanças, redirecionando sua prática ao atendimento de pessoas que passam a buscar apenas o serviço de fisioterapia como no início de seu trabalho. A equipe já estava desarticulada. 


\section{O perfil dos usuários: retratos do trabalho assistencial}

O banco de dados utilizado não resulta de uma amostra estatisticamente representativa do universo de pessoas atendidas na ARS-6, pelas razões já apontadas no Capítulo II. Cabe portanto reafirmar que o perfil dos usuários expressa apenas parcialmente características da população atendida em saúde mental e pelos profissionais de reabilitação.

As principais características dos usuários, são apresentadas, primeiro, com informações gerais como: número de usuários nas unidade de saúde, sexo, idade, local de moradia e escolaridade. Em seguida, segundo serviços: UBS, CECCO, HD, Unidade de Reabilitação e Enfermaria Psiquiátrica, acrescidos daqueles sobre hipótese diagnóstica.

\section{1. Características gerais}

O banco de dados é composto de 1093 usuários, distribuídos entre os diferentes serviços em 1996, conforme Gráfico 5.

Em algumas UBS (Ponte Rasa, Jardim Helena, Pedro Nunes de Souza), as informações são relativas a usuários atendidos em terapia ocupacional, profissional ligado às equipes de saúde mental e de reabilitação (BARROS, 1995). Na UBS Camargo Novo as informações são relativas aos usuários acompanhados por fisioterapeuta, e na UBS Pedro de Souza Campos são informações de usuários acompanhados por psiquiatra. Dessa forma, existe a possibilidade de refletir sobre diferentes ângulos das experiências assistenciais em andamento.

A amostra é composta por cerca de $43 \%$ de usuários que pertencem às UBS, o que possibilitaria conhecer as demandas desses serviços, serviço considerado estratégico para as duas propostas. Os CECCO contribuem com $10 \%$ dos usuários da amostra, a Enfermaria Psiquiátrica com $23 \%$ e o HD com 12\%, conforme Gráfico 5. 
GRÁFICO 5. Usuários de serviços de saúde mental e da pessoa com deficiência, segundo tipos de Unidades de Saúde, na ARS-6, 1996

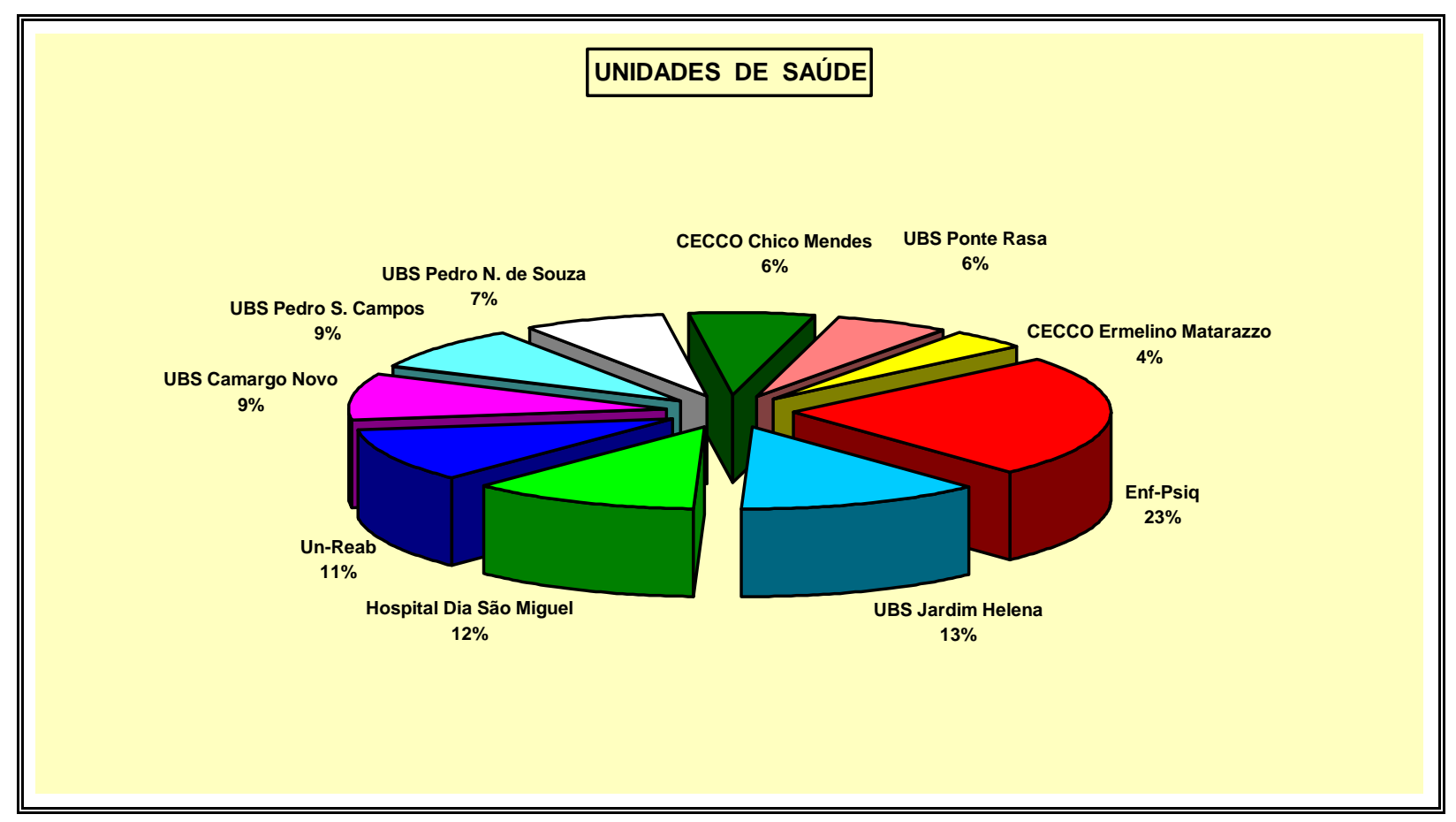

Na amostra, a Unidade de Reabilitação do hospital geral conta com 11\%, facilitando caracterizar a demanda de usuários com deficiências ou incapacidades. Os usuários dessa Unidade representam importante grupo que seria beneficiado pela maior estruturação da assistência a pessoas com deficiência. O fato da atenção ambulatorial a esse grupo ser restrita dificulta a continuidade de acompanhamento, que poderia ser desenvolvido nas UBS ou CECCO, mas que, na prática pela inexistência de uma rede de serviços de reabilitação, continuava sendo realizado na própria Unidade hospitalar.

Observa-se na Tabela 28, que 46,6\% tinham até 29 anos e entre 30 e 49 anos estavam 42,3\% dos usuários. 
TABELA 28. Usuários de serviços de saúde mental e da pessoa com deficiência, segundo faixa etária, na ARS-6, 1996

\begin{tabular}{cccc}
\hline Faixa Etária & Frequência & $\%$ & Acumulado \% \\
\hline$<1$ & 11 & 1,0 & 1,0 \\
1 a 4 & 27 & 2,5 & 3,5 \\
5 a 9 & 109 & 10,0 & 13,5 \\
10 a 14 & 70 & 6,4 & 19,9 \\
15 a 19 & 53 & 4,8 & 24,7 \\
20 a 29 & 201 & 18,4 & 43,1 \\
30 a 39 & 197 & 18,0 & 61,1 \\
40 a 49 & 140 & 12,8 & 73,9 \\
50 a 59 & 91 & 8,3 & 82,2 \\
60 a 69 & 74 & 6,8 & 89,0 \\
> 70 & 38 & 3,5 & 92,5 \\
ignorada & 82 & 7,5 & 100,0 \\
\hline Total & 1093 & 100,0 & 100,0 \\
\hline
\end{tabular}

As mulheres representavam 52,9\% com média de idade de 38 anos; enquanto que os homens representavam 47,1\% com média de idade de 28 anos, conforme Anexo III (p. LXIII).Com exceção do HD e da UBS Pedro Nunes de Souza todas as unidades tinham maior percentual de mulheres. Na UBS Camargo Novo, o grupo feminino representava $68 \%$, enquanto que o grupo masculino da UBS Pedro Nunes de Souza significava $64 \%$ dos usuários da unidade, conforme Tabela 29.

TABELA 29. Usuários dos serviços de saúde mental e da pessoa com deficiência, segundo unidade de saúde e sexo, na ARS-6, 1996

\begin{tabular}{lcccc}
\hline Unidade de Saúde & Fem. & Masc. & Total & N \\
\hline Unidade de Reabilitação & 57,6 & 42,4 & 100,0 & $(262)$ \\
UBS Jardim Helena & 58,4 & 41,6 & 100,0 & $(137)$ \\
Hospital Dia São Miguel & 48,8 & 51,2 & 100,0 & $(127)$ \\
Enfermaria Psiquiátrica & 56,4 & 43,6 & 100,0 & $(117)$ \\
UBS Camargo Novo & 68,0 & 32,0 & 100,0 & $(100)$ \\
UBS Pedro S. Campos & 58,1 & 41,9 & 100,0 & $(93)$ \\
UBS Pedro N. de Souza & 35,8 & 64,2 & 100,0 & $(81)$ \\
CECCO Chico Mendes & 30,9 & 69,1 & 100,0 & $(68)$ \\
UBS Ponte Rasa & 29,2 & 70,8 & 100,0 & $(65)$ \\
CECCO Ermelino Matarazzo & 65,1 & 34,9 & 100,0 & $(43)$ \\
\hline
\end{tabular}

Apenas 29,1\% dos prontuários de usuários apresentavam informações sobre escolaridade, sendo que a maior parte tinha cursado primeiro grau, conforme Anexo III (p. LXIII). 
Como está apresentado na Tabela 30, os homens em todos os graus de escolaridade eram mais jovens que as mulheres, o que poderia ser explicado pela idade média das mulheres de 38 anos, enquanto para os homens esta era de 28 anos, indicando diferentes oportunidades de acesso à escola.

TABELA 30. Escolaridade dos usuários, segundo sexo e média de idade, na ARS-6, 1996

\begin{tabular}{lcccc}
\hline \multirow{2}{*}{ Escolaridade } & \multicolumn{4}{c}{ SEXO } \\
\cline { 2 - 5 } & \multicolumn{2}{c}{ Homens } & \multicolumn{3}{c}{ Mulheres } \\
\cline { 2 - 5 } & Idade $(\mathrm{M})$ & $\mathrm{N}$ & Idade $(\mathrm{M})$ & $\mathrm{n}$ \\
\hline Primeiro Grau & 16,82 & 107 & 26,60 & 62 \\
Segundo Grau & 28,31 & 61 & 33,45 & 55 \\
Superior & 30,00 & 3 & 38,70 & 3 \\
Sem resposta & 32,71 & 313 & 40,57 & 407 \\
\hline
\end{tabular}

Como o número de respostas para escolaridade era pequeno $(29,1 \%)$ procurou-se conhecer as idades médias daqueles casos sem informação, cujos resultados estão na Tabela 31.

TABELA 31. Idades médias dos usuários, sem resposta para questão escolaridade, segundo Unidade de Saúde, na ARS-6, 1996

\begin{tabular}{lc}
\hline \multicolumn{1}{c}{ Unidade de Saúde } & Idade (M) \\
\hline Unidade de Reabilitação Ermelino Matarazzo & 45,15 \\
CECCO Ermelino Matarazzo & 34,38 \\
UBS Jardim Helena & 27,06 \\
Hospital Dia São Miguel & 30,68 \\
Enfermaria Psiquiátrica Ermelino Matarazzo & 35,17 \\
UBS Camargo Novo & 45,37 \\
UBS Pedro S. Campos & 41,68 \\
UBS Pedro N. de Souza & 27,58 \\
CECCO Chico Mendes & 25,24 \\
UBS Ponte Rasa & 21,08 \\
\hline
\end{tabular}

Nas UBS e nos CECCO as idades médias dos usuários eram menores, sugerindo que acompanhavam clientela mais jovem, principalmente no sexo masculino. Nas UBS as idades médias variavam entre 12 e 26 anos para os homens, 20 a 25 anos para as mulheres; com exceção da UBS Pedro de Souza Campos. No CECCO Chico Mendes as idades médias eram menores que no CECCO Ermelino Matarazzo, conforme Tabela 31. 
A idade média está próxima daquela dos usuários para os quais se conhece o grau de escolaridade, conforme Tabela 32.

TABELA 32. Usuários dos serviços de saúde mental e da pessoa com deficiência, segundo sexo, média de idade e Unidade de Saúde, na ARS-6, 1996

\begin{tabular}{lcc}
\hline \multirow{2}{*}{ Unidade de Saúde } & \multicolumn{2}{c}{ SEXO } \\
\cline { 2 - 3 } & Feminino & Masculino \\
\cline { 2 - 3 } & Idade (M) & Idade (M) \\
\hline Unidade de Reabilitação Ermelino Matarazzo & 47,39 & 35,48 \\
UBS Jardim Helena & 25,12 & 12,21 \\
Hospital Dia São Miguel & 33,16 & 28,33 \\
Enfermaria Psiquiátrica Ermelino Matarazzo & 34,20 & 36,00 \\
UBS Camargo Novo & 45,57 & 42,48 \\
UBS Pedro S. Campos & 42,43 & 41,03 \\
UBS Pedro N. de Souza & 20,41 & 14,28 \\
CECCO Chico Mendes & 30,17 & 23,52 \\
UBS Ponte Rasa & 24,37 & 26,07 \\
CECCO Ermelino Matarazzo & 43,80 & 24,20 \\
\hline Total & 38,17 & 28,62 \\
\hline
\end{tabular}

Conforme Tabela 32, as mulheres mais velhas eram acompanhadas na Unidade de Reabilitação e na UBS Camargo Novo, com serviços que se caracterizavam por atendimento fisioterápico; enquanto que os homens mais velhos estavam também nessa UBS e na Pedro de Souza Campos. Nesta os usuários eram acompanhados por psiquiatra, a média de idade de homens e mulheres era de cerca de 41 anos, enquanto que na Enfermaria Psiquiátrica a idade média era de 35 anos. No HD as idades de homens e mulheres eram menos próximas.

No CECCO Ermelino Matarazzo as mulheres tinham idade média de 43 anos, enquanto que os homens tinham 24 anos, diferença importante em relação ao CECCO Chico Mendes, que acompanhava população feminina mais jovem, com idade média de 30 anos.

Conforme Tabela 33, cerca de 34\% dos usuários residiam com pais e/ou irmãos, $24 \%$ com esposa e/ou filhos, enquanto que apenas 1,6\% moravam sozinhos, sendo a família importante referência para essas pessoas. 
TABELA 33. Distribuição da Unidade de Saúde, segundo moradia dos usuários, na ARS-6, 1996

\begin{tabular}{|c|c|c|c|c|c|}
\hline \multirow[b]{2}{*}{ Unidade de Saúde } & \multicolumn{5}{|c|}{ Residência (\%) } \\
\hline & $\begin{array}{l}\text { Esposa } \\
\text { e/ou Filhos }\end{array}$ & $\begin{array}{c}\text { Pais } \\
\text { e/ou } \\
\text { Irmãos }\end{array}$ & Parentes & Sozinho & Total \\
\hline Unidade de Reabilitação & 52,1 & 47,9 & --- & --- & 100,0 \\
\hline Ermelino Matarazzo & & & & & (94) \\
\hline UBS Jardim Helena & 34,5 & 65,5 & --- & --- & $\begin{array}{l}100,0 \\
(119)\end{array}$ \\
\hline Enfermaria Psiquiátrica & 51,4 & 45,8 & 1,9 & 0,9 & 100,0 \\
\hline Ermelino Matarazzo & & & & & (107) \\
\hline UBS Camargo Novo & 64,7 & 30,9 & 2,9 & 1,5 & $\begin{array}{c}100,0 \\
(68)\end{array}$ \\
\hline UBS Pedro S. Campos & 56,0 & 42,0 & --- & 2,0 & $\begin{array}{c}100,0 \\
(50)\end{array}$ \\
\hline UBS Pedro N. de Souza & 4,3 & 88,4 & 7,2 & --- & $\begin{array}{c}100,0 \\
(69)\end{array}$ \\
\hline CECCO Chico Mendes & 21,7 & 73,9 & 2,2 & 2,2 & $\begin{array}{l}100,0 \\
(46)\end{array}$ \\
\hline UBS Ponte Rasa & 29,7 & 64,1 & 4,7 & 1,6 & $\begin{array}{c}100,0 \\
(64)\end{array}$ \\
\hline $\begin{array}{l}\text { CECCO Ermelino } \\
\text { Matarazzo }\end{array}$ & 42,5 & 52,5 & --- & 5,0 & $\begin{array}{c}100,0 \\
(40) \\
\end{array}$ \\
\hline Total & 24,3 & 33,9 & 1,2 & 1,6 & 61.0 \\
\hline
\end{tabular}

Os usuários que moravam com esposa e/ou filhos estavam em sua maioria nas UBS Camargo Novo, Pedro de Souza Campos, na Unidade de Reabilitação e na Enfermaria Psiquiátrica, respectivamente.

A maior parte dos usuários que residiam com pais e /ou irmãos era acompanhada na UBS Pedro de Souza Campos (88\%) e no CECCO Chico Mendes (73\%).

As hipóteses diagnósticas foram levantadas a partir de lista das informações diagnósticas encontradas nos prontuários. Está apresentada no Anexo III (p. LXI-LXII). Esses dados foram organizados em grandes grupos a saber: transtornos mentais, distúrbios neurológicos, problemas reumatológicos, ortopédicos e traumatológicos. Essas categorias procuraram respeitar as informações colhidas em prontuários.

Apesar de todas dificuldades relacionadas ao diagnóstico em saúde, seja em psiquiatria e saúde mental, com diferentes propostas de classificação (Classificação Internacional de Doenças, Diagnostic and Statistical Manual of Mental Disorders - DSM 
III $^{\varpi}$ ) optou-se por apresentar as informações diagnósticas agrupadas, conforme Anexo III (p. LXI).

Problema semelhante se coloca para o diagnóstico da deficiência ${ }^{\square}$. Neste caso, as informações sobre hipótese diagnóstica foram agrupadas no Anexo III (p. LXII) e é a partir delas que foram construídas as Tabelas 34 e 35 e o Gráfico 6.

Conforme a Tabela 34, 46,5\% dos usuários tinham hipóteses diagnósticas que indicavam problemas neurológicos, ortopédicos e traumatológicos. Enquanto que 53,4\% dos usuários tinham hipótese relativas a transtornos mentais.

TABELA 34. Distribuição dos usuários dos serviços de saúde mental e da pessoa com deficiência, segundo Hipótese Diagnóstica, na ARS-6, 1996

\begin{tabular}{lc}
\hline \multicolumn{1}{c}{ Hipótese Diagnóstica } & $\%$ \\
\hline Disfunção ortopédica traumatológica & 28,3 \\
Psicose & 25,6 \\
Disfunção neurológica adulto & 9,1 \\
Paciente psiquiátrico & 9,0 \\
Depressão & 4,3 \\
Disfunção reumatológica & 4,3 \\
DM & 3,9 \\
Disfunção neurológica infantil & 3,0 \\
Problemática de aprendizagem & 2,6 \\
Atraso DNPM & 2,1 \\
Transtorno neurótico & 2,0 \\
Outros 1* & 1,7 \\
Outros 2* & 1,7 \\
Alcoolismo & 1,3 \\
Epilepsia & 0,7 \\
Drogadição & 0,3 \\
Disfunção cárdio respiratória & 0,1 \\
\hline Total & 100,0 \\
& $(700)^{*}$ \\
\hline
\end{tabular}

*Sem resposta 393

*Outros 1: problemas emocionais (bloqueio emocional, conflito emocional, confusão emocional), distúrbio de comportamento, hiperatividade, drogadição.

*Outros 2: amputação, deficiente físico, dor, queimadura.

\footnotetext{
$\square$ Neste caso são importantes as contribuições trazidas por SARACENO et al(1994) quando sugerem a simplificação dos diagnósticos em saúde mental em grandes categorias.

[a É importante apontar que vem sendo implementada pela OMS o uso da Classificação Internacional de Deficiência, Incapacidade e Desvantagem, que procura trabalhar com outras categorias além do comprometimento seja motor ou sensorial, incorporando as oportunidades e facilidades colocadas no entorno social como fatores essenciais na definição da deficiência, desvantagem e incapacidade (OMS, 1989).
} 
Os usuários com problemas de ordem neurológica, adultos representavam 9\%, enquanto que as crianças 3\%. As disfunções traumatológicas e ortopédicas representavam $28,3 \%$ e as disfunções reumatológicas $4,3 \%$.

Os usuários com hipótese diagnóstica de psicose representavam 25,6\% e somados aqueles caracterizados como "paciente psiquiátrico" $\square$, esse índice subiria para 34,6\%.

Esse perfil diagnóstico sugere que as populações-alvo das propostas assistenciais puderam ser acompanhadas na região; exceção feita aos problemas relativos a alcoolismo e drogadição, com pequeno número de usuários, como também às disfunções neurológicas infantis e à deficiência mental, grupos que os programas se propunham a dar prioridade.

Ao se observar no Gráfico 6 a média de idade dos usuários e respectivas hipóteses diagnósticas, percebe-se que os usuários com disfunções de ordem reumatológica tinham idade de 47 anos, os com problemas ortopédico-traumatológicos em torno de 42 anos, e aqueles com problemas de ordem neurológica, idades médias de 39 anos.

GRÁFICO 6. Hipóteses Diagnósticas dos usuários de serviços de saúde mental e da pessoa com deficiência, segundo média de idade, na ARS-6, 1996

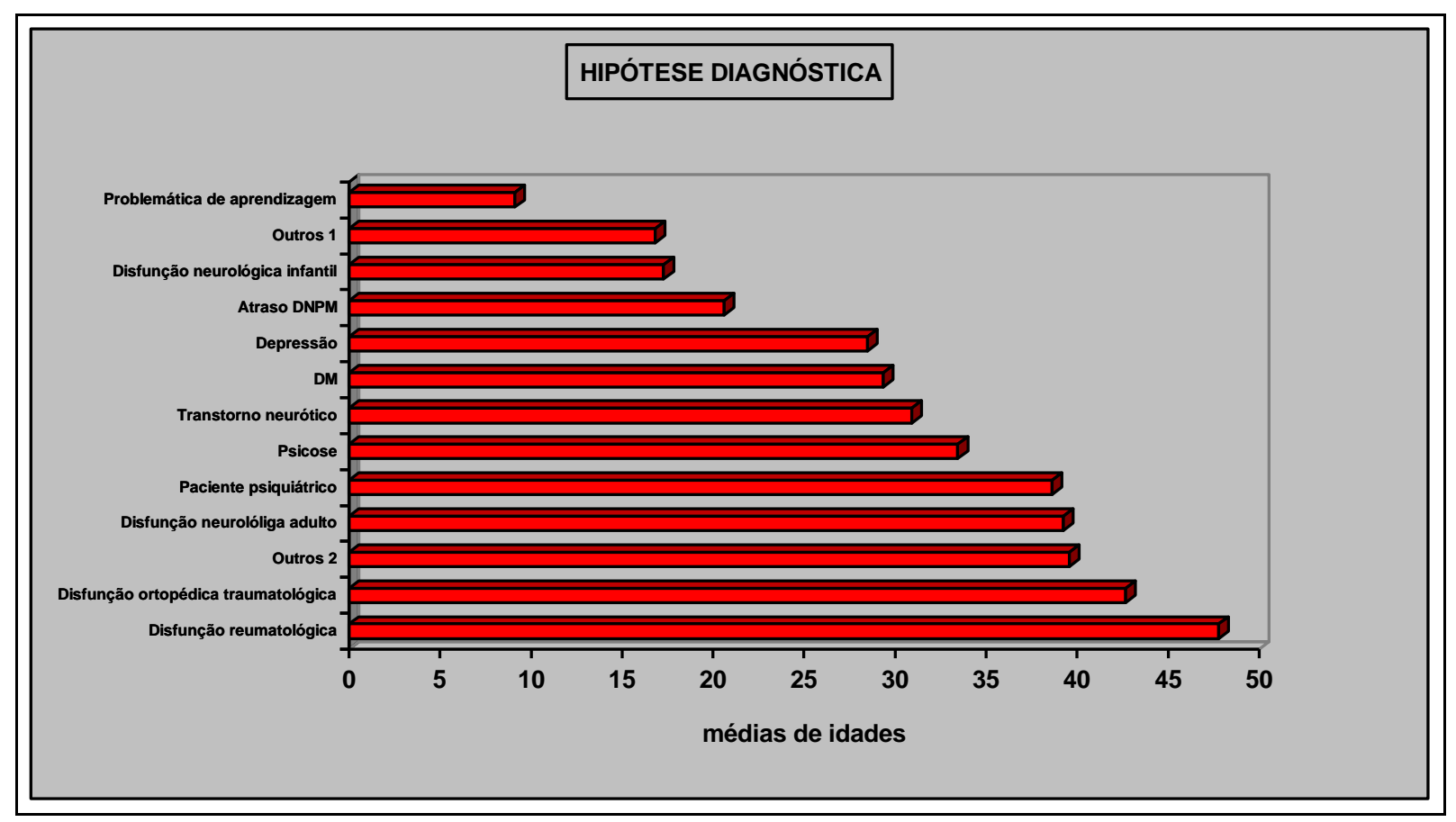

\footnotetext{
Sugeria usuário com transtorno mental, acompanhado por médico psiquiatra ou que passou por internação e que comumente é assim tratado nos serviços de saúde.
} 
No caso específico das disfunções neurológicas infantis os usuários tinham idade média de 17 anos, com longa convivência com a deficiência, sugerindo necessidade de outros apoios sociais que não, somente, serviços de saúde.

Os usuários com hipótese diagnóstica de alcoolismo tinham a idade média de 31 anos, população jovem, característica talvez do serviço ou do pequeno número de casos.

Para aqueles com diagnóstico de depressão a idade média era de 28 anos, enquanto que para aqueles com transtornos neuróticos era de 30 anos. Aqueles que tiveram como hipótese as psicoses ou acompanhamento psiquiátrico tinham idades entre 33 e 38 anos, respectivamente.

Para os problemas de aprendizagem a média de idade estava em 9 anos e meio, período de entrada na escola. Possivelmente a maior parte dessas crianças não participou de experiência pré-escolar, dificultando sua adaptação às exigências escolares, sem contar as dificuldades que a escola tem de oferecer vivências e oportunidades de desenvolvimento pessoal compatíveis com as necessidades da criança e de seu entorno social.

Os usuários com hipótese relativas a problemas de aprendizagem e atraso no desenvolvimento psicomotor representavam 4,7\%. Admitia-se, pelos depoimentos dos profissionais, que esse contingente fosse maior. Como não foi possível obter dados dos usuários acompanhados por todos os entrevistados, optou-se por conhecer as idades médias daqueles para os quais não havia informações diagnósticas.

TABELA 35. Idades médias dos usuários sem resposta para hipótese diagnóstica, segundo unidade de saúde, na ARS-6, 1996

\begin{tabular}{lc}
\hline \multicolumn{1}{c}{ Unidade de Saúde } & Idade $(\mathrm{M})$ \\
\hline Unidade de Reabilitação Ermelino Matarazzo & 51,50 \\
CECCO Ermelino Matarazzo & 33,65 \\
UBS Jardim Helena & 19,43 \\
Hospital Dia São Miguel & 31,81 \\
Enfermaria Psiquiátrica Ermelino Matarazzo & 44,00 \\
UBS Camargo Novo & 44,39 \\
UBS Pedro S. Campos & 40,03 \\
UBS Pedro N. de Souza & 12,61 \\
CECCO Chico Mendes & 30,36 \\
UBS Ponte Rasa & 12,30 \\
\hline
\end{tabular}


Provavelmente, as idades médias para usuários com disfunções reumatológicas, traumatológicas, ortopédicas e neurológicas eram baixas porque, na Unidade de Reabilitação, aqueles sem informação tinham idade média de 51 anos.

O mesmo poderia ocorrer para as hipóteses de depressão e alcoolismo, pois na Enfermaria Psiquiátrica e na UBS Pedro Souza Campos, os que não tinham informação diagnóstica tinham idade média 44 anos e 40 anos, respectivamente. Ou seja, é provável que as idades médias para esses problemas fosse maior, caso houvesse esse registro em maior número de casos.

Conforme sugere a Tabela 35, nas UBS os usuários sem informação diagnóstica tinham idades médias de 12 anos nas UBS Pedro Nunes de Souza e Ponte Rasa, unidades que acompanhavam usuários mais jovens. Seria possível que entre os que não tinham esse registro, estivessem os usuários com problemas de aprendizagem e de desenvolvimento neuropsicomotor apontados pelos técnicos como parte importante da clientela que era acompanhada nesses serviços e para as quais as agendas de psicólogos, fonoaudiólogos tinham longas listas de espera (Entrevista $\left.{ }^{\circ} 34-38 ; 58-60,1996\right)$

No Anexo III (p. LXII), os motivos de encaminhamento foram organizados em categorias que buscavam traduzir os principais aspectos levantados pelos profissionais ou serviços que referenciavam usuários para as Unidades de Saúde.

As informações sobre os motivos de encaminhamento estavam presentes em apenas $15,7 \%$, mas traduziam certa visão de técnicos e serviços sobre os objetivos e aptidões das unidades de saúde. Poderiam demonstrar, através do Anexo III (p. LXIII), conhecimento dos objetivos dos serviços quando se apontava necessidade de acompanhamento/tratamento (20,9\%), problemática/ diagnóstico $(31,4 \%)$ ou mesmo convivência/atividade (32\%). Reconhecia-se nessas unidades capacidade de acompanhamento para determinadas populações e com objetivos definidos previamente. Essa visão era mais presente do que aquela que inspirava o encaminhamento para intervenções específicas (14,5\%), dando ao acompanhamento pretendido um caráter mais geral. 


\section{2. Usuários das UBS}

Os usuários das UBS representavam cerca de $43 \%$ dos usuários, oferecendo condições para analisar esses serviços como porta de entrada para o sistema de atenção proposto.

Conforme Tabela 36, as mulheres eram a maioria (68\%) dos usuários na UBS Camargo Novo, possivelmente o acompanhamento fisioterapêutico realizado e o horário de funcionamento do serviço (entre 8:00 e 18:00) limitaram o acesso aos homens. Já, na UBS Ponte Rasa os homens representavam 70\% dos atendidos e na Pedro Nunes de Souza 64\%, o que provavelmente teria relação com as prioridades dadas à problemática e faixa etária desses usuários.

Nas UBS Jardim Helena e Pedro de Souza Campos a proporção entre homens (41\%) e mulheres (58\%) atendidos era próxima da distribuição geral.

TABELA 36. Sexo dos usuários dos serviços de saúde mental e da pessoa com deficiência, segundo as Unidades Básicas de Saúde, na ARS-6, 1996

\begin{tabular}{lccccc}
\hline & \multicolumn{5}{c}{ UBS $(\%)$} \\
\cline { 2 - 6 } \multicolumn{1}{c}{ SEXO } & 1 & 2 & 3 & 4 & 5 \\
\hline Feminino & 29,2 & 58,1 & 35,8 & 58,4 & 68,0 \\
Masculino & 70,8 & 41,9 & 64,2 & 41,6 & 32,0 \\
\hline Total & 100,0 & 100,0 & 100,0 & 100,0 & 100,0 \\
$\mathrm{~N}$ & $(65)$ & $(93)$ & $(81)$ & $(137)$ & $(100)$ \\
\hline
\end{tabular}

1. Ponte Rasa 2- Pedro Souza Campos 3- Pedro Nunes de Souza

4- Jardim Helena 5- Camargo Novo

Ao se observar as faixas etárias, conforme Gráfico 7, na UBS Pedro Nunes de Souza $81 \%$ dos usuários tinham até 14 anos sendo que no grupo de 5- 9 anos estavam 56\%. Na UBS Jardim Helena 59\% tinham até 14 anos, sendo que 26\% tinham entre $10-14$ anos. 
GRÁFICO 7. Faixa etária dos usuários das UBS, na ARS, 1996

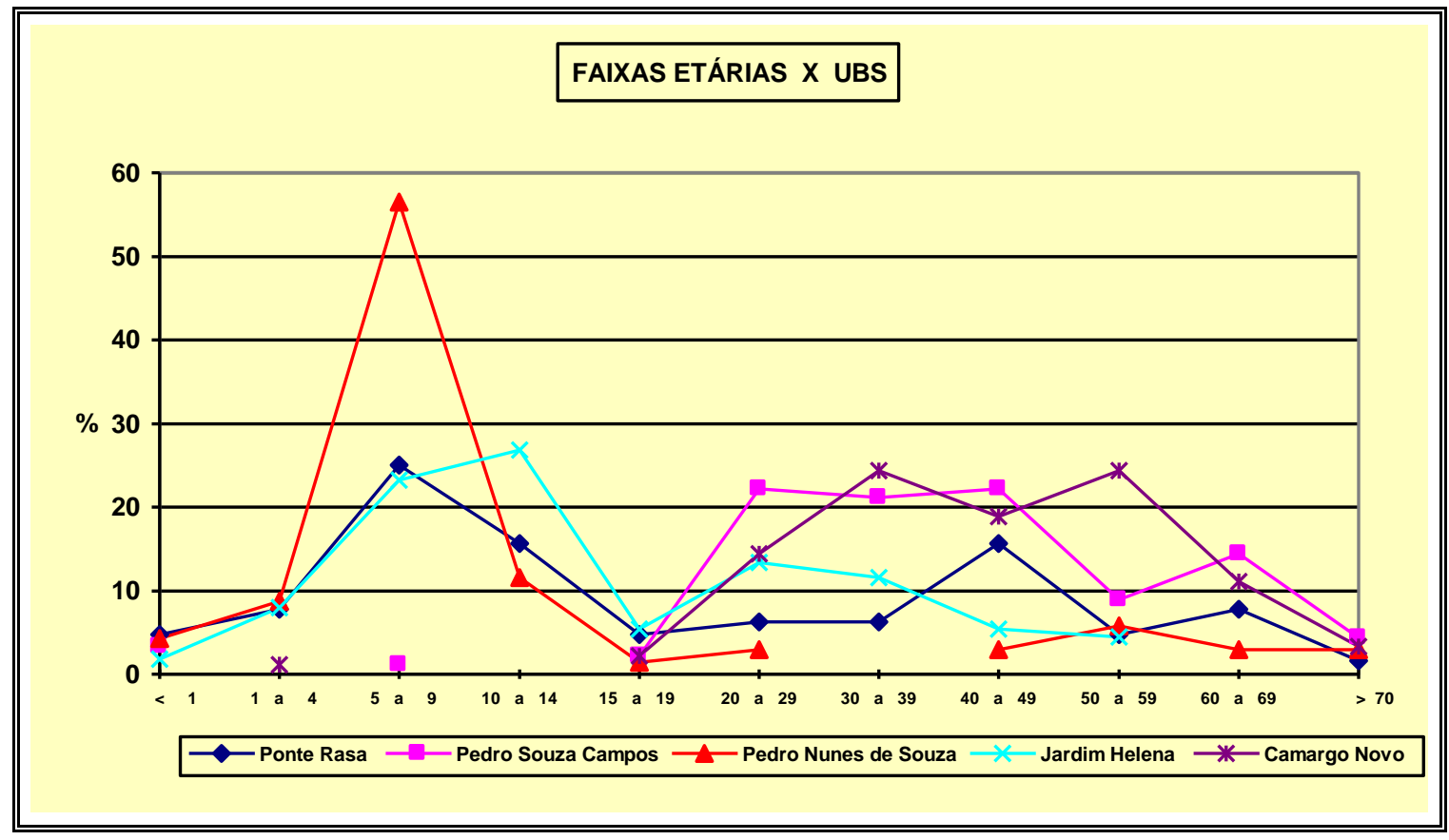

No distrito censitário de Jardim Helena também estava o maior índice de analfabetismo juvenil e de mulheres chefes de família não alfabetizadas (SPOSATTI, 1996 p.28). Isto sugere que esse grupo etário teria outras necessidades e estaria menos protegido pelas propostas educacionais em curso.

Já na UBS Pedro de Souza Campos 66\% dos usuários tinham entre 20 e 49 anos, com distribuição semelhante entre as faixas etárias, caracterizando-se como uma UBS diferenciada, que acompanhava adultos e também maiores de 60 anos (18,8\%). Poderia ser um exemplo de perfil de uma Unidade com acompanhamento psiquiátrico. Apesar de contar com profissionais como psicólogos, terapeuta ocupacional, fonoaudiólogo e fisioterapeuta não eram desenvolvidas atividades de equipe em saúde mental (Anexo I p. XXII).

Na UBS Ponte Rasa 53\% tinham até 14 anos, sendo 25\% entre 5-9 anos. Nesse distrito censitário o índice de analfabetismo juvenil e o índice de mulheres chefes de família não alfabetizadas eram os menores da região, o que poderia supor maior disponibilidade das mães para acompanhamento de seus filhos quer para permanência na escola, quer para o atendimento nos serviços de saúde (SPOSATTI, 1996 p. 28). 
Na Tabela 37 sobre a escolaridade, na UBS Pedro Nunes de Souza 98\% tinham o primeiro grau, seguida da UBS Jardim Helena e Ponte Rasa, pois a maior parte eram crianças atendidas que estavam matriculadas nas escolas, inclusive cursando segundo grau.

TABELA 37. Escolaridade dos usuários, segundo UBS, na ARS-6, 1996

\begin{tabular}{lccccc}
\hline & \multicolumn{5}{c}{ UBS (\%) } \\
\cline { 2 - 6 } Escolaridade & 1 & 2 & 3 & 4 & 5 \\
\hline Primeiro grau & 63,4 & 8 & 98,0 & 74,3 & 9 \\
Segundo grau & 34,1 & 2 & 2,0 & 24,3 & 4 \\
Terceiro grau & 2,4 & 1 & --- & 1,4 & 1 \\
\hline Total & 100,0 & 100,0 & 100,0 \\
$\mathrm{~N}$ & $(41)$ & $(11)^{*}$ & $(50)$ & $(70)$ & $(14)^{*}$ \\
\hline * não foram calculadas porcentagens porque os totais são baixos \\
1. Ponte Rasa 2- Pedro Souza Campos 3- Pedro Nunes de Souza \\
4- Jardim Helena 5- Camargo Novo
\end{tabular}

Conforme Tabela 38, a maior parte dos usuários acompanhados na UBS Pedro Nunes de Souza (88\%) residia com pais e/ou irmãos, o mesmo ocorrendo na UBS Jardim Helena e Ponte Rasa, que tinham a maior parte de seus usuários até 14 anos. Na UBS Camargo Novo e Pedro de Souza Campos estavam a maior parte daqueles que residiam com esposa e/ou filhos. Essa distribuição revela que existe apoio social na família, importante fator para adesão desses usuários ao acompanhamento nos serviços.

TABELA 38. Residência dos usuários, segundo UBS, na ARS-6, 1996

\begin{tabular}{lccccc}
\hline \multirow{2}{*}{ Residência } & 1 & 2 & 3 & 4 & 5 \\
\cline { 2 - 6 } & 29,7 & 56,0 & 4,3 & 34,5 & 64,7 \\
Esposa e/ou filhos & 64,1 & 42,0 & 88,4 & 65,5 & 30,9 \\
Pais e/ou irmãos & 4,7 & -- & 7,2 & -- & 2,9 \\
Parentes & 1,6 & 2,2 & -- & -- & 1,5 \\
Sozinho & 100,0 & 100,0 & 100,0 & 100,0 & 100,0 \\
\hline Total & $(64)$ & $(50)$ & $(69)$ & $(119)$ & $(68)$ \\
$\mathrm{N}$ & Ponte Rasa 2. Pedro Souza Campos 3. Pedro Nunes de Souza \\
\hline \multicolumn{5}{c}{ 4. Jardim Helena 5. Camargo Novo }
\end{tabular}

Nas UBS Camargo Novo e Jardim Helena as informações sobre hipóteses diagnósticas eram extremamente precárias, conforme Tabela 39. 
TABELA 39. Hipótese Diagnóstica, segundo UBS, na ARS-6, 1996

\begin{tabular}{lccccc}
\hline \multirow{2}{*}{ Hipótese Diagnóstica } & \multicolumn{7}{c}{ UBS } \\
\cline { 2 - 6 } & 1 & 2 & 3 & 4 & 5 \\
\hline Disfunção reumatológica & --- & --- & --- & --- & 1 \\
Disfunção ortopédica traumatológica & 1,8 & --- & --- & --- & 7 \\
Disfunção neurológica adulto & 47,3 & --- & 30,0 & --- & 5 \\
Paciente psiquiátrico & 1,8 & 71,9 & 2,5 & --- & --- \\
Epilepsia & --- & 1,8 & --- & --- & --- \\
Psicose & --- & 15,8 & --- & --- & --- \\
Alcoolismo & --- & --- & --- & --- & 1 \\
Transtorno neurótico & --- & 5,3 & --- & --- & --- \\
DM & 5,5 & 1,8 & 10,0 & 1 & --- \\
Depressão & --- & 3,5 & --- & --- & --- \\
Atraso DNPM & 9,1 & --- & 17,5 & --- & --- \\
Disfunção neurológica infantil & 14,5 & --- & 10,0 & 1 & --- \\
Outros 1 & 12,7 & --- & --- & --- & --- \\
Problemática de aprendizagem & 5,5 & --- & 30,0 & 1 & --- \\
Disfunção cárdio respiratória & 1,8 & --- & --- & --- & --- \\
\hline Total & 100,0 & 100,0 & 100,0 \\
N & $(55)$ & $(57)$ & $(40)$ & $(3)^{*}$ & $(14)^{*}$ \\
\hline *não foram calculadas porcentagens porque os totais são baixos & & & \\
\multicolumn{1}{c}{ 1.Ponte Rasa 2. Pedro Souza Campos 3. Pedro Nunes de Souza } & \\
\multicolumn{1}{c}{ 4. Jardim Helena 5. Camargo Novo } & &
\end{tabular}

A problemática de aprendizagem $(35,5 \%)$ somada à de atraso no desenvolvimento neuropsicomotor, totalizava $52,1 \%$ dos usuários. Os usuários com problemas de ordem neurológica eram 40\% e aqueles com problemas de ordem mental, como "paciente psiquiátrico" e deficiência mental somavam, apenas, 12,5\%; o que supõe profissional preocupado com atendimento de pessoas com deficiência, e com as questões relativas à aprendizagem e desenvolvimento neuropsicomotor. $\mathrm{O}$ espectro de usuários em terapia ocupacional era amplo. Apesar desse técnico ter sido contratado para o programa de saúde mental sua atividade assistencial estava centrada em outro grupo.

Na UBS Pedro de Souza Campos, os prontuários consultados foram dos usuários acompanhados pelo psiquiatra; 15,8\% destes tinham como hipótese diagnóstica psicose, seguidos de 71,9\% conhecidos como paciente psiquiátrico, que, provavelmente, significaria pessoas que já passaram por internação psiquiátrica. Os usuários com outros problemas, como depressão, transtorno neurótico somavam 8,8\%. O perfil do acompanhamento psiquiátrico estava próximo da população-alvo do programa; no entanto a abordagem 
desenvolvida privilegiava apenas o acompanhamento médico, conforme Anexo I (p. XXIII).

Na UBS Ponte Rasa, os prontuários levantados, também foram de usuários acompanhados em terapia ocupacional; neste caso a maior parte destes (61\%) apresentavam disfunção neurológica. Os problemas de aprendizagem e atraso no desenvolvimento neuropsicomotor somavam apenas 14,6\%; caracterizando-se como uma unidade com atenção à pessoa com deficiência. A população-alvo do programa de saúde mental não estava sendo acompanhada pelo profissional, integrante da equipe de saúde mental. Naquele período a Unidade também contava com médico psiquiatra, mas não foi possível ter acesso aos prontuários de seus pacientes.

Acredita-se que se tivesse sido possível levantar informações sobre os usuários acompanhados em psicologia e fonoaudiologia, os percentuais daqueles com problemas de aprendizagem e emocionais nas UBS teriam sido maiores. 


\section{3. Usuários dos CECCO}

Os CECCO acompanhavam populações com características diferentes. No de Ermelino Matarazzo a maior parte eram mulheres e no Chico Mendes eram homens, conforme Gráfico 8.

GRÁFICO 8. Usuários dos CECCO, segundo sexo, na ARS-6, 1996

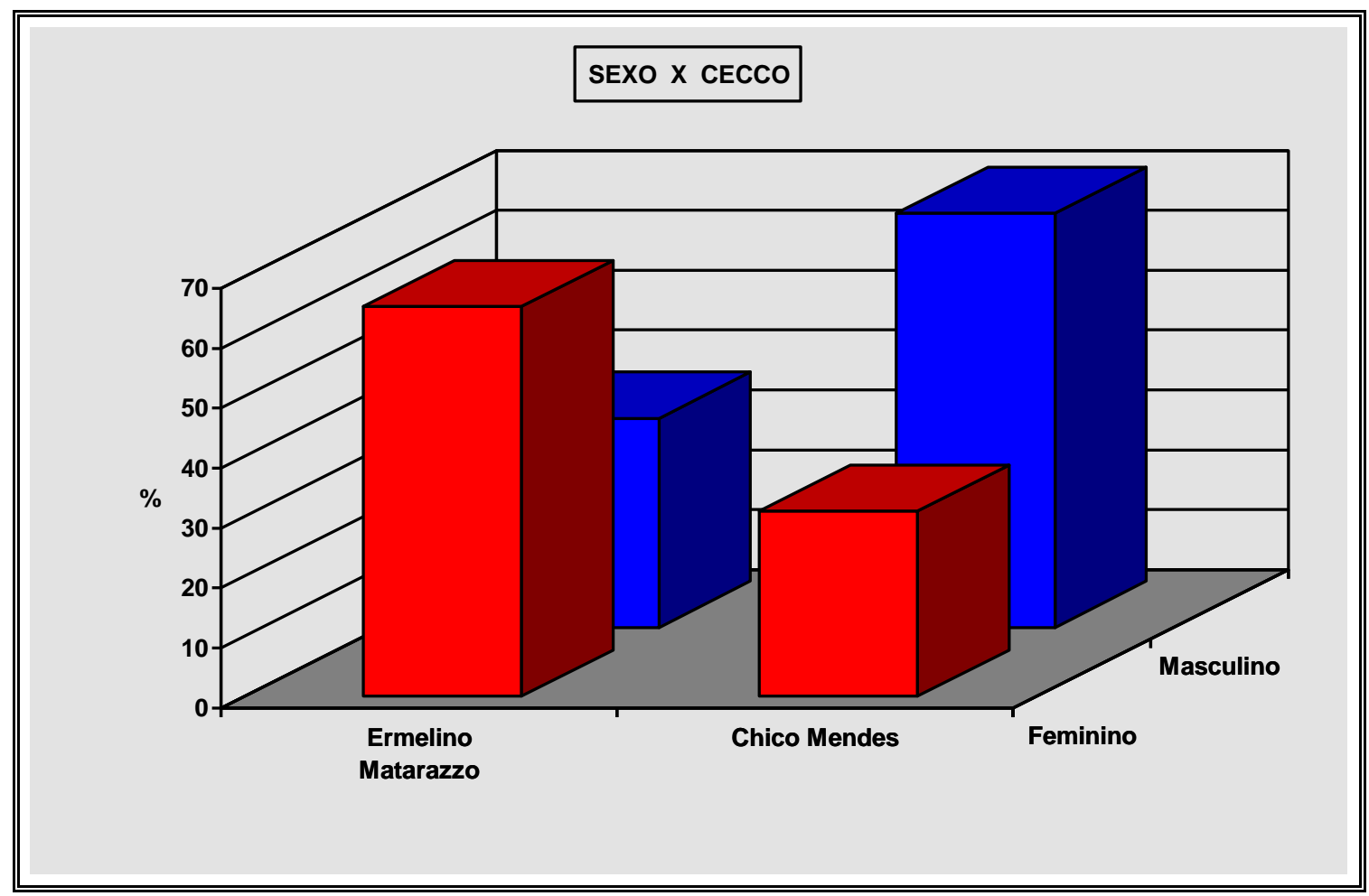

No CECCO de Ermelino a idade média era de 43 anos para as mulheres e 24 para os homens, influenciada por $20 \%$ de usuárias com mais de 60 anos. Enquanto que no Chico Mendes era de 30 anos para as mulheres e 23 para os homens, influenciada por $40 \%$ de usuários de zero a 19 anos, conforme Gráfico 9.

No entanto, o CECCO Ermelino tinha 52,5\% dos usuários entre 20 e 49 anos e no Chico Mendes havia 56,7\% nessa faixa etária, semelhanças importantes entre os serviços. 
GRÁFICO 9. Faixa etária dos usuários dos CECCO, na ARS-6, 1996

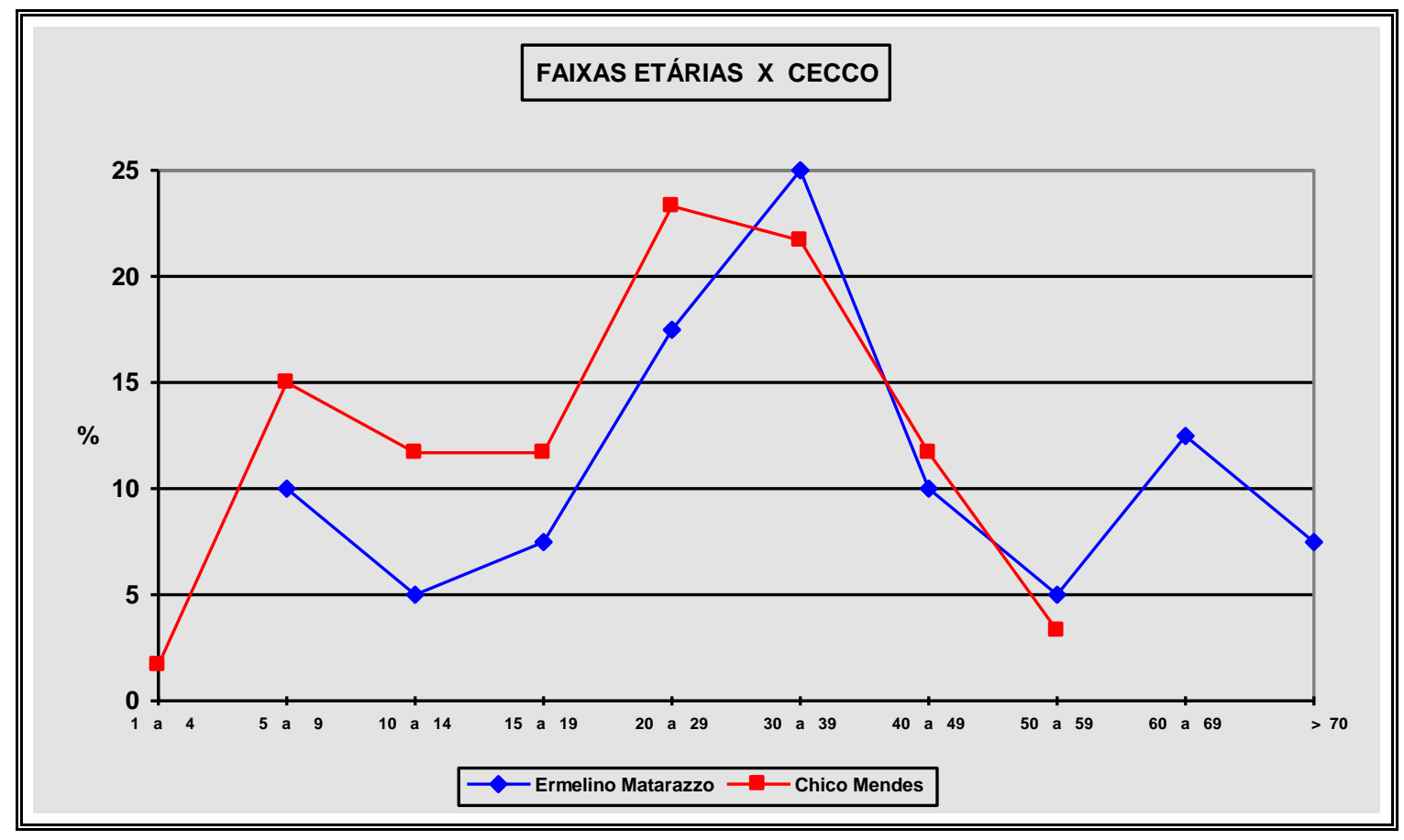

No CECCO Chico Mendes 73,9\% dos usuários residiam com os pais e/ou irmãos, enquanto que em Ermelino Matarazzo esse número era de 52,5\%. Em Ermelino Matarazzo estava a maior parte dos usuários que viviam sozinhos, conforme Anexo III (p. LXIV). Em ambos os serviços a maior escolaridade era de segundo grau, apesar do pequeno número de respostas nesse item, o que sugere que para os usuários com essa informação as possibilidades de participação na escola já estavam dadas, com perfil até mais abrangente que o da população total de usuários.

Infelizmente, o número de informações sobre hipótese diagnóstica no CECCO Ermelino era pequeno, impossibilitando comparação com o Chico Mendes, conforme Tabela 40. No CECCO Chico Mendes cerca de 73\% dos usuários eram pessoas da população-alvo do programa de saúde mental, com especial ênfase em psicóticos e "pacientes psiquiátricos" (46,2\%) e deficientes mentais (17,3\%). Era um dos poucos serviços que acompanhavam alcoolistas e usuários de drogas. 
TABELA 40. Hipótese diagnóstica dos usuários, segundo CECCO, na ARS-6, 1996

\begin{tabular}{lcc}
\hline \multirow{2}{*}{ Hipótese diagnóstica } & \multicolumn{2}{c}{ CECCO } \\
\cline { 2 - 3 } & Ermelino Matarazzo & Chico Mendes \\
\hline Disfunção reumatológica & 2 & --- \\
Paciente psiquiátrico & 1 & 23,1 \\
Epilepsia & 1 & 3,8 \\
Psicose & 1 & 23,1 \\
Alcoolismo & --- & 3,8 \\
Transtorno neurótico & --- & 3,8 \\
DM & 3 & 17,3 \\
Depressão & --- & 3,8 \\
Atraso DNPM & --- & 5,8 \\
Disfunção neurológica & --- & 1,9 \\
infantil & & 7,7 \\
Outros 1 & --- & --- \\
Outros 2 & 2 & 1,9 \\
Drogadição & --- & 3,8 \\
Problemática de & --- & 100,0 \\
aprendizagem & & $(52)$ \\
\hline Total & & \\
N & $(12)^{*}$ & \\
\hline
\end{tabular}

*não foram calculadas porcentagens porque os totais são baixos

Pode-se observar na Tabela 41, que os usuários acompanhados por psiquiatra, neurologista e psicólogo eram cerca de 70\% no CECCO Ermelino e 75,6\% no Chico Mendes.

No CECCO Ermelino, a maior parte dos usuários foi acompanhada por psiquiatra $(34,8 \%)$ e no CECCO Chico Mendes esse percentual era de 41,5\%. O acompanhamento por neurologista era de 19,6\% para os usuários de Ermelino e de 14,6\% do Chico Mendes.

Já para outras especialidades médicas como ortopedia, fisiatria, clínica geral, cardiologia, pediatria e geriatria o percentual era de 26,1\% em Ermelino Matarazzo o que sugere usuários com disfunções mais específicas, que foram acompanhados, talvez até na Unidade de Reabilitação do hospital geral.

No caso de acompanhamento anterior por profissionais não médicos, em Ermelino o acompanhamento anterior por psicólogo era de 15,2\% dos usuários, enquanto que no Chico Mendes era de 19,5\%. Muito possivelmente o tipo de acompanhamento anterior influenciou o encaminhamento dessa população aos serviços. 
TABELA 41. Usuários dos CECCO, segundo acompanhamento anterior, na ARS-6, 1996

\begin{tabular}{lcc}
\hline \multirow{2}{*}{$\begin{array}{c}\text { Acompanhamento } \\
\text { Anterior }\end{array}$} & \multicolumn{2}{c}{ CECCO } \\
\cline { 2 - 3 } Médico/clínico & Ermelino Matarazzo & Chico Mendes \\
Fisiatra & 6,5 & 2,4 \\
Ortopedista & 4,3 & --- \\
Cardiologista & 4,4 & --- \\
Neurologista & 6,5 & 4,9 \\
Psicólogo & 19,6 & 14,6 \\
Psiquiatra & 15,2 & 19,5 \\
Otorrino & 34,8 & 41,5 \\
Fisioterapia & --- & 2,4 \\
Fonoaudiologia & 2,2 & --- \\
Pediatra & 2,2 & 9,8 \\
Geriatra & 2,2 & 2,4 \\
Assistente Social & 2,2 & --- \\
\hline Total & --- & 2,4 \\
$\mathrm{~N}$ & 100,0 & 100,0 \\
*total de respostas & $(46)^{*}$ & $(41)^{*}$ \\
\hline
\end{tabular}

No CECCO Chico Mendes estavam os usuários acompanhados anteriormente por otorrinolaringologista e fonoaudiólogo, e o fato da equipe desse CECCO contar com profissional de fonoaudiologia, "drenaria" usuários com essa trajetória nos serviços de saúde, em busca de continuidade de atendimento.

Os CECCO foram os serviços que maior preocupação demonstraram com o registro dessa informação. 


\section{4. Usuários da Unidade de Reabilitação e da Enfermaria Psiquiátrica}

Por se tratarem de unidades para acompanhamento de grupos específicos num mesmo hospital geral, as suas informações serão apresentadas conjuntamente. A distribuição dos usuários por sexo é semelhante, com predomínio da população feminina, tanto na Unidade de Reabilitação (57,6\%), como na Enfermaria Psiquiátrica $(56,4 \%)$ com valores próximos, conforme Gráfico 10.

GRÁFICO 10. Usuários da Unidade de Reabilitação e da Enfermaria Psiquiátrica, segundo sexo, na ARS-6, 1996

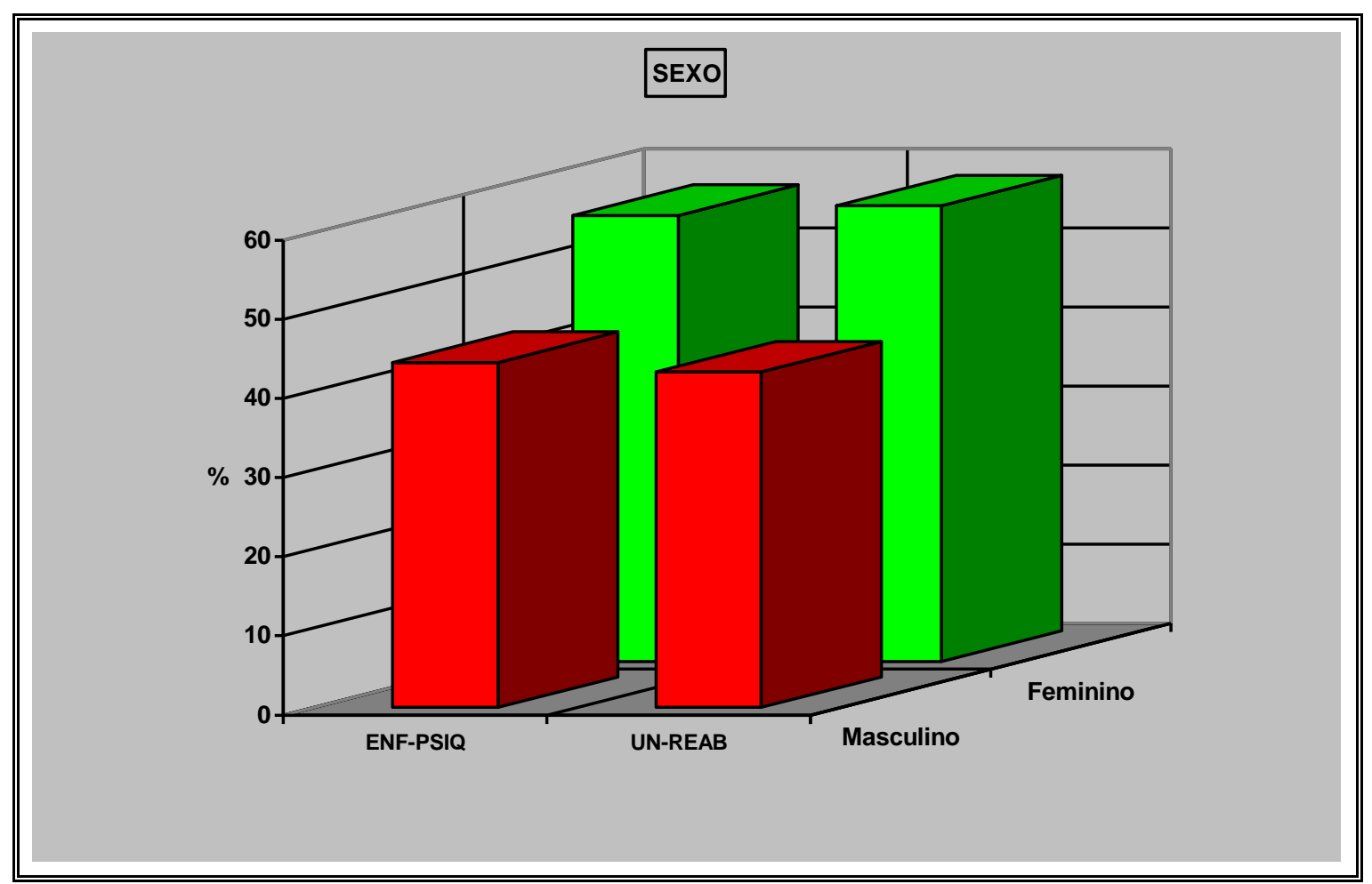

Conforme observa-se no Gráfico 11, a Unidade de Reabilitação acompanhava 11,6\% de usuários entre 1-14 anos e 22,6\% acima de 60 anos. Entre 30-59 anos estavam $48,8 \%$ dos usuários, e entre 20 e 49 anos estavam $47,2 \%$, importante contingente em plena idade produtiva.

Na Enfermaria, o grupo mais jovem tinha entre 10-19 anos, representando 8,5\% de seus usuários, enquanto que o grupo de maiores de 50 anos representava 7,7\%. 
Caracterizava-se por ser um serviço que oferecia acompanhamento para o grupo de jovens e adultos jovens, entre 20 e 39 anos com $61,2 \%$ dos usuários.

GRÁFICO 11. Usuários da Unidade de Reabilitação e da Enfermaria Psiquiátrica, segundo faixa etária, na ARS-6, 1996

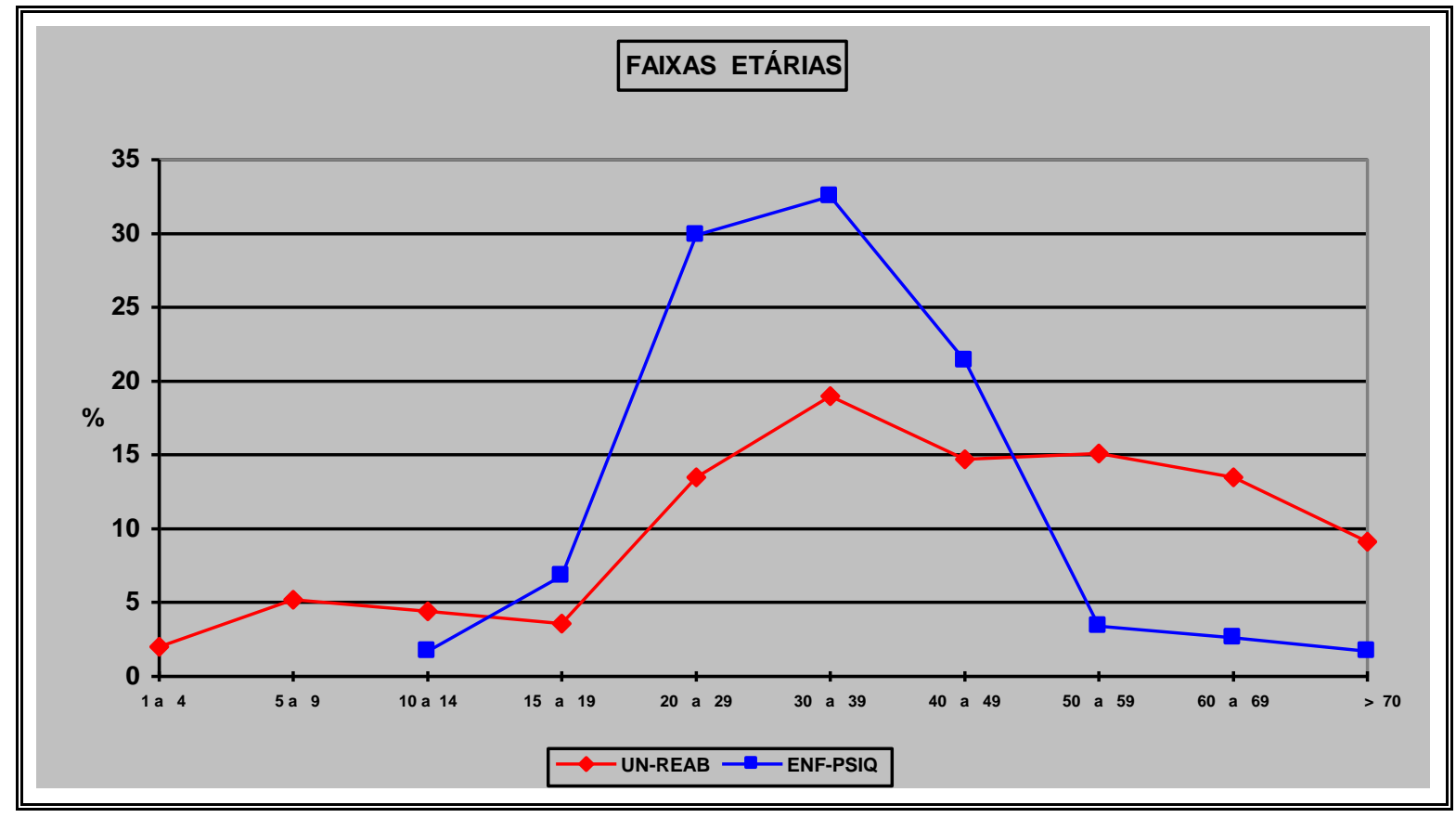

Grande parte dos usuários da Enfermaria estava sendo acompanhada, em internação, pela primeira vez, conforme Tabela 42. É possível que nos casos de internação anterior em hospital geral, se esteja incorporando tanto aquelas para acompanhamento de problemas clínicos em geral, como para acompanhamento de alguma intercorrência ligada ao quadro mental, que permitiu a internação atual.

Nesse grupo de usuários 16,2\% passaram por internação anterior em hospital psiquiátrico e apenas $1,7 \%$ já haviam sido internados naquele serviço. Isto indica que a Enfermaria era uma alternativa ao hospital psiquiátrico para a população jovem. Exatamente um dos objetivos da proposta de assistência em saúde mental. 
TABELA 42. Usuários da Enfermaria Psiquiátrica que passaram por internações anteriores, segundo tipo de instituição,na ARS-6, 1996

\begin{tabular}{l|cc}
\hline \multicolumn{1}{c|}{ INSTITUIÇÃO } & $\mathrm{N}$ & $\%$ \\
\hline Hospital Psiquiátrico & 19 & 16.2 \\
Hospital Geral* $^{*}$ & 30 & 25.6 \\
Enfermaria Psiquiátrico Ermelino & 2 & 1.7 \\
Nenhuma** & 66 & 56.5 \\
\hline Total & 117 & 100.0 \\
\hline
\end{tabular}

* Não estava claro nos prontuários se era internação em enfermaria psiquiátrica de Hospital Geral.

** Como não havia informação admite-se que esses usuários nunca tenham sido internados, anteriormente, em outras instituições.

Conforme Tabela 43, foram pequenas as informações sobre escolaridade, principalmente, para os usuários da Unidade Reabilitação, por isso o fato de terem maior grau de escolaridade que aqueles da Enfermaria Psiquiátrica deve ser relativizado.

TABELA 43. Escolaridade dos usuários, segundo unidade de saúde, na ARS-6, 1996

\begin{tabular}{lcc}
\hline & \multicolumn{2}{c}{ Unidade de Saúde } \\
\cline { 2 - 3 } Escolaridade & Unidade de Reabilitação & Enfermaria Psiquiátrica \\
\hline Primeiro grau & 21,6 & 39,1 \\
Segundo grau & 75,7 & 60,9 \\
Terceiro grau & 2,7 & --- \\
\hline Total & 100,0 & 100,0 \\
$\mathrm{~N}$ & $(37)$ & $(46)$ \\
\hline
\end{tabular}

O local de moradia era semelhante para os dois grupos, conforme Tabela 44. Em ambos a maior parte residia com esposa e/ou filhos. Na Enfermaria Psiquiátrica, alguns usuários residiam com parentes ou sozinhos, o que não ocorria na Unidade de Reabilitação, talvez pelo menor número de respostas para essa questão. 
TABELA 44. Residência dos Usuários, segundo unidade de saúde

\begin{tabular}{lcc}
\hline \multirow{2}{*}{ Residência } & \multicolumn{2}{c}{ Unidade de Saúde } \\
\cline { 2 - 3 } & Unidade de Reabilitação & Enfermaria Psiquiátrica \\
\hline Esposa e/ou filhos & 52,1 & 51,4 \\
Pais e/ou irmãos & 47,9 & 45,8 \\
Parentes & --- & 1,9 \\
Sozinho & --- & 0,9 \\
\hline Total & 100,0 & 100,0 \\
$\mathrm{~N}$ & $(94)$ & $(107)$ \\
\hline
\end{tabular}

Conforme Tabela 45, a maior parte dos usuários da Enfermaria, tinham como hipótese diagnóstica psicose (78\%), o que era esperado pela função do serviço, chamando a atenção o pequeno percentual de alcoolistas e usuários de outras drogas internados. $\mathrm{Na}$ Unidade de Reabilitação o perfil da problemática dos usuários também era o esperado pela proposta assistencial da pessoa com deficiência. Cerca de $77 \%$ das pessoas tinham disfunções ortopédico-traumatológicas, $12 \%$ reumatológicas e 10,3\% neurológicas.

TABELA 45. Hipóteses Diagnósticas dos usuários, segundo unidade de saúde, na ARS-6, 1996

\begin{tabular}{lcc}
\hline \multirow{2}{*}{ Hipótese Diagnóstica } & \multicolumn{2}{c}{ Unidade de Saúde } \\
\cline { 2 - 3 } & Unidade de Reabilitação & Enfermaria Psiquiátrica \\
\hline Psicose & --- & 78,2 \\
Disfunção ortopédica & 77,9 & --- \\
traumatológica & & -- \\
Disfunção reumatológica & 11,9 & --- \\
Disfunção neurológica adulto & 7,8 & 5,5 \\
Depressão & --- & 4,5 \\
DM & --- & 3,6 \\
Alcoolismo & --- & 3,6 \\
Paciente psiquiátrico & --- & 1,8 \\
Transtorno neurótico & --- & 0,9 \\
Epilepsia & --- & 0,9 \\
Drogadição & --- & 0,9 \\
Disfunção neurológica & 2,5 & \\
infantil & & 100,0 \\
\hline Total & 100,0 & $(110)$ \\
N & $(244)$ & \\
\hline
\end{tabular}

Conforme Tabela 7 (Anexo III-5), apenas na Enfermaria Psiquiátrica havia registros sobre acompanhamento anterior, prevalecendo o acompanhamento médico/clínico em $65,3 \%$, psiquiátrico em 24,5\%, sendo pequeno o número de usuários acompanhados por 
psicólogo. A experiência de internação na enfermaria e a possível referência para outros serviços da região poderia ampliar o leque de possibilidades de atenção a essas pessoas, incorporando outras abordagens a sua problemática, objetivo também da proposta assistencial em estudo.

\section{5. Usuários do HD}

As informações sobre os usuários do HD são relativas apenas a idade, sexo, hipótese diagnóstica. No momento da coleta vivia-se as incertezas quanto à chegada do PAS, o que impossibilitou levantamento mais detalhado.

Os usuários do HD eram em sua maioria mulheres, em proporção semelhante ao conjunto dos usuários dos serviços, conforme Gráfico 11.

GRÁFICO 12. Usuários do Hospital-Dia, segundo sexo, na ARS-6, 1996

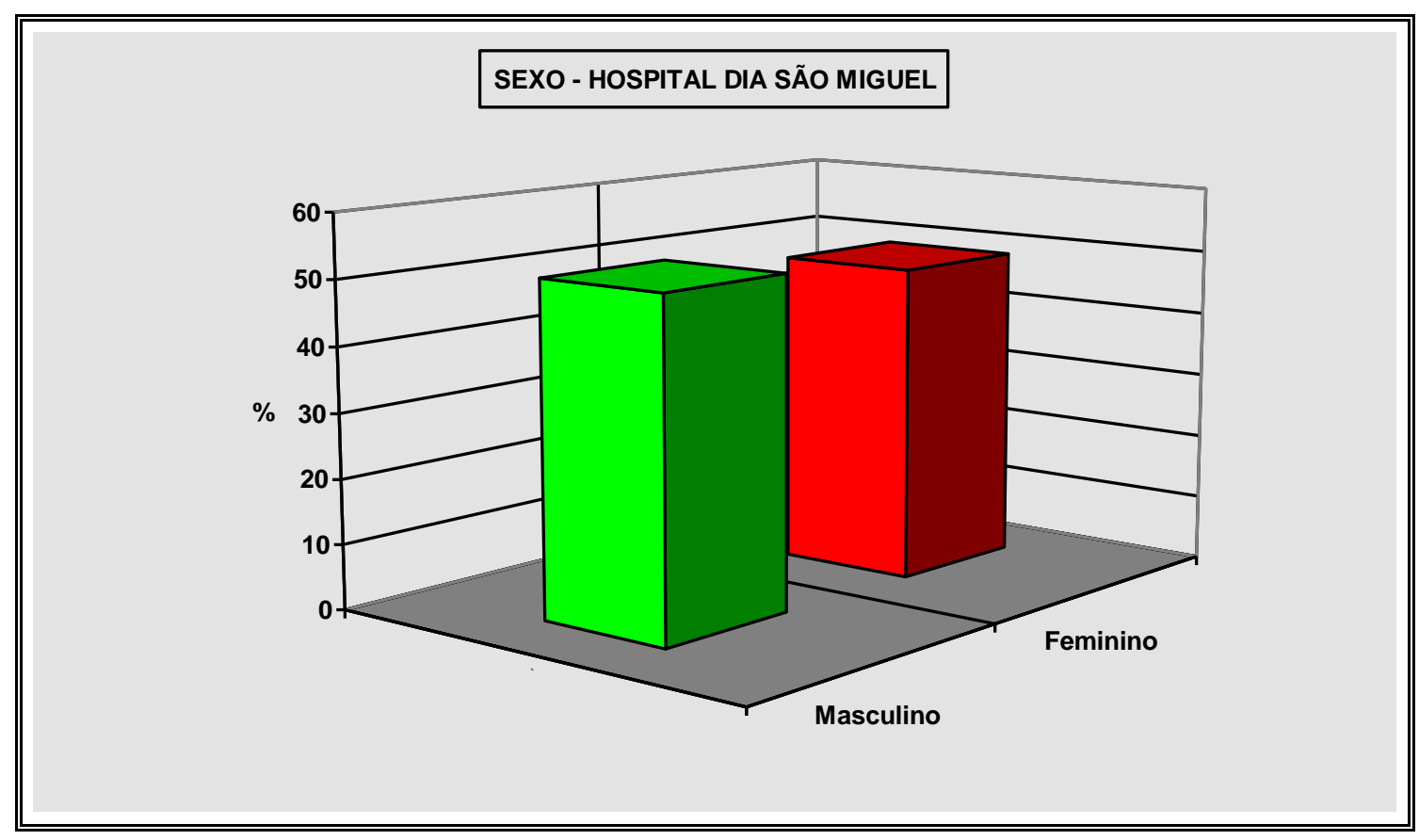

Conforme Gráfico 13, as mulheres tinham idade média de 33 anos e os homens de 28 anos. Da mesma forma que na Enfermaria Psiquiátrica, os usuários entre 20 e 39 anos 
somavam $62,4 \%$ enquanto que aqueles entre 40 e 59 anos eram $24,8 \%$. Os mais jovens entre 10 e 19 anos, somavam 8,5\%.

GRÁFICO 13. Usuários do Hospital-Dia, segundo faixa etária, na ARS-6, 1996

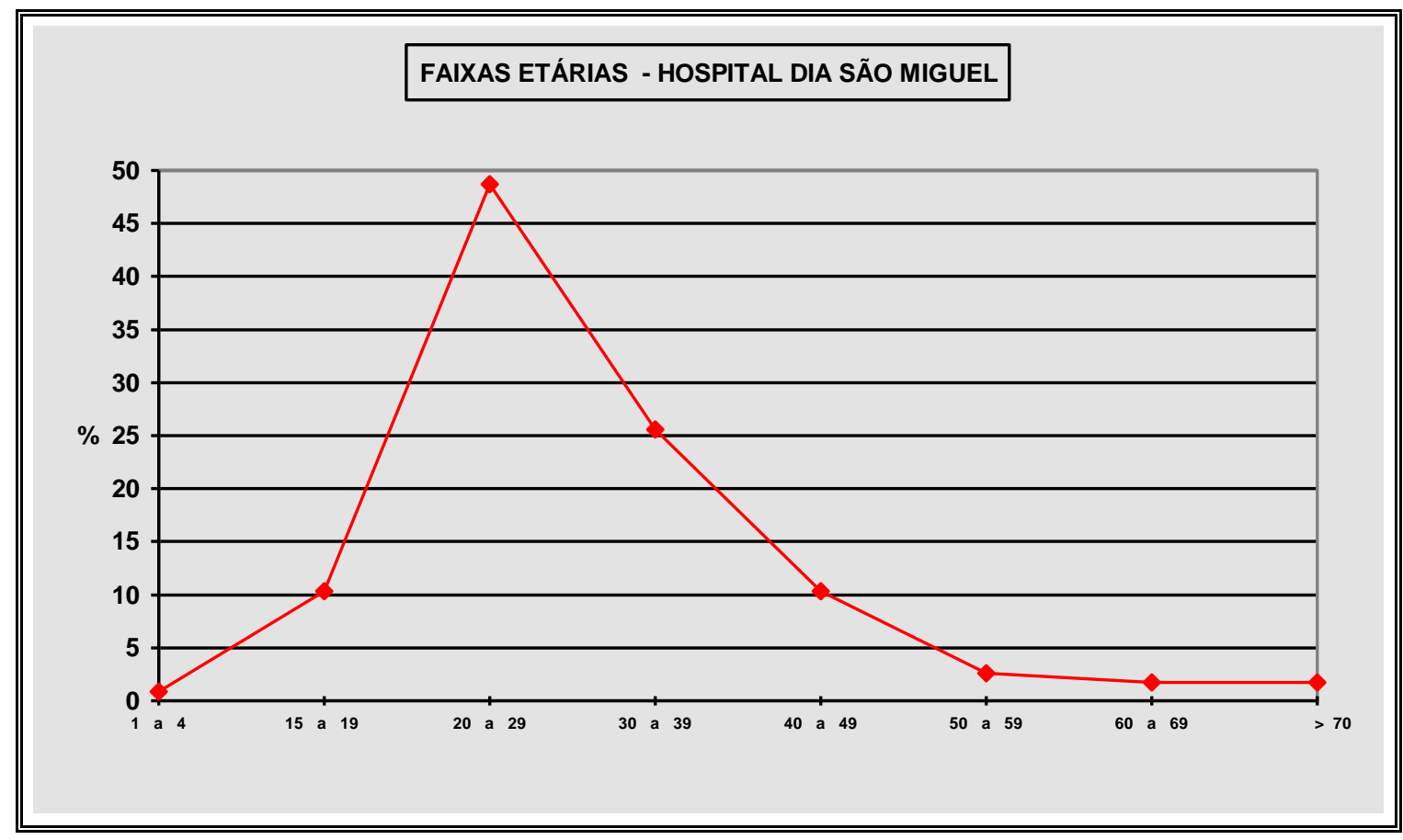

O HD se caracterizava por acompanhar a jovens e adultos jovens. As hipóteses diagnósticas mais presentes foram psicose $(68,9 \%)$ e depressão $(19,4 \%)$, conforme Tabela 46. Os critérios de eleição dos usuários, como idade e tipo de problemática, referidos nas entrevistas estavam presentes e eram aqueles apontados como essenciais para o serviço pelo documento que trata das normas de funcionamento do serviços de saúde mental.

TABELA 46. Hipóteses Diagnósticas dos usuários do Hospital Dia São Miguel, na ARS-6, 1996

\begin{tabular}{lc}
\hline \multicolumn{1}{c}{ Hipótese Diagnóstica } & Hospital Dia São Miguel (\%) \\
\hline Psicose & 68,9 \\
Depressão & 19,4 \\
DM & 1,0 \\
Alcoolismo & 1,9 \\
Transtorno neurótico & 6,8 \\
Outros 1 & 1,0 \\
\hline Total & 100,0 \\
N & $(103)$ \\
\hline
\end{tabular}


O HD funcionava desde dezembro de 1992 e entre seus usuários havia cerca de $6 \%$ com mais de uma internação no serviço, conforme Tabela 47. Isso indica a necessidade de se avaliar o significado do acompanhamento no HD para essas pessoas e para a dinâmica do trabalho.

TABELA 47. Usuários do HD, segundo internações anteriores no serviço

\begin{tabular}{lcc}
\hline \multicolumn{1}{c}{ Internações } & $\mathrm{N}^{\circ}$ & $\%$ \\
\hline Primeira & 110 & 94,0 \\
Segunda & 4 & 3,4 \\
Terceira & 3 & 2,6 \\
\hline Total & 117 & 100,0 \\
\hline
\end{tabular}

\section{6 . Mais sobre o perfil de assistência}

Após apresentar as principais informações sobre os usuários e características da demanda dos serviços pode-se inferir que, ao contrário do que se pensava realizar quando da proposição dos programas, os serviços desenvolveram ações que definiram os usuários a serem atendidos a partir da oferta do serviço, abarcando determinados grupos de usuários, dando características específicas aos serviços.

No caso das UBS, o que definiu sua clientela foi a disponibilidade de especialistas para determinadas áreas e consequente proposição de assistência seja para adultos (UBS Camargo Novo) ou para jovens e crianças (UBS Jardim Helena, Pedro Nunes de Souza e Ponte Rasa).

O mesmo ocorreu com o HD, mas o fato de esse serviço, a Enfermaria Psiquiátrica e a Unidade de Reabilitação terem dinâmicas próprias de funcionamento, também circunscreveu a assistência para determinados grupos.

A idéia geral das propostas de atenção era de trabalhar a partir das necessidades de saúde das regiões, visto o empenho em se estruturar os distritos entre 1989 e 1992 . O fato de se priorizar populações-alvo para saúde mental e da pessoa com deficiência não garantiu que na criação dos serviços estivesse garantida a rede de assistência pensada em termos de um sistema de referência e contra-referência. Pretendia-se trabalhar com as mesmas 
clientelas em momentos distintos de seu percurso para sua saúde. Isto não se verificou. O que parece ter ocorrido é que os serviços responderam por momentos de adoecimento, para grupos específicos.

No caso dos psicóticos, nos equipamentos em que não havia psiquiatras, a presença desse grupo era quase inexistente; ao mesmo tempo, naqueles em que esse profissional estava presente as dificuldades foram inúmeras para se constituir trabalho em equipe. $\mathrm{O}$ atendimento se deu ambulatorialmente, baseado na consulta/intervenção específica de determinado profissional, fosse ele psiquiatra, psicólogo, terapeuta ocupacional ou fonoaudiólogo, tendo prevalecido a atenção centrada na intervenção dos técnicos.

Equipamentos como HD e Enfermaria Psiquiátrica, centraram-se nos usuários psicóticos, com pequena proporção de usuários alcoolistas ou de outras drogas. Suas populações eram jovens, o que fazia crer que para aquelas pessoas com trajetória nos hospitais psiquiátricos tradicionais, esses serviços possivelmente não fossem alternativas de assistência.

Conforme apresentado no Anexo I (p.XXXI), a população usuária de droga foi objeto de proposta específica a partir de 1993 no Ambulatório Tito Lopes.

No caso de pessoas com deficiência houve maior limite do trabalho, a maior parte dos serviços não atendia esses usuários, apesar de contar com determinados profissionais em algumas UBS, sem experiência profissional em serviços básicos. O perfil da clientela acompanhada na Unidade de Reabilitação também privilegiava determinados problemas. Apesar de algumas UBS contarem com profissionais de reabilitação, a maior parte deles não acompanhava usuários com deficiências graves (motoras ou sensoriais), que era parte importante da população a que o programa pretendia abarcar. 


\section{O ponto de vista dos representantes das Organizações e Movimento Popular de Saúde}

Existem diferentes visões sobre o significado da participação no contexto da democracia nos países ocidentais. Num primeiro plano pode-se dizer que a participação seria a possibilidade de integrar grupos com as instituições do Estado e da sociedade, aumentando-lhes sua legitimidade política. Possibilitar a participação democrática teria a função de detectar e apontar as necessidades e demandas de diferentes grupos sociais. Nesse sentido a participação, o desenvolvimento de ações coletivas teria por função pressionar as instituições por maiores recursos para o atendimento dessas demandas. Mas nesse processo de construção de ações coletivas na esfera pública, forjam-se novas identidades e atores sociais (ADORNO, 1992).

O movimento social e esse sentido de participação foram inovadores no cenário político nacional, tanto na qualidade da pressão que exerceram sobre o Estado como pelas novas identidades sociais e políticas que puderam concretizar. Assim, o "que parece estar em jogo é a possibilidade de uma nova contratualidade que construa uma medida de eqüidade e as regras da civilidade nas relações sociais" (TELLES, 1994 p. 98).

No caso específico do setor saúde os movimentos populares surgem como resultado da organização da sociedade civil na luta por melhores condições de vida e por acesso à infra-estrutura urbana de serviços. Na Zona Leste do município de São Paulo o movimento popular em saúde se articulou na década dos 70, discutindo e reivindicando serviços básicos de assistência à saúde, numa região onde eram insuficientes em número e grau de complexidade para atender a população moradora. Seus militantes foram sempre, em sua maioria, mulheres sensibilizadas pelas condições concretas de existência e disponíveis à participação política, que se constituiu nesse processo de organização e luta social.

Parte das lideranças desse movimento está "na luta" desde seu início, cresceram politicamente em organização e representação social. Elegeram vereadores, deputados estaduais e federais em diversas legislaturas, desde 1980. Organizaram e elegeram representantes nos Conselhos de Saúde dos serviços básicos estaduais de saúde desde o final dos anos 70 (JACOBI, 1989). Pautaram suas ações em torno da apresentação de reivindicações de criação de serviços, mas também participando ativamente de uma nova proposta de controle social. O setor saúde é um dos primeiros a apresentar e incorporar formas de controle social sobre as políticas públicas, como na proposta de Sistema Único de Saúde, 
que aponta e indica a participação da população e de técnicos do setor em Conselhos de Gestão, reconhecendo nos representantes da população novos sujeitos sociais (CARVALHO, 1997; RAMOS, 1996b; VALLA, 1993; FARIA et al, 1995 a,b)

A militância e participação partidária das lideranças dos movimentos populares de saúde teve grande importância na eleição para prefeito em 1988. A vitória de Luisa Erundina representava a possibilidade de dar voz e vez a grande parte dos excluídos.

O movimento de saúde havia construído e defendido um discurso e mobilização social na defesa da Reforma Sanitária e do Sistema Único de Saúde, a saúde como direito e como acesso real a serviços (COHN, 1992). A administração municipal, recém eleita, comprometida com essa luta, poderia traduzir em ações concretas as propostas apresentadas na Conferência Nacional de Saúde de 1986 e inscritas na constituição de 1988, recém promulgada quando do início da gestão municipal petista.

É nesse processo de construção de novas relações entre poder executivo e movimentos sociais que estarão se concretizando as propostas de saúde mental e da pessoa com deficiência, com a criação de serviços que também passam a ter Conselhos Gestores, possibilitando a discussão institucional das demandas desses grupos da população. A experiência de criação dos Conselhos Gestores traz para a administração pública a interlocução direta do Estado com a sociedade civil, organizada tanto para defesa da atenção pública em saúde como definindo juntamente com técnicos das áreas o perfil da assistência a ser prestada. É um possibilidade de diálogo para a ampliação da consciência sanitária e da cidadania seja da população em geral seja dos usuários desses serviços em particular.

Nas entrevistas, parte importante das lideranças do movimento reconheceu que, inicialmente, foram sensibilizados pelos técnicos para as questões específicas da assistência em saúde mental. Este seria resultado de uma estratégia de trabalho do próprio movimento que passa a funcionar, a partir de 1985, em comissões de trabalho, como as comissões de saúde da mulher e de saúde mental, que seriam uma forma de aglutinar pessoas e aprofundar a discussão de questões importantes para a continuidade do trabalho de organização popular.

É nesse contexto que passou a existir um envolvimento maior das lideranças e membros do movimento na discussão sobre condições de saúde das mulheres, onde as questões relativas às condições de vida e de existência levantavam suas principais inquietações e suas relações com a saúde mental, como por exemplo a educação dos filhos, as questões 
relativas à sexualidade e condição feminina na família e na sociedade. Essa foi uma primeira aproximação que parte das lideranças do movimento de saúde teve com a questão da saúde mental, entendida a partir da discussão sobre as questões femininas e feministas em sua inter-relação com os aspectos da saúde mental das mulheres na periferia. Talvez por essa forma de aproximação com o tema, existia uma tendência a focalizar as questões de saúde mental no contexto do universo feminino.

Havia uma visão controvertida entre as representantes do movimento sobre as questões relativas ao envolvimento dos militantes da saúde mental no conjunto do movimento de saúde. Algumas apontavam certo isolamento desse grupo de trabalho, que por elas é visto como consequência do pequeno número de mulheres envolvidas e do volume de atividades e tarefas colocados pela participação no movimento da luta antimanicomial, em nível local e nacional; participação nas intervenções em hospitais psiquiátricos realizadas na gestão Luisa Erundina e vistorias em serviços de saúde mental. As representantes participavam como membros do Conselho Municipal de Saúde.

Para as militantes do movimento de saúde em geral, ficou mais claro o que se pretendia discutir por luta antimanicomial, quando passaram a existir os serviços como os Centros de Convivência e Enfermaria Psiquiátrica, na região. Esse reconhecimento foi maior pelo resultado concreto que produziu, pois alguns deles puderam, por suas estratégias de organização da assistência e de relacionamento com a população, sensibilizar representantes do movimento e população atendida sobre o significado do aprisionamento no manicômio, da exclusão de quem é diferente, diferença essa reconhecida como imposta pelas próprias condições de vida, de saúde e de trabalho a que está exposta a maior parte da população que vive nas regiões periféricas da cidade.

Por outro lado, houve resistências do movimento e de técnicos quando da implantação da Enfermaria Psiquiátrica no Hospital de Ermelino. Foi necessário que os assessores de saúde mental da SMS e da ARS realizassem muitas reuniões para sensibilização do movimento de saúde de Ermelino Matarazzo sobre as questões relativas à loucura e às oportunidades de assistência aos doentes mentais no país, com debates, filmes e discussões de situações concretas, que fizeram com que se compreendesse a necessidade de serviços de saúde mental. 
As lideranças conheceram as propostas de funcionamento dos serviços, seja participando do Conselho Gestor do Distrito de Saúde, do Hospital e de algumas dessas unidades, seja conhecendo usuários que se beneficiaram do atendimento.

Mas a visão predominante no movimento de saúde em geral ainda era aquela em que para o "louco", ou seja os mais agressivos, o atendimento deveria se realizar em instituição fechada, mais próxima do local de moradia e, portanto de sua rede social, mas, também, com melhores condições de assistência, sem maus tratos.

Existia maior conhecimento sobre o funcionamento dos CECCO, pelas razões já apresentadas. Esse seria um equipamento entendido como para dar maiores possibilidades às pessoas, para "ficarem mais felizes". Numa alusão às oportunidades de convivência e de maiores iniciativas de inclusão social, que puderam ser oferecidas tanto para aqueles que necessitaram de serviços de saúde mental quanto para as pessoas com deficiências físicas, mentais e/ou sensoriais, que puderam participar da experiência.

Se houvesse um investimento maior no aprofundamento do trabalho desses serviços de caráter mais aberto, como os $\mathrm{HD}$ e CECCO, durante várias gestões, a visão e espaço concreto de participação dessa população estaria num processo mais favorável para criar oportunidades de inclusão, no próprio movimento social. O processo de transformação cultural poderia ser ampliado para além do que a experiência no período possibilitou.

O discurso do direito, a cidadania, aparece no movimento mais fortalecido em relação aos loucos ou doentes mentais. Para os deficientes, esse discurso se fragiliza um pouco mais por ser também uma população menos visível.

A população com deficiência se torna mais conhecida na região, com o resultado de levantamento e censo específico em Ermelino Matarazzo que, em 1987, identificou 280 pessoas com deficiências graves, que não dispunham de assistência de nenhum tipo, seja em saúde, seja social. Estavam limitadas ao espaço doméstico. Esse foi um movimento da igreja católica da região, de apoio a propostas para lidar com problemas da população, para os quais as políticas públicas limitam-se a ter existência apenas "no papel".

Propôs-se, então, a organização de uma associação de apoio a deficientes, movimento de solidariedade para a criação de uma casa para oferecer assistência, oportunidades de saída do espaço doméstico e de convivência em grupos. Inicialmente as atividades foram realizadas no salão paroquial, duas ou três vezes por semana. Os esforços eram grandes para 
levantamento de recursos de entidades internacionais para compra de imóvel e para manutenção das atividades. A inauguração da casa ocorre no mesmo período da gestão Luisa Erundina, atendendo 60 pessoas nos dois horários de funcionamento. A PMSP contribuía com subsídio de refeições, desde 1987, e o suporte técnico foi solicitado à APAE, que orientou o trabalho durante dois anos. A casa atendia pessoas de 5 a 60 anos, com problemas graves, sendo o único serviço na região.

O movimento pela criação da $\mathrm{ACDEM}$ e de efetivação da casa passou à margem da organização popular na região e também das propostas de assistência em saúde da pessoa com deficiência desenvolvidas pela SMS, como programa específico em 1992. Novamente é o papel do setor público se limitar a subsidiar as iniciativas de caráter filantrópico e beneficente, prevalecendo essa visão e não aquela da universalização da assistência. Esse movimento de defesa das pessoas com deficiências parecia ter pequena interlocução com os técnicos da saúde e essa não adesão demonstra a dificuldade das iniciativas de inclusão desse grupo no contexto de implantação do SUS.

As pessoas com deficiência ainda não estavam na agenda para a saúde pública e integral; inscreveram-se na agenda da beneficência, porque suas próprias famílias não as enxergavam como pessoas que têm direitos de se locomover, de participar da escola comum, das oportunidades de lazer. Essas consideravam que se os deficientes pudessem ter seus problemas gerais de saúde controlados, seria o suficiente. Os familiares não se envolviam na luta por serviços específicos e apenas poucas pessoas, movidas pela solidariedade, constituem-se em porta-vozes desse grupo.

A prioridade ao estabelecimento da participação popular nos serviços durante a gestão de 1989-92 pode ampliar o processo de constituição de uma nova cidadania. Conforme apresenta TELLES (1994) a nova cidadania estaria estreitamente ligada aos movimentos sociais urbanos e aos movimentos de mulheres e negros, onde é clara a luta pelo direito à igualdade e à diferença, sendo mais radical na compreensão da democracia. Passa-se a incluir nas discussões sobre os movimentos sociais a dimensão da cultura e da política também na constituição das subjetividades, novos sujeitos e novos direitos exigindo transformações culturais, ampliando a noção de democracia.

Assim, num momento posterior entre 1993-95 a participação popular passou a ocupar outro lugar na gestão dos serviços, onde a administração conservadora não reconhecia o 
papel dos conselhos de saúde no controle social e tornava a existência desses conselhos mera formalidade.

O retorno de uma administração não democrática possibilitou que os representantes do movimento social avaliassem o processo e as articulações possíveis entre poder público e movimento social no período de 1989 a 1992, pois havia uma ligação quase que natural entre os representantes do movimento e da administração, pela trajetória do movimento social e dos apoios à candidatura Luisa Erundina. As informações fluíam, era uma experiência inédita de diálogo institucional.

Com a administração Maluf havia uma postura autoritária disfarçada, que prometia e não cumpria, mas fazia com que a população acreditasse que iria realizar o que estava sendo solicitado, estratégias mais perversas porque se utilizam habilmente das principais características de submissão ao paternalismo, tão presentes na cultura brasileira.

Existiu um desmonte progressivo dos serviços e eram colocados obstáculos ao movimento social de oposição e de defesa da participação social. O esforço por desmontar serviços e neutralizar o movimento de população e de técnicos significava reconhecimento do seu poder político. Ao mesmo tempo em que se estabeleciam estratégias contundentes de trabalho de comunicação para demonstrar a eficiência das propostas antagônicas. No trabalho de comunicação de massas a agora oposição ocuparia o lugar dos que "tiveram oportunidades para fazer e não realizaram.”

Existiu uma dificuldade da sociedade em geral, e dos movimentos sociais em particular, de fazerem frente a essas estratégias do poder neoliberal, que ampliam os ideais individualistas de ascensão social, onde as iniciativas de organização popular têm que ser redimensionadas ganhando novas práticas e novas adesões. Ampliar adesão entre os mais jovens para renovar as lideranças, eram questões colocadas para e pelo movimento social no confronto com as novas formas de oposição/diferenciação dos grupos sociais mais excluídos, no diálogo com o conjunto da sociedade.

Parte dos serviços historicamente reivindicados pela população foram criados nos anos 80 e 90 e por isso o grande tema aglutinador da população da região, a construção do hospital (isto é a disponibilidade de serviço de emergência que representava interesses de diferentes estratos sociais) também não seria mais suficiente, exigindo novas formas de estruturação do trabalho do movimento. 
Os representantes dos movimentos acreditavam que seria necessário rediscutir a visão de assistência à saúde, colocando o tema de uma "saúde mais preventiva", utilizando-se de uma metodologia mais sistemática de discussão. Acreditava-se também necessário ampliar o número de participantes e recolocar o tema da organização do Sistema Único de Saúde como uma saída para ampliar o poder de resistência do movimento na defesa da melhoria da qualidade da vida e da assistência. Para tanto reivindicavam a participação dos técnicos subsidiando as discussões com a informação que possuem sobre o tema.

Os representantes do movimento acreditavam que foram muitas as conquistas legais no campo da saúde como o código de saúde e a comissão nacional da reforma sanitária, mas que faltavam condições políticas para garantir a fiscalização das leis. Essa percepção reitera a idéia de que existe uma distância entre a formulação da política em si e sua implantação, pelo fato de que, ao se propor uma política, ao mesmo tempo deveriam estar sendo colocadas à disposição as condições para sua execução seja com recursos humanos, financeiros, disposição para alteração de mecanismos de funcionamento institucional e legal (THOMPSON, 1981).

Para a população foram inúmeras conquistas "em cima" mas "embaixo" existiu o desmonte, como foi o caso do PAS. Ao mesmo tempo, colocaram exemplos concretos de retrocesso na assistência com o SUS, caso da saúde da mulher, com menor número de leitos para parto, pré-natal e assistência de emergência, levando a crer que no período do INAMPS havia melhores condições de atenção a esse grupo, com menores repercussões para sua saúde mental também.

Por outro lado, representantes dos movimentos criticaram a postura dos partidos de esquerda, pois as disputas internas levariam a uma lentidão nas propostas de sensibilização da população para os grandes temas. Consideravam necessário investir em discussões sobre as iniciativas que favorecessem a autogestão, como aquelas do campo da habitação e enxergar a região de uma forma mais complexa, pois a zona leste tem carências em muitos campos, saúde, transporte, habitação, entre outros. Reconheceram a inexistência de política pública mínima com continuidade aos trabalhos implantados, independente do partido político que estivesse na administração e essa deveria ser uma bandeira do movimento a discussão e defesa da presença do Estado nas políticas sociais. Recoloca-se a necessidade de discussões sobre acordos, pactos sociais em defesa de políticas públicas de continuidade. 


\section{O modelo assistencial: o que se conseguiu implementar}

Aborda-se o modelo assistencial em seus aspectos gerais entre os períodos de 1989 a 1992 e de 1993 a 1995, nas duas propostas e, em particular, o que se implementou no trabalho dos diferentes serviços criados.

No período de 1989-92 havia forte movimento na SMS, que procurava traduzir em assistência os princípios básicos do SUS, referendados por uma necessária rediscussão do processo saúde-doença, que buscava romper com a tradição de entendimento do adoecer como vinculado à História Natural da Doença (LEAVELL \& CLARK apud ROUQUAYROL, 1993).

Nessa discussão foram recolocados o modo de produção econômico-social, as condições de vida, de trabalho e de acesso aos bens poduzidos socialmente como fatores determinantes do modo e qualidade de vida e também de adoecimento e cura. Nesse contexto se discutia como viabilizar, então, um modelo assistencial compatível com essa visão de processo saúde - doença e com a forma concreta de organização dos serviços municipais de saúde, herdada de outras gestões. Tratava-se de realizar a política de saúde de uma gestão comprometida com a implantação do SUS.

As discussões sobre o modelo assistencial ${ }^{\varpi}$ recolocavam os princípios dos SUS, o compromisso com a construção e ampliação dos espaços de participação popular nos serviços, vitoriosos pela efetivação do Conselho Municipal de Saúde, das Conferências Municipais de Saúde e dos Conselhos Gestores dos Serviços.

É nesse sentido que se coloca aqui a discussão sobre modelo assistencial.

CAMPOS (1989 p.53) sugere a noção de modelo assistencial “o modo como são produzidas as ações de saúde e a maneira como os serviços de saúde e o Estado se organizam para produzí-las e distribuí-las". O autor aponta o modelo liberal-privatista, o racionalizador-reformista e o do Sistema Único de Saúde, a ser construído no processo de efetivação da Reforma Sanitária.

\footnotetext{
SILVA JR.(1996) apresentou uma análise e discussão de diferentes propostas de modelos tecnoassistenciais em experiências de constituição do SUS.
} 
O período entre 1989 e 1992 foi momento de reflexões importantes sobre os caminhos de constituição do SUS, os modelos assistenciais eram um dos temas de debate para a $9^{\text {a }}$ Conferência Nacional de Saúde. É nesse período que MERHY et al (1991) lançam suas reflexões sobre experiências de construção da assistência como projetos de política e apresentam a idéia de modelo tecno-assistencial "Em defesa da Vida" como:

"Organização da produção de serviços a partir de um determinado arranjo dos saberes da área, bem como de projetos de construção de ações sociais específicas como estratégia política de determinados agrupamentos sociais" (Nesse caso,) os "modelos tecno-assistenciais estão sempre se apoiando em uma dimensão assistencial e em uma tecnológica, para expressar-se como um projeto de política, articulado à determinadas forças e disputas sociais, damos preferência a uma denominação dos modelos como tecno-assistenciais, pois achamos que deste modo estamos expondo dimensões chaves que o compõem como projeto político"(MERHY et al, 1991, p.84).

Esse modelo tecno-assistencial estaria baseado nos princípios de gestão democrática, entendida como co-gestão entre usuários organizados, prestadores e governo; saúde como direito de cidadania e serviço público voltado para a defesa da vida individual e coletiva. A assistência médica atuaria articulando ação individual e coletiva, incorporando as demandas espontâneas em saúde, como uma das formas de acesso a serviços, que se construiu historicamente e à qual os serviços devem responder. Ou seja, a epidemiologia não seria o parâmetro principal para se trabalhar a atenção em saúde (CECILIO, 1997 p.23; MEHRY, 1997b).

E aqui acrescentaria a noção de território, como contexto e complexidade e não apenas área geográfica e população a que os serviços devem oferecer cobertura. A complexidade do território e de serviços de saúde contextualizados poderia traduzir-se na identificação das demandas da população, qualificando-as. Na maior parte das vezes, o que ocorre é que a oferta de serviços, a priori definida pelos técnicos, determina o perfil da assistência prestada. Se essa forma de organizar os serviços pode muitas vezes não atender a demandas específicas da população em geral, no caso particular de pessoas com deficiência, e com transtornos mentais graves, a complexidade de sua condição exige que se conheça o território, qualificando serviços e técnicos para a atenção em saúde, fazendo da experiência assistencial espaços de ampliação das oportunidades de inserção social, de aumento da contratualidade social.

Por outro lado, é importante pontuar que quando se pensa na atenção em saúde, e em particular em saúde mental, e da pessoa com deficiência, a problemática desses grupos exige 
discussões de caráter epistemológico, filosófico, cultural e antropológico, que não deveriam ser aprisionados pelo modelo clínico e epidemiológico predominante. Estes saberes deveriam sinalizar para os profissionais da saúde a necessidade de conhecer as demais práticas sociais para lidar com esses tipos de sofrimento e de condição humanos, tratando-as como bens culturais indissociáveis dessas experiências. Levá-las em conta seria redimensionar o tecnocentrismo médico-científico e seus desdobramentos (TESSER, 1994).

Esses são elementos para discutir o modelo assistencial desenvolvido no período em análise.

\section{O modelo tecno-assistencial desenvolvido em saúde mental}

\subsection{O período de 1989 a 1992}

As utopias perseguidas pelos defensores do modelo tecno-assistencial "Em defesa da Vida" como: acesso, recepção e acolhida, vínculo entre trabalhadores e usuários, defesa de ações resolutivas que levassem à efetividade e à satisfação de profissionais e usuários e que construíssem um horizonte de possibilidades de autonomia para os usuários, também eram compartilhadas pelos militantes do movimento da luta antimanicomial.

Em sua dimensão assistencial a idéia central apresentada tanto nos textos oficiais de 89-92 como nas entrevistas com os gestores e assessores de saúde mental era de que o combate à cultura manicomial seria efetivo com a criação de serviços. Deveria ser diretriz geral da política de saúde mental conferindo autonomia ao nível regional e distrital de saúde para desenvolver a assistência segundo a realidade local.

Garantir que os princípios gerais da proposta pudessem ser discutidos dependeria da constituição de assessorias e interlocução, que inicialmente foi tensa, permeada pela postura autoritária da assessoria em nível central, segundo afirmação dos profissionais da assistência. Havia dificuldade para tornar a proposta de saúde mental questão relevante para as ARS, preocupadas em conseguir que os serviços já existentes, pudessem funcionar, ameaçados que estavam pela falta de recursos materiais e humanos vinda da gestão anterior. 
A definição das prioridades regionais não obedecia o caráter "prioritário" dos problemas definidos em nível central. Havia que adaptá-los à realidade local, no que dissesse respeito à preparação de quadros para gerência de serviços básicos, identificação de parcerias possíveis com os profissionais dos diferentes níveis: administrativo, técnico e assistencial.

Num segundo momento, após estabilizadas as dinâmicas de funcionamento geral dos serviços sob a nova administração e sensibilizadas as direções técnicas para a importância da saúde mental era possível dialogar regionalmente. Parte dos técnicos assumiu funções de assessoria e direção de serviços, colocando no cotidiano do trabalho de planejamento as questões pertinentes à política de saúde mental, criação de novos serviços e ampliação das equipes existentes nas UBS em hospitais gerais.

Os articuladores da política de saúde mental consideraram que foi possível compatibilizar os princípios de combate à cultura manicomial com a criação dos serviços propostos.

A questão que aqui se coloca seria como se procurou garantir o acesso, recepção e acolhida à população-alvo do programa, que tradicionalmente esteve excluída dos serviços? De que maneira se estruturaram os serviços para atender aos princípios de hierarquização e regionalização, segundo grau de complexidade: Enfermaria e Emergência Psiquiátricas, Hospital-dia, Unidades Básicas de Saúde e Centros de Convivência e Cooperativa. Como essa estrutura atendeu às diferentes demandas ou aspectos da problemática daqueles que sofrem psiquicamente?

Houve dinâmicas distintas de acesso e recepção desses grupos nas UBS, nos CECCO, nos HD e na Enfermaria Psiquiátrica.

$O$ vínculo entre trabalhadores e usuários, a defesa de ações resolutivas que levassem à efetividade e à satisfação e construíssem um horizonte de possibilidades de autonomia para os usuários, tramas menos aparentes, tiveram maiores dificuldades para serem observadas durante a pesquisa, principalmente nas UBS. 


\section{A UBS como porta de entrada e como Unidade Primária de Atendimento}

Trabalhou-se com a idéia de que a UBS deveria ser o local da atenção primeira, mais próxima da realidade local da população e não no sentido de atenção primitiva (TESTA 1992). Apesar de ser uma afirmação em nível dos princípios, muitas vezes esses serviços se caracterizam pela precariedade da assistência prestada, entendendo primária ou primeira como precária, de pobre conteúdo e resolutividade para pobres. A mudança dessa condição de funcionamento dependeu do investimento continuado na criação de um sistema de saúde comprometido com o direito à saúde e numa mudança da postura dos profissionais da saúde, que está alimentada pela visão hegemônica e redutora da especialização e da tecnologia no campo da atenção em saúde.

A UBS como porta de entrada foi definida como uma "posição estratégica" para incluir equipes de saúde mental nos equipamentos já existentes. Fazia-se a crítica a outras iniciativas semelhantes realizadas pela SES, na década dos 80 e pela própria SMS. Estas propostas anteriores reduziriam o papel das equipes a acompanhamento de determinados grupos de risco, sem atingir a população psiquiatrizada (Entrevista no. 3, 1996).

Na prática, observou- se que a porta de entrada para a população-alvo do programa (psicóticos, alcoolistas e usuários de drogas) era a emergência psiquiátrica. Os filtros existentes para os demais serviços se articulavam segundo a definição quase que autônoma das equipes, apesar das diretrizes gerais colocadas na proposta de normatização da assistência em 1992. Essa situação revelou a dificuldade que os serviços básicos tiveram para romper com seu papel tradicional de atenção materno-infantil.

A UBS seria porta de entrada, apenas, para o acompanhamento das crianças com

problemas de aprendizagem e adaptação escolar, o que já significava um "diagnóstico" anterior da escola, que identifica na criança o foco do problema, transformando em demanda de saúde mental as contradições do sistema educacional público.

No tocante às equipes de saúde mental nas UBS, poderiam atender outras demandas ou outras dimensões dos sujeitos, como a relação da pessoa com seu processo de adoecimento, sua sexualidade, desempenho de papéis, questões de todo e qualquer usuário da saúde. O caráter redutor à queixa, sintoma e terapêutica, do modelo tecno-assistencial hegemônico desloca para a equipe de saúde mental "recortes" da vida, como campos específicos de 
intervenção dessa equipe e não dimensões a serem integradas ao contexto da assistência à saúde.

É nesse âmbito, muitas vezes, que as equipes de saúde mental são chamadas a intervir como um campo da "prevenção" em saúde mental ou como uma das formas de integração da equipe no serviço.

Trata-se de construir a integralidade das ações em uma nova clínica, renovada, e para a qual se exigiria redefinição de práticas fundadas em novos paradigmas, gestão participativa e democrática, grande autonomia profissional com responsabilidade, questionamento do saber e práticas hegemônicos em saúde, ampliação do poder e contratualidade social de usuários.

Nas UBS em que foi possível realizar parte dessa discussão, tentava-se integrar a dimensão assistencial tradicional do serviço e a necessária mudança para a construção da atenção integral, desafio para a saúde pública (MERHY, 1997).

Percebeu-se um esforço real de equipes de saúde mental tentando se articular, concretizando as diretrizes da política, mas sem referências sobre se o que se realizava seria o "necessário e esperado" pela equipe de coordenação regional e central do programa. Trabalhava-se a partir do previsto, dos pressupostos colocados. Faltavam parâmetros para avaliar as diretrizes propostas. A gestão colegiada que se implementou foi capaz de trabalhar na criação dos serviços, mas não na discussão de resultados esperados nesse processo, qual seria a assistência a ser desenvolvida no cotidiano dos serviços e como se pretendia atingir os objetivos colocados.

A complexidade do trabalho nesse serviço e sua fragilidade no que diz respeito a garantir a atenção à saúde como utopia, e assistência médica individualizada como realidade, trazia a contradição presente entre o papel necessário da equipe e do serviço a ser construído no processo de gestão.

A implantação de um novo modelo assistencial em defesa da vida, não se apresentava para os técnicos da assistência como a construção de um modelo, com problemas específicos, numa cidade com as dimensões de São Paulo. Esses técnicos a entendiam como "caótica" e “confusa", atributos dos "militantes". Por outro lado reconheciam, já no período Maluf (1993-96), que anteriormente (1989-92) havia vontade política de realizar a proposta, de acertar. 
Seria falta de identificação profissional com a proposta? Falta de adesão dos profissionais? Falta de "militância" dos profissionais em mesmo nível e grau que os interlocutores do programa? Problemas, muitas vezes, apresentados pelos interlocutores de saúde mental, como obstáculos que dificultavam a implantação da proposta.

Talvez fossem sinais das dificuldades encontradas para favorecer o processo de produção de sujeitos, entre técnicos das UBS e população atendida. Seria esse processo facilitado por uma gestão planejada, segundo as possibilidades locais e regionais, mais do que os princípios gerais. Em que medida se realizou cotidianamente a discussão das dificuldades objetivas percebidas pelos profissionais e se traçaram objetivos e metas a serem atingidos tanto pelos técnicos da assistência como por aqueles que representavam a Secretaria, isto é a política de saúde? Em que medida as metas do trabalho puderam ser "cobradas e monitoradas" nesse percurso? Em que medida o projeto político poderia se viabilizar nas condições concretas da administração pública?

Ao mesmo tempo, é paradoxal

“(...) para se democratizar o poder institucional exige-se concentração de poder. Alguém - governo? Movimento? Grupos de trabalhadores? - que banque o processo. Para a manutenção e prosseguimento das experiências de participação também parece ser indispensável a presença ativa de garantidores: novamente, governos, ou movimentos, que preservem o conquistado. Talvez até leis ou regulamentos que dificultassem a destruição dos dispositivos democráticos conquistados parece ser também indispensável à continuação desses projetos, já que atribuir apenas a movimentos sociais a garantia de tais processos tem resultado muito caro e difícil. Ninguém aguenta pelejar o tempo todo contra desmandos governamentais" (CAMPOS, 1997a p.261).

O processo de gestão experimentado no período de 1989-92 era frágil para construir e garantir seus princípios de trabalho no campo da UBS. Um importante indicador da dificuldade de se estabelecer a proposta nas UBS foi o ocorrido na remoção zerada, onde a UBS era o equipamento para o qual não se exigia experiência prévia em saúde mental dos profissionais, critério colocado como fundamental por exemplo para os HD. Ou seja, não havia clareza sobre como lidar com as contradições existentes nesse modelo assistencial, para favorecer a integração de grupos populacionais não tradicionais nos serviços, sem transformá-las em questões específicas da saúde mental e sim da proposta assistencial. 
Não foi possível realizar essa discussão sobre o trabalho geral. Foram poucos os serviços na região que conseguiram estruturar a assistência ampliando o papel da UBS para além da clientela materno-infantil.

No entanto é importante ressaltar que o trabalho de criação e contratação de equipes para os serviços propostos bem como seu funcionamento, mesmo com problemas, foi mérito importante desse governo municipal.

\section{CECCO - uma possibilidade de construir a inserção social}

Os profissionais que participaram de seu desenvolvimento revelaram grande identificação e envolvimento com a construção dos serviços, defenderam e experimentaram formas de trabalho para facilitar a convivência entre população com transtornos graves e os usuários dos espaços públicos, no Parque Chico Mendes, na Praça Santa Amélia ou no Centro Desportivo Municipal.

Trabalharam intensamente para fazer na prática as "oportunidades", sendo oficineiros, coordenadores de atividades grupais, facilitadores dessa convivência proporcionada, criando "um espaço cultural e educativo para lidar com as necessidades de integração desses grupos populacionais marginalizados"(SECRETARIA MUNICIPAL DE SAÚDE, 1992b p.35).

No entanto, apenas a Secretaria Municipal de Saúde se responsabilizou por investir na contratação de recursos humanos próprios para esses centros, sendo que as demais secretarias como Cultura, Educação tiveram envolvimento pontual com a proposta.

A proposta exigiu a articulação de uma rede de relações entre os CECCO e as comunidades e territórios, num processo contínuo e incessante de convencimento, para que parte da clientela acompanhada em saúde mental participasse do serviço. A clientela potencial do CECCO não estava na UBS, deveria ser encontrada em outras dimensões do contexto, restrita que estava ao convívio apenas no espaço doméstico exigindo contato com a população organizada, divulgação nos serviços do bairro, na escola, nas igrejas entre outros. São pessoas que estão excluídas socialmente, para as quais não existem políticas específicas, que dêem conta da complexidade de seus problemas. Podem estar circunstancialmente na saúde, em 
momentos de acompanhamento de intercorrências clínicas. Não participam da escola, não têm oportunidades de preparação para o trabalho e não estão incluídas nas escassas iniciativas culturais e de lazer do contexto. A proposta intersetorial dos CECCO teria essa finalidade, cumprida em parte, por exemplo, para alguns grupos de crianças com deficiências que tiveram oportunidades de participar da escola comum, acompanhadas pelos serviços de saúde e de educação.

Os profissionais da região que trabalhavam nos CECCO sempre estiveram presentes nos grupos de estudo e trabalho para implementação desses serviços no município. Alguns questionavam o caráter da convivência que se pretendia construir como facilitador da integração social, pois havia usuários com muitas dificuldades pessoais para que essa convivência pudesse se realizar, sem a intermediação constante dos técnicos. Uma das questões colocadas por eles era sobre o papel dos técnicos nesse serviço. $O$ que seria possível conseguir em nível de convivência com a população em geral? Até que ponto se estaria forçando uma situação artificial de convivência, que deveria estar ocorrendo mais "naturalmente", isto é a partir de um reconhecimento mais concreto desse grupo pela população em geral e não de atividades mais ou menos tuteladas por técnicos para facilitar a convivência?

A idéia central de integração e de desenvolvimento de grupos auto-geridos, a partir das oficinas de atividades e das oportunidades colocadas pode ser concretizada inicialmente. Pela complexidade das condições objetivas da população que veio participar dos Centros de Convivência, e também, pelo pequeno período para se implementar o trabalho, a autogestão contava com grande apoio dos técnicos que ainda detinham grande parte das iniciativas. A criação de núcleos de trabalho foi acontecendo, à medida que alguns usuários se vinculavam mais ao serviço e que apresentavam uma demanda pessoal no sentido de desenvolverem alguma atividade produtiva. Como no caso dos núcleos de trabalho para horta, para estamparia e encadernação, em um dos CECCO, que conseguiu realizar tanto a atividade em si como a colocação dos produtos no mercado da região, vendendo diretamente no CECCO ou nas papelarias das redondezas. Era uma outra dimensão da proposta do serviço, com grande significado para usuários e seus familiares e para o processo de inclusão e integração social em curso. 
Repensar os princípios norteadores do trabalho era uma necessidade constante desses profissionais. Havia grande envolvimento pessoal e profissional com a proposta, disponibilidade para reverem as estratégias de trabalho no contexto, serem atores sociais em interlocução direta com a população, com compromisso e responsabilidade na construção do modelo assistencial. Grande parte deles só se desvinculou dos serviços após a implantação do PAS.

Esse equipamento era inovador no conteúdo e na maneira de inventar seu funcionamento nos serviços públicos, tentando articular setores importantes para lidar com as questões das populações que atendeu.

\section{Hospital- Dia}

$\mathrm{Na}$ implantação dos $\mathrm{HD}$ na região se construiu um serviço que privilegiava o atendimento a pessoas que estivessem passando por sua primeira crise, que tivessem família disposta a participar das atividades do tratamento e sem história de uso de drogas, mesmo que eventual. A equipe, autonomamente, diante da possibilidade de organizar um serviço, priorizou critérios que facilitassem o trabalho técnico mais do que critérios consonantes com a proposta geral para esses serviços ou com as necessidades da população da região. Ou seja, aquelas pessoas que tinham uma carreira de diferentes internações, trajetória comum, ficariam excluídas do atendimento do HD. Situação bastante cômoda para a equipe, que passaria a organizar seu trabalho a partir de uma situação idealizada de usuário em "primeiro surto". Poderiam, assim, proteger-se das situações limite da assistência psiquiátrica como a de pessoas com trajetória de diversas internações, cujo suporte familiar e/ou social estaria bastante fragilizado, exigindo intervenções redimensionadas para essa realidade. Como o HD era um equipamento novo na região, havendo demanda reprimida também para os casos de primeiro surto, seria possível "escolher" a problemática que se iria privilegiar, sem contudo discutir o que fazer com aqueles casos previstos que necessitariam de acompanhamento intensivo, que não se encaixariam nos critérios colocados.

Essa contradição ficava colocada para os profissionais da Enfermaria Psiquiátrica, dos CECCO e das UBS. A autonomia dos profissionais se chocava muito intensamente com a 
proposta de criação de um sistema de saúde mental conforme preconizado, criando uma possibilidade de "privilégio" para esse grupo de profissionais, que cria uma modalidade de assistência refratária às influências dos demais serviços.

Essas características do funcionamento dos HD, após um determinado período de trabalho, também viveriam seu momento de crise como modelo, pois o enfoque clínico prioritário recolocou para os profissionais as contradições de seu próprio trabalho.

Existia um reconhecimento da complexidade da situação a ser trabalhada pelo serviço, mas uma atuação da equipe em ampliar o tempo para o desenvolvimento do "seu" projeto terapêutico, sem rediscutir o caráter do sistema de saúde mental proposto. O que fazer com os usuários que entravam em crise quando o serviço não estava em funcionamento, com o seu encaminhamento para serviços com retaguarda de psiquiatras para acompanhamento medicamentoso, situação limite das UBS da região. Nos dois HD se instalou um trabalho ambulatorial de acompanhamento médico, principalmente, para os usuários em condições de alta, tornando necessária uma revisão do papel do HD no sistema.

Reconhecido, ao mesmo tempo, como lugar privilegiado, onde as equipes poderiam ser refratárias às orientações gerais da proposta, seria também frágil para lidar com as demandas colocadas pelos usuários em crise. Numa proposta de sistema que dimensiona a atenção em momentos tão diferenciados, como se fosse possível estabelecer mecanismos de referência e contra-referência destituídos de sentido para os usuários. Afinal de quem é a responsabilidade pelo acompanhamento dessa população? E os momentos descobertos, como períodos noturnos e finais de semana?

Nesse equipamento os prejuízos da autonomia profissional e da equipe deixavam claro para os demais serviços uma das maiores contradições da proposta, as raízes sanitaristas da reforma que se pretendeu implementar.

Num dos HD a equipe definiu seu trabalho e se organizou contratando profissional para supervisão institucional, já que por consenso, considerava-se que as supervisões gerais, proporcionadas pelo programa, não atendiam às necessidades de discussão dos problemas específicos do funcionamento de cada serviço. Avaliação compartilhada por todos os profissionais da assistência, que participaram dessa proposta. A ausência de mecanismos de avaliação mais profunda dos projetos levaram a esse tipo de solução, de dentro e para dentro do serviço. 
Quando solicitados a discutir a contribuição do HD para a assistência em saúde mental, os profissionais referiam que os usuários que passaram pelo tratamento oferecido tiveram ganhos pessoais importantes.

Para os HD e algumas equipes de UBS prevaleceu o discurso da assistência clínica individual e grupal, a partir da experiência da clínica-privada na equipe de saúde mental. A autonomia profissional, nesses casos, construiu espaços de exercício profissional privilegiado. Estariam "autorizados" por uma determinada forma de gestão dos serviços, que não conseguiu constituir vínculos entre técnicos, usuários e gestores como sujeitos e atores no modelo. Gestores, aqui entendidos como representantes da política, isto é, das propostas de governo.

É necessário ressaltar que o pequeno período da experiência como política assistencial de fato, apenas 1992, ano de agenda eleitoral para a sucessão municipal, impossibilitou que de dentro da própria proposta surgisse sua avaliação.

Em 1995, a iminência do PAS, pôs em risco também o funcionamento do HD, possibilitou a rearticulação dos profissionais com os demais trabalhadores de saúde mental, recolocando outra dimensão do serviço; isto é, sua relação com os demais equipamentos de saúde da região e as estratégias de defesa da assistência em sua dupla face, que contemplaria também a continuidade da assistência e do trabalho dos profissionais da instituição.

\section{A normatização das ações dos serviços de saúde mental}

As normas ou diretrizes gerais sobre o funcionamento dos serviços propostas em final de 1992, foram o resultado de discussões de grupos de trabalho sobre CECCO, UBS, Enfermaria e Emergência Psiquiátrica, HD que trabalharam avaliando e redimensionando a assistência nesses serviços, a partir de uma prática assistencial acumulada naquele ano. Esses parâmetros de funcionamento teriam dupla dimensão, resultado de discussões sobre os serviços e, noutro, possibilidades de sua continuidade, estabelecendo metas de atividades e dinâmica de trabalho.

Ao mesmo tempo poderia ser uma posição estratégica (de sobrevivência na gestão conservadora que viria) que procurava recolocar as dimensões gerais da política, traduzidas em ações e propostas mais específicas. O caminho procurado era o da generalização das 
ações, isto é, independente da realidade regional e distrital, as normas estavam colocadas para o conjunto do município.

O sistema de saúde real, concreto e as dificuldades enfrentadas para o estabelecimento do modelo assistencial, presentes em todo o período não foram explicitadas. Apontava-se para a necessária reavaliação das condições de cada região, no que dissesse respeito a espaço, recursos humanos e materiais. O conteúdo assistencial geral seria ainda tratado como condições de funcionamento, número de técnicos, procedimentos gerais, sem tratar de resultados esperados para se discutir qual a materialidade desse combate à cultura manicomial.

A proposta em curso também tinha um eixo político, de defesa das questões jurídicas, dos direitos, da denúncia das condições de aprisionamento dos manicômios, mas como prática não articulada organicamente no programa. Era como se existisse um momento técnico, entendido como assistencial dissociado de sua dimensão política, a luta e defesa dos direitos e da cidadania dos doentes mentais. A mobilização institucional e dos usuários era em defesa de uma sociedade sem manicômios, mas sem percebê-lo concretamente, pelo menos na região de São Miguel.

Houve maior investimento nas articulações intersetoriais para discussão da saúde mental e cidadania, o significado do manicômio, como um discurso socialmente construído em diversos seminários, exposições de semanas de Luta Antimanicomial, juntamente com a Secretaria Municipal de Cultura. Essa era uma parte do trabalho de denúncia e problematização das questões relativas à cidadania de grupos excluídos socialmente. $\mathrm{Na}$ prática assistencial as articulações intersetoriais foram experimentadas nas discussões necessárias para criação de serviços como o CECCO.

A proposta em curso estava articulada em seu conteúdo político no eixo da defesa da cidadania e dos direitos, na sua dimensão assistencial avançou contraditoriamente na criação de uma rede de serviços em substituição ao manicômio. O sistema criado ao mesmo tempo que reproduzia as contradições de outras experiências de saúde mental como a dos ambulatórios de saúde mental e das equipes mínimas das UBS da Secretaria de Estado inovou criando serviços abertos como os CECCO e como proposta para o conjunto do município, colocando a atenção em saúde mental, hospitalar e extra-hospitalar na pauta dos serviços municipais. 


\subsection{O período de 1993-95}

No período de 1993-95 as normas anteriores não seriam sequer recolocadas pelos dirigentes, planejadores, passando a ser referência maior apenas para os técnicos das equipes que participaram de sua elaboração. Nessa administração se trabalhou a partir dos boletins de produção, com projeções esperadas de desempenho para os diferentes serviços e categorias profissionais, estimulando uma visão de atividade assistencial centrada na produção de ações, mais do que na reflexão sobre seu significado (Entrevistas no. 12, 19, 21, 1996).

Trabalhou-se, desde 1992, para a constituição de planilha de dados específicos dos HD e CECCO, que buscavam identificar número de pessoas acompanhadas, média de permanência, tipo de atividades desenvolvidas, caracterizando a assistência prestada.

No caso das UBS, as informações sobre a produção dos serviços estavam mescladas no conjunto das atividades assistenciais e apareciam numericamente colocados apenas como: consulta psiquiátrica, atendimento em grupos, consultas psicológicas, atendimento de terapia ocupacional ou de fonoaudiologia. Não traduziam a complexidade da assistência à população-alvo, não sendo possível identificar, quem e quantos eram os usuários que foram atendidos em saúde mental, sendo muito difícil recuperar essa informação, até para projetar ou construir parâmetros de assistência.

Em 1993, a atividade assistencial se desenvolvia como resultado da política anterior, os recursos estavam destinados previamente.

A desarticulação dos serviços foi progressiva entre 1994 e 1995. Pode-se dizer que a criação e implantação dos diferentes tipos de serviços, a caracterização geral de seu papel foram acompanhados de forma frágil, em nível regional e local, isto é, dependeu das iniciativas e autonomia das equipes locais e regionais. Em alguns serviços havia autonomia com maior responsabilidade para com a proposta da política do que em outros. Ou seja, o redimensionamento da política e o modelo tecno-assistencial em curso exigiriam outras articulações entre técnicos, população usuária e gestores, que não foi possível experimentar, tendo em vista os novos caminhos apontados pela proposta de criação do PAS. 


\section{O modelo assistencial em saúde da pessoa com deficiência}

Os mesmos princípios apontados pelo modelo tecno-assistencial "Em defesa da Vida" também eram compartilhados pelo grupo que apresentou a proposta de Programa de Saúde do Deficiente, em abril de 1992 (SECRETARIA MUNICIPAL DE SAÚDE, 1992a).

Na ARS-6 a assistência às pessoas com deficiência se desenvolveu como proposta, com apoio institucional, na Unidade de Reabilitação do Hospital de Ermelino, desde 1991, antes da apresentação da proposta de programa específico. O serviço tinha dinâmica própria e surgiu da avaliação do Distrito de Ermelino sobre a necessidade de acompanhamento fisioterápico daqueles que passavam por internação, devido a problemas traumato-ortopédicos, reumatológicos ou neurológicos, seja nas enfermarias ou na UTI. Terminado o período de internação seria necessária a vinculação dos pacientes às UBS que dispusessem de profissionais de reabilitação nas suas equipes. A contratação de profissionais de reabilitação, na maior parte das UBS do Distrito, veio responder a uma visão dos gestores distritais de ampliação da assistência a outros grupos populacionais e não, propriamente, à criação de um programa assistencial específico.

Foi quase que um desdobramento natural da contratação dos profissionais a pressão que estes iriam exercer para que se criassem as condições objetivas de assistência, como espaço, recursos materiais e proposta assistencial.

Esperava-se que isso fosse ocorrer à medida, e como tarefa, da admissão dos profissionais contratados responsáveis pela assistência a esse grupo. No entanto, os profissionais contratados também esperavam a contrapartida institucional para o desenvolvimento da assistência. E, para eles, esta seria o oferecimento, por parte dos gestores, de espaço e de recursos materiais que possibilitassem desenvolver a atenção a usuários com um mínimo de qualidade. Isto é, para se garantir pelo menos o acesso desses usuários aos serviços era necessário esse mínimo, do ponto de vista dos profissionais da assistência. Já para os planejadores e gestores de nível distrital e regional, seria possível desenvolver assistência, mesmo sem espaço e recursos materiais específicos, a partir do que já estava disponível nas UBS. 
O esforço maior e constante dos profissionais da assistência era no sentido de conquistar as condições mínimas de funcionamento, principalmente nas UBS, equipamentos mais distantes das direções distritais e que, por isso, teriam menores condições de conseguir os recursos básicos de funcionamento. A discussão sobre a proposta assistencial limitava-se a essa questão, revelando mais intensamente os limites objetivos da visão dos técnicos contratados e dos profissionais que, num primeiro momento, seriam os interlocutores para essa proposta.

Os demais aspectos como recepção, acolhida e vínculo entre trabalhadores e usuários foram constituídos na relação direta que se estabeleceu entre profissionais e usuários atendidos, na maior parte das vezes como demanda espontânea das Unidades, nos acompanhamentos semanais e periódicos, seja de pessoas com transtornos motores graves, minoria dos usuários acompanhados, seja daqueles com problemas mais leves, que as equipes se sentiram em condições de acompanhar. Assim, por exemplo, os fisioterapeutas acompanhavam usuários com seqüelas de AVC recentes, com lombalgias diversas, com problemas respiratórios e acompanhamento de crianças com asma entre outros. Os fonoaudiólogos acompanhavam em sua maioria, crianças com problemas relacionados ao desenvolvimento da linguagem e da escrita e alfabetização, com grande demanda reprimida nos serviços. Os terapeutas ocupacionais também acompanhavam usuários com sequelas de AVC, idosos e crianças com problemas de aprendizagem num trabalho conjunto com a psicologia e fonoaudiologia. Todos os profissionais se ressentiam da impossibilidade de trabalho em equipe multidisciplinar, limitado apenas à discussão de casos, quando os profissionais responsáveis compartilhassem do mesmo horário de trabalho.

Ou seja, a possibilidade de discussão sobre a efetividade do trabalho desenvolvido para facilitar a autonomia para os usuários, estava restrita à ação de cada profissional em particular e para aqueles sensibilizados por esses aspectos da atenção em saúde. Observou-se muito mais um exercício clínico individual sob essas condições adversas de funcionamento, do que uma preocupação em refletir sobre a atenção desenvolvida. Essa era uma tarefa para os "outros" os gestores, os representantes da política de assistência.

Nesse sentido, a atenção às pessoas com deficiência não conseguia estabelecer-se como uma proposta de diretriz assistencial nos mesmos moldes da atenção em saúde mental. Não foi percebida, e de fato não era nem sequer no discurso dos gestores, uma proposta 
assistencial mas, sim, atividades assistenciais pontuais, desenvolvidas por determinados profissionais de algumas unidades e equipamentos. No entanto, como proposta de programa de saúde estava amplamente argumentada, definida e pensada em distintas dimensões da assistência, quer nas UBS, quer nos hospitais gerais ou em futuros centros de reabilitação.

Não foi possível, no último ano de gestão do período de 1989-92, discutir a questão como proposta assistencial a ser implementada. O programa apresentado tornou-se muito mais uma maneira de tentar sensibilizar gestores e profissionais da assistência para as questões da pessoa com deficiência. Os resultados mais imediatos foram a criação de atendimentos em determinadas especialidades, em alguns equipamentos, principalmente UBS, durante o ano de 1992.

Entre 1993-95 mantém-se a idéia de criação de atendimento nas UBS. Como já referido anteriormente, equipou-se com materiais de fisioterapia uma unidade que, posteriomente ao término das reformas e da compra de equipamentos, perdeu seu profissional para o PAS, em região central da cidade. Assim, quando estavam disponíveis os recursos, adaptações e equipamentos para a assistência, o processo de gestão não garantia que o serviço se desenvolvesse. Os profissionais revelaram autonomia em defesa muito mais de seu papel profissional específico, do que na construção responsável da assistência e aqueles que permaneceram cumprindo suas atividades assistenciais o fazem de maneira quase independente e comprometidos com uma agenda e clientela específicos, sem muitas condições de se perceberem como atores também da gestão dessa proposta assistencial. 


\section{Considerações finais}

As propostas de atenção em saúde mental, e da pessoa com deficiência, diretrizes para estabelecimento de política, foram fundamentais como marcos institucionais, parâmetros concretos para discutir a universalização da assistência no SUS. Demonstraram o compromisso e adesão de servidores públicos na defesa da organização de assistência para esses grupos.

No entanto, para a implantação da assistência outros obstáculos estavam colocados destacando-se aqueles inerentes à administração pública. Se a criação de novos serviços e equipes de profissionais naqueles já existentes eram os principais elementos para a consecução da política, os recursos necessários para sua manutenção e funcionamento também deveriam estar disponíveis. O que se notou nesse processo é que foi necessário, no início da proposta em 1989, trabalho intenso de assessores e interlocutores de saúde mental "forçando a porta". Em nível regional e distrital a discussão era cotidiana para convencimento dos dirigentes locais, revelando a militância dos profissionais. Esse mesmo grau de envolvimento de profissionais de reabilitação não ocorreu, o programa de saúde da pessoa com deficiência foi resultado da pressão de movimento de deficientes e não de militância de técnicos nesse movimento, a exemplo do que ocorreu na saúde mental.

A falta de experiência em planejamento e organização de serviços obrigava a uma jornada de trabalho extenuante, para resultados nem sempre compensadores. Os profissionais investiram "muitas horas" numa proposta de trabalho, que representava o conteúdo político e pessoal das opções realizadas para a vida profissional. Era o exercício concreto da busca e construção das utopias.

Não se procurou trabalhar com projetos piloto, áreas geográficas de prioridade; não seria ético. Nesse sentido a possibilidade de operar mudanças de qualidade e de impacto na assistência estavam determinadas pela capacidade de trabalho, de investimento pessoal de muitos militantes e não militantes, que foram aderindo à proposta no processo.

Havia resistências no processo de criação dos serviços, os profissionais contratados pelos concursos da administração de 89-92 e outros já pertencentes ao quadro da Secretaria, não se manifestavam contra as diretrizes da luta antimanicomial, mas sim questionadores de como realizá-la na prática cotidiana dos serviços. A maior questão era levantada pelos 
profissionais das UBS, que se sentiam pouco preparados para definir formas de trabalho em um serviço que tradicionalmente atendeu à demanda materno-infantil e que, na prática, não oferecia condições para acompanhar demandas da complexidade daquelas das pessoas com sofrimento psíquico, por exemplo. Havia problemas como falta de espaço para o trabalho dos novos profissionais, recursos materiais, equipes interprofissionais completas e capacitadas para isso. Não havia clareza por parte dos interlocutores de saúde mental de qual seria a tarefa na assistência nas UBS, seria resultado de um processo de discussão.

Por outro lado, o acompanhamento da implantação, sempre problematizado em grandes reuniões e fóruns coletivos nos distritos ou na região, era entendido como vontade política de viabilização de uma proposta, mas, que na prática, manteve as dificuldades das equipes de saúde mental em suas UBS, quer pela visão dos interlocutores, quer pelo tempo necessário para a implantação da proposta.

Já nos CECCO, a maior parte dos profissionais optou pelo trabalho nesses serviços, participando de sua estruturação em grupos de trabalho que criaram os serviços e que normatizaram suas ações, no final de 1992. Para estes, o fato de não haver clareza sobre qual a dinâmica de funcionamento significava a possibilidade de ousar, experimentar, exercitar seu papel profissional, autorizados que estavam pelas direções locais e regionais a implementar uma proposta assistencial na direção da luta antimanicomial. O fato de se lidar com usuários que poderiam permanecer grande parte do dia em atendimento, participando das oficinas e atividades nos parques e centros e não se trabalhar com agendamento da mesma forma que na UBS, trazia para o cotidiano do trabalho as contradições da qualidade e das oportunidades de vida dos usuários, tornando-se referência cotidiana para esse grupo.

Também nos HD os profissionais optaram pelas atividades nesses serviços, a autonomia profissional desses técnicos foi tão intensa que delineou a proposta assistencial a partir de critérios que privilegiam o papel dos técnicos na delimitação do trabalho institucional. Ao mesmo tempo, para que esse serviço pudesse oferecer a continência necessária para lidar com os usuários em situação de crise, suas condições de funcionamento não possibilitavam assumir a complexidade dos problemas que ocorriam no cotidiano da assistência. Limitar o tipo de usuários a ser acompanhado exigindo determinadas condições seria uma forma concreta da equipe lidar com uma das principais questões colocadas pela proposta de sistema de saúde mental, como se contrapor fortemente ao papel 
desempenhado pelo manicômio? Com estruturas assistenciais fortes o suficiente para isso. E nesse sentido o HD e a Enfermaria Psiquiátrica não pareciam poder desempenhar esse papel.

Foi necessário romper com o papel tradicional, clínico institucional do HD para se criarem os vínculos mais estreitos entre usuários, técnicos e movimento social organizado, tornando mais visível para essa região esse grupo da população e suas necessidades de assistência.

Muitos profissionais foram pouco conservadores em seus valores ousando exercitar a possibilidade de inventar propostas de serviços e de construí-las de forma articulada e permanentemente discutida. Aqueles mais resistentes às propostas de saúde mental, pareceram contaminados por ela, principalmente a partir de 1993-95, quando se teve maior clareza do que se pretendia, já que a maior parte dos serviços na ARS-6 foram criados em meados de 1992, momento de disputa eleitoral acirrada, que altera substancialmente as dinâmicas institucionais e as possibilidades de trabalho.

A proposta de saúde da pessoa com deficiência foi resultado da luta do movimento de pessoas deficientes a partir do Conselho Municipal do Deficiente efetivada como programa apenas em 1992, apesar das inúmeras gestões do Conselho junto ao governo municipal em 1989 e 1990, com propostas concretas apresentadas como Centros de Reabilitação Regionais, leitos hospitalares para tratamento de deficientes com escaras e as Casas Comunitárias. Talvez uma das questões fosse a pequena adesão de técnicos ao movimento de deficientes, que assumissem a defesa da assistência como direito. O que se observou foi que o programa de atenção estava tecnicamente bastante articulado, mas sua apresentação em 1992, também foi resultado de uma visão hegemônica de que a atenção a deficientes deva ser tarefa das instituições beneficentes porque já teriam a tradição e competência técnica necessária para tanto.

Parte dos profissionais das UBS tinham formação profissional para atendimento a portadores de deficiência, o que não foi suficiente para o delineamento da assistência. Também nesse caso estava colocada a dificuldade para definição de qual seria o papel de uma equipe de reabilitação numa UBS, como implementar atividades no campo da prevenção de deficiências e incapacidades, como lidar com as atividades relativas ao tratamento/acompanhamento dos casos de deficiências já instaladas, para as quais não havia serviço na região e a UBS também deveria ser uma referência. Como ampliar o trabalho 
desenvolvido pela Unidade de Reabilitação do Hospital Geral seus recursos materiais e humanos, como capacitar os profissionais para uma prática em serviços públicos de saúde.

Mas o processo de incorporação da atenção em saúde mental e da pessoa com deficiência também sofreu resistências no interior do movimento social organizado quando da implantação da Enfermaria Psiquiátrica no Hospital de Ermelino. Foi necessária a sensibilização do movimento de saúde de Ermelino Matarazzo sobre as questões relativas à loucura e às oportunidades de assistência aos doentes mentais no país, com debates, filmes e discussões de situações concretas, que fizeram com que se compreendesse a necessidade de serviços de saúde mental.

Entre as militantes do movimento existia maior conhecimento sobre o funcionamento dos CECCO, que seria um equipamento entendido como para dar maiores possibilidades às pessoas, para "ficarem mais felizes"; numa alusão às oportunidades de convivência e de maiores iniciativas de inclusão social, que puderam ser oferecidas tanto para aqueles que necessitaram de serviços de saúde mental quanto para as pessoas com deficiências físicas, mentais e/ou sensoriais, que puderam participar da experiência.

Com investimento maior no aprofundamento do trabalho desses serviços de caráter mais aberto, como os HD e CECCO, durante várias gestões, a visão e espaço concreto de participação dessa população estaria num processo mais favorável para criar oportunidades de inclusão social, no próprio movimento social. O processo de transformação cultural poderia ser ampliado para além do que a experiência no período possibilitou.

O discurso do direito, a cidadania, aparecem no movimento mais fortalecido em relação aos loucos ou doentes mentais. Para os deficientes esse discurso se fragiliza um pouco mais, era também uma população menos visível.

As pessoas com deficiência ainda não estavam na agenda para a saúde, pública e integral, inscrevem-se na agenda da beneficência, porque suas próprias famílias não as enxergam como pessoas que têm direito, consideravam que estar com problemas gerais de saúde controlados seria o suficiente. Por isso, os familiares não se envolviam na luta por serviços específicos; apenas poucas pessoas movidas pela solidariedade, constituem-se em porta-vozes desse grupo.

Ao mesmo tempo, na construção das propostas, principalmente de saúde mental, os problemas relativos aos processos de avaliação estavam circunscritos à discussão militante 
da experiência, grandes fóruns, convencimento cotidiano de diferentes níveis da secretaria e em algumas situações tensionamento entendido como autoritário. A maior parte dos profissionais não havia participado de implantação de política para município desse porte. Não foram dimensionados mecanismos de avaliação e de esclarecimento de objetivos e procedimentos a serem implementados, que foram construídos no processo, o que dificultou a qualidade e alcance de sua implantação. Não seria possível falar em implantação e funcionamento pleno dos serviços quando a maior parte deles funcionou apenas em 1992. Os interlocutores da proposta não haviam produzido sua própria revisão, não a esgotaram, o tempo não foi suficiente.

Nesse sentido, a administração pública com seus mecanismos e lógica próprios de orçamento, contratação de pessoal, criação de cargos se encarrega de dar grande parte do ritmo do trabalho.

Produzir modelo assistencial centrado no acesso, na recepção dos usuários de forma a mudar qualitativamente o lugar que ocupam, a passagem de usuários para sujeitos sociais vinculados aos serviços e à qualidade das propostas exigiria outro pacto, outra dimensão ética para o entendimento do papel do Estado no setor saúde. Seria necessário uma administração pública com mecanismos gerenciais que de fato transferissem poder, recursos, atrelassem propostas assistenciais a recursos humanos e materiais previamente definidos. A realidade da política geral hoje, se distancia em muito daquela defendida e encontrada nos anos 80 .

Pensar em redimensionar o modelo assistencial num município como São Paulo, já é uma ousadia. Empreender a proposta é trabalho árduo.

A lógica da assistência individual, especializada e privada, que pouco leva em conta a dimensão coletiva do processo saúde doença para a mudança de modelo assistencial exigiria mudanças substantivas na cidadania, nas dimensões da exclusão social. Sem dúvida, o setor saúde poderia contribuir para que a população usuária tivesse maior consciência sanitária, se exercitasse em espaços de subjetividade diferenciados.

Nesse sentido, o período de 1989-92 contribuiu com a criação de serviços e de oportunidades para grupos anteriormente excluídos, não sendo possível atingir integralmente a população-alvo e combater, no sentido mais literal do termo, a cultura manicomial. Não foram produzidas mudanças significativas no processo de aprisionamento dos que sofrem 
psiquicamente e daqueles que estão a cargo da assistência caridosa das instituições para pessoas com deficiência pelo poder institucional da Secretaria Municipal de Saúde e pelas estratégias utilizadas pelos programas criados.

O processo de implantação dos serviços não permitiu rever as contradições colocadas entre os princípios da proposta e o tipo de sistema assistencial preconizado. A hierarquização de ações e serviços em distintos graus de complexidade não construiu uma rede com a força necessária, para se prescindir, contrapor ao manicômio, enquanto instituição social. Foram criadas formas específicas de atenção para determinados grupos, como no caso das UBS e dos HD, redimensionando a proposta inicial desses serviços para populações restritas. Não somente por falta de adesão ou de conhecimento dos profissionais.

Estava em questão o sistema assistencial proposto. A experiência demonstrou que os princípios do SUS como hierarquização, descentralização e incorporação de ações em UBS não são suficientes para construir uma rede assistencial para populações cujas propostas de atenção foram aqui estudadas.

No entanto, essa experiência contribuiu para se discutir como construir serviços no contexto do SUS, pela primeira vez essa temática aparece no cenário dos serviços municipais de saúde como política para a cidade. Deu visibilidade para essas populações, que sem dúvida estão entre os contingentes da população pobre e excluída socialmente. As dimensões mais concretas dessa exclusão poderiam ser estudadas mais especificamente para se redimensionar novas estratégias de políticas públicas para esses grupos.

Essas propostas foram alguns dos exemplos da qualidade da motivação do movimento social organizado, de sua participação cidadã, criando as condições para um exercício singular de poder democrático nos serviços muncipais de saúde. A radicalidade na construção de possibilidades de participação entre técnicos, usuários e movimento social; resultado de muito trabalho institucional e engajamento pessoal e político na construção dessa proposta de gestão de serviços levou a mudanças significativas no conjunto da Secretaria. Não seria mais possível o retorno a formas anteriores tradicionalmente conservadoras na gestão da política de saúde.

Se para aqueles que participaram da construção coletiva da utopia não se chegou aos objetivos primeiros que seriam a atenção integral, com qualidade técnica e política, a 
experiência do período de 1989-92, não deixava dúvidas de que seria necessário contrapor-se a essa proposta de SUS, vigorosamente.

O processo de construção da política foi abortado em 1993, com a mudança radical na gestão dos serviços. A nova administração pretendia contrapor-se ao SUS. Inicialmente, não era necessário produzir um discurso contrário, bastava desarticular as condições básicas da proposta anterior, diminuir orçamento, e recursos financeiros, não reconhecer as instâncias de participação popular e democrática.

Construir o trabalho foi extremamente desgastante, mas vê-lo destruído, em algumas situações, foi vivência insuportável levando alguns à desestruturação pessoal.

A radicalidade da articulação do SUS no município no período entre 1989 e 1992 , torna a questão da saúde na gestão seguinte um ponto a ser tocado na administração municipal. E é nesse sentido que pode ser compreendido o PAS, como uma delimitação concreta de que papel teria a administração municipal na política social, demonstrando os compromissos do governo em curso.

Nesse sentido a proposta PAS teria que neutralizar os principais aspectos da proposta SUS tocando de perto no princípio da universalização da assistência, na forma de contratação e gerência dos recursos humanos, redimensionando o uso dos equipamentos e serviços de saúde, fazendo na prática um tipo de reforma neoliberal na saúde, à revelia das forças sociais que defenderam a ampliação do papel do Estado no setor saúde.

Os serviços de saúde mental e para a pessoa com deficiência foram assumidos pelo PAS, provavelmente seu funcionamento foi alterado significativamente necessitando novas discussões sobre a qualidade da assistência prestada

Neste estudo foi possível descrever e analisar experiências de assistência que traduzem as dificuldades que a administração pública tem para implantar e implementar políticas de uma maneira geral, e em particular para determinados grupos.

É grande a fragilidade das iniciativas, como em distintos casos de política pública. Existe dificuldade para imprimir a agilidade necessária para seu desenvolvimento, um dos exemplos seria os mecanismos específicos de contratação e de definição de orçamento, regulamentados em instâncias distintas dos órgãos executores, o que impede que o ritmo da implantação/criação de propostas seja ágil, aquele necessário para lidar com as necessidades de determinados serviços públicos. 
No caso das políticas sociais, em especial na saúde, a natureza dos problemas e das necessárias soluções exige maior sintonia e continuidade de gestões ou acordos sociais possíveis para manter propostas em funcionamento, que não estejam totalmente à mercê dos governos, cuja duração é temporária e em alguns casos a ruptura entre as diretrizes políticas é evidente, como se observou na experiência analisada.

O fato da contratação de servidores se realizar a partir de concursos públicos, mecanismo legítimo, exige estratégias de capacitação e formação de profissionais de forma a tentar garantir o projeto político em questão. À medida que os governos se alternam, e que não existem possibilidades de continuidade nas propostas, o servidor público tende a não aderir completamente aos projetos, pois reconhecem que o mandato é temporário e que na prática as propostas de trabalho institucional mudam levando a que a adesão a novas diretrizes de trabalho seja difícil. A possibilidade de recondução aos cargos eletivos, em mandatos consecutivos pode vir a facilitar a continuidade de políticas, fato novo no cenário brasileiro para o qual é necessário estar atento.

São também conhecidos os prejuízos que a não destinação de recursos financeiros específicos para os projetos trazem para o desenvolvimento e implementação das propostas. Nesse sentido, a resistência cotidiana ao desenvolvimento de novas propostas, sentida nos casos estudados era esperada.

Por outro lado, as propostas aqui apresentadas foram momentos privilegiados para se exercitar a universalização de assistência proposta pelo SUS, para também repensar seus pressupostos básicos de hierarquização de serviços e ações, redimensionando estratégias de atenção para grupos com características especiais. Foi possível, também, compreender a necessidade de se investir na formação da consciência sanitária da população e do movimento social organizado, sensibilizando-os para as questões relativas às condições de assistência e vida daqueles que se utilizam de serviços de saúde mental e também das pessoas com deficiência.

Espera-se que em trabalhos posteriores seja possível aprofundar as questões colocadas pelo modelo assistencial em questão, repensando novas formas de investigação e análise sobre o dilema autonomia profissional necessária versus atenção em saúde com qualidade, entre formas de gestão dos serviços e renovação dos mecanismos de administração pública. É urgente continuar inventando formas de atender e de administrar em defesa dos direitos, que 
contribuam para a emancipação daqueles que sofrem de maneira singular com o processo de exclusão social, como os grupos aqui estudados. 


\section{BIBLIOGRAFIA}

ADORNO, R. C. F. Movimento social e participação: a saúde na esfera pública. Saúde e Sociedade. Faculdade de Saúde Pública da USP, v.1-2, 1992, p. 111-124.

ALMEIDA FILHO, N. \& ROUQUAYROL, M.Z. Introdução à epidemiologia moderna. 2ed. Belo Horizonte/Salvador/Rio de Janeiro, COOPMED/APCE/ABRASCO, 1992.

ALMEIDA, M. C. A pessoa portadora de deficiência física em seu cotidiano: reflexos e reflexões sobre reabilitação. 1993, 117p. Dissertação (mestrado) Instituto de Psicologia da Universidade de são Paulo.

ALVES, D. S. N. A reestruturação da atenção em saúde mental no Brasil. In: V Congresso da Associação Mundial de Reabilitação Psicossocial, Roterdã Holanda, 1996 (mimeo).

AMARANTE, P. (org.). Loucos pela vida: a trajetória da reforma psiquiátrica no Brasil. Rio de Janeiro, Secretaria de Desenvolvimento Educacional, 1995, 143p.

AMARANTE, P. A trajetória do pensamento crítico em saúde mental no Brasil: planejamento na desconstrução do aparato manicomial. In: LANCETTI, A. (org.). Saúde Mental e cidadania no contexto dos sistemas locais de saúde. Saúdeloucura (Textos) 7. São Paulo - Salvador, Hucitec Cooperação Italiana em Saúde, 1992, p.103-120.

AMARANTE, P. Asilos, alienados, alienistas: uma pequena História da Psiquiatria no Brasil. In: (org.). Psiquiatria social e reforma psiquiátrica. Rio de Janeiro, FIOCRUZ, 1994, p.73-84.

ASSOCIAÇÃO DE PAIS E AMIGOS DOS EXCEPCIONAIS, APAE. Guia DM-SP. São Paulo, Menom, 1992.

BARROS, D.D. Operadores de saúde na área social. Rev. Ter. Ocup. USP, 1(1): 11-16, 1990.

BARROS, D. D. et al Novas propostas assistenciais em São Paulo 1991: estudo da recente incorporação da terapia ocupacional no contexto das ações de saúde mental e saúde da pessoa portadora de deficiência, no município de São Paulo. Relatório parcial de pesquisa, 1995, São Paulo, 83 p.

BENJAMIN, A. H. V. A tutela das pessoas portadoras de deficiência pelo ministério público.

In: ADOVOCACIA \& SOCIEDADE. Direitos da pessoa portadora de deficiência. São Paulo, Instituto Brasileiro de Advocacia Pública, 1997. 
BERLINGUER, G. Existe um direito à assistência? In: Ética da Saúde. São Paulo, Editora Hucitec, 1996a, p. 71-80.

BERLINGUER, G. Saúde para todos ou para poucos? In: Ética da Saúde. São Paulo, Editora Hucitec, 1996b, p. 21-28.

BERNARDO, A. C. Previdência social e assistência psiquiátrica no Brasil. In: D`INCAO, M. A. (org.). Doença Mental e Sociedade: uma discussão interdisciplinar. Rio de Janeiro, Graal, 1992, p. 162-176.

BERTI, M. Epidemiologia I - Faculdade de Ciências Médicas da UNICAMP, Campinas, 1997. (Anotações de aulas)

BRASIL. Constituição, 1988. Constituição Federal do Brasil, promulgada em 1 de outubro de 1988. São Paulo, Ícone, 1988.

BRASIL. Leis, etc. Senado Federal. "Projeto de lei da Câmara no.8, de 1991". Dispõe sobre a extinção progressiva dos manicômios e sua substituição por outros recursos assistenciais e regulamente internação psiquiátrica compulsória.

BRASIL. Proposta de política de saúde mental da Nova República. Ministério da Saúde. Divisão Nacional de Saúde Mental, apresentada na I Conferência Nacional de Saúde Mental, Rio de Janeiro, 1987

CAMPOS, F. C. B.; HENRIQUES, C. M. P. (org.). Contra a maré à beira mar: a experiência do SUS em Santos. São Paulo, Pagina Aberta, 1996.

CAMPOS, G.W.S. et al Planejamento sem normas. São Paulo, HUCITEC, 1989.

CAMPOS, G. W. S. O sistema público de saúde no Brasil e o processo de descentralização. In: Reforma da reforma: repensando a saúde. São Paulo, HUCITEC, 1992a, p. 91-103.

CAMPOS, G. W. S. Sistema Único de Saúde: ainda um desafio (mais uma possibilidade do que uma realidade). In: Reforma da reforma: repensando a saúde. São Paulo, HUCITEC, 1992b, p.17-32.

CAMPOS, G. W. S. Sobre a reforma da reforma: repensando o SUS. In: Reforma da reforma: repensando a saúde. São Paulo, HUCITEC, 1992c, p. 133-214.

CAMPOS, G. W. S. Subjetividade e administração de pessoal: considerações sobre modos de gerenciar trabalho em equipe de saúde. In: MERHY, E. E. (org.) Agir em saúde: um desafio para o público. São Paulo, HUCITEC, 1997, p. 229-266. 
CAPISTRANO, D. A saúde em Santos: propostas. In: Da saúde e das cidades. São Paulo, HUCITEC, 1995, p. 121-126.

CARVALHO, A. I. Conselhos de Saúde, responsabilidade pública e cidadania: a reforma Sanitária como reforma de Estado. In: FLEURY, S. Saúde e Democracia a luta do CEBES. São Paulo, Lemos, 1997, p.93-111.

CASTEL, R. Da indigência à exclusão, a desfiliação: precariedade do trabalho e vulnerabilidade relacional. In: BAREMBLITT, G. F. et. al. SaúdeLoucura 4. São Paulo, HUCITEC, 1993. p. 21-48.

CATÂNIO, P. A. G. Em busca da desinstitucionalização do doente mental. In A construção do SUS a partir do município: etapas para municipalização plena da saúde. São Paulo, HUCITEC, 1996 p. 105-111.

CECILIO, L. C. O. Contribuições para uma teoria da mudança do setor público. In: (org.). Inventando a mudança na saúde. São Paulo, HUCITEC, $2^{\text {a }}$ edição, 1997 p. 235-329.

CENTRO DE ESTUdO DE CULTURA CONTEMPORÂNEA. CEDEC. Participação e saúde. Boletim Informativo, 05/08/92.

CESARINO, A.C. Uma experiência de saúde mental In: LANCETTI, A. et al. SaúdeLoucura 1. São Paulo, HUCITEC, 1989. p.3-32.

CHIZZOTTI, A. Pesquisa em ciências humanas e sociais. São Paulo, Cortez, 1991, 164p.

COHN, A. Processos políticos e saúde no município de São Paulo: a proposta de um novo modelo de gestão. In: Saúde e cidadania. São Paulo, Livre docência Faculdade de Saúde Pública da USP, 1992, p.209-238.

COHN, A. Mudanças econômicas e políticas de saúde no Brasil. In: LAURELL, A. C. Estado e políticas sociais no Neoliberismo. São Paulo, Cortez, 1995a, p.225-244.

COHN, A. (coord.) Descentralização, saúde e democracia O caso do município de São Paulo 1989-1992. São Paulo. Cadernos CEDEC n. 44, 1995b. 104p.

COHN, A. A saúde na Previdência Social e na Seguridade Social: antigos estigmas e novos desafios. In: CONH, A; ELIAS, P. E. Saúde no Brasil: políticas e organização de serviços. São Paulo, Cortez Editora, 1996a. 
COHN, A. Saúde e cidadania: análise de uma experiência de gestão local In: EIBENSCHUTZ, C. (org.). Política de Saúde: o público e privado. Rio de Janeiro, FIOCRUZ, 1996b, p. 315-328.

COHN, A. \& ELIAS, P.M.(coord.) O processo de implantação do PAS: universalidade ou seletividade no acesso à saúde? Terceira etapa. São Paulo, CEDEC, 1997. 76p.

CONSELHO REGIONAL PSICOLOGIA. Trancar não é tratar, a liberdade é o melhor remédio: coletânea de relatórios, declarações e projetos de lei sobre a luta antimanicomial. São Paulo, 1997.

COORDENADORIA DE SAÚDE MENTAL. Proposta de trabalho para equipes multiprofissionais em unidades básicas de saúde e em ambulatórios de saúde mental.

Divisão de ambulatórios de Saúde Mental. Secretaria de Estado da Saúde, São Paulo, 1983.

COORDENADORIA PARA INTEGRAÇÃO DA PESSOA PORTADORA DE DEFICIÊNCIA - CORDE. $1^{\circ}$ Plano de Ação. Brasília , s.d. [mimeografado])

DAGNINO, E. Os movimentos sociais, e a emergência de uma nova cidadania. In: Anos 90: Política e sociedade no Brasil. São Paulo, Brasiliense, 1994, p.103-115.

DALLARI, S. et. al. Saúde Mental no nível local: rumo à cidadania. In: LANCETTI, A. (org.). Saúde Mental e cidadania no contexto dos sistemas locais de saúde. Saúdeloucura (Textos) 7. São Paulo - Salvador, Hucitec Cooperação Italiana em Saúde, 1992, p. 27-64.

DELGADO, P.G.G. Perspectivas da psiquiatria pós-asilar no Brasil (com apêndice sobre a questão dos cronificados) In: TUNDIS, S. A.(org). Cidadania e loucura - políticas de saúde mental no Brasil, Petrópolis, ABRASCO-Vozes, 1987. p.171-202.

DIMITROV, P. Em defesa da vida In: BITTAR, J.(org.) O modo petista de governar. São Paulo, PT, 1992 p. 139-153.

DRAIBE,S. \& HENRIQUE, W. "Welfare State", crise e gestão da crise: um balanço da literatura internacional. Revista brasileira de Ciências Sociais 3(6): 53-78, 1988

ESCOREL, S. Exclusão social - fenômeno totalitário na democracia brasileira. Saúde e Sociedade. Faculdade de Saúde Pública da USP, 2(1): 41-58,1993.

ESPING-ANDERSEN, G. O futuro do Welfare State na nova ordem mundial Revista Lua Nova. 35: 72-111, 1995. 
FARIA, M. M.; JATENE A. (org.). Movimentos populares e o surgimento do SUS no Estado de São Paulo. In: Saúde e Movimentos Sociais: o SUS no contexto da revisão constitucional de 1993. São Paulo, EDUSP, 1995. p. 19-26.

FARIA, M. M.; JATENE A. (org.). Tendências atuais dos movimentos sociais em relação ao SUS. In: Saúde e Movimentos Sociais: o SUS no contexto da revisão constitucional de 1993. São Paulo, EDUSP, 1995. p. 191-206.

FAVERET FILHO, P. \& OLIVEIRA, P.J. reflexões sobre as tendências do sistema de saúde. DADOS - Revista de Ciências Sociais Rio de Janeiro 33(2): 257-283, 1990

FLEURY, S. Em busca de uma teoria do welfare state. In: Estado sem cidadãos: seguridade social na América Latina. Rio de Janeiro, FIOCRUZ, 1994 p.101-127.

FLEURY, S. Paradigmas da reforma da seguridade social: liberal produtivista versus universal publicista In: EIBENSCHUTZ, C. (org.). Política de Saúde: o público e privado. Rio de janeiro, FIOCRUZ, 1996 p. 69-92.

FUNDAÇÃO SEADE. Anuário Estatístico do Estado de São Paulo. Fundação Sistema Estadual de Análise de Dados - SEADE. São Paulo, 1989, p. 91, 93, 95.

FUNDAÇÃO SEADE. Anuário Estatístico do Estado de São Paulo. Fundação Sistema Estadual de Análise de Dados - SEADE. São Paulo, 1990, p. 95, 98-99, 102-103, 105-108, 110-111, 296-297.

FUNDAÇÃO SEADE. Anuário Estatístico do Estado de São Paulo. Fundação Sistema Estadual de Análise de Dados - SEADE. São Paulo, 1991, p. 167, 172-174, 180-183, 186-187, 197-201.

FUNDAÇÃO SEADE. Anuário Estatístico do Estado de São Paulo. Fundação Sistema Estadual de Análise de Dados - SEADE. São Paulo, 1992, p. 253-255, 262-265, 272-275, 282-285, 300-301, 350.

FUNDAÇÃO SEADE. Anuário Estatístico do Estado de São Paulo. Fundação Sistema Estadual de Análise de Dados - SEADE. São Paulo, 1993, p. 101-104, 170-232.

FUNDAÇÃO SEADE. Anuário Estatístico do Estado de São Paulo. 1995. [on line] www.seade.gov.br/cgi obtido em 12/11/97.

FUNDAÇÃO SEADE. Município de São Paulo 1996. [on line] www.seade.gov.br/cgi obtido em $12 / 11 / 97$. 
FUNDO SOCIAL DE SOLIDARIEDADE DO ESTADO DE SÃO PAULO. Atenção às pessoas Portadoras De Deficiência E Ações De Prevenção Situação no Estado de São Paulo. Pesquisa sobre recursos nos municípios. São Paulo, 1993, 140 p.

FUNDO SOCIAL DE SOLIDARIEDADE DO ESTADO DE SÃO PAULO. Direitos das pessoas portadoras de deficiência. São Paulo, 1996.

FUNDO SOCIAL DE SOLIDARIEDADE DO ESTADO DE SÃO PAULO. Programa Estadual de Atenção à Pessoa Portadora de Deficiência. São Paulo, 1991.

GALLO, E.et al Gestão inovadora e cultura organizacional: ferramentas para a qualidade nos serviços públicos de saúde IN: COSTA, N. R. \& RIBEIRO, J.M.(org.) Política de saúde e inovação institucional - uma agenda para os anos 90. Rio de Janeiro, ENSP, 1996. p. 127-144.

GHIRARDI, M.I.G. O convívio com o portador de Síndrome de Down: um estudo exploratório a partir do relato de mães. São Paulo. Dissertação (mestrado) Instituto de Psicologia da Universidade de São Paulo. 1993

JACOBI, P. Movimentos sociais e políticas públicas: demandas por saneamento básico e saúde, São Paulo, 1974-1984. São Paulo, Cortez, 1989.

KALIL, M.E. X. Saúde mental e cidadania no contexto dos sistemas locais de saúde. Anais de um encontro. Santos, SP, 18 a 21 de junho de 1991, Centro de Documentação para Sistemas Locais de Saúde/ Cooperação Italiana, São Paulo - Salvador, HUCITEC Cooperação Italiana em Saúde, 1992

LAURELL, A. C. Avançando em direção ao passado: a política social do neoliberalismo. In: . Estado e políticas sociais no Neoliberismo. São Paulo, Cortez, 1995, p.151-178.

LAURENTI, R. et al Estatísticas de saúde. 2ed. São Paulo, EPU, 1987.

LUZ, M. T. A história de uma marginalização: a política oficial de saúde mental ontem, hoje, alternativas e possibilidades. In: AMARANTE, P. (org.). Psiquiatria social e reforma psiquiátrica. Rio de Janeiro, FIOCRUZ, 1994 p.85-96.

LUZ, M. T. Notas sobre as políticas de saúde no Brasil de transição democrática, anos 80. Physis (1); 77-97, 1991.

MAFFESOLI, M. O debate comunitário. In: A contemplação do mundo. Porta Alegre, 1995. p.11-14. 
MÂNGIA, E. T. Terapia Ocupacional: da política à contra-política asilar. Relatório de Pesquisa. Curso de Terapia Ocupacional, FMUSP, 1990.

MARSIGLIA, R. Funcionários Públicos, Estado e saúde no Brasil. Saúde e Sociedade. Faculdade de Saúde Pública da USP 2(1): 93-118, 1993.

MARSIGLIA, R. G. et al Saúde mental e cidadania. São Paulo, Mandacaru - Plenário de Trabalhadores em Saúde Mental do Estado de São Paulo, 1987.

MARSIGLIA, R. G. Servidor, funcionário, trabalhador: interesses e culturas organizacionais no setor público.. 1993. Vol. I. 411p. Tese (doutorado) - Faculdade de Filosofia Ciências e Letras da Universidade de São Paulo.

MELLO JORGE, M.H. P.; GAWRYSZEWSKI,V.P.; LATORRE, M.R. Análise dos dados de mortalidade. Rev. Saúde Pública, 31(4 suplemento):5-25, 1997.

MENDES, E. V (org.). Distrito Sanitário: o processo de mudança das práticas sanitárias do Sistema Único de Saúde. São Paulo, HECITEC-ABRASCO, 1993.

MENDES, E. V. Uma agenda para a saúde. São Paulo, HUCITEC, 1996, 300 p.

MERHY, E. E. A rede básica como uma construção da saúde pública e seus dilemas. In: (org.) Agir em saúde: um desafio para o público. São Paulo, HUCITEC, 1997a, p. 197-228.

MERHY, E. E. Em busca da qualidade dos serviços de saúde: os serviços de porta aberta para a saúde e o modelo tecno-assistencial em defesa da vida (ou como aproveitar os ruídos do cotidiano dos serviços de saúde e colegiadamente reorganizar o processo de trabalho na busca da qualidade das ações de saúde. In: CECILIO, L. C. O. (org.). Inventando a mudança na saúde. $2^{\mathrm{a}}$ ed. São Paulo, HUCITEC, 1997b, p. 117-160.

MINAYO, M. C. S.(org.) Os muitos brasis: saúde e população na década de 80. São Paulo - Rio de Janeiro, HUCITEC-ABRASCO, 1992. 338p.

MINAYO, M. C. S. O desafio do conhecimento: pesquisa qualitativa em saúde, São Paulo - Rio de Janeiro, HUCITEC-ABRASCO, 1992.

MINISTÉRIO DA JUSTIÇA. Os direitos das pessoas portadoras de deficiência. Secretaria dos Direitos da Cidadania Coordenadoria Nacional para integração da pessoa portador de deficiência. Brasília, 1996.

MINISTÉRIO DA SAÚDE. A atenção à pessoa portadora de deficiência no Sistema Único de Saúde: planejamento e organização de serviços. Coordenação de Atenção a Grupos 
Especiais. Programa de Atenção à Saúde da Pessoa portadora de Deficiência. Brasília, 1993 48p.

MINISTÉRIO DA SAÚDE. Relatório final da 2a. Conferência Nacional de Saúde Mental.

Secretaria de Assistência à Saúde. Departamento de Assistência e Promoção à Saúde. Coordenação de Saúde Mental. Brasília, 1994. 63p.

MISÈS, R. A criança deficiente mental. Rio de Janeiro. Zahar, 1977, p.41.

MORTARI, L. M.; PAULA, P. A. G. de. A defesa dos interesses da pessoa portadora de deficiência. In: ADOVOCACIA \& SOCIEDADE. Direitos da pessoa portadora de deficiência. São Paulo, Instituto Brasileiro de Advocacia Pública, 1997.

NALLIN, A. A reabilitação em instituição: suas razões e procedimentos. Análise de Representação no Discurso. 1992, 282p. Dissertação (mestrado) Instituto de Psicologia da Universidade de São Paulo.

OLIVEIRA, J.A. \& TEIXEIRA, S.M.F. (Im)previdência social: 60 anos de história da Previdência no Brasil. Petrópolis, ABRASCO-Vozes, 1989.

OLIVER, F.C. A atenção à saúde da pessoa portadora de deficiência no sistema de saúde no município de São Paulo: uma questão de cidadania. São Paulo. Dissertação (mestrado). Faculdade de Saúde Pública da USP, 1990.

OLIVER, F.C. Contribuições para o estudo da população institucionalizada nas Casas André Luiz: o problema do diagnóstico. Relatório de pesquisa, São Paulo, 1993. (mimeografado).

ORGANIZAÇÃO DAS NAÇÕES UNIDAS. Programa de Ação Mundial para as pessoas com deficiência. Documentos Oficiais da Assembléia Geral, $37^{\circ}$ período; suplemento 51. Traduzido do Espanhol pelo CEDIPOD - Centro de Documentação e Informação do Portador de Deficiência, São Paulo, 1992.

ORGANIZAÇÃO PANAMERICANA DA SAÚDE. Reestruturação da Assistência Psiquiátrica: bases conceituais e caminhos para sua implementação. Conferência Regional 11 a 14 de novembro de 1990. Caracas. Publicado por Programa Prevenção de Saúde Brasília, 1992, 126 p.

ORGANIZAÇÃO MUNDIAL DA SAÚDE. Classificação Internacional das Deficiências, Incapacidades e Desvantagens (Handicaps). Um manual de classificação das 
consequências das doenças. Trad. Secretariado Nacional de Reabilitação. Ministério do Emprego e da Segurança Social. Lisboa, 1989, 204p.

ORGANIZACIÓN MUNDIAL DE LA SALUD. Comité de Expertos en Prevención de Incapacidads y Rehabilitación, Ginebra, 1981. Informe. Genebra. 1981, p. 7-18 (Série de Informes Técnicos, 668).

PEDERSEN, P. El dilema de lo cuantitativo y lo cualitativo: de as encuestas a los métodos rápidos de investigación en salud. Conferencia Internacional sobre metodologías de Evaluación Rápida en Salud, Washington. D.C. 12-15/11/90. (mimeografado).

PITTA, A. M. \& DALLARI, S.G. A cidadania dos doentes mentais no sistema de saúde no Brasil. Saúde em Debate, 36 : 19-23, 1992

POSSAS, C. A articulação entre público-privado e o cuidado com a saúde dos pobres: implicações das políticas de ajuste estrutural na América Latina In: EIBENSCHUTZ, C. (org.). Política de Saúde: o público e privado. Rio de janeiro, FIOCRUZ, 1996 p. 49-68.

POSSAS, C. Epidemiologia e sociedade: heterogeneidade estrutural e saúde no Brasil. São Paulo, HUCITEC, 1989. 271p.

RAMOS, C.R.S.\& AVELINO, E.L. \& ASHERMAN, L. \& COSTA, M. J. T.O. \& SILVA, Z.P. O Plano de Atendimento à Saúde do município de São Paulo - análise crítica. Departamento de Prática de Saúde Pública. Faculdade de Saúde Pública da USP. São Paulo. Série monográfica n.1, 1996. 46p.

RAMOS, C.L. Conselhos de saúde e controle social. In: EIBENSCHUTZ, C. (org.). Política de Saúde: o público e privado. Rio de Janeiro, FIOCRUZ, 1996. p. 329-344.

REZENDE, H. Política de saúde mental no Brasil: uma visão histórica. In: TUNDIS, S.A. Cidadania e loucura: políticas de saúde mental no Brasil. Petrópolis, ABRASCO-Vozes, 1987. p.15-74.

ROCHA, E. F. Corpo Deficiente: em busca de reabilitação? Uma reflexão a partir da ética das pessoas portadoras de deficiências físicas. 1990, 310p. Dissertação (mestrado) Instituto de Psicologia da Universidade de São Paulo.

ROCHA, J. S. Y. Sistema Único de Saúde: avaliação e perspectivas. Saúde e Sociedade. Faculdade de Saúde Pública da USP, 3(1): 3-10, 1994. 
ROTELLI, F. Superando o manicômio - o circuito psiquiátrico de Trieste. In AMARANTE, P. (org.). Psiquiatria social e reforma psiquiátrica. Rio de Janeiro, FIOCRUZ, 1994 p. $149-170$

ROUQUAYROL, M.Z. e col Epidemiologia \& saúde. 4ed. Rio de Janeiro, MEDSI, 1993

SÁ, E.N.C. Êxodo forçado de servidores da Secretaria Municipal de Saúde em decorrência da implantação do PAS - Plano de Atendimento à Saúde. Departamento de Prática de Saúde Pública. Faculdade de Saúde Pública da USP. São Paulo. Série monográfica n. 6, 1997. $38 \mathrm{p}$.

SANJUAN, A. B. \& SOUZA, A. L. Aspectos etiológico da deficiência mental e caracterização das famílias dos deficientes. J. Bras. Psiq., 35 (2): 123-128, 1986.

SARACENO, B. et al Manual de saúde mental. São Paulo, HUCITEC, 1994. 83p.

SECRETARIA DE ESTADO DA SAÚDE. Documento básico sobre sistema de atendimento à saúde e reabilitação da pessoa com deficiência. São Paulo, 1985. (mimeografado)

SECRETARIA DE ESTADO DA SAÚDE. Grupo Especial de Programas de Saúde do Deficiente. Sistema de atendimento à saúde e reabilitação da pessoa com deficiência. São Paulo, 1988. (mimeografado).

SECRETARIA MUNICIPAL DE SAÚDE. Assessoria de saúde mental Para compreender a atual política de saúde mental do governo democrático e popular da cidade de São Paulo. São Paulo, 1989.

SECRETARIA MUNICIPAL DE SAÚDE. Assessoria de saúde mental. Avanços e concretização da política municipal de saúde mental do governo democrático e popular da cidade de São Paulo Janeiro/89 à agosto/90. São Paulo, 1990.

SECRETARIA MUNICIPAL DE SAÚDE. Grupo de Trabalho de Atenção à Saúde da Pessoa Deficiente. Proposta de atenção à saúde da pessoa deficiente. Centro de Organização da Atenção à Saúde. São Paulo, 1992a.

SECRETARIA MUNICIPAL DE SAÚDE. Programa de Saúde Mental. Normatização das ações desenvolvidas nos serviços de saúde mental., São Paulo,1992b.

SECRETARIA MUNICIPAL DE SAÚDE. Distrito de Saúde de Ermelino Matarazzo ARS-6. São Paulo, 1992c. 98p. 
SECRETARIA MUNICIPAL DE SAÚDE. Programa de atenção à Pessoa Portadora de Deficiência . COAS, São Paulo, 1993. 4p.

SECRETARIA MUNICIPAL DE SAÚDE. PRO-AIM Programa de Aprimoramento das informações de mortalidade do município. São Paulo, 1994. 14p.

SECRETARIA MUNICIPAL DE SAÚDE. Relatório anual de produção dos serviços- ARS-6 de 1990-95, NEPI-ARS-6, São Paulo, 1996a .300p.

SILVA, S. F. A assistência à saúde na área básica: problemas e soluções. In: A construção do SUS a partir do município: etapas para municipalização plena da saúde. São Paulo, HUCITEC, 1996. p.50-61.

SILVA, W. L.R. Seguridade Social e a pessoa portadora de deficiência. In: ADVOCACIA \& SOCIEDADE. Direitos da pessoa portadora de deficiência. São Paulo, Instituto Brasileiro de Advocacia Pública, 1997.

SILVA JUNIOR, A. G. Modelos assistenciais em saúde: o debate no campo da saúde coletiva. Rio de Janeiro, 1996. Tese (doutorado) Escola Nacional de Saúde Pública FIOCRUZ. 151p.

SOARES, C. B. J. Terapia Ocupacional: lógica do capital ou do trabalho? São Carlos, 1987. Dissertação (mestrado) Universidade Federal de São Carlos.

SOUZA, S. S. Diversidade. In: ADVOCACIA \& SOCIEDADE. Direitos da pessoa portadora de deficiência. São Paulo, Instituto Brasileiro de Advocacia Pública, 1997.

SPOSATI, A. (coord.). Mapa da exclusão / inclusão social da cidade de São Paulo. São Paulo, EDUC, 1996a.

SPOSATI, A. (coord.) Que cidade é esta? Mapa da exclusão / inclusão social da cidade de São Paulo - Região Leste 2. São Paulo, EDUC, 1996b 33p.

STENZEL, A. C. B. A temática da avaliação no campo da saúde coletiva: uma bibliografia comentada. Campinas. 1996. Dissertação (mestrado) Faculdade de Ciências Médicas Universidade Estadual de Campinas 251p.

TELES, V. S. Sociedade civil e a construção de espaços públicos. In: DAGNINO, E. (org.). Anos 90: política e sociedade no Brasil. São Paulo, Brasiliense, 1994. p.91-102.

TESTA, M. Pensar em saúde. Porto Alegre, Artes Médicas, 1992. 226p.

TESSER, C.D. A clínica, a epidemiologia e os outros saberes em saúde: pensando os modelos assistenciais. Saúde em Debate, 45: 38-42, 1994 
THOMPSON, F. J. Health policy and the bureaucracy: politics and implementation. Cambridge, MIT Press, 1981.

VALLA, V. V. Participação popular e saúde: A questão da capacitação técnica no Brasil. In: STOTZ, E. N.; VALLA, V. V. (org.). Participação popular, educação e saúde: teoria e prática. Rio de Janeiro, Relume-Dumará, 1993. p. 55-86.

VERMELHO, L.L.; MELLO JORGE, M.H.P. Mortalidade de jovens: análise do período de 1930 a 1991 (a transição epidemiológica para a violência) Rev. Saúde Pública, 30 (4): 319-31, 1996. 
ANEXO I

ENTREVISTAS 


\section{ROTEIRO 1}

\section{Gestores Centrais}

Secretário de Saúde Municipal; Assessor de Saúde Mental; Assessor de Saúde da Pessoa Portadora de Deficiência

1. Como avalia a situação anterior do município na sua área? Qual o quadro específico na assistência à saúde mental e à saúde da pessoa portadora de deficiência?

2. Quais as correspondentes propostas que sua gestão pretendeu implementar?

3. De que forma essas propostas foram construídas?

4. Quais as razões da opção por essas propostas?

5. Quais as dificuldades antevistas?

6. Quais as estratégias pensadas para implementação daquelas propostas?

7. Na sua área de recursos humanos e, particularmente, no que se refere aos terapeutas ocupacionais, quais razões levaram à decisão de sua incorporação nas equipes de saúde dos serviços municipais? Qual o perfil exigido desses profissionais? Quais as propostas para sua capacitação e reciclagem?

8. Como foi, na prática, a dinâmica da implementação das propostas de sua gestão?

9. Quais as limitações concretas enfrentadas, em termos de recursos materiais (estrutura física, equipamento, manutenção, etc.) e de recursos humanos (existência de vagas, verbas para contratação, formação adequada doa profissionais, etc.)? Qual sua avaliação sobre o impacto do trabalho dos terapeutas ocupacionais no contexto da assistência?

10. Na sua opinião, o que foi o fato implementado?

11. Que expectativa se tinha sobre a permanência das propostas implementadas?

12. Qual sua avaliação atual sobre essa permanência? 


\section{ROTEIRO 2}

\section{Gestores regionais e distritais}

Administrador da ARS; Coordenador do programa de atenção à Saúde Mental na ARS; Coordenador do programa de atenção à Saúde da Pessoa com Deficiência na ARS; Coordenadores dos programas nos Distritos.

As perguntas abaixo devem ser respondidos tendo com referência a região e distritos municipais respectivos.

1. Como se avalia a situação d município e o quadro específico na assistência à saúde mental e à saúde da pessoa portadora de deficiência?

2. Quais as correspondentes propostas que sua gestão pretendeu implementar?

3. De que forma essas propostas foram construídas?

4. Quais as razões da opção por essas propostas?

5. Quais as dificuldades antevistas?

6. Quais as estratégias pensadas para implementação daquelas propostas?

7. Na área de recursos humanos e, particularmente no que se refere aos terapeutas ocupacionais, quais razões levaram à decisão de sua incorporação nas equipes de saúde dos serviços municipais?

8. Como foi, na prática, a dinâmica da implementação das propostas de sua gestão?

9. Quais as limitações concretas enfrentadas, em termos de recursos materiais (estrutura física, equipamento, manutenção, etc.) e de recursos humanos (existência de vagas, verbas para contratação, formação adequada doa profissionais, etc.)? Qual sua avaliação sobre o impacto do trabalho dos terapeutas ocupacionais no contexto da assistência?

10. Na sua opinião, o que foi o fato implementado?

11. Que expectativa se tinha sobre a permanência das propostas implementadas?

12. Qual sua avaliação atual sobre essa permanência? 


\section{ROTEIRO 3}

\section{Gestores locais:}

Responsáveis pelos serviços de saúde

1. Como avalia a situação anterior do município e o quadro específico na assistência à saúde mental e/ou à saúde da pessoa portadora de deficiência no serviço de saúde sob direção?

2. Como foram recebidas, no seu serviço, as propostas de mudanças da nova gestão?

3. Qual a sua avaliação do grau de correspondência entre as propostas formuladas e as demandas de serviço?

4. Houve participação do serviço na formulação das propostas?

5. Quais as dificuldades percebidas pelo serviço para implementação das propostas?

6. Quais as estratégias pensadas para implementação daquelas propostas?

7. Na área de recursos humanos e, particularmente no que se refere aos terapeutas ocupacionais, quais razões levaram à decisão de sua incorporação nas equipes de saúde dos serviços municipais?

8. Como foi, na prática, a dinâmica da implementação das propostas de sua gestão?

9. Quais as limitações concretas enfrentadas, em termos de recursos materiais (estrutura física, equipamento, manutenção, etc.) e de recursos humanos (existência de vagas, verbas para contratação, formação adequada doa profissionais, etc.)? Qual sua avaliação sobre o impacto do trabalho dos terapeutas ocupacionais no contexto da assistência?

10. Na sua opinião, o que foi o fato implementado?

11. Que expectativa se tinha sobre a permanência das propostas implementadas?

12. Qual sua avaliação atual sobre essa permanência? 


\section{ROTEIRO 4}

\section{Técnicos}

Os componentes das equipes dos serviços de saúde municipais variavam conforme o equipamento. De maneira geral compreendiam: médicos, psicólogos, assistentes sociais, fisioterapeutas, fonoaudiólogos, enfermeiros, terapeutas ocupacionais, nutricionistas, educadores em saúde pública, auxiliares de enfermagem, auxiliares de farmácia, auxiliares administrativos, serventes e vigias.

1. Porque você decidiu trabalhar na prefeitura?

2. O que mudou concretamente no dia-a-dia do trabalho durante a gestão $89 / 92$ ?

3. O que você acho que essa gestão, através de suas propostas, pretendeu implementar na assistência à saúde mental e/ou à saúde da pessoa portadora de deficiência? Quais os principais pontos positivos e/ou negativos percebidos na propostas?

4. Como você viu o processo de construção e implementação das propostas?

5. Como você descreve seu trabalho com a população?

6. Quais eram as condições objetivas, tais como existência (ou não) de espaço físico apropriado, equipamentos, materiais e recursos humanos e de que forma isso influenciava seu trabalho?

7. Você considera que sua formação profissional era adequada à realização do trabalho proposto?

8. Qual sua avaliação da contribuição do (categoria profissional) para implementação das propostas?

9. Qual sua avaliação da contribuição do terapeuta ocupacional para implementação das propostas?

10. O que você acha que foi de fato implementado de novo?

11. O que você acha que permaneceu na atual gestão?

12. Porque continua trabalhando na prefeitura? [ou porque resolveu deixar o trabalho na prefeitura?] 


\section{ROTEIRO 5}

\section{Organizações / movimentos da sociedade civil na área da saúde em geral e da saúde mental e saúde da pessoa com deficiência em particular}

1. Qual a trajetória de sua organização / movimento na região?

2. Quais as principais reivindicações de sua organização / movimento?

3. Qual a avaliação de sua organização / movimento sobre os serviço da saúde da prefeitura antes da gestão Erundina?

4. Como foram vistas as propostas da gestão Erundina para assistência à saúde mental e/ou à saúde da pessoa portadora de deficiência?

5. Sua organização de sua organização / movimento participou da elaboração e implementação das propostas?

6. Qual a avaliação de sua organização / movimento sobre o que foi realmente implementação na gestão Erundina?

7. Que importância á atribuída à incorporação de terapeutas ocupacionais às equipes de atendimentos da prefeitura?

8. Qual a avaliação de sua organização / movimento sobre a situação atual? 


\section{Lista de Profissionais Entrevistados}

1. Entrevista ${ }^{\circ} 1$, Secretário Municipal da Saúde à Nível Central, 13/06/96, 22p.

2. Entrevista n², Secretário Municipal da Saúde à Nível Central, 26/09/96, 23p.

3. Entrevista n³, Assessor à Nível Central, 13/07 e 17/07/96, 111p.

4. Entrevista ${ }^{\circ} 4$, Assessor à Nível Central, 10/95.

5. Entrevista n5, Assessor à Nível Central, 23/05/96, 34p.

6. Entrevista nº ${ }^{\circ}$, Assessor à Nível Central, 10/95 e 28/03/96. 14p.

7. Entrevista nº 7 , Diretor à Nível Regional, 06/05/96, 41p.

8. Entrevista n ${ }^{\circ}$, Diretor à Nível Regional, 10/95.

9. Entrevista n 9, Diretor à Nível Regional, 10/95 e 28/03/96.

10. Entrevista ${ }^{\circ} 10$, Interlocutor à Nível Regional, 20/06/96, 48p.

11. Entrevista nº 11, Interlocutor à Nível Regional, 10/04/96, 28p.

12. Entrevista ${ }^{\circ} 12$, Interlocutor à Nível Regional, 25/04/96, 55p.

13. Entrevista n 13 , Interlocutor à Nível Regional, 10/95.

14. Entrevista ${ }^{\circ} 14$, Diretor do Distrito Ermelino Matarazzo, 04/06/96. 25p.

15. Entrevista ${ }^{\circ} 15$, Diretor do Distrito Ermelino Matarazzo, 03/09/96, 24p.

16. Entrevista ${ }^{\circ} 16$, Diretor do Distrito São Miguel Paulista, 20/08/96.

17. Entrevista ${ }^{\circ} 17$, Diretor do Distrito de Itaim Paulista, 08/05/96, 17p.

18. Entrevista ${ }^{\circ} 18$, Diretor do Distrito de Itaim Paulista, 20/08/96, 27p.

19. Entrevista $\mathrm{n}^{\circ} 19$, Interlocutor do Distrito de Ermelino Matarazzo, 16/05/96, 48p.

20. Entrevista ${ }^{\circ}$ 20, Interlocutor do Distrito Ermelino Matarazzo, 15/05/96.

21. Entrevista ${ }^{\circ} 21$, Hospital Municipal "Dr. Alípio Corrêa Neto" do Distrito de Ermelino Matarazzo, 20/08/96, 31p.

22. Entrevista $\mathrm{n}^{\circ} 22$, Hospital Municipal “Dr. Alípio Corrêa Neto” do Distrito de Ermelino Matarazzo, 23/05/96, 27p.

23. Entrevista n²3, Hospital Municipal "Dr. Alípio Corrêa Neto" do Distrito de Ermelino Matarazzo, 04/96, 23p. 
24. Entrevista ${ }^{\circ}$ 24, Hospital Municipal "Dr. Alípio Corrêa Neto" do Distrito de Ermelino Matarazzo, 04/96, 23p.

25. Entrevista $\mathrm{n}^{\circ} 25$, Chefia da Unidade de Reabilitação do Distrito de Ermelino Matarazzo, 23/05/96, 31p.

26. Entrevista ${ }^{\circ} 26$, Unidade de Reabilitação do Distrito de Ermelino Matarazzo, 23/05/96, 31p.

27. Entrevista ${ }^{\circ} 27$, Unidade de Reabilitação do Distrito de Ermelino Matarazzo, 22/05/96, 23p.

28. Entrevista ${ }^{\circ} 28$, Chefia no HD do Distrito de Ermelino Matarazzo, 09/07/96, 24p.

29. Entrevista n²9, Chefia no HD do Distrito de Ermelino Matarazzo, 29/04/96, 15p.

30. Entrevista n³0, HD do Distrito de Ermelino Matarazzo, 17 e 24/04/96, 10p.

31. Entrevista n$^{\circ} 31$, HD do Distrito de Ermelino Matarazzo, 17 e 24/04/96, 10p.

32. Entrevista n³2, HD do Distrito de Ermelino Matarazzo, 06/05/96, 22p.

33. Entrevista ${ }^{\circ} 33$, Chefia no CECCO do Distrito de Ermelino Matarazzo, 16/05/96, 27p.

34. Entrevista $\mathrm{n}^{\circ} 34$, Chefia na UBS Pedro de Souza Campos do Distrito de Ermelino Matarazzo, 18/06/96.

35. Entrevista $\mathrm{n}^{\circ} 35$, UBS Pedro de Souza Campos do Distrito de Ermelino Matarazzo, 23/04 e 16/05/96, p.

36. Entrevista ${ }^{\circ} 36$, UBS Pedro de Souza Campos do Distrito de Ermelino Matarazzo, 11/06/96.

37. Entrevista n³7, UBS Pedro de Souza Campos de Ermelino Matarazzo, 24/06/96, 18p.

38. Entrevista ${ }^{\circ}{ }^{\circ} 38$, UBS Pedro de Souza Campos do Distrito de Ermelino Matarazzo, 18/06/96, $20 \mathrm{p}$.

39. Entrevista ${ }^{\circ} 39$, UBS Vila Cisper do Distrito de Ermelino Matarazzo, 24/04/96, 12p.

40. Entrevista ${ }^{\circ} 40$, UBS Vila Cisper do Distrito de Ermelino Matarazzo, 23/04/96, 10p.

41. Entrevista ${ }^{\circ} 41$, Chefia UBS Dr. Carlos Olivaldo Muniz do Distrito de Ermelino Matarazzo, 03/09/96, 30p.

42. Entrevista ${ }^{\circ} 42$, UBS Dr. Carlos Olivaldo Muniz do Distrito de Ermelino Matarazzo, 29/05/96, 15p.

43. Entrevista $\mathrm{n}^{\circ} 43$, UBS Dr. Carlos Olivaldo Muniz do Distrito de Ermelino Matarazzo, 07/05/96, 15p.

44. Entrevista $\mathrm{n}^{\circ} 44$, UBS Dr. Carlos Olivaldo Muniz do Distrito de Ermelino Matarazzo, 29/05/96.

45. Entrevista n 45, Interlocutor do Distrito de São Miguel, 12/04/96. 
46. Entrevista n46, Interlocutor do Distrito de São Miguel, 10/04/96, 18p.

47. Entrevista ${ }^{\circ}$ 47, Interlocutor do Distrito de São Miguel, 23/05/96, 10p.

48. Entrevista n 48, Hospital “Tide Setúbal” do Distrito de São Miguel, 03/05/96. 39p.

49. Entrevista n49, Hospital “Tide Setúbal” do Distrito de São Miguel, 03/05/96, 39p.

50. Entrevista n50, Chefia HD do Distrito de São Miguel, 17/04/96, 24p.

51. Entrevista n51, HD do Distrito de São Miguel, 17/04/96, 39p.

52. Entrevista n52, HD do Distrito de São Miguel, 09/07/96, 16p.

53. Entrevista n ${ }^{\circ 53}$, HD do Distrito de São Miguel, 17/04/96, 19p.

54. Entrevista n ${ }^{\circ}$ 4, CECCO Parque Chico Mendes do Distrito de São Miguel, 24/04/96, 25p.

55. Entrevista n55, Chefia no UBS Jardim Helena do Distrito de São Miguel, 02/07/96, 12p.

56. Entrevista n56, UBS Jardim Helena do Distrito de São Miguel, 22/05/96, 9p.

57. Entrevista n57, UBS Jardim Maia do Distrito de São Miguel, 28/08/96, 17p.

58. Entrevista n58, UBS Vila Jacuí do Distrito de São Miguel, 15/05/96, p.

59. Entrevista n59, UBS Vila Jacuí do Distrito de São Miguel, 15/05/96, p.

60. Entrevista ${ }^{\circ} 60$, UBS Vila Jacuí do Distrito de São Miguel, 15/05/96, p.

61. Entrevista n61, UBS Vila Nova Curuçá do Distrito de São Miguel, 30/04/96, 22p.

62. Entrevista n62, Ambulatório Municipal “Tito Lopes”, 10/95.

63. Entrevista ${ }^{\circ}$ 63, Interlocutora do Distrito de Itaim Paulista, 22/05/96, 19p.

64. Entrevista n64, Interlocutor do Distrito de Itaim Paulista, 07/05/96, 20p.

65. Entrevista $n^{\circ} 65$, Chefia no CECCO Parque Santa Amélia do Distrito de Itaim Paulista, 02/05/96, 25p.

66. Entrevista n66, CECCO Parque Santa Amélia do Distrito de Itaim Paulista, 10/04/96, 22p.

67. Entrevista ${ }^{\circ} 67$, UBS Atualpa Girão Rabelo do Distrito de Itaim Paulista, 08/05/96, 45p.

68. Entrevista ${ }^{\circ} 68$, Chefia na UBS Jardim Camargo Novo do Distrito de Itaim Paulista, 18/09/96, 20p.

69. Entrevista ${ }^{\circ}{ }^{69}$, Defensor da Saúde Pública, Movimento Popular, do Distrito de Ermelino Matarazzo, 22/05/96, 21p. 
70. Entrevista ${ }^{\circ} 70$, Defensor da Saúde Pública, Movimento Popular, do Distrito de Ermelino Matarazzo, 23/05/96, 5p.

71. Entrevista $\mathrm{n}^{\circ} 71$, Coordenador da ACDEM, Movimento Popular, do Distrito de Ermelino Matarazzo, 23.05.96, 8p.

72. Entrevista ${ }^{\circ} 72$, Defensor da Saúde Pública, Movimento Popular, do Distrito de Ermelino Matarazzo, 29.05.96, 8p.

73. Entrevista nº73, Movimento Popular do Distrito de Ermelino Matarazzo, 30/05/96, 14p.

74. Entrevista n74, Movimento Popular do Distrito de São Miguel, 26/04 e 12/06/96, 24p.

75. Entrevista ${ }^{\circ} 75$, Movimento Popular do Distrito de São Miguel, 12/06/96, 24p.

76. Entrevista nº 76, Movimento Popular do Distrito de São Miguel, 12/06/96, 24p.

77. Entrevista n77, Movimento Popular do Distrito de São Miguel, 12/06/96, 24p.

78. Entrevista ${ }^{\circ} 78$, Conselho Gestor do Distrito de São Miguel, 12/06/96, 24p.

79. Entrevista ${ }^{\circ} 79$, Movimento Popular do Distrito de São Miguel, 12/06/96, 24p.

80. Entrevista n 80 , Movimento Popular do Distrito de São Miguel, 12/06/96, 24p.

81. Entrevista nº 81 , Diretor em Nível Central, 14/08/96, 30p.

82. Entrevista ${ }^{\circ} 82$, Recursos Humanos da Saúde do Distrito de Ermelino Matarazzo, 25/06/96, $34 \mathrm{p}$.

83. Entrevista $n^{\circ} 83$, Curso de formação de recursos humanos em saúde mental no SMS, gestões 89-92 e 93-96, 30/05/96. 


\section{ANEXO I}

TABELA 1. Profissionais de saúde entrevistados ligados à gerência e planejamento, segundo função na Secretaria Municipal de Saúde e categoria profissional, 1989-1996

\begin{tabular}{|c|c|c|c|c|c|c|c|c|c|c|}
\hline \multirow[b]{2}{*}{ UNIDADES } & \multicolumn{5}{|c|}{ 1989-1992 } & \multicolumn{4}{|c|}{$1993-1996$} & \multirow[b]{2}{*}{ TOTAL } \\
\hline & $M E D$. & $\overline{A S}$. & $P S I C O$ & $E N F$ & $T O$. & $M E D$. & $A S$. & $E N F$. & FISIO. & \\
\hline 1. Secretários & 1 & $\begin{array}{l}-- \\
-1\end{array}$ & $\overline{---}$ & & $\overline{---}$ & 1 & $\overline{---}$ & $\overline{---}$ & $\overline{---}$ & 2 \\
\hline \multicolumn{11}{|l|}{ 2. COAS } \\
\hline Saúde Mental & 1 & --- & $\begin{array}{ll}-- \\
--\end{array}$ & & $\begin{array}{ll}-- \\
--\end{array}$ & 1 & $\begin{array}{ll}-- \\
--\end{array}$ & $\overline{---}$ & $\begin{array}{ll}-- \\
--\end{array}$ & 2 \\
\hline Saúde do Deficiente & --- & 1 & --- & & --- & 1 & --- & --- & --- & 2 \\
\hline Recursos Humanos & 1 & --- & --- & & --- & --- & --- & --- & --- & 1 \\
\hline 3. CEFOR & $\begin{array}{ll}-- \\
--\end{array}$ & --- & --- & $1(\mathrm{a})$ & --- & --- & $\begin{array}{ll}-- \\
--\end{array}$ & (a) & $\begin{array}{ll}-- \\
--\end{array}$ & 1 \\
\hline \multicolumn{11}{|l|}{ 4. ARS-6 } \\
\hline Administrador & 1 & --- & --- & & -- & 2 & --- & --- & --- & 3 \\
\hline Assessor S. Mental & -- & --- & 1 & & --- & $1(\mathrm{c})$ & --- & --- & --- & 2 \\
\hline $\begin{array}{l}\text { Assessor S. } \\
\text { Deficiente }\end{array}$ & --- & --- & --- & & 1(b) & -- & 1 & --- & --- & 2 \\
\hline \multicolumn{11}{|l|}{ 5. Distrito Sanitário } \\
\hline \multicolumn{11}{|l|}{ 5.1 Ermelino } \\
\hline Diretor & 1 & --- & --- & & --- & 1 & --- & --- & --- & 2 \\
\hline Assessor SM & --- & --- & --- & & 1 & (c) & --- & --- & --- & 1 \\
\hline Assessor SD & --- & --- & --- & & (b) & -- & 1 & --- & & 1 \\
\hline Assessor & --- & 1 & --- & & -- & --- & --- & --- & --- & 1 \\
\hline \multirow{2}{*}{\multicolumn{11}{|c|}{$\begin{array}{l}\text { R.Humanos } \\
\text { 5.2 São Miguel }\end{array}$}} \\
\hline & & & & & & & & & & \\
\hline Diretor & --- & --- & --- & & --- & 1 & --- & --- & --- & 1 \\
\hline Assessor SM & --- & --- & 1 & & --- & 1 & --- & --- & --- & 2 \\
\hline Assessor SD & --- & --- & --- & & --- & --- & 1 & --- & --- & 1 \\
\hline \multicolumn{11}{|l|}{ 5.3 Itaim } \\
\hline Diretor & $1 \mathrm{DEN}$ & --- & --- & & --- & 1 & --- & --- & --- & 2 \\
\hline Assessor SM & --- & --- & $1(d)$ & & --- & --- & --- & --- & --- & 1 \\
\hline Assessor SD & --- & --- & (d) & & --- & --- & --- & --- & 1 & 1 \\
\hline TOTAL & 6 & 2 & 3 & 1 & 2 & 10 & 3 & --- & 1 & 28 \\
\hline
\end{tabular}

Observações: (...) indicam o mesmo profissional para as duas assessorias.

MED: médico; AS: assistente social; PSICO: psicólogo; TO: terapeuta ocupacional; FISIO: fisioterapeuta,

DEN: dentista; ENF: enfermeiro 


\section{ANEXO I}

TABELA 2. Profissionais de saúde ligados à assistência entrevistados do Distrito Sanitário de Ermelino Matarazzo (EM), segundo unidades assistenciais e categoria profissional, 1989-1996

\begin{tabular}{|c|c|c|c|c|c|c|c|c|c|c|c|c|c|}
\hline \multirow[b]{2}{*}{ DISTRITO EM } & \multicolumn{6}{|c|}{ 1989-1992 } & \multicolumn{6}{|c|}{ 1993-1996 } & \multirow[b]{2}{*}{ TOTAL } \\
\hline & $M E D$ & $\overline{A S}$ & $P S I C O$ & $T O$ & $F O N O$ & FISIO & $M E D$ & $A S$ & $P S I C O$ & $T O$ & FONO & FISIO & \\
\hline $\begin{array}{l}\text { 1. HMDACN } \\
\text { 1.2 Enf. } \\
\text { Psiquiátrica }\end{array}$ & --- & --- & --- & 1 & --- & --- & & --- & --- & 3 & --- & --- & 4 \\
\hline $\begin{array}{l}1.3 \text { Unidade de } \\
\text { Reabilitação }\end{array}$ & --- & --- & --- & --- & --- & 1 & --- & --- & --- & --- & 1 & 1 & 3 \\
\hline 2. HD & --- & --- & 1 & 2(a) & --- & --- & 1 & 1 & --- & (a) & --- & --- & 5 \\
\hline 3. CECCO & --- & 1 & --- & $1(\mathrm{~b})$ & --- & --- & --- & --- & --- & $* *$ & --- & --- & 2 \\
\hline $\begin{array}{l}\text { 4. UBS Pedro } \\
\text { Souza Campos }\end{array}$ & $2(\mathrm{c})$ & --- & --- & $1(\mathrm{~d})$ & $1(\mathrm{e})$ & --- & (c) & --- & --- & (d) & (e) & 1 & 5 \\
\hline 5. UBS V. Císper & --- & --- & --- & --- & --- & --- & 1 & --- & --- & (b) & --- & --- & 1 \\
\hline $\begin{array}{l}\text { 6. UBS Carlos } \\
\text { Muniz }\end{array}$ & --- & 1 & 1(f) & $1(\mathrm{~g})$ & $1(\mathrm{~h})$ & --- & --- & --- & (f) & (g) & (h) & --- & 4 \\
\hline TOTAL & 2 & 2 & 2 & 6 & 2 & 1 & 2 & 1 & --- & 3 & 1 & 2 & 24 \\
\hline
\end{tabular}

Observações: (...) indicam o mesmo profissional que também desenvolveu atividades em outro período e não foi computado duplamente.

* indicam profissional que desenvolveu atividade de assessoria no período anterior.

MED: médico; AS: assistente social; PSICO: psicólogo; TO: terapeuta ocupacional; FONO: fonoaudiólogo; FISIO: fisioterapeuta. 


\section{ANEXO I}

TABELA 3. Profissionais de saúde ligados à assistência entrevistados do Distrito Sanitário de São Miguel (SM), segundo unidade assistencial e categoria profissional, 1989-1996

\begin{tabular}{|c|c|c|c|c|c|c|c|c|c|c|c|}
\hline \multirow[b]{2}{*}{ DISTRITO SM } & \multicolumn{4}{|c|}{ 1989-1992 } & \multicolumn{6}{|c|}{ 1993-1996 } & \multirow[b]{2}{*}{ TOTAL } \\
\hline & $\begin{array}{c}M E \\
D \\
\end{array}$ & PSICO & TO & FONO & $M E D$ & $\overline{A S}$ & PSICO & $T O$ & $\begin{array}{c}F O N \\
O\end{array}$ & FISIO & \\
\hline 1. Hosp. Tide Setúbal & --- & --- & 1(a) & --- & * & --- & --- & $2(a)$ & --- & --- & 2 \\
\hline 2. Amb. T.Lopes & --- & 1(b) & --- & --- & $*$ & --- & (b) & --- & --- & --- & 1 \\
\hline 3. HD & $1(\mathrm{c})$ & --- & --- & --- & (c) & 1 & (d) & (e) & --- & --- & 2 \\
\hline 4. $\mathrm{CECCO}$ & --- & --- & $1(f)$ & --- & --- & --- & --- & (f) & & --- & 1 \\
\hline 5. UBS J.Helena & --- & $1(\mathrm{~g})$ & --- & --- & 1 & --- & (g) & --- & --- & --- & 2 \\
\hline 6. UBS J.Maia & --- & --- & $1(\mathrm{~h})$ & --- & --- & --- & -- & (h) & --- & --- & 1 \\
\hline 7. UBS V.Jacuí & --- & 1(i) & $1(\mathrm{e})$ & $1(\mathrm{j})$ & --- & --- & (i) & --- & (j) & 1 & 4 \\
\hline 8. UBS N.Curuçá & --- & --- & $1(\mathrm{k})$ & --- & --- & --- & --- & (k) & --- & --- & 1 \\
\hline 9. UBS V.Progresso & --- & $1(d)$ & --- & --- & --- & --- & (d) & --- & --- & --- & 1 \\
\hline TOTAL & 1 & 3 & 6 & 1 & 1 & 1 & $\begin{array}{ll}--- \\
\end{array}$ & 1 & $\begin{array}{ll}--- \\
\end{array}$ & 1 & 15 \\
\hline
\end{tabular}

Observações: (...) indicam o mesmo profissional que também desenvolveu atividades em outro período ou local e não foi computado duplamente.

* indicam profissional que desenvolveu atividade de assessoria no período anterior.

MED: médico; PSICO: psicólogo; TO: terapeuta ocupacional; FONO: fonoaudiólogo; AS: assistente social; FISIO: fisioterapeuta. 


\section{ANEXO I}

TABELA 4. Profissionais de saúde ligados à assistência entrevistados do Distrito Sanitário Itaim Paulista, segundo unidade assistencial e categoria profissional, 1989-1996

\begin{tabular}{|c|c|c|c|c|c|c|c|}
\hline \multirow[b]{2}{*}{$\begin{array}{c}\text { DISTRITO } \\
\text { ITAIM }\end{array}$} & \multicolumn{2}{|c|}{ 1989-1992 } & \multicolumn{4}{|c|}{$1993-1996$} & \multirow[b]{2}{*}{ TOTAL } \\
\hline & PSICO. & FISIO. & $E N F$. & DENT. & PSICO. & FISIO. & \\
\hline 1. CECCO & 1 & --- & --- & --- & 1 & --- & 2 \\
\hline 2. UBS Attualpa & $1(\mathrm{a})$ & --- & --- & --- & (a) & --- & 1 \\
\hline $\begin{array}{l}\text { 3. Jd. Camargo } \\
\text { Novo }\end{array}$ & $* *$ & $*$ & 1 & $*$ & --- & $(*)$ & 1 \\
\hline TOTAL & 2 & --- & 1 & --- & 1 & --- & 4 \\
\hline
\end{tabular}

Observações: (...) indicam o mesmo profissional, não foram computados duplamente.

* indicam profissional que desenvolveu atividade de assessoria no período anterior.

PSICO: psicólogo; FISIO: fisioterapeuta; ENF: enfermeira; DENT: dentista. 


\section{ANEXO I}

QUADRO 1. CRONOLOGIA DAS PRINCIPAIS MEDIDAS E AÇÕES PARA A INCORPORAÇÃO DA ASSISTÊNCIA EM SAÚDE MENTAL E DA PESSOAS PORTADORA DE DEFICIÊNCIA NA ARS-6

\begin{tabular}{|c|c|c|c|c|}
\hline$A N O$ & PERÍODO & DESCRIÇÃO & UNIDADE & DISTRITO DE SAÚDE \\
\hline 1989 & Janeiro & $\begin{array}{l}\text { Criação da assessoria de Saúde Mental } \\
\text { Criação da assessoria de Recursos Humanos } \\
\text { Reforma administrativa - criação das ARS } \\
\text { Criação de comissões de trabalho para discussão do perfil } \\
\text { profissional de diferentes categoria e para as quais se realizaram } \\
\text { concursos para cargos e funções (terapia ocupacional, } \\
\text { fisioterapia, médico entre outras). } \\
\text { Incorporação dos profissionais das miniclínicas Departamento de } \\
\text { Saúde do Escolar da Secretaria da Educação à SMS. } \\
\text { Discussão com a Câmara para criação de cargos para ampliação } \\
\text { do quadro de pessoal. } \\
\text { Realização de concursos para contratação de profissionais, } \\
\text { terapeuta ocupacional, fisioterapeutas, médicos. } \\
\text { Ampliação do quadro de serviço social } \\
\text { Comissionamento de profissionais da SES para realizar } \\
\text { interlocução regional de Saúde Mental } \\
\text { Discussão com a Câmara para criação de cargos para ampliação } \\
\text { do quadro de pessoal. } \\
\text { psicólogos, assistentes social, fonoaudiólogos. }\end{array}$ & $\begin{array}{l}\text { Secretaria } \\
\text { Secretaria } \\
\text { COAS } \\
\text { Ambulatório Tito Lopes } \\
\text { ARS-6 }\end{array}$ & São Miguel \\
\hline
\end{tabular}


QUADRO 1. CONTINUAÇÃO

\begin{tabular}{|c|c|c|c|c|}
\hline$A N O$ & PERÍODO & DESCRIÇÃO & UNIDADE & DISTRITO DE SAÚDE \\
\hline 1992 & Agosto & $\begin{array}{l}\text { Contratação de equipe técnica para criação da Emergência Enfermaria } \\
\text { Psiquiátrica. } \\
\text { Remoção de psicólogos, fonoaudiólogos, assistentes social das } \\
\text { miniclínicas de Saúde do Escolar para as UBS e outras unidades da } \\
\text { Secretaria Municipal de Saúde. } \\
\text { Criação do Centro de Convivência e Cooperativa Parque Chico } \\
\text { Mendes. } \\
\text { Ampliação das equipes de profissionais das UBS e hospitais } \\
\text { (assistentes social, psiquiatras, psicólogos). } \\
\text { Pressão junto à Câmara Municipal para criação de cargos para saúde. } \\
\text { Ampliação das equipes dos Hospitais gerais. } \\
\text { Criação dos Distritos Sanitários. } \\
\text { Estudo para a territorialização. } \\
\text { Estudo e proposição da TLP para os serviços de saúde. } \\
\text { Programa Hospital Alberto } \\
\text { Apresentação do Programa de Saúde da Pessoa Deficiente - CTA; } \\
\text { público. Remoção zerada dos profissionais dos quadros de saúde. } \\
\text { Contratação de profissionais para equipe de Saúde Mental. }\end{array}$ & $\begin{array}{c}\text { CECCO } \\
\text { Serviço de fiosioterapia do Hosp. } \\
\text { Alípio Corrêa Netto } \\
\end{array}$ & $\begin{array}{l}\text { Ermelino Matarazzo } \\
\text { Ermelino Matarazzo } \\
\text { Ermelino, Itaim, São } \\
\text { Miguel } \\
\text { Ermelino Matarazzo }\end{array}$ \\
\hline
\end{tabular}


QUADRO 1. CONTINUAÇÃO

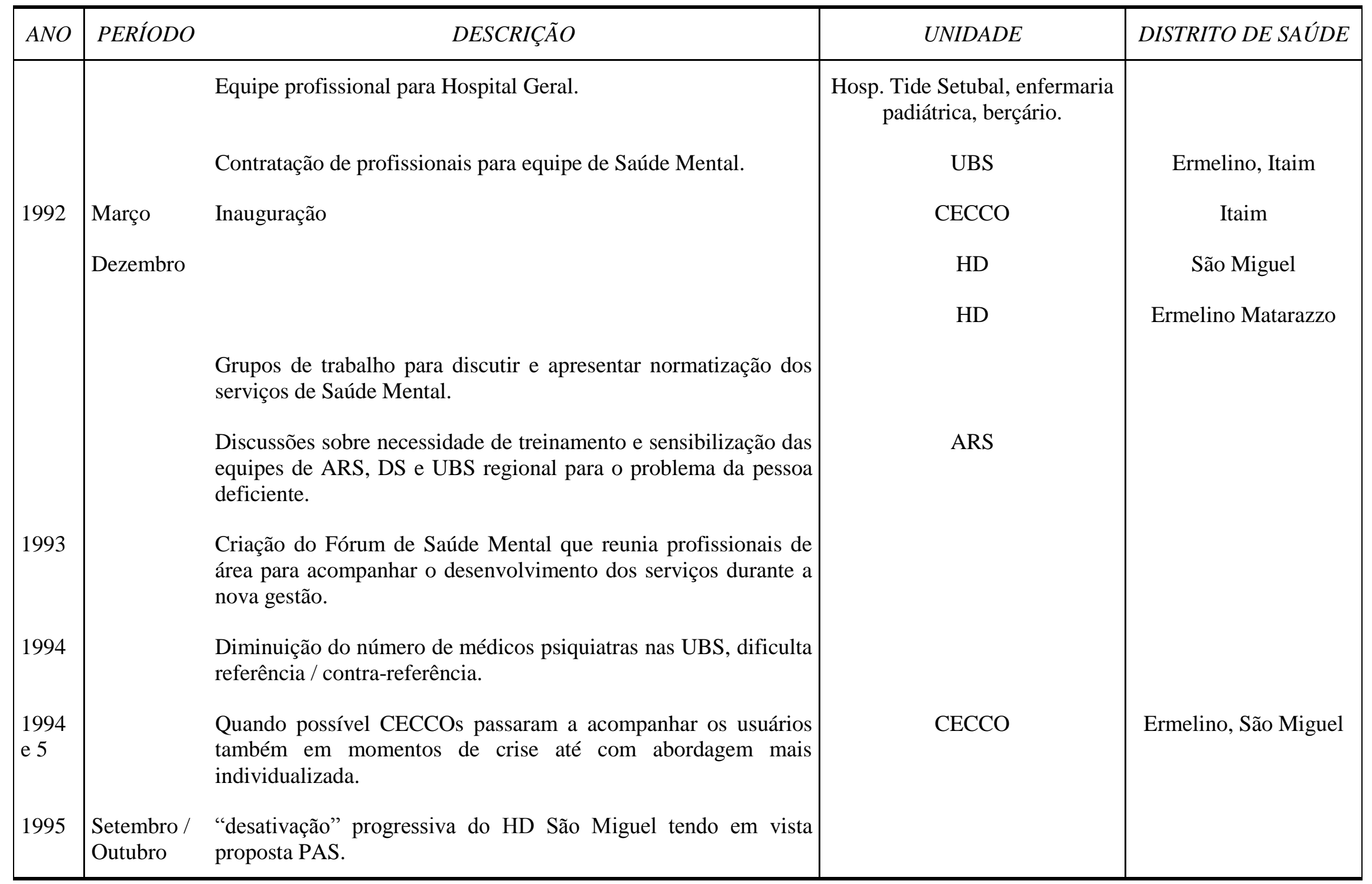


ANEXO I

QUADRO 2. CRONOLOGIA DE INSERÇÃO DOS PROFISSIONAIS ENTREVISTADOS NO DISTRITO DE SAÚDE ERMELINO MATARAZZO

\begin{tabular}{|c|c|c|c|c|c|c|c|}
\hline ENTREVISTA & INÍCIO & LOCAL & $\begin{array}{l}\text { CATEGORIA } \\
\text { PROF. }\end{array}$ & $\begin{array}{c}\text { DATA } \\
\text { MUDANÇA } \\
\end{array}$ & FUNÇÃO & LOCAL & EM 1996 \\
\hline 43 & 1987 & UBS Ponte Rasa & Psicóloga & --- & --- & --- & Até 06. PAS (?) \\
\hline 41 & 1989 & --- & Enfermeira & 1990 & Diretora & UBS Carlos Muniz & --- \\
\hline 41 & $01 / 91$ & --- & Enfermeira & 1993 & Enfermeira & UBS V. Assis & --- \\
\hline 41 & $08 / 94$ & $\begin{array}{l}\text { UBS Fidelis } \\
\text { Ribeiro }\end{array}$ & Enfermeira & 1996 & Enfermeira & $\begin{array}{l}\text { Secret. B.Estar } \\
\text { Social }\end{array}$ & $\begin{array}{l}\text { Secret. B.Estar } \\
\text { Creche }\end{array}$ \\
\hline 19 & $\begin{array}{l}\text { 01/90 (comiss. } \\
\text { SES) }\end{array}$ & $\begin{array}{c}\text { Interlocução S. } \\
\text { Mental }\end{array}$ & TO & $\begin{array}{l}\text { 1991(Concurso da } \\
\text { PMSP) }\end{array}$ & TO & --- & --- \\
\hline 19 & $\begin{array}{l}\text { 01/90 (comiss. } \\
\text { SES) }\end{array}$ & $\begin{array}{c}\text { Interlocução S. } \\
\text { Mental }\end{array}$ & TO & 1993 & TO & CECCO & Até 06. PAS ? \\
\hline 21 & 09/1990 & Enf. Psiq. & TO & Set./92 & TO & HD Butantã & Até 06. PAS? \\
\hline 11 & $\begin{array}{l}12 / 90 \\
01 / 91\end{array}$ & Emerg. Psiq. & Psiquiatra & 1993 & $\begin{array}{c}\text { Interlocução S. } \\
\text { Mental de ARS-6 e } \\
\text { Distrito }\end{array}$ & Enf. Psiq. & $\begin{array}{l}\text { Até 06, aderiu ao } \\
\text { PAS (Enf. Psiq.) }\end{array}$ \\
\hline 40 & $01 / 91$ & UBS V.Cisper & Psiquiatra & --- & --- & --- & Até 06. PAS ? \\
\hline 12 & 1991(?) & $\begin{array}{l}\text { Interlocução PPD e } \\
\text { Idoso }\end{array}$ & TO & --- & --- & --- & --- \\
\hline 20 & 1991 & Hospital & AS & 1995 & Interlocução PPD & $\begin{array}{c}\text { Unidade } \\
\text { Reab/Hospital }\end{array}$ & Até 06. PAS? \\
\hline 33 & 1991 & $\begin{array}{c}\text { Assessoria Técnica } \\
\text { ARS-6 }\end{array}$ & AS & $2^{\circ}$ SEM. 92 & $\begin{array}{c}\text { Coordenadora } \\
\text { equipe }\end{array}$ & CECCO & --- \\
\hline 33 & --- & --- & AS & $05 / 95$ & AS & CECCO & Serviço autônomo \\
\hline 25 & 09/91 & Enf. Hospital & FISIO & Maio/92 & Fisiot. chefia & $\begin{array}{c}\text { Unidade } \\
\text { Reab/Hospital }\end{array}$ & Até 06. PAS ? \\
\hline 28 & 12/91 comiss. SES & $\begin{array}{l}\text { D.Sanit. para } \\
\text { implantar HD }\end{array}$ & Psicóloga & 09/92 & Diretora & HD & --- \\
\hline
\end{tabular}


QUADRO 2. CONTINUAÇÃO

\begin{tabular}{|c|c|c|c|c|c|c|c|}
\hline ENTREVISTA & INÍCIO & LOCAL & $\begin{array}{l}\text { CATEGORIA } \\
\text { PROF. } \\
\end{array}$ & $\begin{array}{c}\text { DATA } \\
\text { MUDANÇA } \\
\end{array}$ & FUNÇÃO & LOCAL & EM 1996 \\
\hline 28 & $04 / 96$ & $\begin{array}{c}\text { Interlocução } \\
\text { regional SM, CS } \\
\text { Estado }\end{array}$ & Psicóloga & $06 / 96$ & Psicóloga & CECCO & $\begin{array}{c}\text { Instituto Saúde - } \\
\text { SES }\end{array}$ \\
\hline 22 & $02 / 06 / 92$ & Enf. Psiq. & TO & --- & --- & --- & Até 06. PAS ? \\
\hline 23 & $06 / 92$ & Enf. Psiq. & TO & --- & --- & --- & Até 06. PAS? \\
\hline 42 & $06 / 92$ & UBS Ponte Rasa & TO & --- & --- & --- & Aderiu ao PAS (?) \\
\hline 29 & $08 / 92$ & HD & Psiquiatra & $03 / 93$ & Diretora & HD & Até 06. PAS? \\
\hline 24 & $09 / 92(?)$ & Enf. Psiq. & TO & --- & --- & --- & Até 06. PAS? \\
\hline 26 & $09 / 92$ & Hospital & FISIO & 95 & Fisio. Chefia & $\begin{array}{l}\text { Uni. Reab. } \\
\text { HOSPITAL }\end{array}$ & Aderiu PAS \\
\hline 27 & $10 / 92$ & Hospital & FONO & 05/1995, PAS & --- & --- & Serviço privado \\
\hline 30 & $10 / 92$ & HD & TO & --- & --- & --- & Até 06. PAS ? \\
\hline 31 & $10 / 92$ & HD & TO & --- & --- & --- & Até 06. PAS ? \\
\hline 32 & Há anos PMSP & Secret. Habitação & AS & 1993 & AS & HD & Até 06. PAS ? \\
\hline 34 & --- & UBS Pedro Campos & médica & 1993 & Diretora & UBS Pedro Campos & Até 06. PAS ? \\
\hline 35 & 92 & UBS Pedro Campos & TO & --- & --- & --- & Até 06. PAS? \\
\hline 36 & 92 & UBS Pedro Campos & Psiquiatra & --- & --- & --- & Aderiu ao PAS \\
\hline 37 & $09 / 92$ & UBS Pedro Campos & FONO & --- & --- & --- & --- \\
\hline 38 & $07 / 92$ & UBS Atualpa & FISIO & $07 / 92$ & FISIO & UBS Pedro Campos & --- \\
\hline 39 & 92 & CECCO - EM & TO & $12 / 92$ & TO & UBS V.Cisper & --- \\
\hline 40 & $06 / 92$ & UBS Ponte Rasa & FONO & --- & --- & --- & --- \\
\hline
\end{tabular}


ANEXO I

QUADRO 3. CRONOLOGIA DE INSERÇÃO DOS PROFISSIONAIS ENTREVISTADOS NO DISTRITO DE SAÚDE DE SÃO MIGUEL

\begin{tabular}{|c|c|c|c|c|c|c|c|}
\hline ENTREVISTA & INÍCIO & LOCAL & $\begin{array}{l}\text { CATEGORIA } \\
\text { PROF. }\end{array}$ & DATA MUDANÇA & FUNÇÃO & LOCAL & EM 1996 \\
\hline 52 & 1982 & Secretaria Educação & Psicóloga & 1987 & Psicóloga & $\begin{array}{l}\text { Mini-clínica } \\
\text { V. Prudente }\end{array}$ & --- \\
\hline 52 & 1990 & $\begin{array}{l}\text { Secretaria Saúde } \\
\text { UBS V.Ramos }\end{array}$ & Psicóloga & 03/93 12/94 & Psicóloga & HD & --- \\
\hline 52 & 1995 & $\begin{array}{l}\text { Psicóloga UBS } \\
\text { V.Progresso }\end{array}$ & Psicóloga & 1996 06/PAS & Psicóloga & UBS Fidelis Ribeiro & UBS V. Progresso até 06 \\
\hline 46 & 1988 & $\begin{array}{l}\text { Médico Assist. } \\
\text { Hospital }\end{array}$ & Psiquiatria & 1993 & $\begin{array}{c}\text { Interlocutor S. } \\
\text { Mental }\end{array}$ & Hospital & $\begin{array}{c}\text { Hosp. Emergência } \\
\text { psiquiátrica, ambulatório } \\
\text { espec., programa usuário } \\
\text { de droga }\end{array}$ \\
\hline 45 & 1990 & $\begin{array}{l}\text { Interlocutor S. } \\
\text { Mental/CECCO }\end{array}$ & Psicóloga & 1993 & Psicólogo & CECCO & CECCO \\
\hline 47 & 1990 & Amb. Espec. & Assist. Social & 1993 & $\begin{array}{c}\text { Interlocutor PP DEF. } \\
\text { idoso }\end{array}$ & Ambulat. Esp. & --- \\
\hline 48 & 1990 & $\begin{array}{c}\text { Pediatria, hospital } \\
\text { geral }\end{array}$ & Terapia Ocupacional & --- & --- & --- & Até 06. PAS? \\
\hline 55 & 1990 & $\begin{array}{l}\text { Assis. UBS Jd. } \\
\text { Helena }\end{array}$ & Pediatria & 1993 & Chefia & UBS Jd. Helena & $\begin{array}{c}\text { UBS Jd. Helena } \\
\text { continuou com PAS }\end{array}$ \\
\hline 50 & 1991 & $\begin{array}{c}\text { Médico Assis. / } \\
\text { equipe planejamento }\end{array}$ & Psiquiatra & $12 / 1992$ & Psiquiatra & $\mathrm{HD}$ & --- \\
\hline 50 & --- & --- & Psiquiatra & 1994 & Diretora & HD & --- \\
\hline 50 & --- & --- & Psiquiatra & $11 / 95$ & Diretora & $\mathrm{HD}$ & Até 06. PAS ? \\
\hline 53 & $11 / 91$ & $\begin{array}{l}\text { UBS V. Nova } \\
\text { Curuçá }\end{array}$ & Assist. Social & 1992 & Assist. Social & HD & $\mathrm{HD}$ \\
\hline 56 & $11 / 91$ & UBS Jd. Helena & Psicologia & --- & Psicóloga & UBS Jd. Helena & Com PAS para? \\
\hline
\end{tabular}


QUADRO 3. CONTINUAÇÃO

\begin{tabular}{|c|c|c|c|c|c|c|c|}
\hline ENTREVISTA & INÍCIO & LOCAL & $\begin{array}{l}\text { CATEGORIA } \\
\text { PROF. }\end{array}$ & $\begin{array}{c}\text { DATA } \\
\text { MUDANÇA }\end{array}$ & FUNÇÃO & LOCAL & EM 1996 \\
\hline 49 & 1992 & $\begin{array}{l}\text { Pediatria, hospital } \\
\text { geral }\end{array}$ & $\begin{array}{c}\text { Terapia } \\
\text { Ocupacional }\end{array}$ & --- & --- & --- & Até 06. PAS? \\
\hline 54 & 09/92 & CECCO & T.O. & --- & T.O. & CECCO & CECCO \\
\hline 51 & $11 / 92$ & UBS V.Jacuí & $\begin{array}{c}\text { Terapia } \\
\text { Ocupacional }\end{array}$ & 03/1993 & T.O. & HD & HD até 06 . PAS? \\
\hline 57 & $12 / 92$ & UBS Jd.Maia & T.O. & 1995 & T.O. & $\begin{array}{c}\text { CECCO/UBS Jd. } \\
\text { Maia }\end{array}$ & $\begin{array}{l}\text { UBS Jd. Helena } \\
07 / 96 \text { - HD PAS }\end{array}$ \\
\hline 61 & $12 / 92$ & $\begin{array}{l}\text { UBS V.Nova } \\
\text { Curuçá }\end{array}$ & T.O. & 1996 & T.O. & $\begin{array}{c}\text { PAS não } \\
\text { conhecia a } \\
\text { unidade para qual } \\
\text { iria }\end{array}$ & $\begin{array}{l}\text { Até 06. UBS V.Nova } \\
\text { Curuçá }\end{array}$ \\
\hline 62 & $199 ?$ & Ambul. Espec. & Psicologia & --- & Psicóloga & Ambulat. Esp. & $\begin{array}{c}\text { Ambulat. Espec., } \\
\text { programa usuário de } \\
\text { drogas }\end{array}$ \\
\hline 58 & $05 / 91$ & UBS V. Jacuí & FONO & --- & --- & --- & Até 06 PAS? \\
\hline 59 & $07 / 92$ & UBS V. Jacuí & Psicóloga & --- & --- & --- & Até 06 PAS? \\
\hline 60 & $05 / 92$ & $\begin{array}{c}\text { Hospital de outra } \\
\text { ARS }\end{array}$ & FISIO & $01 / 93$ & FISIO & UBS V. Jacuí & Até 06 PAS? \\
\hline
\end{tabular}


ANEXO I

QUADRO 4. CRONOLOGIA DE INSERÇÃO DOS PROFISSIONAIS ENTREVISTADOS NO DISTRITO SANITÁRIO ITAIM PAULISTA

\begin{tabular}{|c|c|c|c|c|c|c|c|}
\hline ENTREVISTA & INÍCIO & LOCAL & $\begin{array}{c}\text { CATEGORIA } \\
\text { PROF } \\
\end{array}$ & $\begin{array}{c}\text { DATA } \\
\text { MUDANCSA }\end{array}$ & $F U N C ̧ A \tilde{O} O$ & LOCAL & EM 1996 \\
\hline 63 & $07 / 90$ & $\begin{array}{l}\text { UBS Camargo } \\
\text { Novo }\end{array}$ & Psicóloga & $04 / 91$ & $\begin{array}{c}\text { Interlocutora } \\
\text { S.Mental da PPD e } \\
\text { de Movi. } \\
\text { Populares }\end{array}$ & Distrito & \\
\hline 63 & --- & --- & --- & 1993 & Psicóloga & UBS / ARS-4 & Até PAS ? \\
\hline 65 & $06 / 91$ & UBS Kemel & Psicóloga & $03 / 92$ & Coordenadora & CECCO & --- \\
\hline 65 & 06/91 & CECCO & Psicóloga & $01 / 93$ & Psicóloga & CECCO & --- \\
\hline 65 & $06 / 91$ & CECCO & Psicóloga & $01 / 94$ & $\begin{array}{l}\text { Licença sem } \\
\text { vencimento }\end{array}$ & --- & --- \\
\hline 65 & --- & CECCO & Psicóloga & $01 / 96$ & Rec. Humanos & Distrito & Até 06. PAS ? \\
\hline 67 & 1992 & UBS Atualpa & Psicóloga & -- & -- & --- & Até 06. PAS? \\
\hline 64 & $06 / 92$ & $\begin{array}{c}\text { UBS Camargo } \\
\text { Novo }\end{array}$ & Fisioterapeuta & 1993 & $\begin{array}{l}\text { Interlocução } \\
\text { PPD/FISIO }\end{array}$ & UBS C. Novo & Até 06. PAS? \\
\hline 66 & $01 / 93$ & $\begin{array}{l}\text { UBS Keimel UBS } \\
\text { Atualpa }\end{array}$ & Psicóloga & $06 / 93$ & Psicóloga & CECCO & Até 06. PAS? \\
\hline 68 & 1994 & $\begin{array}{l}\text { UBS Camargo } \\
\text { Novo }\end{array}$ & Diretora & 08/96 / PAS & Enfermeira & $\begin{array}{c}\text { UBS Camargo } \\
\text { Novo }\end{array}$ & Aderiu ao PAS \\
\hline 68 & 1994 & $\begin{array}{l}\text { UBS Camargo } \\
\text { Novo }\end{array}$ & Diretora & 09/96 & Enfermeira & $\begin{array}{l}\text { HD São } \\
\text { Miguel }\end{array}$ & --- \\
\hline
\end{tabular}


ANEXO I

QUADRO 5. PRÁTICA ASSISTENCIAL EM SAÚDE MENTAL, PRINCIPAIS ATIVIDADES DESENVOLVIDAS NAS UBS, PERÍODO $1989-1996$.

\begin{tabular}{|c|c|c|c|c|c|c|c|c|c|}
\hline & \multicolumn{3}{|c|}{ ERMELINO } & \multicolumn{5}{|c|}{ SÃO MIGUEL } & \multirow{2}{*}{$\begin{array}{c}\text { ITAIM } \\
9 . \\
\end{array}$} \\
\hline & 1. & 2. & 3. & 4. & 5. & 6. & 7. & 8. & \\
\hline \multicolumn{10}{|l|}{ 1.Profissional: } \\
\hline $\begin{array}{c}\text { 1.1 Experiência anterior em } \\
\text { Saúde Mental }\end{array}$ & Psiq, TO. & Psiq. & Psiq. & --- & $\begin{array}{l}\text { Psico, Psiq, } \\
\text { TO. }\end{array}$ & TO. & --- & Psico. & Psico. \\
\hline $\begin{array}{l}\text { 1.2 Experiência anterior } \\
\text { com grupo de risco }\end{array}$ & TO. & TO & Psiq. & Psiq. & --- & --- & --- & --- & --- \\
\hline 1.3 Equipe Saúde Mental & $\begin{array}{l}\text { Psiq,psico, } \\
\text { fono, TO, AS, } \\
\text { Fisio. }\end{array}$ & $\begin{array}{l}\text { Fono, psiq, } \\
\text { TO, psico }\end{array}$ & $\begin{array}{l}\text { Psiq, TO, } \\
\text { psico, fisio, } \\
\text { fono }\end{array}$ & $\begin{array}{l}\text { Psiq, TO, } \\
\text { psico }\end{array}$ & $\begin{array}{l}\text { Psiq, fisio, } \\
\text { fono, TO }\end{array}$ & $\begin{array}{l}\text { TO, psico, } \\
\text { AS, } \\
\text { Educadora. }\end{array}$ & $\begin{array}{l}\text { TO, fono, } \\
\text { psiq, psico }\end{array}$ & $\begin{array}{l}\text { Psico, fono, } \\
\text { Psiq, AS, TO, } \\
\text { Educadora. }\end{array}$ & Psico, AS. \\
\hline $\begin{array}{l}\text { 1.4 Proposta Assistencial } \\
\text { definida em } 1989\end{array}$ & $\begin{array}{c}\text { Conhece, } \\
\text { resiste, } \\
\text { discute, apóia. }\end{array}$ & $\begin{array}{c}\text { Conhece, } \\
\text { discute, } \\
\text { timidamente. }\end{array}$ & $\begin{array}{c}\text { Conhece, } \\
\text { discute, apoio } \\
\text { parcial. }\end{array}$ & $\begin{array}{l}\text { Conhece } \\
\text { princípios. }\end{array}$ & Conhece & $\begin{array}{l}\text { Conhece } \\
\text { princípios. }\end{array}$ & $\begin{array}{c}\text { Conhece, } \\
\text { apoio } \\
\text { parcial. }\end{array}$ & $\begin{array}{l}\text { Conhece, } \\
\text { discute, apóia. }\end{array}$ & $\begin{array}{l}\text { Conhece, } \\
\text { discute, apóia. }\end{array}$ \\
\hline \multicolumn{10}{|l|}{ 2. População atendida } \\
\hline \multicolumn{10}{|l|}{$\begin{array}{l}\text { 2.1 Atendimento grupo de } \\
\text { risco }\end{array}$} \\
\hline a) psicoses & $\begin{array}{l}\text { Psiq, TO, } \\
\text { psico }\end{array}$ & Psiq. & Psiq & $\begin{array}{l}\text { Psico, TO, } \\
\text { Psiq. }\end{array}$ & $\begin{array}{c}\text { Psiq, TO } \\
\text { (somente até } \\
\text { 93) Psico (até } \\
\text { 96). }\end{array}$ & TO. & --- & Psico & Psico \\
\hline b) alcoolismo & Psiq. & --- & Psiq & Psico. & --- & --- & --- & Psico. & --- \\
\hline c) drogadição & Psico. & --- & --- & Psico. & --- & --- & --- & --- & $\begin{array}{r}\text { Pais de adolesc. } \\
\text { com problemas }\end{array}$ \\
\hline d) neuróticos & Psico. & Psiq, Psico. & Psiq. & Psico. & Psico. & TO. & --- & --- & $\begin{array}{l}\text { Adolesc. } \\
\text { com problemas }\end{array}$ \\
\hline e) tentativa suicídio & Psico. & --- & --- & --- & --- & --- & --- & --- & --- \\
\hline
\end{tabular}


QUADRO 5. CONTINUAÇÃO

\begin{tabular}{|c|c|c|c|c|c|c|c|c|c|}
\hline & \multicolumn{3}{|c|}{ ERMELINO } & \multicolumn{5}{|c|}{ SÃO MIGUEL } & \multirow{2}{*}{$\begin{array}{c}\text { ITAIM } \\
9 . \\
\end{array}$} \\
\hline & 1. & 2. & 3. & 4. & 5. & 6. & 7. & 8. & \\
\hline \multicolumn{10}{|l|}{ 2.2 Tipo de atendimento } \\
\hline - Individual & Psiq, psico. & Psiq. & Psiq. & Psiq, Psico. & Psiq, Psico. & Psiq, Psico. & Psico. & Psico. & Psico. \\
\hline - Grupo & TO, Psico. & --- & --- & --- & Psico. & --- & Psico. & --- & --- \\
\hline - Família/orientação & $\begin{array}{c}\text { TO, AS, } \\
\text { Fono, Psico. }\end{array}$ & Psiq. & --- & --- & Fono, Psico. & --- & --- & --- & --- \\
\hline - Interprofissional & & --- & --- & --- & --- & --- & --- & --- & --- \\
\hline - $\quad$ Semi intensivo & --- & --- & --- & --- & --- & --- & --- & --- & --- \\
\hline \multirow{2}{*}{\multicolumn{10}{|c|}{$\begin{array}{l}2.3 \text { Outra demanda não } \\
\text { pertencente, ao grupo risco } \\
\text { a) Problema aprendizagem }\end{array}$}} \\
\hline & & & & & & & & & \\
\hline - Individual & Psico. & TO & TO, psico & Psico, TO. & Psico, Fono. & TO. & TO, Médico. & Psico. & Psico \\
\hline - Grupo & Psico. & TO & & Psico, TO. & Fono. & TO. & TO, Psico. & Psico & Psico \\
\hline $\begin{array}{l}\text { - Orientação / família } \\
\text { b) Outros }\end{array}$ & Psico, Psiq. & TO & & Psico. & & & & TO. & \\
\hline - Individual & $\begin{array}{l}\text { DM, TCE, } \\
\text { AVC. }\end{array}$ & $\begin{array}{l}\text { Atraso } \\
\text { DNPM, AVC, } \\
\text { DM, PC }\end{array}$ & --- & & $\begin{array}{l}\text { Pouco tempo } \\
\text { afasicos. }\end{array}$ & PC. & $\begin{array}{l}\text { Caso neuro, SD, } \\
\text { distrofia, EM, } \\
\text { AVC. }\end{array}$ & & \\
\hline - Grupo & $\begin{array}{l}\text { Tuberculose, } \\
\text { sexualidade. }\end{array}$ & $\begin{array}{l}\text { Problema de } \\
\text { aprendizagem }\end{array}$ & & Idoso. & & $\begin{array}{l}\text { Gestante, } \\
\text { diabéticos. }\end{array}$ & DST, AIDS. & $\begin{array}{c}\text { Gestantes, } \\
\text { criança subnutr. }\end{array}$ & \\
\hline \multicolumn{10}{|c|}{$\begin{array}{l}\text { 3. Ações de Saúde Mental } \\
\text { junto a: }\end{array}$} \\
\hline \multicolumn{10}{|l|}{ 3.1 Instituições } \\
\hline a) escola & Eventual & SIM & Eventual & SIM & $\begin{array}{l}\text { Adolescentes, } \\
\text { grupo de } \\
\text { orientação } \\
\text { sexual. }\end{array}$ & --- & SIM & SIM & \\
\hline
\end{tabular}


QUADRO 5. CONTINUAÇÃO

\begin{tabular}{|c|c|c|c|c|c|c|c|c|c|}
\hline & \multicolumn{3}{|c|}{ ERMELINO } & \multicolumn{5}{|c|}{ SÃO MIGUEL } & \multirow{2}{*}{$\frac{\text { ITAIM }}{9 .}$} \\
\hline & 1. & 2. & 3. & 4. & 5. & 6. & 7. & 8. & \\
\hline b) creche / pré-escola & $\begin{array}{l}\text { Antes de } 89 \\
\text { sistemática. }\end{array}$ & --- & Eventual & --- & $\begin{array}{l}\text { Fono trabalho } \\
\text { preventivo. }\end{array}$ & --- & --- & --- & \\
\hline 3.2 Grupos da comunidade & & & & --- & & --- & --- & --- & \\
\hline $\begin{array}{l}\text { 4. Equipe de Saúde } \\
\text { Mental }\end{array}$ & Completa & Completa & completa & incompleta & $\begin{array}{c}\text { Completa em } \\
93 \text { com Psico, } \\
\text { Psiq, Fono até } \\
94 .\end{array}$ & Incompleta & $\begin{array}{c}\text { Completa em } \\
\text { determinados } \\
\text { períodos. }\end{array}$ & incompleta & $\begin{array}{l}\text { Inexis } \\
\text { tente }\end{array}$ \\
\hline 4.1 Reuniões & --- & --- & --- & --- & $\begin{array}{l}\text { Tentativa de } \\
\text { periódicas no } \\
\text { início, } \\
\text { esporádicas } \\
\text { depois. }\end{array}$ & --- & --- & --- & --- \\
\hline 4.2 Contato prof./prof. & $\begin{array}{c}\text { Para } \\
\text { discussão de } \\
\text { caso }\end{array}$ & $\begin{array}{l}\text { Eventual para } \\
\text { discussão } \\
\text { caso }\end{array}$ & $\begin{array}{l}\text { Eventual para } \\
\text { discussão } \\
\text { caso }\end{array}$ & --- & $\begin{array}{c}\text { Atualmente / } \\
\text { discussão } \\
\text { decasos. }\end{array}$ & --- & Eventual / casos & $\begin{array}{l}\text { Para discussão } \\
\text { de casos. }\end{array}$ & --- \\
\hline 4.3 Atividades conjuntas & --- & --- & --- & SIM & $\begin{array}{l}\text { No início } \\
\text { tentativas. }\end{array}$ & --- & --- & & --- \\
\hline 4.4 Participação na UBS & $\begin{array}{l}\text { Equipe } \\
\text { isolada }\end{array}$ & $\begin{array}{l}\text { Equipe } \\
\text { isolada }\end{array}$ & Esporádica & --- & $\begin{array}{c}\text { Participação } \\
\text { esporádica }\end{array}$ & SIM & Equipe isolada & --- & --- \\
\hline \multicolumn{10}{|l|}{$\begin{array}{l}\text { 5. Referência / } \\
\text { Contrareferência }\end{array}$} \\
\hline 5.1 CECCO & $\begin{array}{c}\text { Sem } \\
\text { problemas. }\end{array}$ & $\begin{array}{c}\text { Sem } \\
\text { problemas. }\end{array}$ & $\begin{array}{c}\text { Sem } \\
\text { problemas. }\end{array}$ & $\begin{array}{c}\text { Sem } \\
\text { problemas. }\end{array}$ & $\begin{array}{c}\text { Sem } \\
\text { problemas. }\end{array}$ & $\begin{array}{c}\text { Sem } \\
\text { problemas. }\end{array}$ & Sem problemas. & Sem problemas. & \\
\hline $5.2 \mathrm{HD}$ & $\begin{array}{c}\text { Com } \\
\text { problemas. }\end{array}$ & $\begin{array}{c}\text { Com } \\
\text { problemas. }\end{array}$ & $\begin{array}{c}\text { Com } \\
\text { problemas. }\end{array}$ & $\begin{array}{l}\text { Com } \\
\text { problemas. }\end{array}$ & $\begin{array}{l}\text { Com } \\
\text { problemas. }\end{array}$ & --- & --- & Com problemas. & --- \\
\hline 5.3 Enf. Psiq. & $\begin{array}{c}\text { Sem } \\
\text { problemas. }\end{array}$ & $\begin{array}{c}\text { Sem } \\
\text { problemas. }\end{array}$ & $\begin{array}{c}\text { Sem } \\
\text { problemas. }\end{array}$ & De Ermelino. & De Ermelino. & --- & --- & De Ermelino. & --- \\
\hline
\end{tabular}


QUADRO 5. CONTINUAÇÃO

\begin{tabular}{|c|c|c|c|c|c|c|c|c|c|}
\hline & \multicolumn{3}{|c|}{ ERMELINO } & \multicolumn{5}{|c|}{ SÃO MIGUEL } & \multirow{2}{*}{$\begin{array}{c}\text { ITAIM } \\
9 .\end{array}$} \\
\hline & 1. & 2. & 3. & 4. & 5. & 6. & 7. & 8. & \\
\hline \multicolumn{10}{|l|}{$\begin{array}{l}\text { 6. Principais } \\
\text { problemas }\end{array}$} \\
\hline $\begin{array}{l}6.1 \text { Recursos } \\
\text { materiais } \\
\text { e físicos }\end{array}$ & $\begin{array}{l}\text { Sala pequena para } \\
\text { atendimento em } \\
\text { grupos, materiais } \\
\text { doados. }\end{array}$ & $\begin{array}{l}\text { Sala pequena } \\
\text { para } \\
\text { atendimento } \\
\text { em grupos, } \\
\text { materiais } \\
\text { insuficientes. }\end{array}$ & $\begin{array}{c}\text { Sala pequena } \\
\text { para atendimento } \\
\text { em grupo. }\end{array}$ & $\begin{array}{c}\text { Sala pequena } \\
\text { para atendimento } \\
\text { em grupo. }\end{array}$ & $\begin{array}{c}\text { Sala pequena } \\
\text { para } \\
\text { atendimento } \\
\text { em grupos, } \\
\text { materiais } \\
\text { doados pela } \\
\text { equipe. }\end{array}$ & & $\begin{array}{c}\text { Sala } \\
\text { pequena } \\
\text { para } \\
\text { atendimento } \\
\text { em grupos, } \\
\text { materiais } \\
\text { insuficiente } \\
\text { s. }\end{array}$ & $\begin{array}{c}\text { Materiais } \\
\text { insuficientes. }\end{array}$ & $\begin{array}{c}\text { No início até } \\
\text { inexistência de } \\
\text { cadeiras; } \\
\text { posterior se } \\
\text { organizou sala } \\
\text { para atendimento } \\
\text { psicológico }\end{array}$ \\
\hline $\begin{array}{l}6.2 \text { Recursos } \\
\text { humanos }\end{array}$ & --- & --- & $\begin{array}{c}\text { TO, Psico, Fono } \\
\text { não tem } \\
\text { experiência em } \\
\text { saúde mental. }\end{array}$ & $\begin{array}{l}\text { Inexistência de } \\
\text { Psiq durante } \\
\text { grande parte do } \\
\text { período. }\end{array}$ & Psiq até 94. & $\begin{array}{l}\text { Nunca } \\
\text { existiu } \\
\text { Psiq. }\end{array}$ & --- & --- & $\begin{array}{l}\text { Não existe } \\
\text { equipe }\end{array}$ \\
\hline $\begin{array}{l}6.3 \text { Proposta } \\
\text { assistencial }\end{array}$ & $\begin{array}{l}\text { Faltou clareza, sem } \\
\text { as ações esperadas. } \\
\text { Faltou suporte } \\
\text { técnico, tecnológico, } \\
\text { supervisão. Não pode } \\
\text { excluir população } \\
\text { infantil. }\end{array}$ & $\begin{array}{l}\text { Faltou clareza, } \\
\text { sem as ações } \\
\text { esperadas. Faltou } \\
\text { suporte técnico, } \\
\text { tecnológico, } \\
\text { supervisão. }\end{array}$ & $\begin{array}{c}\text { Faltou clareza, sem } \\
\text { as ações esperadas. } \\
\text { Faltou suporte } \\
\text { técnico, } \\
\text { tecnológico, } \\
\text { supervisão. Tem } \\
\text { que pensar na } \\
\text { prevenção de } \\
\text { problemas. }\end{array}$ & $\begin{array}{c}\text { Tem que pensar na } \\
\text { prevenção de } \\
\text { problemas. }\end{array}$ & $\begin{array}{l}\text { Faltou clareza, } \\
\text { sem as ações } \\
\text { esperadas. Faltou } \\
\text { suporte técnico, } \\
\text { tecnológico, } \\
\text { supervisão. Qual } \\
\text { papel da saúde } \\
\text { com demanda } \\
\text { infantil, se existe } \\
\text { trabalho } \\
\text { psicopedagógico } \\
\text { ? Tem que pensar } \\
\text { na prevenção de } \\
\text { problemas. }\end{array}$ & $\begin{array}{c}\text { Tem que } \\
\text { pensar na } \\
\text { prevenção } \\
\text { de } \\
\text { problemas. } \\
\text { Proposta } \\
\text { inviável } \\
\text { pela } \\
\text { inexistên } \\
\text { cia de } \\
\text { equipe. }\end{array}$ & $\begin{array}{c}\text { Tem que } \\
\text { pensar na } \\
\text { prevenção } \\
\text { de } \\
\text { problemas. } \\
\text { Proposta } \\
\text { inviável } \\
\text { pela } \\
\text { inexistência } \\
\text { de equipe. }\end{array}$ & $\begin{array}{c}\text { Faltou clareza, } \\
\text { sem as ações } \\
\text { esperadas. Faltou } \\
\text { suporte técnico, } \\
\text { tecnológico, } \\
\text { supervisão. Qual } \\
\text { papel da saúde } \\
\text { com demanda } \\
\text { infantil, se existe } \\
\text { trabalho } \\
\text { psicopedagógico } \\
?\end{array}$ & $\begin{array}{c}\text { Faltou clareza, } \\
\text { sem as ações } \\
\text { esperadas. Qual } \\
\text { papel da saúde } \\
\text { com demanda } \\
\text { infantil, se existe } \\
\text { trabalho } \\
\text { psicopedagógico } \\
\text { ? Não pode } \\
\text { excluir } \\
\text { população } \\
\text { infantil. Proposta } \\
\text { inviável pela } \\
\text { inexistência de } \\
\text { equipe. }\end{array}$ \\
\hline
\end{tabular}




\section{ANEXO I \\ QUADRO 6. Prática Assistencial em Saúde Mental, principais atividades desenvolvidas nos CECCO, período 1991-1996}

\begin{tabular}{|c|c|c|c|}
\hline & ERMELINO & $S \tilde{A} O$ MIGUEL & ITAIM \\
\hline 1. Equipe composta por: & TO, Psico, AS, Educadora. & TO, Psico, Fono. & $\begin{array}{l}\text { Psico, (Fono e TO por um } \\
\text { pequeno período) }\end{array}$ \\
\hline \multicolumn{4}{|l|}{ 2. Encaminhamento de usuários } \\
\hline $\begin{array}{l}\text { 2.1 UBS / HD / Enfermaria } \\
\text { psiquiátrica }\end{array}$ & $\begin{array}{l}\text { Necessário contato constante com } \\
\text { os serviços para estimular o } \\
\text { encaminhamento. }\end{array}$ & $\begin{array}{l}\text { Necessário contato constante com } \\
\text { os serviços para estimular o } \\
\text { encaminhamento. }\end{array}$ & $\begin{array}{l}\text { Necessário contato constante com } \\
\text { as UBS e arredores do local para } \\
\text { estimular o encaminhamento. }\end{array}$ \\
\hline 2.2 Entre usuários & A maioria dos encaminhamentos. & A maioria dos encaminhamentos. & A maioria dos encaminhamentos. \\
\hline 3. Contra referência & $\begin{array}{l}\text { HD - com problemas pelos } \\
\text { critérios rígidos de admissão dos } \\
\text { pacientes; Enfermaria - não havia } \\
\text { problemas; UBS dependia da } \\
\text { disponibilidade de médicos } \\
\text { psiquiatras. }\end{array}$ & $\begin{array}{c}\text { HD - com problemas pelos } \\
\text { critérios rígidos de admissão dos } \\
\text { pacientes; Enfermaria de } \\
\text { Ermelino; UBS dependia da } \\
\text { disponibilidade de médicos } \\
\text { psiquiatras. }\end{array}$ & $\begin{array}{c}\text { Emergência Psiquiátrica de São } \\
\text { Miguel ou Ermelino Matarazzo. } \\
\text { UBS não dispunha de médicos } \\
\text { psiquiatras. }\end{array}$ \\
\hline 4. População atendida & $\begin{array}{l}\text { Portadores de transtornos mentais } \\
\text { graves, portadores de } \\
\text { necessidades especiais, população } \\
\text { geral. }\end{array}$ & $\begin{array}{l}\text { Portadores de transtornos mentais } \\
\text { graves, portadores de } \\
\text { necessidades especiais, população } \\
\text { geral. }\end{array}$ & $\begin{array}{l}\text { Portadores de transtornos } \\
\text { mentais, população geral, } \\
\text { mulheres donas de casa. }\end{array}$ \\
\hline \multicolumn{4}{|l|}{ 5. Atividades } \\
\hline \multicolumn{4}{|l|}{ 5.1 Internas } \\
\hline $\begin{array}{l}\text { a) recepção acolhida, } \\
\text { entrevistas }\end{array}$ & SIM & SIM & SIM \\
\hline $\begin{array}{l}\text { b) atendimento individual / } \\
\text { familiares }\end{array}$ & SIM & SIM & SIM \\
\hline c) plenária & SIM & SIM & --- \\
\hline d) almoço comunitário & SIM & NÃO & NÃO \\
\hline e) festas / palestras & SIM & SIM & SIM \\
\hline f) reuniões equipe & SIM & SIM & SIM \\
\hline \multicolumn{4}{|l|}{ 5.2 Atividades Externas } \\
\hline $\begin{array}{l}\text { a) com movimentos sociais e } \\
\text { populares, fóruns, grupos } \\
\text { tarefas }\end{array}$ & Frequente & Frequente & --- \\
\hline b) visitas, ações domiciliares & SIM & De rotina & --- \\
\hline $\begin{array}{l}\text { c) passeios, atividades externas } \\
\text { para sociabilização }\end{array}$ & SIM & Freqüente & --- \\
\hline 5.3 Oficinas / núcleos de trabalho & NÃO & $\begin{array}{l}\text { Grupo de jardinagem, horta, de } \\
\text { estamparia e encardenação. }\end{array}$ & $\begin{array}{c}\text { Mulheres se organizando para } \\
\text { produzir panos de prato. }\end{array}$ \\
\hline
\end{tabular}




\section{ANEXO I}

QUADRO 7. Prática Assistencial em Saúde Mental, principais atividades desenvolvidas nos HDs, período 1991-1996

\begin{tabular}{|c|c|c|}
\hline & ERMELINO & SÃO MIGUEL \\
\hline \multicolumn{3}{|l|}{ 1. Equipe de profissionais } \\
\hline 1.1 Composta por: & 2Psiq, 1AS, 2Psico, 2TO, 1Enf. & Psiq, AS, Psico, TO \\
\hline $\begin{array}{l}\text { 1.2 Participação na } \\
\text { organização / criação do } \\
\text { serviço }\end{array}$ & Psico. & TO, Psiq. \\
\hline \multicolumn{3}{|l|}{$\begin{array}{l}\text { 2. Usuários / } \\
\text { Encaminhamentos }\end{array}$} \\
\hline 2.1 Demanda espontânea & NÃO & NÃO \\
\hline $\begin{array}{l}\text { 2.2 Encaminhamento de } \\
\text { serviços }\end{array}$ & Enfermaria Psiquiátrica, UBS & Emergência / Enfermaria Psiquiátrica \\
\hline 2.3 Fila / Espera & SIM & Desativando pelo PAS \\
\hline \multicolumn{3}{|l|}{ 3. Atividades desenvolvidas } \\
\hline a) recepção e triagem & SIM & SIM \\
\hline b) estudo de caso & $\begin{array}{c}\begin{array}{l}\text { SIM, pelo PAS restrição de casos novos } \\
\text { desde dez/95 }\end{array} \\
\end{array}$ & $\begin{array}{c}\text { SIM, pelo PAS restrição de casos novos } \\
\text { desde out/95 }\end{array}$ \\
\hline \multicolumn{3}{|l|}{ 3.1 Atividades básicas } \\
\hline a) socioculturais & Festas mensais, churrasco. & --- \\
\hline $\begin{array}{l}\text { b) assembléias de pacientes e } \\
\text { técnicos }\end{array}$ & SIM & De pacientes a cargo de um técnico. \\
\hline c) esportivas & $\begin{array}{l}\text { Uso da piscina e jogos eventuais, } \\
\text { campeonato anual de jogos de mesa. }\end{array}$ & --- \\
\hline d) rotina & --- & --- \\
\hline e) convivência & $\begin{array}{l}\text { Aquela que ocorre "naturalmente" nos } \\
\text { momentos sem atividades. }\end{array}$ & $\begin{array}{l}\text { Aquela que ocorre "naturalmente" nos } \\
\text { momentos sem atividades. }\end{array}$ \\
\hline f) atendimento familiar & SIM, feito pelo Serviço Social. & SIM, feito pelo Serviço Social. \\
\hline g) medicação & SIM & SIM \\
\hline h) grupo reencontro & SIM & SIM \\
\hline i) grupo fim de semana & SIM & --- \\
\hline j) oficinas & De cozinha, expressão plástica. & NÃO \\
\hline k) acomp. Médico & SIM & SIM \\
\hline 1) acomp. Psicoterápico & SIM, individual & NÃO \\
\hline
\end{tabular}




\section{QUADRO 7. CONTINUAÇÃO}

\section{ERMELINO}

4. Atividades específicas

4.1 Externas

4.2 Grupo terapêutico verbal

4.3 Grupo terapêutico nãoverbal

4.4 Atendimento individual

4.5 Visita / atendimento domiciliar

4.6 Educação e saúde

4.7 Comissões
Eventualmente

Psicoterapia

TO, sensibilização corporal.

SIM

NÃO

SIM

Para criação da Associação Recriar em 1996.
SÃO MIGUEL

Eventualmente

Psicoterapia

TO

SIM

SIM

$---$

$---$

5. Reuniões

a) administração

SIM

b) clínicas

SIM

SIM

c) supervisão

SIM (3meses, financiado pelos profissionais, no período de out. a

SIM (1 mês) dez. de 1993)

\section{Referência e Contra} referência

\begin{tabular}{|c|c|c|}
\hline 6.1 UBS & $\begin{array}{l}\text { Falta de psiquiatra nesses serviços } \\
\text { dificulta desligamento para UBS. }\end{array}$ & $\begin{array}{l}\text { Falta de psiquiatra nesses serviços } \\
\text { dificulta desligamento para UBS. }\end{array}$ \\
\hline 6.2 CECCO & $\begin{array}{l}\text { Consideram que os critérios de } \\
\text { admissão para o HD são rígidos. }\end{array}$ & $\begin{array}{l}\text { Consideram que os critérios de admissão } \\
\text { para o HD são rígidos. }\end{array}$ \\
\hline 6.3 Enfermaria psiquiátrica & $\begin{array}{c}\text { Aceita encaminhamento para } \\
\text { internação; tem maior dificuldade } \\
\text { para encaminhar pacientes para o HD } \\
\text { (critérios rígidos). }\end{array}$ & $\begin{array}{l}\text { Para internação é necessário recorrer à } \\
\text { enfermaria psiquiátrica de Ermelino e } \\
\text { outros hospitais psiquiátricos. }\end{array}$ \\
\hline \multicolumn{3}{|l|}{ 7. Principais problemas } \\
\hline 7.1 Recursos materiais e físicos & $\begin{array}{l}\text { Infra-estrutura adequada, algumas } \\
\text { salas sem isolamento acústico, } \\
\text { material insuficiente, inexistente para } \\
\text { determinadas atividades. }\end{array}$ & $\begin{array}{l}\text { Infra-estrutura adequada, material } \\
\text { insuficiente, inexistente para } \\
\text { determinadas atividades. }\end{array}$ \\
\hline 7.2 Recursos humanos & $\begin{array}{l}\text { Maior dificuldade para fixação de } \\
\text { médicos, mas equipe completa. } \mathrm{N}^{\circ} \\
\text { insuficiente de Psiq e TO. }\end{array}$ & $\begin{array}{l}\text { Muita dificuldade para fixação de } \\
\text { médicos. } \mathrm{N}^{\circ} \text { insuficiente de Psiq e TO. }\end{array}$ \\
\hline
\end{tabular}




\section{QUADRO 7. CONTINUAÇÃO}

\begin{tabular}{|c|c|c|}
\hline & ERMELINO & SÃO MIGUEL \\
\hline 7.3 Proposta assistencial & $\begin{array}{l}\text { Definida autonomamente pela equipe } \\
\text { tornando o serviço um equipamento } \\
\text { isolado na rede de saúde mental. } \\
\text { Estruturada pelo modelo clínico de } \\
\text { equipe interdisciplinar privilegiando o } \\
\text { olhar sobre os usuários, família, } \\
\text { equipe. Pressão regional e distrital } \\
\text { (1994-96) para aumento do número } \\
\text { de usuários atendidos é entendida } \\
\text { como diminuição da qualidade da } \\
\text { assistência. }\end{array}$ & $\begin{array}{l}\text { Centrada em atendimento por } \\
\text { profissionais; Conflitos entre os } \\
\text { diferentes saberes e o poder } \\
\text { institucional inviabiliza a constituição } \\
\text { da equipe; Pressão da administração } \\
\text { 93-96 aumenta êxodo de profissionais } \\
\text { e do conflito. Muito aberta onde a } \\
\text { autonomia profissional e a falta de } \\
\text { acompanhamento da implantação do } \\
\text { serviço inviabilizam a constituição da } \\
\text { equipe e o desenvolvimento da } \\
\text { proposta assistencial ao longo de todo } \\
\text { período. }\end{array}$ \\
\hline
\end{tabular}




\section{ANEXO I}

QUADRO 8. ELEMENTOS PARA DISCUSSÃO DA PRÁTICA ASSISTENCIAL EM SAÚDE MENTAL, GESTORES, PLANEJADORES DE NÍVEL REGIONAL, DISTRITAL, PERÍODO DE 1993-1995.

\begin{tabular}{|c|c|c|c|c|c|}
\hline Fases do Processo & COAS & ARS-6 & D.S. ERMELINO & D.S. SÃO MIGUEL & D.S. ITAIM \\
\hline \begin{tabular}{|l|} 
I. Constituição das \\
Assessorias Técnicas
\end{tabular} & $\begin{array}{l}\text { Indicação da } \\
\text { Coordenação de } \\
\text { profissionais de saúde } \\
\text { com experiência em } \\
\text { saúde mental. }\end{array}$ & $\begin{array}{l}\text { Profissional da região } \\
\text { trabalhando no Hospital } \\
\text { acumula função de } \\
\text { interlocutor no D.S. }\end{array}$ & $\begin{array}{l}\text { O mesmo profissional } \\
\text { da ARS. }\end{array}$ & $\begin{array}{l}\text { Profissional da região } \\
\text { desde 1988, com função } \\
\text { assistencial no Hospital } \\
\text { e disponibilidade para } \\
\text { pensar a assistência no } \\
\text { DS. }\end{array}$ & $\begin{array}{l}\text { Foi indicado um } \\
\text { profissional de nível } \\
\text { superior com cargo } \\
\text { administrativo que não } \\
\text { permaneceu. }\end{array}$ \\
\hline $\begin{array}{l}\text { II. Proposta } \\
\text { Assistencial }\end{array}$ & $\begin{array}{l}\text { 1. Teoricamente a } \\
\text { mesma no que diz } \\
\text { respeito à criação dos } \\
\text { serviços com } \\
\text { redimensionamento de } \\
\text { suas competências nas } \\
\text { UBS e HD. } \\
\text { 2. Discutindo qual é o } \\
\text { caráter do CECCO. }\end{array}$ & $\begin{array}{l}\text { Permanece a mesma, no } \\
\text { entanto sem o apoio } \\
\text { institucional necessário } \\
\text { para viabilizar a não } \\
\text { internação em hospital } \\
\text { psiquiátrico e o } \\
\text { acompanhamento nos } \\
\text { outros serviços (HD, } \\
\text { CECCO, UBS). }\end{array}$ & $\begin{array}{l}\text { Permanece a mesma, no } \\
\text { entanto sem o apoio } \\
\text { institucional necessário } \\
\text { para viabilizar a não } \\
\text { internação em hospital } \\
\text { psiquiátrico e o } \\
\text { acompanhamento nos } \\
\text { outros serviços (HD, } \\
\text { UBS). }\end{array}$ & $\begin{array}{l}\text { 1. Denúncia do } \\
\text { discurso técnico da } \\
\text { administração anterior } \\
\text { que "não colocava a } \\
\text { mão na massa". } \\
\text { 2. População não foi } \\
\text { trabalhada, continua } \\
\text { pressionando } \\
\text { (fisicamente e } \\
\text { politicamente). } \\
\text { 3. Por internação na } \\
\text { administração anterior } \\
\text { havia boicote dos } \\
\text { profissionais que não } \\
\text { eram do mesmo grupo. } \\
\text { 4. Em } 1994 \text { criação do } \\
\text { programa para usuário } \\
\text { de drogas (700 } \\
\text { pacientes). }\end{array}$ & $\begin{array}{l}\text { Permanece a mesma } \\
\text { com necessidade de } \\
\text { atender maior número } \\
\text { de pessoas nos } \\
\text { equipamentos } \\
\text { específicos como } \\
\text { CECCO e HD na } \\
\text { região. }\end{array}$ \\
\hline
\end{tabular}


QUADRO 1. CONTINUAÇÃO

\begin{tabular}{|c|c|c|c|c|c|}
\hline Fases do Processo & COAS & ARS-6 & D.S. ERMELINO & D.S. SÃO MIGUEL & D.S. ITAIM \\
\hline $\begin{array}{l}\text { III. Principais } \\
\text { Problemas } \\
\text { 1. Proposta assistencial }\end{array}$ & Está sendo repensada. & $\begin{array}{l}\text { Com muitas dificuldades } \\
\text { pelas diferenças de } \\
\text { prioridades na gestão dos } \\
\text { recursos. }\end{array}$ & $\begin{array}{l}\text { 1. "a mesma em ritmo } \\
\text { lento". } \\
\text { 2. Tentativa de manter o } \\
\text { funcionamento. } \\
\text { 3. A transferência de } \\
\text { pacientes para hospital } \\
\text { psiquiátrico aumentou de } \\
3 \% \text { em } 90-92 \text { para quase } \\
50 \% \text { da demanda do PS } \\
\text { em 1993-96. }\end{array}$ & $\begin{array}{l}\text { Permanece a mesma, mais } \\
\text { é necessário discutir o } \\
\text { problema da emergência } \\
\text { psiquiátrica no Hospital. }\end{array}$ & $\begin{array}{l}\text { Defesa do trabalho } \\
\text { multiprofissional do } \\
\text { atendimento em grupo e } \\
\text { do CECCO. }\end{array}$ \\
\hline 2. Recursos Humanos & $\begin{array}{l}\text { Existem mas havia grande } \\
\text { êxodo. }\end{array}$ & $\begin{array}{l}\text { Esvaziamento de recursos } \\
\text { humanos pelos baixos } \\
\text { salários e pela } \\
\text { possibilidade de } \\
\text { transformar profissionais } \\
\text { diaristas em plantonistas } \\
\text { nos hospitais. Êxodo de } \\
\text { médicos para os serviços } \\
\text { hospitalares deixando os } \\
\text { outros serviços. }\end{array}$ & $\begin{array}{l}\text { 1. Postura de não } \\
\text { transferir médicos de } \\
\text { UBS para Enfermaria, } \\
\text { mas o êxodo se dá por } \\
\text { emissão ou transferência } \\
\text { para outra ARS. } \\
\text { 2. Profissionais não } \\
\text { médicos mais fixados } \\
\text { aos serviços e por } \\
\text { menores privilégios. }\end{array}$ & $\begin{array}{l}\text { 1. Êxodo de médicos } \\
\text { para os serviços } \\
\text { hospitalares deixou UBS } \\
\text { sem quadros. } \\
\text { 2. HD com grandes } \\
\text { problemas para fixar } \\
\text { profissionais e pequena } \\
\text { clientela atendida. }\end{array}$ & $\begin{array}{l}\text { 1. Grande autonomia } \\
\text { profissional no serviço } \\
\text { público. } \\
\text { 2. Profissionais têm } \\
\text { discurso de defesa da } \\
\text { população mas não } \\
\text { aceitam programas } \\
\text { propostos. }\end{array}$ \\
\hline $\begin{array}{l}\text { 3. Recursos Materiais / } \\
\text { físicos }\end{array}$ & Existem com problemas. & São insuficientes. & São insuficientes. & $\begin{array}{l}\text { Enfermaria psiquiátrica } \\
\text { nunca se efetivou apenas } \\
\text { planejada na reforma do } \\
\text { hospital. São insuficientes. }\end{array}$ & --- \\
\hline $\begin{array}{l}\text { 4. Formação / } \\
\text { Capacitação }\end{array}$ & $\begin{array}{l}\text { Com cursos periódicos e } \\
\text { sobre temas pontuais. }\end{array}$ & $\begin{array}{l}\text { Necessária mas não } \\
\text { existem recursos. } \\
\text { Discussões ampliadas no } \\
\text { fórum de s. mental. }\end{array}$ & Necessária. & Necessária. & --- \\
\hline
\end{tabular}




\section{ANEXO I}

\section{QUADRO 9. ELEMENTOS PARA DISCUSSÃO DO MODELO ASSISTENCIAL EM SAÚDE MENTAL NAS UBS, PERÍODO 1989-1996}

\begin{tabular}{|c|c|c|c|c|}
\hline \multirow{2}{*}{ PROCESSO } & \multicolumn{2}{|c|}{ ERMELINO } & \multirow{2}{*}{$\frac{\text { SÃO MIGUEL }}{\text { Novos prof. }}$} & \multirow{2}{*}{$\begin{array}{c}\text { ITAIM } \\
\text { Novos prof. }\end{array}$} \\
\hline & Prof. Existente & Novos prof. & & \\
\hline \multicolumn{5}{|l|}{ 1. Acolhida do prof. } \\
\hline $\begin{array}{l}\text { 1.2 Reconhecimento do } \\
\text { papel profissional } \\
\text { 1.3 Definição do papel } \\
\text { prof. Esperado. }\end{array}$ & $\begin{array}{l}\text { Não é clara a nova } \\
\text { proposta. } \\
\text { Prévia sem discussão. }\end{array}$ & $\begin{array}{l}\text { Não explicada, não } \\
\text { trabalhada. } \\
\text { Não foi percebido. } \\
\\
\text { A cargo do } \\
\text { profissional autonomia } \\
\text { diante de cenário } \\
\text { desconhecido } \\
\text { (funcionamento do } \\
\text { serviço, grupos de } \\
\text { risco). }\end{array}$ & $\begin{array}{l}\text { A cargo do profissional } \\
\text { autonomia diante de } \\
\text { cenário desconhecido } \\
\text { (funcionamento do } \\
\text { serviço, grupos de risco). }\end{array}$ & \begin{tabular}{|c} 
Sem cadeira para \\
sentar, nos \\
corredores com os \\
usuários. \\
Cobrança de \\
trabalho de \\
psicólogos. \\
A cargo do \\
profissional \\
autonomia diante de \\
cenário \\
desconhecido \\
(funcionamento do \\
serviço, grupos de \\
risco). \\
\end{tabular} \\
\hline \multicolumn{5}{|l|}{ 2. Implantação } \\
\hline $\begin{array}{l}2.1 \text { Divulgação, } \\
\text { convencimento para } \\
\text { adesão }\end{array}$ & $\begin{array}{l}\text { Qual destino dos usuários } \\
\text { já atendidos? Falta de } \\
\text { preparo para trabalhar } \\
\text { com grupo de risco. }\end{array}$ & $\begin{array}{c}\text { Dificuldade para } \\
\text { explicitação de } \\
\text { opiniões e de } \\
\text { diferentes visões sobre } \\
\text { a Luta } \\
\text { Antimanicomial. }\end{array}$ & $\begin{array}{c}\text { Em grandes reuniões, } \\
\text { especificando os grupos } \\
\text { de risco a serem } \\
\text { atendidos. } \\
\text { Em grandes reuniões sem } \\
\text { espaço para aprofundar os } \\
\text { desdobramentos da } \\
\text { proposta; } \\
\text { Para os problemas da } \\
\text { UBS não havia resposta } \\
\text { clara: como se trabalhar, o } \\
\text { que fazer? }\end{array}$ & $\begin{array}{c}\text { Feito convencimento } \\
\text { do prof. para escolha } \\
\text { de vaga pela } \\
\text { proposta de trabalho } \\
\text { por colega de RH do } \\
\text { Distrito. } \\
\text { Fóruns grandes, } \\
\text { muitas queixas, } \\
\text { lamentações sobre as } \\
\text { condições de } \\
\text { trabalho. }\end{array}$ \\
\hline \multicolumn{5}{|l|}{$\begin{array}{l}\text { 3. Acompanhamento } \\
\text { da implantação }\end{array}$} \\
\hline $\begin{array}{l}\text { 3.1 Discussão, } \\
\text { problematização, } \\
\text { suporte }\end{array}$ & $\begin{array}{c}\text { Embates profissionais } \\
\text { levando a ambiente } \\
\text { desfavorável ao trabalho } \\
\text { em equipe. } \\
\text { Reivindicação de } \\
\text { supervisão contínua do } \\
\text { trabalho. } \\
\text { Visível, necessário } \\
\text { autoritário. }\end{array}$ & $\begin{array}{c}\text { Como trabalhar com } \\
\text { grupos de risco, como } \\
\text { instrumentalizar os } \\
\text { prof., como viabilizar } \\
\text { um serviço sem } \\
\text { tradição para tal. } \\
\text { Visível, necessário. }\end{array}$ & $\begin{array}{c}\text { Não era claro se as } \\
\text { propostas de viabilização } \\
\text { da assistência eram as que } \\
\text { estavam em curso. } \\
\text { Supervisão reivindicada } \\
\text { pelos técnicos } \\
\text { O necessário }\end{array}$ & $\begin{array}{c}\text { Existia vontade } \\
\text { política, na prática } \\
\text { da UBS não foi } \\
\text { possível romper com } \\
\text { as dificuldades do } \\
\text { grupo de trabalho e } \\
\text { da instituição. } \\
\text { Visível, autoritário }\end{array}$ \\
\hline
\end{tabular}


QUADRO 2. CONTINUAÇÃO

\begin{tabular}{|c|c|c|c|c|}
\hline \multirow{2}{*}{ PROCESSO } & \multicolumn{2}{|l|}{ ERMELINO } & \multirow{2}{*}{$\begin{array}{c}\text { SÃO MIGUEL } \\
\text { Novos prof. }\end{array}$} & \multirow{2}{*}{$\begin{array}{c}\text { ITAIM } \\
\text { Novos prof. }\end{array}$} \\
\hline & Prof. Existente & Novos prof. & & \\
\hline 4. Modelo real & $\begin{array}{l}\text { Incorporaram parte de pacientes } \\
\text { graves no acompanhamento } \\
\text { ambulatorial. } \\
\text { Aumento da demanda de outros } \\
\text { problemas (aprendizagem, } \\
\text { emocionais, etc) Extensa lista de } \\
\text { espera, dificuldade de trabalho em } \\
\text { equipe. }\end{array}$ & $\begin{array}{c}\text { Incorporaram } \\
\text { ambulatorialmente, } \\
\text { pacientes com } \\
\text { transtornos graves } \\
\text { em } \\
\text { acompanhamento } \\
\text { multiprofissional } \\
\text { Continuidade do } \\
\text { trabalho com outros } \\
\text { grupos não } \\
\text { previstos. } \\
\text { Não constituição de } \\
\text { trabalho em equipe } \\
\text { interprofissional. }\end{array}$ & $\begin{array}{c}\text { Incorporou } \\
\text { ambulatorialmente, } \\
\text { paciente com } \\
\text { transtornos graves em } \\
\text { acompanhamento } \\
\text { multiprofissional } \\
\text { Proposta sempre } \\
\text { cobrada, mas não } \\
\text { articulada. } \\
\text { Prof. requisitados a } \\
\text { participar de outros } \\
\text { programas, dificulta } \\
\text { agendamento em saúde } \\
\text { mental. }\end{array}$ & $\begin{array}{l}\text { Incorporação de } \\
\text { clientela com } \\
\text { transtornos mentais } \\
\text { graves e jovens, } \\
\text { somente } \\
\text { acompanhamento } \\
\text { psicológico. } \\
\text { Grande demanda de } \\
\text { crianças com } \\
\text { problemas de } \\
\text { aprendizagem. } \\
\text { Pais de adolescentes } \\
\text { com problemas de } \\
\text { adaptação. } \\
\text { Extensa lista de } \\
\text { espera. Inexistência } \\
\text { de equipe. } \\
\end{array}$ \\
\hline
\end{tabular}




\section{ANEXO I}

\section{QUADRO 10. ELEMENTOS PARA DISCUSSÃO DA PRÁTICA ASSISTENCIAL NOS CECCO, NO PERÍODO DE 1989-1996}

\begin{tabular}{|c|c|c|c|}
\hline PROCESSO & $\begin{array}{c}\text { ERMELINO }\left(2^{\circ} \text { semestre de }\right. \\
1992)\end{array}$ & SÃO MIGUEL (1991) & ITAIM $(22 / 03 / 92)$ \\
\hline \multicolumn{4}{|l|}{$\begin{array}{l}\text { 1. Constituição da } \\
\text { equipe }\end{array}$} \\
\hline 1.1 Chegada & $\begin{array}{l}\text { Para montagem do serviço (TO, } \\
\text { Psico.) }\end{array}$ & $\begin{array}{c}\text { Para montagem do serviço (Psico, } \\
\text { TO, Fono.) }\end{array}$ & $\begin{array}{c}\text { Para montagem do serviço } \\
\text { Psico. foi "convencido" por } \\
\text { prof. da região a escolher vaga } \\
\text { naquele serviço. }\end{array}$ \\
\hline $\begin{array}{l}1.2 \text { Equipe de } \\
\text { profissionais }\end{array}$ & TO/Psico/Fono/AS. & TO/Psico/Fono. & $\begin{array}{c}\text { Psico (Fono e TO por períodos } \\
\text { menores) }\end{array}$ \\
\hline $\begin{array}{l}\text { 1.3 Profissionais que } \\
\text { optaram por trabalhar } \\
\text { nesse equipamento, } \\
\text { pelas diretrizes } \\
\text { assistenciais. }\end{array}$ & TO. & TO/Psico/Fono & TO, Psico. \\
\hline $\begin{array}{l}\text { 1.4 Experiência em } \\
\text { Saúde Mental }\end{array}$ & TO/Psico. & TO/Psico. & --- \\
\hline $\begin{array}{l}\text { 2. Proposta } \\
\text { assistencial }\end{array}$ & $\begin{array}{l}\text { Técnicos também participaram da } \\
\text { interlocução de saúde mental e da } \\
\text { saúde da pessoa com deficiência. }\end{array}$ & $\begin{array}{c}\text { Técnicos participaram da elaboração } \\
\text { da proposta desde } 91 \text { e do grupo de } \\
\text { trabalho para normalização. }\end{array}$ & $\begin{array}{l}\text { Técnicos participaram dos } \\
\text { grupos de trabalho para } \\
\text { discussão e normatização. }\end{array}$ \\
\hline \multicolumn{4}{|l|}{ 3. Implantação } \\
\hline $\begin{array}{l}\text { 3.1 Divulgação / } \\
\text { convencimento }\end{array}$ & $\begin{array}{l}\text { Junto aos profissionais das UBS, } \\
\text { grupos comunitários e às demais } \\
\text { secretarias. }\end{array}$ & $\begin{array}{c}\text { Junto aos serviços de saúde, grupos } \\
\text { comunitários, prof. das UBS e as } \\
\text { demais secretarias. }\end{array}$ & $\begin{array}{l}\text { Junto aos serviços de saúde e } \\
\text { nas imediações do local. }\end{array}$ \\
\hline $\begin{array}{l}\text { 3.2 Discussão / } \\
\text { problematização }\end{array}$ & Constante & $\begin{array}{l}\text { Constante sobre o papel dos técnicos } \\
\text { e o lugar dos usuários. }\end{array}$ & $\begin{array}{l}\text { Constante e com apoio do } \\
\text { distrito. }\end{array}$ \\
\hline $\begin{array}{l}3.3 \text { Suporte para } \\
\text { encaminhamento de } \\
\text { pacientes ao serviço }\end{array}$ & Do distrito de parte das UBS. & $\begin{array}{l}\text { Do distrito para viabilização para } \\
\text { discussão com as demais secretarias. }\end{array}$ & $\begin{array}{c}\text { Do distrito, principalmente nas } \\
\text { negociações e com as demais } \\
\text { secretarias. }\end{array}$ \\
\hline $\begin{array}{l}\text { 4. Modelo } \\
\text { desenvolvido }\end{array}$ & $\begin{array}{l}\text { Serviço aberto à participação dos } \\
\text { usuários/comunidade e do } \\
\text { conselho gestor; baseado no } \\
\text { desenvolvimento de oficinas } \\
\text { como facilitadores de } \\
\text { convivência/formação de grupos. } \\
\text { Forte ligação com os movimentos } \\
\text { sociais da região. }\end{array}$ & $\begin{array}{l}\text { Serviço aberto à participação dos } \\
\text { usuários/comunidade e do conselho } \\
\text { gestor, baseado no desenvolvimento } \\
\text { de oficinas como facilitadores de } \\
\text { convivência/formação de grupos. } \\
\text { Revendo o seu papel e } \\
\text { funcionamento pela desestruturação } \\
\text { dos demais serviços da rede de saúde } \\
\text { mental (94-96). Serviço isolado, num } \\
\text { modelo fragmentado. }\end{array}$ & $\begin{array}{c}\text { Serviços abertos com } \\
\text { dificuldade de funcionamento } \\
\text { pelas instalações físicas. } \\
\text { Dificuldade para atender } \\
\text { população alvo pela não } \\
\text { existência de serviços básicos } \\
\text { com equipe de saúde mental, } \\
\text { HD e outros serviços. }\end{array}$ \\
\hline
\end{tabular}




\section{QUADRO 10. CONTINUAÇÃO}

\begin{tabular}{|c|c|c|c|}
\hline PROCESSO & ERMELINO & SÃO MIGUEL & ITAIM \\
\hline \multicolumn{4}{|l|}{ 5. Principais problemas } \\
\hline $\begin{array}{l}5.1 \text { Recursos materiais e } \\
\text { espaço físico }\end{array}$ & $\begin{array}{l}\text { Espaço físico razoável, recursos } \\
\text { materiais insuficientes. }\end{array}$ & $\begin{array}{c}\text { Espaço físico adequado, recursos } \\
\text { materiais insuficientes. }\end{array}$ & $\begin{array}{c}\text { "Container" numa praça/ parque; } \\
\text { material de consumo insuficiente } \\
\text { / inexistente. }\end{array}$ \\
\hline 5.2 Recursos humanos & $\begin{array}{l}\text { Falta de oficineiros, limita oferta } \\
\text { de oportunidades diferentes de } \\
\text { aprendizagem/ convivência. }\end{array}$ & $\begin{array}{l}\text { Falta de oficineiro limita as } \\
\text { opções às experiências dos } \\
\text { técnicos. }\end{array}$ & $\begin{array}{l}\text { Equipe técnica sempre } \\
\text { incompleta, inexistência de } \\
\text { oficineiro. }\end{array}$ \\
\hline 5.3 Proposta assistencial & $\begin{array}{l}\text { Exige contato constante com } \\
\text { serviços e com população para } \\
\text { estimular encaminhamento. }\end{array}$ & $\begin{array}{l}\text { Exige contato constante com } \\
\text { serviços e com população para } \\
\text { estimular encaminhamento. } \\
\text { Existe fragmentação de serviços } \\
\text { e do modelo assistencial em } \\
\text { saúde mental. }\end{array}$ & $\begin{array}{l}\text { Exige contato constante com } \\
\text { serviços e com população para } \\
\text { estimular encaminhamento. }\end{array}$ \\
\hline $\begin{array}{l}\text { 5.3.1 Clareza / } \\
\text { construção do serviço }\end{array}$ & $\begin{array}{l}\text { Técnicos com papel fundamental } \\
\text { de questionamento da viabilidade } \\
\text { da proposta e as necessidades de } \\
\text { mudanças ao longo do período. }\end{array}$ & $\begin{array}{l}\text { Viabilidade do “modelo" de } \\
\text { participação população alvo x } \\
\text { população geral? Convivência e } \\
\text { possibilidades concretas de } \\
\text { inserção social são construções } \\
\text { complexas. }\end{array}$ & $\begin{array}{l}\text { Proposta de funcionamento não } \\
\text { era clara, não era possível para } \\
\text { serviço sem equipes e sem } \\
\text { condições mínimas. }\end{array}$ \\
\hline $\begin{array}{l}\text { 5.3.2 Papel dos técnicos } \\
\text { / o que é Terapêutico? }\end{array}$ & $\begin{array}{l}\text { Levantar as dúvidas; discutir o } \\
\text { caminho do terapêutico no } \\
\text { percurso do trabalho na equipe, } \\
\text { facilitadores da inclusão dessa } \\
\text { população. }\end{array}$ & $\begin{array}{l}\text { Como acompanhar o trabalho } \\
\text { dos oficineiros? Como lidar com } \\
\text { situações de crise dos usuários } \\
\text { onde inexiste serviços de } \\
\text { referência? "Encaminhar" para } \\
\text { outros serviços é dificultar a } \\
\text { recuperação e o retorno do } \\
\text { usuário. }\end{array}$ & $\begin{array}{l}\text { Facilitadores, mantenedores do } \\
\text { funcionamento. }\end{array}$ \\
\hline $\begin{array}{l}\text { 5.3.3 Formação / } \\
\text { capacitação para o } \\
\text { trabalho }\end{array}$ & $\begin{array}{c}\text { Necessidade fundamental para o } \\
\text { desenvolvimento, } \\
\text { aprofundamento da proposta. }\end{array}$ & $\begin{array}{l}\text { Deveria ser continuada e na } \\
\text { região para não favorecer } \\
\text { abandono dos serviços por parte } \\
\text { do técnicos. }\end{array}$ & $\begin{array}{l}\text { Necessidade para criar o } \\
\text { trabalho. }\end{array}$ \\
\hline
\end{tabular}


ANEXO I

QUADRO 11. ELEMENTOS PARA DISCUSSÃO DA PRÁTICA ASSISTENCIAL NOS HD, NO PERÍODO DE 1989-96

\begin{tabular}{|c|c|c|}
\hline PROCESSO & ERMELINO (07/92) & SÃO MIGUEL (17/12/92) \\
\hline \multicolumn{3}{|l|}{ 1. Constituição da equipe } \\
\hline 1.1 Chegada & $\begin{array}{l}\text { 1992, para montagem, criação do serviço: } \\
\text { Psico, TO. }\end{array}$ & $\begin{array}{l}\text { 1992, para montagem, criação do } \\
\text { serviço,: Psiq, AS, Psico, TO. }\end{array}$ \\
\hline 1.2 Experiência anterior em HD & TO, Psiq. & TO., AS, Psiq. \\
\hline 2. Proposta Assistencial & $\begin{array}{l}\text { Técnicos da equipe participaram em grupo } \\
\text { de trabalho da SMS que elaborou normas } \\
\text { para os HD em final de } 1992 .\end{array}$ & $\begin{array}{l}\text { Equipe de profissionais conhece e } \\
\text { defende as diretrizes de 1992; } \\
\text { colocam como porta de entrada da } \\
\text { rede o Pronto Socorro (evento } \\
\text { sentinela). }\end{array}$ \\
\hline \multicolumn{3}{|l|}{ 3. Implantação } \\
\hline 3.1 Autonomia das equipes & $\begin{array}{l}\text { Leva a criação de critérios fechados para } \\
\text { admissão de usuários. }\end{array}$ & $\begin{array}{l}\text { Privilegiando as diretrizes } \\
\text { colocadas pelos profissionais. }\end{array}$ \\
\hline 3.2 Discussão / problematização / suporte & $\begin{array}{l}\text { Necessidade dos profissionais buscarem } \\
\text { supervisão técnica para o desenvolvimento } \\
\text { do trabalho reitera autonomia profissional. }\end{array}$ & $\begin{array}{l}\text { Equipe vive conflitos extremos } \\
\text { para definir sua proposta de } \\
\text { abordagem teórica para o } \\
\text { tratamento. }\end{array}$ \\
\hline 4. Modelo desenvolvido & $\begin{array}{l}\text { Equipe interprofissional; equipe profissional } \\
\text { trabalha mantendo os princípios colocados } \\
\text { em } 1993 \text { apesar da falta de apoio entre } \\
\text { 93-96. Supervisão conjunta com demais } \\
\text { serviços de saúde mental pela SMS até 93, } \\
\text { supervisão contratada pela equipe, } \\
\text { quinzenalmente no serviço. }\end{array}$ & $\begin{array}{l}\text { Conflitos levam à divisão de } \\
\text { pacientes entre duas equipes de } \\
\text { técnicos; Atendimento a mais ou } \\
\text { menos 10-15 usuários entre out/95 } \\
\text { - abril/96; Não se consolida } \\
\text { trabalho em equipe e sim por } \\
\text { profissionais; Questões de poder } \\
\text { interno (saber x poder). }\end{array}$ \\
\hline
\end{tabular}




\section{ANEXO I}

\section{QUADRO 12.ELEMENTOS PARA DISCUSSÃO DA PRÁTICA ASSISTENCIAL EM SAÚDE DA PESSOA COM DEFICIÊNCIA NO DISTRITO DE SÃO MIGUEL}

\begin{tabular}{|c|c|c|c|c|c|c|}
\hline \multirow{2}{*}{ PROCESSO } & \multirow{2}{*}{ CECCO } & \multicolumn{5}{|c|}{ UBS } \\
\hline & & JD. Helena & V. Jacuí & V. Nova Curuçá & V. Progresso & Jd. Maia \\
\hline \multicolumn{7}{|l|}{ 1. Constituição da equipe } \\
\hline 1.1 Chegada & $\begin{array}{c}\text { Esperada para montagem de } \\
\text { serviço. }\end{array}$ & Não esperada & Não esperada & Não esperada & Esperada & Não esperada \\
\hline $\begin{array}{l}\text { a) Experiência anterior com } \\
\text { ppd }\end{array}$ & $\mathrm{TO}$ & Psico & Fono, Fisio & TO & --- & $\mathrm{TO}$ \\
\hline b) Equipe & Psico, Fono, TO & $\begin{array}{l}\text { TO, Psico, } \\
\text { Pediatra }\end{array}$ & Fono, TO, Psico & Fono, TO, Psico & Psico, Fisio (92-95) & TO, Psico \\
\hline $\begin{array}{l}\text { 1.2 Reconhecimento do } \\
\text { papel profissional }\end{array}$ & $\begin{array}{l}\text { Percebido, contribuição à } \\
\text { criação do serviço. }\end{array}$ & Não percebido & Não percebido & Não percebido & Percebido & Não percebido \\
\hline 2. Proposta assistencial & Conhece & Não conhece & Não conhece & Não conhece & Não conhece & Não conhece \\
\hline \multicolumn{7}{|l|}{ 3. Implantação } \\
\hline $\begin{array}{l}3.1 \text { autonomia profissional / } \\
\text { definição anterior }\end{array}$ & $\begin{array}{c}\text { Grande autonomia e } \\
\text { participação dos profissionais } \\
\text { no desenvolvimento do serviço. }\end{array}$ & Autonomia & Autonomia & Autonomia & Autonomia & Autonomia \\
\hline $\begin{array}{l}3.2 \text { discussão / } \\
\text { problematização }\end{array}$ & $\begin{array}{l}\text { Constante junto ao grupo de } \\
\text { trabalho do CECCO e pequena } \\
\text { junto à Assessoria PPD. }\end{array}$ & --- & $\begin{array}{l}\text { Tentativa de criar } \\
\text { equipe, não } \\
\text { desistência apenas } \\
\text { diante do PAS. }\end{array}$ & Inexistente & $\begin{array}{l}\text { Foi montada serviço de } \\
\text { fisioterapia com } \\
\text { reformas na área física. }\end{array}$ & $\begin{array}{c}\text { Sobre a } \\
\text { contribuição dos } \\
\text { profissionais nas } \\
\text { atividades } \\
\text { preventivas no } \\
\text { serviço. }\end{array}$ \\
\hline $\begin{array}{l}\text { 3.3 Suporte técnico / nível } \\
\text { regional e central }\end{array}$ & $\begin{array}{l}\text { Pequeno para desenvolver } \\
\text { assistência a PPD. }\end{array}$ & Inexistente & Pequeno, inexistente & $\begin{array}{l}\text { Inexistente para } \\
\text { PPD }\end{array}$ & $\begin{array}{l}\text { Profissional recebeu } \\
\text { apoio e recursos para } \\
\text { criação do serviço. }\end{array}$ & $\begin{array}{l}\text { TO participou } \\
\text { atividades } \\
\text { CECCO } \\
\end{array}$ \\
\hline
\end{tabular}


QUADRO 5. CONTINUAÇÃO

\begin{tabular}{|c|c|c|c|c|c|c|}
\hline \multirow{2}{*}{ PROCESSO } & \multirow{2}{*}{ CECCO } & \multicolumn{5}{|c|}{ UBS } \\
\hline & & JD. Helena & V. Jacuí & V. Nova Curuçá & V. Progresso & Jd. Maia \\
\hline $\begin{array}{l}\text { 3.4 Controle do trabalho } \\
\text { profissional }\end{array}$ & $\begin{array}{c}\text { Constante, maior entre 93-96 } \\
\text { - com cobrança de } \\
\text { produtividade. }\end{array}$ & --- & $\begin{array}{l}\text { Constante entre } \\
89-92 \text { pela } \\
\text { proposta saúde } \\
\text { mental, exigência } \\
\text { posteriormente } \\
\text { produtividade. }\end{array}$ & & $\begin{array}{l}\text { Nenhum } \\
\text { profissional aderia } \\
\text { ao PAS em outra } \\
\text { região e o serviço } \\
\text { não funcionou. }\end{array}$ & Irregular \\
\hline \multicolumn{7}{|l|}{ 4. Modelo desenvolvido } \\
\hline 4.1 População alvo & & & & & & \\
\hline a) atendimento individual & Quando necessário & $\begin{array}{l}\text { Problemas de } \\
\text { aprendizagem }\end{array}$ & $\begin{array}{c}\text { Adultos problemas } \\
\text { posturais, crianças } \\
\text { com problemas. }\end{array}$ & AVC, PC & $\begin{array}{l}\text { Problemas de } \\
\text { aprendizagem, } \\
\text { casos neurológicos } \\
\text { e ortopédicos. }\end{array}$ & RDNPM \\
\hline b) atendimento grupal & DM & Idoso & $\begin{array}{l}\text { Afásicos (pouco } \\
\text { tempo) }\end{array}$ & $\begin{array}{l}\text { Problemas de } \\
\text { aprendizagem }\end{array}$ & $\begin{array}{l}\text { Problema de } \\
\text { aprendizagem }\end{array}$ & RDNPM \\
\hline c) orientação & Mães & & & Idosos, mães & Mães & Mães \\
\hline d) grupo comunitário & --- & & --- & & & --- \\
\hline e) outros serviços & Movimento & $\begin{array}{c}\text { Escola } \\
\text { especializada }\end{array}$ & --- & Escola & Escola & $\begin{array}{l}\text { TO participa do } \\
\text { CECCO }\end{array}$ \\
\hline 4.2 Outros grupos de usuários & --- & Idoso & & --- & $\begin{array}{l}\text { Gestante, crianças } \\
\text { desnutridas }\end{array}$ & \\
\hline 4.3 Equipe & & & & & & \\
\hline a) reuniões & $\begin{array}{c}\text { Periódicas para discussão do } \\
\text { trabalho }\end{array}$ & --- & $\begin{array}{c}\text { Inicialmente } \\
\text { tentativa de serem } \\
\text { periódicas (92-94) }\end{array}$ & --- & --- & --- \\
\hline b) Contato prof/prof & & --- & Contato pessoal & --- & --- & SIM \\
\hline
\end{tabular}


QUADRO 5. CONTINUAÇÃO

\begin{tabular}{|c|c|c|c|c|c|c|}
\hline \multirow{2}{*}{ PROCESSO } & \multirow{2}{*}{ CECCO } & \multicolumn{5}{|c|}{ UBS } \\
\hline & & JD. Helena & V. Jacuí & V. Nova Curuçá & V. Progresso & Jd. Maia \\
\hline c) discussão de caso & Frequente & --- & $\begin{array}{l}\text { Frequentes } \\
\text { quando } \\
\text { necessário } \\
\end{array}$ & SIM & SIM & --- \\
\hline \multicolumn{7}{|l|}{ 5. Principais problemas } \\
\hline $\begin{array}{l}5.1 \text { recursos materiais e } \\
\text { espaço físico }\end{array}$ & Sempre difícil & Sempre difícil & $\begin{array}{l}\text { Sempre difícil do } \\
\text { mais simples } \\
\text { desde } 91 \mathrm{em} \\
\text { diante. }\end{array}$ & $\begin{array}{l}\text { Sempre difícil do } \\
\text { mais simples } \\
\text { desde } 91 \mathrm{em} \\
\text { diante. }\end{array}$ & $\begin{array}{l}\text { Sempre difícil } \\
\text { em 1994-5 } \\
\text { recursos para } \\
\text { reforma. }\end{array}$ & Inexistente \\
\hline 5.2 Recursos humanos & $\begin{array}{l}\text { Equipe motivada mais } \\
\text { pelo comprimento com a } \\
\text { assistência do que pelos } \\
\text { apoios institucionais. }\end{array}$ & $\begin{array}{l}\text { Equipe pequena } \\
\text { e pouco } \\
\text { motivada para } \\
\text { PPD }\end{array}$ & $\begin{array}{c}\text { Com } \\
\text { compromisso no } \\
\text { trabalho em } \\
\text { saúde mental } \\
\text { devendo ser } \\
\text { sensibilizado e } \\
\text { apoiado para } \\
\text { trabalho com } \\
\text { PPD. }\end{array}$ & $\begin{array}{l}\text { Equipe pequena } \\
\text { e pouco } \\
\text { motivada para } \\
\text { PPD }\end{array}$ & $\begin{array}{c}\text { Alguns } \\
\text { profissionais sem } \\
\text { compromisso } \\
\text { com a } \\
\text { assistência. }\end{array}$ & $\begin{array}{l}\text { Equipe } \\
\text { inexistente, } \\
\text { profissionais } \\
\text { desmotivados. }\end{array}$ \\
\hline 5.3 Proposta assistencial & $\begin{array}{c}\text { Importante refletir sobre o } \\
\text { que fazer com o PPD - } \\
\text { para facilitar sua } \\
\text { autonomia. }\end{array}$ & Não discute & $\begin{array}{c}\text { Pouco viável e } \\
\text { pouco discutida } \\
\text { na UBS, } \\
\text { prevenção / } \\
\text { tratamento. O } \\
\text { que priorizar? }\end{array}$ & Não discute & $\begin{array}{l}\text { Pensada com o } \\
\text { serviço de } \\
\text { fisioterapia e não } \\
\text { para a pessoa } \\
\text { com deficiência. }\end{array}$ & $\begin{array}{c}\text { Não chegou a ser } \\
\text { viabilizada }\end{array}$ \\
\hline
\end{tabular}




\section{ANEXO I}

QUADRO 13. ELEMENTOS PARA DISCUSSÃO DA PRÁTICA ASSISTENCIAL EM SAÚDE DA PESSOA COM DEFICIÊNCIA NO DISTRITO DE SAÚDE DO ITAIM PAULISTA, PERÍODO 1989-1996

\begin{tabular}{|c|c|c|c|}
\hline \multirow{2}{*}{ PROCESSO } & \multirow{2}{*}{ CECCO } & \multicolumn{2}{|c|}{ UBS } \\
\hline & & 1.Atualpa & 2.Camargo Novo \\
\hline \multicolumn{4}{|l|}{ 1. Constituição da equipe } \\
\hline 1.1 Chegada & $\begin{array}{l}\text { Esperada para a região, deslocada } \\
\text { para o serviço }\end{array}$ & --- & Esperada \\
\hline a) Experiência anterior com ppd & --- & --- & Fisio, TO \\
\hline b) Equipe & $\begin{array}{l}\text { Psico, TO, Fono em diferentes } \\
\text { momentos }\end{array}$ & Não existente & Fisio, TO, Psico \\
\hline $\begin{array}{l}\text { 1.2 Reconhecimento do papel } \\
\text { profissional }\end{array}$ & $\begin{array}{c}\text { Percebida possibilidade de } \\
\text { contribuição }\end{array}$ & Não percebido & $\begin{array}{l}\text { Percebido no cotidiano do trabalho no } \\
\text { serviço e no contato com o Distrito }\end{array}$ \\
\hline 2. Proposta assistencial & Não conhece & Não conhece & $\begin{array}{c}\text { Não conhecia em 92, em } 94 \text { fisio passa a } \\
\text { ser interlocutor da ppd. }\end{array}$ \\
\hline \multicolumn{4}{|l|}{ 3. Implantação } \\
\hline $\begin{array}{l}3.1 \text { autonomia profissional / definição } \\
\text { anterior }\end{array}$ & Grande autonomia & $\begin{array}{l}\text { Autonomia e poucos recursos } \\
\text { materiais e humanos. }\end{array}$ & $\begin{array}{c}\text { Autonomia dos profissionais, com apoio } \\
\text { da equipe distrital para aquisição de } \\
\text { equipamentos e espaço físico. }\end{array}$ \\
\hline 3.2 discussão / problematização & $\begin{array}{c}\text { Constante junto ao CECCO e } \\
\text { Distrito Saúde. }\end{array}$ & Constante & $\begin{array}{l}\text { Frequente, enriquecedora, } \\
\text { redimencionando expectativa / } \\
\text { possibilidades de trabalho. }\end{array}$ \\
\hline $\begin{array}{l}\text { 3.3 Suporte técnico / nível regional e } \\
\text { central }\end{array}$ & Pequeno para absorção das PPD. & Inexistente para PPD & $\begin{array}{l}\text { Autonomia dos profissionais que passam } \\
\text { a discutir o papel da UBS junto a } \\
\text { população com deficiência (temporárias } \\
\text { e permanentes) no nível distrital. }\end{array}$ \\
\hline
\end{tabular}


QUADRO 13. CONTINUAÇÃO

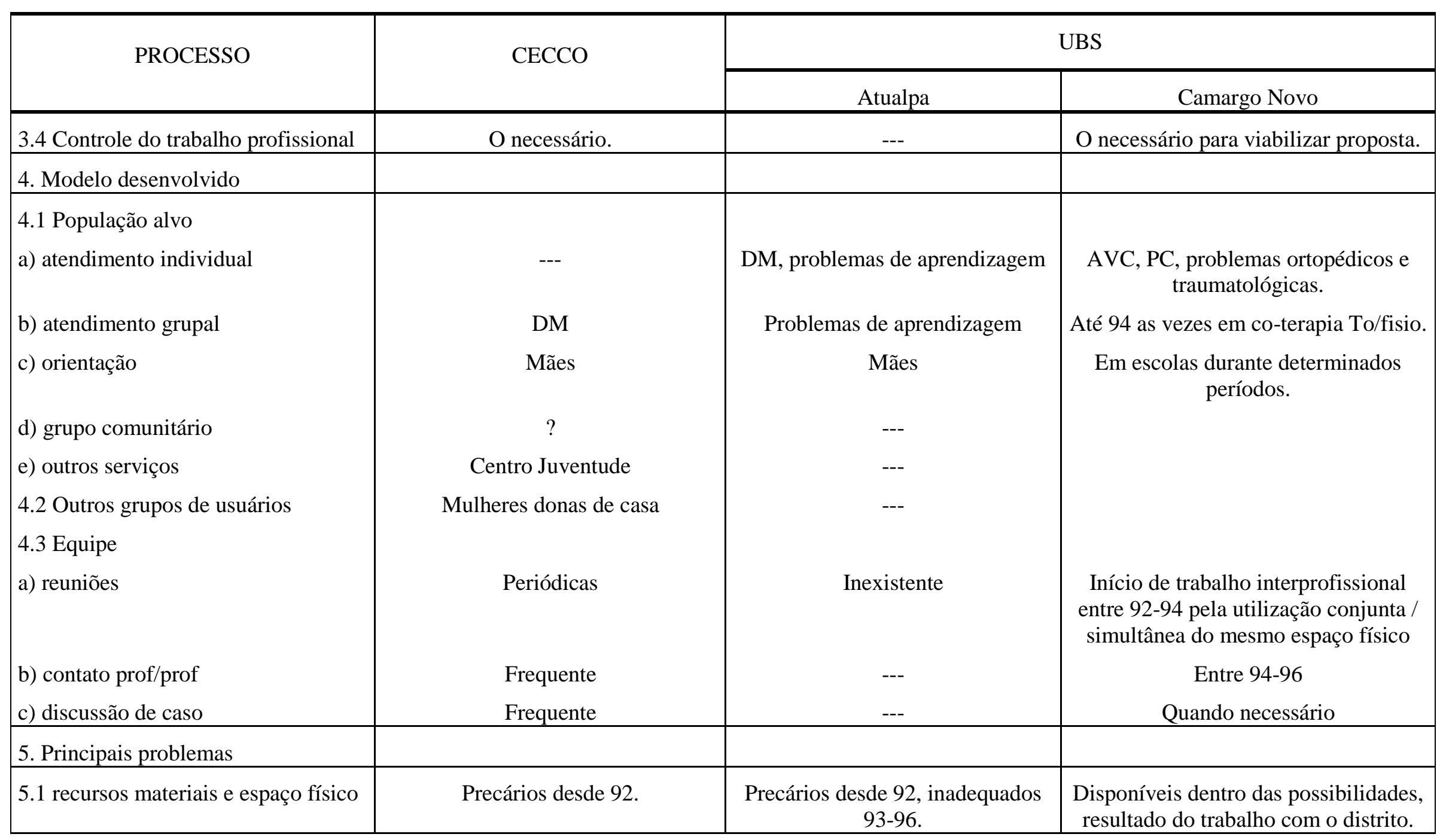


QUADRO 13. CONTINUAÇÃO

\begin{tabular}{|c|c|c|c|}
\hline \multirow{2}{*}{ Modelo Assistencial } & \multirow{2}{*}{ CECCO } & \multicolumn{2}{|c|}{ UBS } \\
\hline & & Atualpa & Camargo Novo \\
\hline 5.2 Recursos humanos & Insuficiente & Insuficiente & $\begin{array}{c}\text { Equipe incompleta até } \\
\text { 1994, entre 94-96 apenas } \\
\text { Fisio e Psico. }\end{array}$ \\
\hline 5.3 Proposta assistencial & $\begin{array}{l}\text { Havia necessidade de } \\
\text { apoio para discussão sobre } \\
\text { assistência à PPD. }\end{array}$ & $\begin{array}{c}\text { Deveria ser viabilizada } \\
\text { discussão sobre assistência } \\
\text { para PPD no contexto das } \\
\text { UBS. }\end{array}$ & $\begin{array}{c}\text { Fisio considera que o } \\
\text { atendimento na UBS } \\
\text { deveria ser preventivo } \\
\text { (crianças, escolas, } \\
\text { orientação e prevenção de } \\
\text { deficiência / } \\
\text { incapacidades) Reconhece } \\
\text { que a falta de serviço de } \\
\text { referência exige } \\
\text { acompanhamento } \\
\text { tratamento de usuários } \\
\text { com problemas já } \\
\text { instalados e que a falta de } \\
\text { equipe inviabiliza a } \\
\text { proposta de trabalho. }\end{array}$ \\
\hline
\end{tabular}


ANEXO II DOCUMENTOS 


\section{Pessoa portadora de deficiência}

SECRETARIA MUNICIPAL DE EDUCAÇÃO \& SECRETARIA MUNICIPAL DE SAÚDE Programa de atendimento ao portador de deficiência em escolas comuns na rede municipal de ensino. São Paulo, mimeo, s/d, 8 p.

SECRETARIA MUNICIPAL DE EDUCAÇÃO \& SECRETARIA MUNICIPAL DE SAÚDE Relatório da reunião conjunta entre SMS e SME sobre saúde escolar. São Paulo, mimeo, 1991, 5p.

SECRETARIA MUNICIPAL DE EDUCAÇÃO. Definindo uma política de atendimento aos portadores de necessidades especiais ( educação especial). São Paulo, em ou pós 1991, $15 \mathrm{p}$.

SECRETARIA MUNICIPAL DE EDUCAÇÃO \& SECRETARIA MUNICIPAL DE SAÚDE Relatório do Grupo de Trabalho de Saúde Escolar sobre levantamento sobre a situação dos portadores de deficiência nas EMEIs e EMPGs da região de ARS-6. São Paulo, mimeo, 1990, 10p.

SECRETARIA MUNICIPAL DE SAÚDE. Proposta de Atenção à Saúde da Pessoa Deficiente. Centro de Organização da Atenção à Saúde - COAS. São Paulo, abril de 1992, $56 \mathrm{p}$.

SECRETARIA MUNICIPAL DE EDUCAÇÃO \& SECRETARIA MUNICIPAL DE SAÚDE \& SECRETARIA MUNICIPAL DE CULTURA. Documento-relatório sobre o processo de construção de uma nova política de enfrentamento à discriminação através do acesso qualificado pela política de transporte adaptado aos serviços especiais: Centro de Convivência e Cooperativa e Centro de Apoio e Projetos. Grupo de Trabalho Intersecretarial Cultura, Cidadania e Saúde Mental, São Paulo, mimeo, 1992, 5p.

SÃO PAULO. Lei n. 11.257 de 7 de outubro de 1992 que autoriza a Prefeita do Município de São Paulo a implantar serviço de "Rádio- Perua", destinado ao atendimento das pessoas portadoras de deficiência física D.O.M. 8/10/92.

SECRETARIA MUNICIPAL DE SAÚDE. Relatório de 1992. Programa de Atenção à Saúde da Pessoa Deficiente. COAS. São Paulo, 11/01/93, 6p.

SECRETARIA MUNICIPAL DE SAÚDE. Atividades desenvolvidas Janeiro a Abril de 1993. Programa de Atenção à Saúde da Pessoa Deficiente. COAS. São Paulo, 30/04/93, 4p.

SECRETARIA MUNICIPAL DE SAÚDE. Relatório Anual Simplificado. Programa de Atenção à Saúde da Pessoa Deficiente. São Paulo, dezembro de 1994, 5p. 
SECRETARIA MUNICIPAL DE SAÚDE. Atividades realizadas no ano de 1995. Programa de Atenção à Saúde da Pessoa Deficiente. COAS. São Paulo, s/d. 2p.

SECRETARIA MUNICIPAL DE SAÚDE. Cronograma referente à apresentação do Plano de Trabalho. Programa de Atenção à saúde da Pessoa Deficiente. COAS. São Paulo, 1993, $5 \mathrm{p}$.

SÃO PAULO. Lei n. 11.607 de 13 de julho de 1994 que dispõe sobre a criação de Oficinas Abertas de trabalho para ensino e profissionalização de deficientes físicos. D.O.M. 14/07/94.

SECRETARIA MUNICIPAL DE SAÚDE. Relação de Serviços. Programa de Atenção à Saúde da Pessoa Deficiente. COAS. São Paulo, 1995/96, 29p. 


\section{Saúde Mental}

SECRETARIA MUNICIPAL DE SAÚDE. Proposta de criação de projeto de lei sobre os Centros de Convivência e Cooperativa. Assessoria de Saúde Mental. COAS, São Paulo, mimeo, s/d, 18p.

SECRETARIA MUNICIPAL DE SAÚDE. Divulgação e solicitação de apoio ao projeto de lei 366/92 que dispõe sobre a promoção de saúde e da reintegração social das pessoas portadoras de sofrimento mental; implantação de modelo de saúde mental alternativo, com substituição dos hospitais psiquiátricos e sua extinção progressiva, regulamenta a internação involuntária e dá outras providências. Assessoria de Saúde Mental. COAS, São Paulo, mimeo, 1992, 10p.

SECRETARIA MUNICIPAL DE SAÚDE. Seminários Clínicos, Projeto de Formação Permanente de Recursos Humanos e Cursos de Aprimoramento. Assessoria de Saúde Mental. COAS. São Paulo, 1992, 4p.

SECRETARIA MUNICIPAL DE SAÚDE. Documento preparatório do Seminário sobre Saúde Mental, Cidadania e Qualidade de Vida da Cidade de São Paulo. Grupo de Trabalho Intersecretarial Cultura, Cidadania e Saúde Mental, São Paulo, mimeo, 1992, 6p.

SECRETARIA MUNICIPAL DE SAÚDE Textos de Psiquiatria para Treinamentos nas Emergências Psiquiátricas. Centro de Formação dos Trabalhadores da Saúde-CEFOR. São Paulo, 1992, 53p.

SECRETARIA MUNICIPAL DE SAÚDE. Atendimento Pré-Hospitalar- Manual para motoristas de Ambulâncias e Auxiliares de Enfermagem Emergências Psiquiátricas. Centro de Formação dos Trabalhadores da Saúde. São Paulo, 1992, 34p.

SECRETARIA MUNICIPAL DE SAÚDE. Diretrizes do Programa de Atenção à Saúde Mental. São Paulo. pós 92, 3p.

SECRETARIA MUNICIPAL DE SAÚDE. Roteiro para Auxiliar o Diagnóstico das Ações de Saúde mental no Distrito. Distrito de Saúde de Ermelino Matarazzo. São Paulo. 29/04/93, 2p.

SECRETARIA MUNICIPAL DE SAÚDE. Critérios para encaminhamento de pacientes ao HD de Ermelino Matarazzo. UNCONVITI D.S. 62. São Paulo, 12/05/93, 3p. 


\section{Centros de Convivência e Cooperativas}

SECRETARIA MUNICIPAL DE SAÚDE. Histórico e funcionamento do CECCO Ermelino Matarazzo. CECCO Ermelino Matarazzo. São Paulo, pós 1992, 5p.

SECRETARIA MUNICIPAL DE SAÚDE. Rotina para entrega de almoço no Hospital-Dia. Divisão Técnica e Administrativa do Distrito de Saúde de Ermelino Matarazzo. São Paulo, junho de 1994, 2p.

SECRETARIA MUNICIPAL DE SAÚDE. Cópia de Projeto de Lei que dispõe sobre o atendimento intersecretarial nos CECCOs. Programa de Saúde Mental. COAS. São Paulo, 23/08/94, 8p.

SECRETARIA MUNICIPAL DE SAÚDE. Sistema Municipal de Informações em Saúde-SIMIS. Módulo: Centro de Convivência e Cooperativa -CECCO Normas e Manual Técnico. Programa de Atenção em Saúde Mental. COAS. São Paulo, 1995, 42p. 


\section{Fórum Distrital de Saúde Mental - Ermelino Matarazzo}

SECRETARIA MUNICIPAL DE SAÚDE. Encaminhamento de ata de reunião de 29/07/93 e 12/08/93 e convocação para reunião de 26/08/93. São Paulo. Assistente Técnico de Direção D.S. 62, 19/08/93, 5p.

SECRETARIA MUNICIPAL DE SAÚDE. Encaminhamento de ata de reunião de 26/08/93 e convocação para reunião de 23/09/93. São Paulo. Assistente Técnico de Direção D.S. 62. São Paulo. 16/09/93, 2p.

SECRETARIA MUNICIPAL DE SAÚDE. Encaminhamento de ata de reunião de 7/10/93 e convocação para reunião de 21/10/93. São Paulo. Assistente Técnico de Direção D.S. 62, 19/10/93, 2p.

SECRETARIA MUNICIPAL DE SAÚDE. Encaminhamento de ata de reunião de 2/12/93 e 14/12/93 e das reuniões regionais de 18/11/93 e 6/01/94 e convocação para reunião de 3/02/94. São Paulo. Assistente Técnico de Direção D.S. 62. 24/01/94, 7p. 


\section{Conselhos Gestores e Participação Popular}

SECRETARIA MUNICIPAL DE SAÚDE \& CONSELHO MUNICIPAL DE SAÚDE. I Conferência Municipal de Saúde Implantação do Sistema Único de Saúde-o desafio da municipalização hoje. São Paulo, 24-26/08/90, 22p.

SECRETARIA MUNICIPAL DE SAÚDE. II Conferência Muncipal de Saúde Distritos de Saúde: construindo o SUS. Resoluções. São Paulo, mimeo, julho de 1991, 20p.

CENTRO DE ESTUDOS DE CULTURA CONTEMPORÂNEA. Participação e saúde. boletim Informativo n.5 agosto de 1992, 8p.

CENTRO DE ESTUdOS DE CULTURA CONTEMPORÂNEA. Participação e saúde. Boletim Informativo n.4 fevereiro de 1992, 8p.

SECRETARIA MUNICIPAL DE SAÚDE. Participação e controle social no sistema único de saúde, São Paulo, junho de 1992, 31p.

SECRETARIA MUNICIPAL DE SAÚDE. Circular n.1 da Comissão Organizadora da III Conferência Municipal de Saúde, São Paulo, mimeo, 26/08/92, 2p.

SECRETARIA MUNICIPAL DE SAÚDE. relatório da II Conferência Regional de Saúde da ARS-6. São Paulo, mimeo, 29/08/92, 4p.

SECRETARIA MUNICIPAL DE SAÚDE. Contribuição da Administração Municipal de Saúde-Introdução ao Documento Tese da IV Conferência Municipal de Saúde para discussão nas Conferências Regionais de Saúde. São Paulo, 1993, 22p.

SECRETARIA MUNICIPAL DE SAÚDE \& CONSELHO MUNICIPAL DE SAÚDE. IV Conferência Municipal de Saúde Municipalização com qualidade: São Paulo crescendo em defesa do Sistema Único de Saúde, São Paulo, setembro de 1993, 47p.

SECRETARIA MUNICIPAL DE SAÚDE \& CONSELHO MUNICIPAL DE SAÚDE. V Conferência Municipal de Saúde Organização do SUS e sua metodologia. São Paulo, dezembro de 1994, 6p.

SECRETARIA MUNICIPAL DE SAÚDE. Documento Tese da VI Conferência Municipal de Saúde de São Paulo, São Paulo, 1995, 7p.

SECRETARIA MUNICIPAL DE SAÙDE. Proposta de regimento interno do Conselhos Distritais de Saúde, São Paulo, mimeo, 26/03/92, 7p.

SECRETARIA MUNICIPAL DE SAÚDE. Proposta de regimento interno do Conselhos Distritais de Saúde, São Paulo, mimeo, penúltima versão s/d, 4p. 
SECRETARIA MUNICIPAL DE SAÚDE. Quadro indicativo da composição da Comissão de Gestão do D.S. de Ermelino Matarazzo, São Paulo, mimeo, s/d (provável 1992) 2p.

PREFEIRUTA MUNICIPAL DE SÃO PAULO. Experiências de participação popular. Programa Integrado de Educação e Participação Popular. São Paulo, março de 1992, 42p.

SECRETARIA MUNICIPAL DE SAÚDE. Relatório do I Encontro regional dos Conselhos gestores e Conselhos Populares da região de Ermelino Matarazzo, São Miguel e Itaim Paulista, São Paulo, mimeo, 30/05/92, 4p. 


\section{Criança e Adolescente}

SÃO PAULO. Decreto - Lei n. 35.179 de 6 de junho de 1995 que cria o Grupo Executivo Municipal Intersecretarial de Articulação de Projetos de Auxílio à Criança e ao Adolescente em Situação de Risco - GEMINTER e dá outras providências D.O.M. 9/06/95

CONSELHO MUNICIPAL DOS DIREITOS DA CRIANÇA E DO ADOLESCENTE. Resolução sobre exclusão de convênios, isenções cooperações e/ou auxílios a instituições públicas ou não que discriminem ou violem os direitos de crianças e adolescentes,. São Paulo, s/d, 2p.

CONSELHO MUNICIPAL DOS DIREITOS DA CRIANÇA E DO ADOLESCENTE. Carta de representante da SMS no Conselho sobre as resoluções enunciadas por ocasião de sua posse. São Paulo, setembro de 1992, 2p.

SECRETARIA MUNICIPAL DE SAÚDE. Exposição na CPI sobre Violência e Extermínio de Crianças e Adolescentes no município de São Paulo. Assessoria de Cidadania e Saúde. São Paulo, 10/06/92, 6p.

SECRETARIA MUNICIPAL DE SAÚDE. Subsídios para a participação da senhora prefeita no painel Violência e Saúde da IX Conferência Nacional de Saúde. Assessoria de Cidadania e Saúde. São Paulo, s/d, 7p.

REGIÃO DE ERMELINO MATARAZZO, SÃO MIGUEL, ITAIM PAULISTA E PENHA. Relatório sumário das reuniões sobre o estatuto da criança e do adolescente 1990-92. São Paulo, 1992, 2p. 


\section{Informações sobre produção dos serviços municipais e sobre morbidade entre outras}

SECRETARIA MUNICIPAL DE SAÚDE. Atendimentos médico-odontológicos realizados na rede da Secretaria Municipal de Saúde de São Paulo entre 1988 e 1991 - relatório final. Centro de Epidemiologia, Pesquisa e Informação. São Paulo, agosto 1992, 22p.

SECRETARIA MUNICIPAL DE SAÚDE. Produção Anual 1992 - Urgência/Emergência, Atendimento Pré-hospitalar, Ambulatorial, Internações e Hospital-Dia (semestral). Centro de Epidemiologia, Pesquisa e Informação. São Paulo, 23/03/93, 4p.

SECRETARIA MUNICIPAL DE SAÚDE. Relatório de Produção - 1993. Assessoria de Planejamento. Coordenadoria de Planejamento. São Paulo, 6p.

SECRETARIA MUNICIPAL DE SAÚDE. Produção por áreas e faixa etária Sistema de Informação Municipal de Saúde- SIMIS. São Paulo, 28/06/94. 3p.

SECRETARIA MUNICIPAL DE SAÚDE. Produção por áreas e primeira consulta do ano. Sistema de Informação Municipal de Saúde - SIMIS. São Paulo, 28/06/94, 3p.

SECRETARIA MUNICIPAL DE SAÚDE. Avaliação da utilização dos recursos humanos. Sistema de Informação Municipal de Saúde - SIMIS. São Paulo, 28/06/94, 3p.

SECRETARIA MUNICIPAL DE SAÚDE. Resumo Mensal 1993 - Hospital-dia em saúde mental. Sistema de Informação Municipal de Saúde - SIMIS. São Paulo, 28/06/96, 2p.

SECRETARIA MUNICIPAL DE SAÚDE. Resumo Mensal 1994 e 1995 - Hospital-dia em saúde mental. Sistema de Informação Municipal - SIMIS. São Paulo, 18/11/97, 4p.

SECRETARIA MUNICIPAL DE SAÚDE. Resumo Mensal 1994 e 1995 - Hospital-dia em saúde mental - ARS-06. Sistema de Informação Municipal - SIMIS. São Paulo, 18/11/97, 4p.

SECRETARIA MUNICIPAL DE SAÚDE. Resumo Mensal - Centros de Convivência e Cooperativa. Sistema de Informação Municipal de Saúde - SIMIS. São Paulo, 28/06/96, $2 \mathrm{p}$.

SECRETARIA MUNICIPAL DE SAÚDE. Resumo Mensal 1994 e 1995 - Centros de Convivência e Cooperativa. Sistema de Informação Municipal - SIMIS. São Paulo, 18/11/97. 2p.

SECRETARIA MUNICIPAL DE SAÚDE. Resumo Mensal 1994 e 1995 - Centros de Convivência e Cooperativa - ARS-06. Sistema de Informação Municipal - SIMIS. São Paulo, 18/11/97. 4p. 
SECRETARIA MUNICIPAL DE SAÚDE \& SERVIÇO FUNERÁRIO MUNICIPAL \& PRODAM. Mortalidade no município de São Paulo. PRO-AIM - Programa de Aprimoramento das informações de mortalidade no município de São Paulo. s/d, 14p.

SECRETARIA MUNICIPAL DE SAÚDE. Demonstrativo de Produção de 1994. Assessoria de Planejamento. Coordenação de Planejamento, Informação e Faturamento. São Paulo, s/d, 7p.

SECRETARIA MUNICIPAL DE SAÚDE. I Plano Municipal de Saúde - 1995. São Paulo. s/d, 44p.

SECRETARIA MUNICIPAL DE SAÚDE. Demonstrativo de Produção de 1995. Assessoria de Planejamento. Coordenação de Planejamento, Informação e Faturamento. São Paulo, s/d, 5p.

SECRETARIA MUNICIPAL DE SAÚDE. Perfil da ARS - 6. São Paulo, s/d, 6p.

SECRETARIA MUNICIPAL DE SAÚDE. Perfil do município de São Paulo de atendimento à saúde. São Paulo, s/d, 3p.

SECRETARIA MUNICIPAL DE SAÚDE. Perfil do módulo de atendimento à saúde Módulo 6. São Paulo, s/d, 2p.

SECRETARIA MUNCIPAL DE SAÚDE. Demonstrativo de produção de 1985 a 1995. Assessoria de Planejamento. São Paulo, janeiro de 1996, 6p.

SECRETARIA MUNICIPAL DE SAÚDE. Relação das Unidades da S.M.S. Assessoria de Planejamento. São Paulo, 25/09/96, 9p.

SECRETARIA MUNICIPAL DE SAÚDE. Relatório anual de produção por áreas, unidades de atendimento e distrito de saúde em 1995, 1994, 1993, 1992, 1991, 1990. 


\section{Outros temas}

MOVIMENTO DE SAÚDE DA ZONA LESTE. Hospital em Ermelino é uma realidade. Festa do povo pela conquista do Hospital de Ermelino Matarazzo. São Paulo, dezembro de 1990, 4p.

FÓRUM PAULISTANO PERMANENTE DE SAÚDE MENTAL. Carta ao Secretário da Saúde Dr. Raul Cutait. São Paulo, 16/03/93, 5p.

FÓRUM PAULISTANO PERMANENTE DE SAÚDE MENTAL. Ata de reunião de 8/09/93 e convocação de reunião de 13/10/93. São Paulo, outubro de 1993, 3p.

CONSELHO FEDERAL DE MEDICINA. Resolução n. 1.407 de 8 de junho de 1994 sobre a assistência em saúde mental. D.O.U. 15/06/94, Brasília, 6p.

CONSELHO FEDERAL DE MEDICINA. resolução n. 1.408 de 8 de junho de 1994 sobre as normas éticas de atendimento em saúde mental. D.O.U. 14/06/94, Brasília, 4p.

SÂO PAULO. Lei n. 11.511, de 19 de abril de 1994 que dispõe sobre a organização do Quadro dos profissionais da Administração da Prefeitura do Município de São Paulo, e dá outras providências. D.O.M. 20/04/94. São Paulo

SÃO PAULO. Lei complementar n. 791, de 9 de março de 1995, que estabelece o Código de Saúde no Estado. São Paulo. D.O.E. 10/03/95. São Paulo, 8p.

SECRETARIA MUNICIPAL DE SAÚDE. Plano de Atendimento à Saúde - PAS um novo modelo de gestão para os serviços públicos de saúde no município de São Paulo - Resumo Executivo versão 5 - junho de 1995. São Paulo, 14p.

CENTRO ACADÊMICO DO CURSO DE PSICOLOGIA DA PUC. O que é o PAS? São Paulo, abril de 1996, 2p. 
ANEXO III

\section{BANCO DE DADOS USUÁRIOS}




\section{ANEXO III}

\section{Caracterização dos Usuários}

I. Unidade de saúde

n. $^{\circ}$

II. Nome

n. ${ }^{\circ}$

III. Data de nascimento

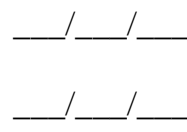

IV. Data de inscrição

V. Moradia

1 .a. ( ) esposa e/ ou filhos

1 .b. ( ) pais e/ ou irmãos

1 .c. ( ) parentes

1 .d. ( ) amigos

1 .e. ( ) sozinho

1 .f. ( ) outro. Especificar

1 .g. ( ) nada consta

VI. Escolaridade

2 .a. ( ) primária incompleta

2 .b. ( ) primária completa

2 .c. ( ) secundária incompleta

2 .d. ( ) secundária completa

2 .e. ( ) segundo grau incompleto

2 .f. ( ) segundo grau completo

2 .g. ( ) terceiro grau incompleto

2 .h. ( ) terceiro grau completo

2 .i. ( ) outra. Especificar

2 .j. ( ) nada consta

VII. Encaminhado por

3. ( ) profissional de saúde isoladamente

4. ( ) serviço de saúde

4 .a. Qual ?

5. ( ) outro tipo de encaminhamento

5 .a. Especificar

6. ( ) nada consta

VIII. Motivo de encaminhamento

7 . Especificar

8. ( ) nada consta

IX. Hipótese diagnóstica

9. Especificar

10. ( ) nada consta 
X. Tipo de encaminhamento anterior

11. ( ) Médico

11 .a. Especificar

11 .b . Freqüência

11 .c. Duração

12. ( ) Psicológico

12 .a. Especificar

12 .b . Freqüência

12 .c . Duração

13. ( ) Familiar

13 .a. Especificar

13 .b. Freqüência

13 .c. Duração

14. ( ) Internação

14 .a. ( ) em hospital psiquiátrico, instituição de reabilitação

14 .b. ( ) em hospital geral

15. ( ) Outro (s)

15 .a. Especificar

15 .b. Freqüência

15 .c. Duração

16. ( ) Outro (s)

16 .a. Especificar

16 .b. Frequiência

16 . c. Duração

XI . Tipo de acompanhamento na unidade

17. ( ) Médico

17 . a . Especificar

17 . b . Freqüência

17 . c . Duração

18. ( ) Psicológico

18 . a . Especificar

18 . b . Freqüência

18 . c . Duração

19. ( ) Familiar

19. a . Especificar

19. b . Frequiência

19. c . Duração

20. ( ) Outro (s)

20 . a . Especificar

20. b . Freqüência

20 . c . Duração

21. ( ) Outro (s)

21. a . Especificar

21 . b. Frequiência

21 . c . Duração

22 . ( ) Internação

22.a.( ) em hospital psiquiátrico

22 .b. ( ) em hospital geral

22 .c. ( ) em asilo ou instituição de reabilitação 
XII. Desligamento

23. Data de desligamento ___

24. ( ) Encaminhamento para outro serviço

24 . a . Especificar

24 . b . Motivo. Especificar

25. ( ) Alta

25.a.( ) a pedido

25 . b . Motivo. Especificar

25.c.( ) por decisão dos profissionais

25. d. Motivo. Especificar

26. ( ) Abandono

26.a. ( ) meses depois

26.b. ( ) anos depois

XIII . Observações

27 . Especificar 


\section{ANEXO III}

QUADRO 1. Hipótese Diagnósticas Relativas a Disfunções Neurológicas, Reumatológicas e Traumatológicas, conforme Citação dos Prontuários

\begin{tabular}{|c|c|c|c|c|c|}
\hline CITAÇÃO & $\mathrm{N}^{\circ}$ & TOTAL & CITAÇÃO & $\mathrm{N}^{\circ}$ & TOTAL \\
\hline 1. Disfunção Neurológico Infantis & --- & 24 & 4.14 Epicondilite & 3 & \\
\hline 1.1 Deficiência auditiva & 1 & & 4.15 Fratura de Membro Inferior & 30 & \\
\hline 1.2 Distrofia muscular tipo Becker & 1 & & 4.16 Fratura de Membro Superior & 27 & \\
\hline 1.3 Doença de Leggi Neuthon & 1 & & 4.17 Fratura & 1 & \\
\hline 1.4 Encurt. Tendão de Aquiles & 1 & & 4.18 Fratura por Arma de Fogo & 1 & \\
\hline 1.5 Lesão nervo periférico & 1 & & 4.19 Fratura Supra Condiliana & 1 & \\
\hline 1.6 Má formação congênita & 1 & & 4.20 Instabilidade Antero-medial & 1 & \\
\hline 1.7 Microcefalia & 1 & & 4.21 Laminectomia & 1 & \\
\hline 1.8 Paralisia cerebral & 12 & & 4.22 Lesão Ligamentar & 4 & \\
\hline 1.9 Paralisia facial & 1 & & 4.23 Lombalgia & 15 & \\
\hline 1.10 Paralisia Infantil & 1 & & 4.24 Lombociatalgia & 1 & \\
\hline 1.11 Paralisia obstétrica & 2 & & 4.25 Lombodorsalgia & 1 & \\
\hline 1.12 Sequelas de meningite & 1 & & 4.26 Lombosacralgia & 5 & \\
\hline $\begin{array}{l}\text { 2. Disfunções Neurológicas } \\
\text { Adulto }\end{array}$ & --- & 57 & 4.27 Luxação & 1 & \\
\hline 2.1 Atrofia generalizada & 1 & & 4.28 Miofaceite plantar & 1 & \\
\hline 2.2 Acidente vascular cerebral & 35 & & 4.29 Osteocondrite & 1 & \\
\hline 2.3 Hemiparesia duplo & 1 & & 4.30 Retirada de Cisto de Joelho & 1 & \\
\hline 2.4 Hemiplegia & 4 & & 4.31 Rotura de Artrodese & 1 & \\
\hline 2.5 Hemiplegia por arma de fogo & 1 & & 4.32 Rotura de Hernia de Disco & 1 & \\
\hline 2.6 Lesão de plexo braquial & 1 & & 4.33 Secção de Tendão extensor & 2 & \\
\hline 2.7 Lesão neurotendinal & 1 & & 4.34 Sequela de Entorse & 15 & \\
\hline 2.8 Neuroartroma de MS & 1 & & 4.35 Sd. De Minorvite- Querran & 1 & \\
\hline 2.9 Neurofibromatose & 1 & & 4.36 Sinovite de Membro Inferior & 7 & \\
\hline 2.10 Paralisia bilateral & 1 & & 4.37Tendinite Bilateral de MI/MS & 21 & \\
\hline 2.11 Paralisia facial & 1 & & 4.38 Tenosinovite de Punho & 1 & \\
\hline $\begin{array}{l}2.12 \text { Traumatismo Crânio } \\
\text { encefálico }\end{array}$ & 9 & & 4.39 Trauma de MS/MI & 3 & \\
\hline $\begin{array}{l}\text { 3. Disfunções Cardio } \\
\text { Respiratórias }\end{array}$ & --- & 1 & 4.40 Vigmbo punho & 1 & \\
\hline 3.1 Tetralogia de Fallot & 1 & & $\begin{array}{l}\text { 5. Disfunções } \\
\text { Reumatológicas }\end{array}$ & --- & 32 \\
\hline $\begin{array}{l}\text { 4. Disfunções Ortopédicas e } \\
\text { Traumatológicas }\end{array}$ & --- & 195 & 5.1 Artralgia & 2 & \\
\hline 4.1 Bursite & 10 & & 5.2 Artrite & 2 & \\
\hline 4.2 Caimbrã do Escrivão & 1 & & 5.3 Artrose & 12 & \\
\hline 4.3 Cervicalgia & 7 & & $\begin{array}{l}\text { 5.4 Espondiloartrose dorso- } \\
\text { Lombar }\end{array}$ & 1 & \\
\hline 4.4 Cervicoanalgesia & 1 & & 5.5 Menicectomia & 1 & \\
\hline 4.5 Cervicobraquialgia & 3 & & 5.6 Osteoartrite & 1 & \\
\hline 4.6 Ciatalgia & 2 & & 5.7 Osteoartrose & 8 & \\
\hline 4.7 Contusão & 6 & & 5.8 Perartrite & 5 & \\
\hline 4.8 Corte de Dedo & 1 & & 6. Outros 2 & --- & 15 \\
\hline 4.9 Distensão de Quadril & 1 & & 6.1 Amputação & 5 & \\
\hline 4.10 Dorsalgia & 6 & & 6.2 Deficiente Físico & 1 & \\
\hline 4.11 Dorsolombalgia & 3 & & 6.3 Dor & 8 & \\
\hline 4.12 Escoliose & 1 & & 6.4 Queimadura & 1 & \\
\hline 4.13 Esmagamento de Dedo & 1 & & & & \\
\hline
\end{tabular}




\section{ANEXO III}

QUADRO 2. Hipóteses Diagnósticas Relativas a Transtornos Mentais, conforme Citação dos Prontuários

\begin{tabular}{|c|c|c|c|c|c|}
\hline CITAÇÃO & $\mathrm{N}^{\circ}$ & TOTAL & CITAÇÃO & $\mathrm{N}^{\circ}$ & TOTAL \\
\hline 1.Atraso do Desenvolvimento & 15 & 15 & a) senil & 1 & \\
\hline 2. Problema de Aprendizagem & 1 & 17 & b) pré-senil & 1 & \\
\hline 2.1 Dislexia & 2 & & c) quadro demencial & 1 & \\
\hline 2.2 Distúrbio de Aprendizagem & 13 & & 9.2 Esquizofrenia & 18 & 73 \\
\hline 2.3 Dificuldade de Aprendizagem & 1 & & a) distúrbio esquizofreniforme & 3 & \\
\hline 3. Alcoolismo & 10 & 11 & b) esquizo agudo & 17 & \\
\hline 3.1 Demência alcóolica & 1 & & c) esquizo catatônico & 2 & \\
\hline 4. Depressão & 9 & 33 & d) esquizo hebefrênico & 4 & \\
\hline 4.1 Depressão Agitada & 1 & & e) esquizo paranóide & 23 & \\
\hline 4.2 Depressão Maior & 2 & & f) esquizo residual & 3 & \\
\hline 4.3 Depressão Neurótica & 3 & & g) transtorno esquizo afetivo & 3 & \\
\hline 4.4 Depressão Psicótica & 6 & & 9.3 Psicose maniaco depressiva & 27 & 34 \\
\hline 4.5 Depressão Reativa & 7 & & a) distúrbio afetivo & 5 & \\
\hline 4.6 Quadro Depressivo & 1 & & b) psicose afetivo & 2 & \\
\hline 4.7 Reação Depressiva Prolongada & 3 & & 9.4 Psicose & 36 & 49 \\
\hline 4.8 Reação Depressiva Breve & 1 & & a) confusão reativa & 1 & \\
\hline 4.9 Distúrbio Delirante & 1 & & b) psicose alcóolica & 1 & \\
\hline 5. Deficiente Mental & 15 & 19 & c) psicose boderline & 1 & \\
\hline 5.1 Oligofrenia & 4 & & d) psicose dissociativa & 1 & \\
\hline 5.2 Down & 8 & & e) psicose doméstica & 1 & \\
\hline 6. Transtorno neurótico & 4 & 13 & f) psicose em deficiência mental & 1 & \\
\hline 6.1 Anorexia & 1 & & g) psicose epilética & 1 & \\
\hline 6.2 Estado de ansiedade & 1 & & h) psicose pós-parto & 1 & \\
\hline 6.3 Histeria & 3 & & i) psicose reativa & 2 & \\
\hline 6.4 Neurastenia & 1 & & 9.5 Quadro psicótico & 6 & 6 \\
\hline 6.5 Neurose obsessivo compulsiva & 1 & & 10. Outros 1 & --- & 15 \\
\hline 6.6 Síndrome do pânico & 3 & & 10.1 Problemas emocionais & 1 & 5 \\
\hline 7. Epilepsia & 6 & 6 & a) bloqueio emocional & 1 & \\
\hline 8. Paciente Psiquiátrico & 44 & 53 & b) conflito emocional & 1 & \\
\hline 8.1 Distúrbio de Memória & 1 & & c) confusão emocional & 2 & \\
\hline 8.2 Quadro Psiquiátrico & 2 & & 10.2 Distúrbio do comportamento & 3 & \\
\hline 9. Psicose & --- & 164 & 10.3 Hiperatividade & 5 & \\
\hline 9.1 Demência & 3 & & 10.4 Drogadição & 2 & \\
\hline
\end{tabular}




\section{ANEXO III}

QUADRO 3. Motivos de encaminhamenteo para as unidades de saúde, segunco citação em prontuários

\begin{tabular}{|c|c|c|c|c|c|}
\hline Citação & $N^{0}$ & Total & Citação & $N^{\circ}$ & Total \\
\hline 1. Problema / Diagnóstico & --- & 50 & 3.1 Atividade & 23 & \\
\hline 1.1 Agressividade & 6 & & 3.2 Avaliação & 6 & \\
\hline 1.2 Crise nervosa & 2 & & 3.3 Convivência & 25 & \\
\hline 1.3 Déficit movimento & 4 & & 3.4 Horta & 1 & \\
\hline 1.4 Depressão & 1 & & 3.5 Para ajudar deficientes & 1 & \\
\hline 1.5 Dificuldade de aprendizagem & 22 & & 3.6 Melhorar AVDS & 1 & \\
\hline $\begin{array}{l}\text { 1.6 Dificuldade de expressão de } \\
\text { sentimentos }\end{array}$ & 2 & & 3.7 Movimentar-se & 1 & \\
\hline 1.7 Dificuldade para deambulação & 1 & & 3.8 Relaxamento & 4 & \\
\hline 1.8 Medo suicídio & 1 & & 3.9 Socialização & 4 & \\
\hline 1.9 Problema de comportamento & 5 & & 4. Intervenções específicas & --- & 38 \\
\hline 1.10 Problema mental & 3 & & $\begin{array}{l}\text { 4.1 Acompanhemento de saúde } \\
\text { mental }\end{array}$ & 6 & \\
\hline 1.11 RDNPM & 2 & & 4.2 Acompanhamento psiquiátrico & 4 & \\
\hline 1.12 Tentativa de suicídio & 1 & & 4.3 Fisioterapia & 17 & \\
\hline 2. Acompanhamento / Tratamento & --- & 21 & 4.4 Fonoaudiologia & 4 & \\
\hline 2.1 Acompanhamento & 2 & & 4.5 Psicologia & 2 & \\
\hline 2.2 Acompanhar o filho & 1 & & 4.6 Psicoterapia & 2 & \\
\hline 2.3 Para melhorar & 1 & & 4.7 Terapia Ocupacional & 2 & \\
\hline 2.4 Tratamento & 16 & & $\begin{array}{l}\text { 4.8 Fisioterapia e Terapia } \\
\text { Ocupacional }\end{array}$ & 1 & \\
\hline 2.5 Tratamento nervosismo & 1 & & 5. Proximidade da moradia & --- & 1 \\
\hline 3. Convivência / Atividade & --- & 66 & 5.1 Proximidade da residência & 1 & \\
\hline
\end{tabular}




\section{ANEXO III}

\section{INFORMAÇÕES ADICIONAIS SOBRE O BANCO DE DADOS}

TABELA 1. Usuários, segundo média de idade e sexo

\begin{tabular}{ll}
\hline Sexo & Idade Média \\
\hline Masculino & 28,62 \\
Feminino & 38,17 \\
\hline
\end{tabular}

TABELA 2. Usuários, segundo escolaridade

\begin{tabular}{ll}
\hline Escolaridade & $\%$ \\
\hline Primeiro Grau & 17,4 \\
Segundo Grau & 11,2 \\
Superior & 0,5 \\
Sem Resposta & 70,9 \\
\hline Total & 100,0 \\
$\mathrm{~N}$ & $(1093)$ \\
\hline
\end{tabular}

TABELA 3. Usuários, segundo motivo de encaminhamento

\begin{tabular}{lc}
\hline Motivo do encaminhamento & $\%$ \\
\hline \multicolumn{1}{c}{ Problemática/diagnóstico } & 31,4 \\
Acompanhamento/tratamento & 20,9 \\
Convivência/atividade & 32,0 \\
Intervenções específicas & 14,5 \\
Moradia & 0,6 \\
Avaliação e conduta & 0,6 \\
\hline Total & 100,0 \\
$\mathrm{~N}$ & $(172)^{*}$ \\
\hline$* 921$ casos sem resposta &
\end{tabular}


TABELA 4. Usuários, segundo distrito sanitário

\begin{tabular}{ll}
\hline \multicolumn{1}{c}{ Distrito Sanitário } & \multicolumn{1}{c}{$\%$} \\
\hline Ermelino Matarazzo & 60,5 \\
São Miguel & 30,4 \\
Itaim Paulista & 9,1 \\
\hline Total & 100,0 \\
& $(1093)$ \\
\hline
\end{tabular}

TABELA 5. Usuários por tipo de residência, segundo o CECCO

\begin{tabular}{lcc}
\hline \multirow{2}{*}{ Residência } & \multicolumn{2}{c}{ CECCO } \\
\cline { 2 - 3 } & Ermelino Matarazzo & Chico Mendes \\
\hline Esposa e/ou filhos & 42,5 & 21,7 \\
Pais e/ou irmãos & 52,5 & 73,9 \\
Parentes & --- & 2,2 \\
Sozinho & 5,0 & 2,2 \\
\hline Total & 100,0 & 100,0 \\
$\mathrm{~N}$ & $(40)$ & $(68)$ \\
\hline
\end{tabular}

TABELA 6. Escolaridade dos usuários, segundo CECCO

\begin{tabular}{lcc}
\hline & \multicolumn{2}{c}{ CECCO } \\
\cline { 2 - 3 } Escolaridade & Ermelino Matarazzo & Chico Mendes \\
\hline Primeiro grau & 8 & 12 \\
Segundo grau & 14 & 15 \\
Terceiro grau & --- & --- \\
\hline Total & $(22)^{*}$ & $(27)^{*}$ \\
$\mathrm{~N}$ & &
\end{tabular}

* não foram calculadas porcentagens porque os totais são baixos 
TABELA 7. Acompanhamento Anterior dos usuários da Enfermaria Psiquiátrica

\begin{tabular}{l|l}
\hline Acompanhamento Anterior & Enfermaria Psiquiátrica \\
\hline Médico/clínico & 65,3 \\
Psicólogo & 10,2 \\
Psiquiatra & 24,5 \\
\hline Total & 100,0 \\
N & $(49)^{* *}$ \\
\hline
\end{tabular}

** não foram calculadas porcentagens porque os totais são baixos

TABELA 8. Sexo dos Usuários do Hospital Dia São Miguel

\begin{tabular}{lc}
\hline SEXO & Hospital Dia São Miguel (\%) \\
\hline Feminino & 56,4 \\
Masculino & 43,6 \\
\hline Total & 100,0 \\
$\mathrm{~N}$ & $(117)$ \\
\hline
\end{tabular}

